\title{
EXPERIMENTAL STUDY OF THE STABILITY OF CORDIERITE AND GARNET IN PELITIC COMPOSITIONS AT HIGH \\ PRESSURES AND TEMPERATURES
}

by

B. J. HENSEN

\begin{abstract}
Thesis submitted for the degree of DOCTOR OF PHILOSOPHY
\end{abstract}

Australian National University

November 1970 
The work and results presented in this thesis are my own unless otherwise indicated in the text.

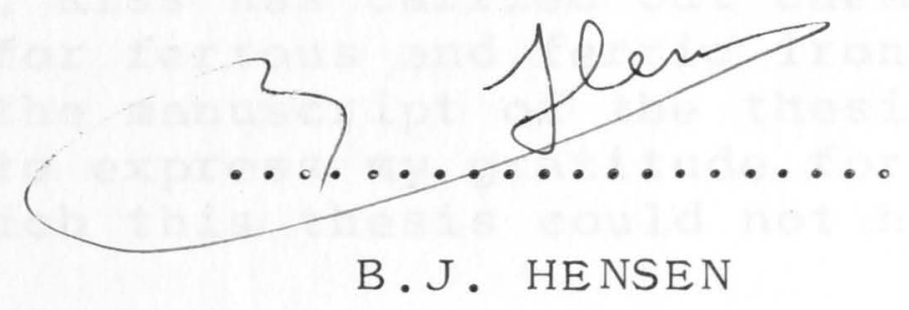




\section{ACKNOWLEDGEMENTS}

I wish to thank Dr D.H. Green for suggesting the project which is the subject of this thesis and for his constant advice and criticism, which have greatly contributed to the progress of the research. The helpful comments of Professor A.E. Ringwood on the project are gratefully acknowledged. I have also greatly benefitted from numerous discussions with Dr E.J. Essene, which have influenced the approach to interpretation of the experimental data. Professor C.W. Burnham is thanked for helpful comments and criticisms. Drs D.H. Green, A.J. Irving and A.L. Graham have read the manuscript, and their advice on clarity of expression has been a great help in completing this thesis.

Mr W. Hibberson instructed me in the use of piston cylinder apparatus. He and Mr A. Major have provided invaluable technical help throughout the course of this research. Mr N. Ware has patiently instructed me in the use of the electron probe microanalyser and has written the computer program for the calculation of the garnet analyses. Mr E. Pederson has prepared the polished sections of the experimental runs. Mr E. Kiss has carried out chemical analyses of the glasses for ferrous and ferric iron. Mrs $J$. Barton has typed the manuscript of the thesis. To all these people I want to express my gratitude for their friendly help without which this thesis could not have been written。 
Model pelitic compositions have been used to experimentally determine the stability of cordierite and garnet relative to their anhydrous breakdown products e.g. hypersthene, sapphirine, olivine, spinel, sillimanite and quartz, under conditions of low oxygen fugacity. Under essentially dry reducing conditions the stability of the mineral pair cordierite-garnet is limited by five quasi-univariant reactions. These are from low temperature and high pressure to high temperature and low pressure: cordierite + garnet $\rightleftharpoons$ hypersthene + kyanite + quartz, cordierite + garnet $\rightleftharpoons$ hypersthene + sapphirine + quartz, cordierite + garnet $\rightleftharpoons$ hypersthene + spinel + quart $z$ and cordierite + garnet $\rightleftharpoons$ olivine + spinel + 2 quartz. In this sequence of reactions the $\mathrm{Mg} / \mathrm{Mg}+\mathrm{Fe}^{2+}$ ratio of all ferromagnesian phases decreases from the first reaction to the fifth. The univariant boundary for the last reaction terminates in the invariant point in the system $\mathrm{FeO}_{-} \mathrm{Al}_{2} \mathrm{O}_{3}-\mathrm{SiO}_{2}$, involving the phases: Fe-cordierite-almandine-fayalite-hercynite-quartz. The first and second of the reactions terminate in two metastable invariant points in the system $\mathrm{MgO}_{-} \mathrm{Al}_{2} \mathrm{O}_{3}-\mathrm{SiO}_{2}$. As a result, the coexistence of pyrope and Mg-cordierite in the presence of quartz is prohibited. The above univariant boundaries delimit a wide P-T range over which cordierite and garnet may coexist. These equilibria can usually only be applied to determine the limiting conditions for the formation of cordierite-garnet assemblages. Two quasi-divariant equilibria in which the $\mathrm{Mg} / \mathrm{Mg}+\mathrm{Fe}{ }^{\circ}$ ratio of the coexisting phases are uniquely determined by pressure and temperature have been studied in detail. These are cordierite $\rightleftharpoons$ garnet + sillimanite + quartz and cordierite + hypersthene $\rightleftharpoons$ garnet + quartz (6). $\mathrm{P}-\mathrm{T}-\mathrm{X}$ grids have been constructed that allow the determination of pressure and temperature from the $\mathrm{Mg} / \mathrm{Mg}+\mathrm{Fe}^{2+}$ ratio of a single garnet-cordierite pair. $\mathrm{P}-\mathrm{T}$ estimates for several high grade metamorphic terranes suggest temperatures of formation of $700^{\circ}-1050^{\circ} \mathrm{C}$ and load pressures of $6-10 \mathrm{~kb}$. 
EXPERIMENTAL STUDY OF THE STABILITY OF CORDIERITE AND GARNET IN PELITIC COMPOSITIONS AT HIGH PRESSURES AND TEMPERATURES

\section{TABLE OF CONTENTS}

\section{CHAPTER 1 - INTRODUCTION}

1.1 Compositions studied

2.1 Apparatus and Techniques

2.2 Preparation of Glasses

2.3 The Seeded Glass Methods: Starting Materials

2.4 Attainment of Equilibrium

2.5 Oxygen Fugacity

2.6 Examination of the Sample

2.7 Procedure for Quantative Electron Probe Analysis of Experimental Phases

CHAPTER 3 - THEORETICAL PHASE RELATIONS IN THE SYSTEM $\mathrm{MgO}-\mathrm{FeO}-\mathrm{Al}_{2} \mathrm{O}_{3}-\mathrm{SiO}_{2}$

3.1 Invariant Points and Univariant Curves

3.2 Divariant Reactions

3.3 Relationships Between Divariant and Univariant Reactions

3.4 Mathematical and Graphical Analysis of Divariant Reactions

Appendix 1 - Note on the Influence of Pressure on the $\mathrm{K}_{\mathrm{D}(\mathrm{Cd}-\mathrm{Ga})}$

Appendix 2 - Alternative Solution for Univariant Curves Involving Garnet and Spinel with $x_{S p}<x_{G a}$ 
CHAPTER 4 - EXPERIMENTAL STUDY OF THE C-SERIES OF COMPOS ITIONS

4.1 Phase Relationships in the $\mathrm{C}_{70}$ Composition 57

4.2 Phase Relationships in the $\mathrm{C}_{30}^{70}$ Composition 74

4.3 P-T-X Relationships in the C-series of Compositions 81

Appendix - The Effect of the Components $\mathrm{CaO}, \mathrm{Na}_{2} \mathrm{O}$ and $\mathrm{K}_{2} \mathrm{O}$ on the Phase Equilibria studied

CHAPTER 5 - EXPERIMENTAL STUDY OF THE B-SERIES OF COMPOS ITION

5.1 Phase Relations in the $B_{70}$ Composition

5.2 Phase Relations in the $B_{50}$ Composition

5.3 Phase Relations in the $\mathrm{B}_{3}$ O Composition

5.4 Phase Relations in the $B$ O Composition

5.5 Phase Relations in the $\mathrm{B}_{0}^{100}$ and Almandine + Quartz Compositions

5.6 P-T-X Relations for B-Series of Compositions

Appendix - The Problem of the Relative Composition of Coexisting Garnet and Hercynite-Spinelss

CHAPTER 6 - PHASE RELATIONS IN A 70 COMPOSITION

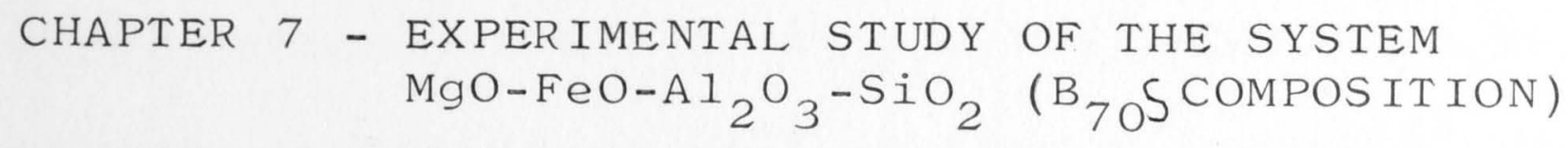

154

CHAPTER 8 - STABILITY OF PYROPE-QUARTZ IN THE SYSTEM $\mathrm{MgO}-\mathrm{Al}_{2} \mathrm{O}_{3}-\mathrm{SiO}_{2}$

CHAPTER 9 - SYNTHESIS OF EXPERIMENTAL PHASE EQUILIBRIA IN MODEL PELITIC COMPOSITIONS

9.1 General P-T Diagram for Silica-Saturated Pelitic Compositions

9.2 P-T-X Grid for the Divariant Equilibria

$\mathrm{Cd} \rightleftharpoons \mathrm{Ga}+\mathrm{Si}+\mathrm{Qz}$ (1) and $\mathrm{Cd}+\mathrm{Hy} \rightleftharpoons \mathrm{Ga}+\mathrm{Qz}$ (6) 
CHAPTER 9 (Continued)

9.3 Influence of Factors other than $\mathrm{Mg} / \mathrm{Mg}+\mathrm{Fe}^{2+}$ Ratio on the P-T-X Relations

9.4 Intersections of Reactions (1) and (6) with Dehydration Reactions Involving Biotite 
CHAPTER 1

\section{INTRODUCTION}

The occurrence of cordierite in rocks from granulite facies terranes has aroused a great deal of interest among petrologists. Cordierite has been regarded as a low pressure mineral, and therefore as atypical of deepseated regional metamorphism. Similarly the occurrence of almandine in contact aureoles has led to controversy, as amandine-rich garnets were thought to be stable only at relatively high pressure. Coexisting cordierite and garnet are known both from high grade amphibolite and granulite facies terranes and from high level, low pressure, contact aureoles. In the latter, however, garnet occurs in addition to cordierite only in very iron-rich rocks. This has led some authors (e.g. Chinner, 1962) to stress the importance of the effect of rock-chemistry as well as that of physical parameters on the stability of cordierite and garnet. A knowledge of the phase equilibria controlling the stability of cordierite and garnet (relative to their anhydrous breakdown products) as a function of pressure, temperature and bulk composition, will therefore be of considerable value for the understanding of the conditions of formation of metamorphic rocks.

Most previous work has concentrated on the determination of the stability of the magnesian and iron end members of the 
minerals cordierite and garnet (under their own compositions), e.g. the stability of pyrope (Boyd and England, 1959), the stability of almandine (Hsu, 1968), the stability of Mg-cordierite (Schreyer and Yoder, 1960; 1964) and Fe-cordierite (Richardson, 1968). These studies provide essential information about the stability of the end member phases, but are of limited value to quantitatively or even qualitatively explain and unravel the more complex equilibria that occur in natural rocks.

A study of the pyrope-almandine join at $2 \mathrm{~kb}$ pressure by Hsu and Burnham (1969) has shown some of the complexities in the phase relationships of intermediate garnets and comes much closer to simulating the actual equilibria of natural rocks.

Hirschberg and Winkler (1968) have studied the stability of garnet and cordierite in two natural Ca-poor, metapelitic compositions. Their work shows the effect of the $\mathrm{Mg} / \mathrm{Mg}+\mathrm{Fe}^{2+}$ ratio on the stability of garnet and demonstrates the existence of a field in which cordierite and garnet coexist in the presence of biotite, sillimanite and quartz, thereby reproducing a natural rock assemblage.

The present investigation differs from the previous studies mentioned above in that it has endeavoured to make a systematic study of the effect of $\mathrm{Mg} / \mathrm{Mg}+\mathrm{Fe}^{2+}$ ratio on the relative stability of the ferromagnesian minerals in 
a chemical environment similar to that existing in natural metapelitic rocks. This has been made possible by the use of the electron microprobe for analysis of the extremely fine grained, experimentally produced phases. As the chemical composition of coexisting ferromagnesian phases can be accurately measured, a detailed consideration of the pressure-temperature-composition relationships is possible. The present experimental investigation using bulk compositions modelled on natural meta-pelites should elucidate the equilibria occurring in metamorphic rocks and provide quantitative information about the physical conditions required for the formation of various cordierite and garnet bearing assemblages.

\subsection{COMPOSITIONS STUDIED}

In order to closely reproduce the mineral assemblages formed in natural rocks during high grade metamorphism, the compositions used in the present study have been modelled on natural pelitic compositions (see Table 1.1).

The single, most important chemical variable that affects the relative stability of ferromagnesian phases is the $\mathrm{Mg} / \mathrm{Mg}+\mathrm{Fe}^{2+}$ ratio. Therefore the compositions studied have been chosen such as to bring out the effect of this ratio on the phase relationships. For practical reasons the synthetic compositions have been enriched in the major elements that 
TABLE 1.1

\begin{tabular}{|c|c|c|c|c|c|c|c|c|}
\hline Composition & ${ }^{\mathrm{B}} \mathrm{O}$ & $\mathrm{B}_{30}$ & $\mathrm{~B}_{50}$ & $\mathrm{~B}_{70}$ & $\mathrm{~B}_{100}$ & $\mathrm{C}_{30}$ & $\mathrm{C}_{70}$ & $\mathrm{~A}_{70}$ \\
\hline $\mathrm{SiO}_{2}$ & 50.61 & 51.91 & 52.84 & 52.82 & 55.35 & 50.94 & 52.15 & 54.84 \\
\hline $\mathrm{Al}_{2} \mathrm{O}_{3}$ & 23.66 & 24.39 & 24.90 & 25.43 & 26.29 & 32.31 & 33.26 & 17.90 \\
\hline $\mathrm{FeO}$ & 20.95 & 15.19 & 11.11 & 6.83 & - & 10.13 & 4.49 & 9.55 \\
\hline $\mathrm{MgO}$ & - & 3.65 & 6.24 & 8.95 & 13.28 & 2.44 & 5.86 & 12.50 \\
\hline $\mathrm{CaO}$ & 2.22 & 2.30 & 2.35 & 2.42 & 2.51 & 1.63 & 1.69 & 2.65 \\
\hline $\mathrm{Na}_{2} \mathrm{O}$ & 1.18 & 1.18 & 1.18 & 1.18 & 1.18 & 1.18 & 1.18 & 1.18 \\
\hline $\mathrm{K}_{2} \mathrm{O}$ & 1.35 & 1.35 & 1.35 & 1.35 & 1.35 & 1.35 & 1.35 & 1.35 \\
\hline $100 \mathrm{Mg} / \mathrm{Mg}+\mathrm{Fe}^{2+}$ & 99.97 & 99.97 & 99.97 & 99.98 & 99.96 & 99.98 & 99.98 & 99.97 \\
\hline & $\mathrm{O}$ & 30 & 50 & 70 & 100 & 30 & 70 & 70 \\
\hline
\end{tabular}

Composition Almandine + Quartz Pyrope + Quartz

${ }_{70}^{\mathrm{S}}$

\begin{tabular}{lccc}
$\mathrm{SiO}_{2}$ & 43.54 & 54.26 & 63.11 \\
$\mathrm{Al}_{2} \mathrm{O}_{3}$ & 18.15 & 20.92 & 19.47 \\
$\mathrm{FeO}$ & 38.32 & - & 7.54 \\
$\mathrm{MgO}$ & - & 24.83 & 9.88 \\
& 100.01 & 100.01 & 100.00 \\
\hline
\end{tabular}




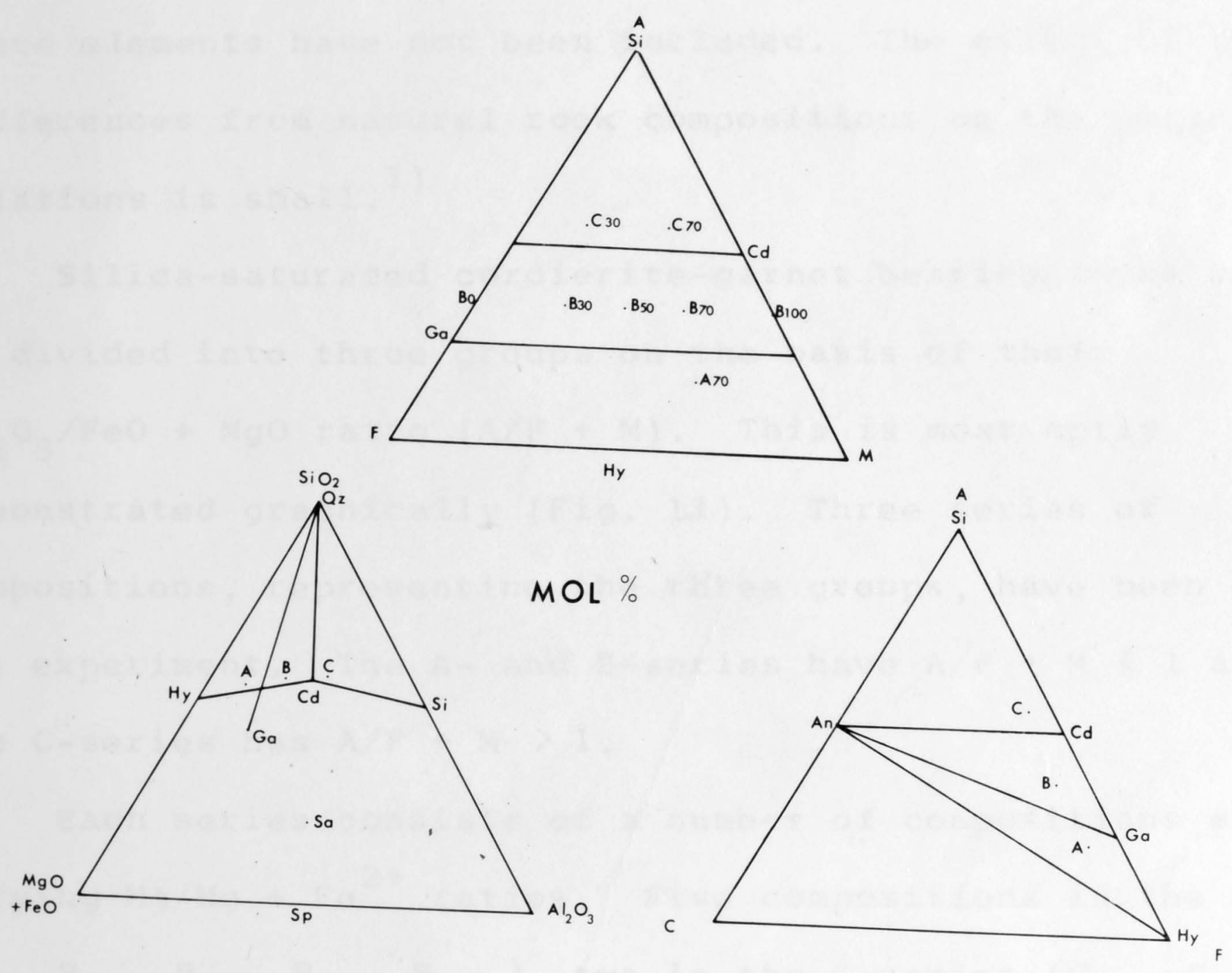

Fig. 1.1. Position of synthetic compositions $A, B$ and $C$ in various compositional diagrams.

ACF: $\begin{aligned} A & =\mathrm{Al}_{2} \mathrm{O}_{3}-\left(\mathrm{K}_{2} \mathrm{O}+\mathrm{Na}_{2} \mathrm{O}\right), \mathrm{C}=\mathrm{CaO}, \\ F & =\mathrm{FeO}_{+} \mathrm{MgO}^{\mathrm{A}},\end{aligned}$

$\begin{aligned} A F M: A & =\mathrm{Al}_{2} \mathrm{O}_{3}-\left(\mathrm{CaO}-\mathrm{K}_{2} \mathrm{O}-\mathrm{Na}_{2} \mathrm{O}\right), \quad \mathrm{F}=\mathrm{FeO}, \\ \mathrm{M} & =\mathrm{MgO} .\end{aligned}$

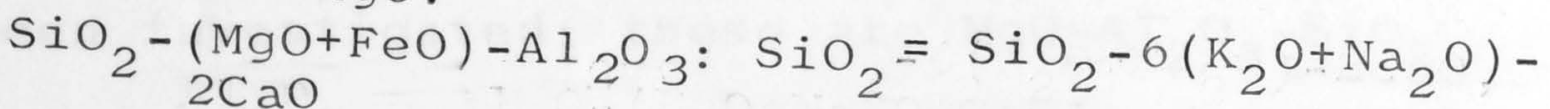
$\mathrm{Al}_{2} \mathrm{O}_{3}=\mathrm{Al}_{2} \mathrm{O}_{3}-\left(\mathrm{K}_{2} \mathrm{O}+\mathrm{Na}_{2} \mathrm{O}+\mathrm{CaO}\right), \mathrm{MgO}+\mathrm{FeO}$. 
constitute the phases of interest (i.e. cordierite, garnet and hypersthene) relative to natural pelites. Minor and trace elements have not been included. The effect of these differences from natural rock compositions on the phase relations is small. 1 )

Silica-saturated cordierite-garnet bearing rocks can be divided into three groups on the basis of their $\mathrm{Al}_{2} \mathrm{O}_{3} / \mathrm{FeO}+\mathrm{MgO}$ ratio $(\mathrm{A} / \mathrm{F}+\mathrm{M})$. This is most aptly demonstrated graphically (Fig. 1.1). Three series of compositions, representing the three groups, have been chosen for experiment. The $\mathrm{A}$ - and $\mathrm{B}$-series have $\mathrm{A} / \mathrm{F}+\mathrm{M}<1$ and the C-series has $\mathrm{A} / \mathrm{F}+\mathrm{M}>1$.

Each series consists of a number of compositions with varying $\mathrm{Mg} / \mathrm{Mg}+\mathrm{Fe}^{2+}$ ratios. Five compositions in the B-series $\left(\mathrm{B}_{0}, \mathrm{~B}_{30}, \mathrm{~B}_{50}, \mathrm{~B}_{70}, \mathrm{~B}_{100}\right)$, two in the $\mathrm{C}-$ series $\left(\mathrm{C}_{30}, \mathrm{C}_{70}\right)$ and one in the A-series $\left(\mathrm{A}_{70}\right)$ have been studied experimentally. Chemical analyses of these compositions are given in Table 1.1 and a graphical representation is given in Figure 1.1. In addition to these series of compositions three simple

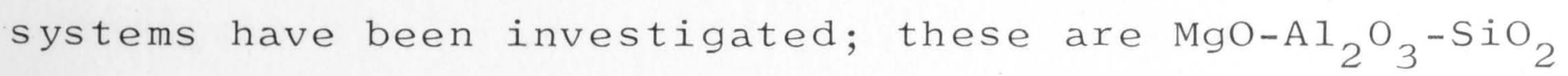

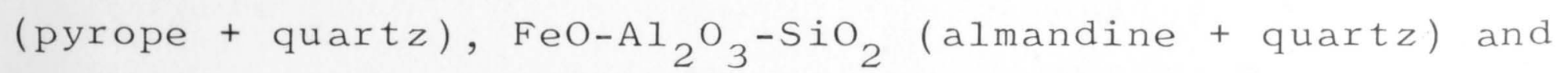

1) The effect of chemical variables, not considered in the experiments, is discussed in Chapter 9. 
$\mathrm{MgO}-\mathrm{FeO}-\mathrm{Al}_{2} \mathrm{O}_{3}-\mathrm{SiO}_{2}\left(\mathrm{~B}_{7} \mathrm{O}\right.$; with $\left.\mathrm{Mg} / \mathrm{Mg}+\mathrm{Fe}^{2+}=7 \mathrm{O}\right)$. The study of these systems allows an evaluation of the influence of the plagioclase on the equilibria studied in $\mathrm{B}_{100}, \mathrm{~B}_{0}$ and $\mathrm{B}_{70}$ respectively. The simple system compositions are also given in Table 1.1. 
TABLE 1.3

Abbreviations and chemical formulae

Mineral

Cordierite

Garnet

Almandine

Pyrope

Grossular

Hypersthene

Enstatite

Ferrosilite

Olivine

Fayalite

Forsterite

Spinel

Hercynite

Magnetite

Sapphirine

Osumilite

Sillimanite

Kyanite

Andalusite

Corundum

Plagioclase

Anorthite

Albite

Orthoclase

Feldspars

Biotite

Phogopite

Annite

Quartz
Abbreviation

Chemical Formula
$\mathrm{Cd}$

$\mathrm{Ga}$

A 1

Py

Gr

Hy

En

FS

O1

$\mathrm{Fa}$

Fo

Sp

$\mathrm{HC}$

Mt

$\mathrm{Sa}$

Os

Si

Ky

And

Co

P1

An

$\mathrm{Ab}$

Or

Fsp

Bi

$\mathrm{Ph}$

Ann

Q 2
$(\mathrm{Mg}, \mathrm{Fe})_{2} \mathrm{Al}_{4} \mathrm{Si}_{5} \mathrm{O}_{18}$

$(\mathrm{Mg}, \mathrm{Fe}, \mathrm{Ga})_{3} \mathrm{Al}_{2} \mathrm{Si}_{3} \mathrm{O}_{12}$

$\mathrm{Fe}_{3} \mathrm{Al}_{2} \mathrm{Si}_{3} \mathrm{O}_{12}$

$\mathrm{Mg}_{3} \mathrm{Al}_{2} \mathrm{Si}_{3} \mathrm{O}_{12}$

$\mathrm{Ca}_{3} \mathrm{Al}_{2} \mathrm{Si}_{3} \mathrm{O}_{12}$

$(\mathrm{Mg}, \mathrm{Fe}) \mathrm{SiO}_{3}$

$\mathrm{MgSiO}_{3}$

$\mathrm{FeSiO}_{3}$

$(\mathrm{Mg}, \mathrm{Fe})_{2} \mathrm{SiO}_{4}$

$\mathrm{Fe}_{2} \mathrm{SiO}_{4}$

$\mathrm{Mg}_{2} \mathrm{SiO}_{4}$

$(\mathrm{Mg}, \mathrm{Fe}) \mathrm{Al}_{2} \mathrm{O}_{4}$

$\mathrm{FeAl}_{2} \mathrm{O}_{4}$

$\mathrm{Fe}_{3} \mathrm{O}_{4}$

$(\mathrm{Mg}, \mathrm{Fe})_{2} \mathrm{Al}_{4} \mathrm{SiO}_{10}$

$\mathrm{Al}_{2} \mathrm{SiO}_{5}$

$\mathrm{Al}_{2} \mathrm{SiO}_{5}$

$\mathrm{Al}_{2} \mathrm{SiO}_{5}$

$\mathrm{Al}_{2} \mathrm{O}_{3}$

$\mathrm{CaAl}_{2} \mathrm{Si}_{2} \mathrm{O}_{8}$

$\mathrm{NaAlSi}_{3} \mathrm{O}_{8}$

$\mathrm{KAISi}_{3} \mathrm{O}_{8}$

$\mathrm{K}(\mathrm{Mg} \mathrm{Fe})_{3} \mathrm{AlSi}_{3} \mathrm{O}_{10}(\mathrm{OH})_{2}$

$\mathrm{KMg}_{3} \mathrm{AlSi}_{3} \mathrm{O}_{1 \mathrm{O}}(\mathrm{OH})_{2}$

$\mathrm{KFe}_{3} \mathrm{AlSi}_{3} \mathrm{O}_{10}(\mathrm{OH})_{2}$

$\mathrm{SiO}_{2}$ 


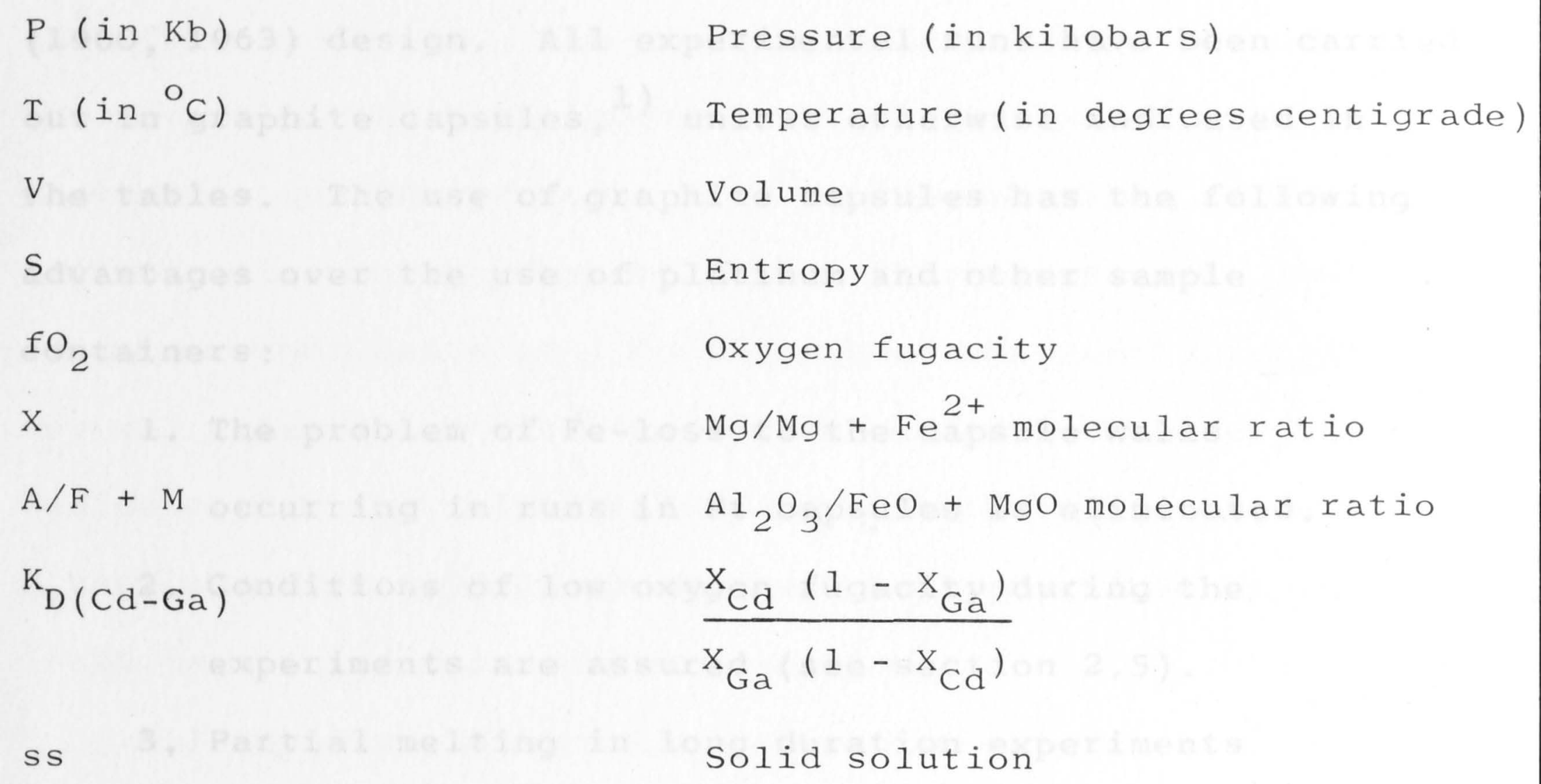

Pressure (in kilobars)

Temperature (in degrees centigrade)

Volume

Entropy

Oxygen fugacity

$\mathrm{Mg} / \mathrm{Mg}+\mathrm{Fe}^{2+}$ molecular ratio

$\mathrm{Al}_{2} \mathrm{O}_{3} / \mathrm{FeO}+\mathrm{MgO}$ molecular ratio

$\frac{x_{\mathrm{Cd}}\left(1-x_{\mathrm{Ga}}\right)}{\mathrm{x}_{\mathrm{Ga}}\left(1-\mathrm{x}_{\mathrm{Cd}}\right)}$

Solid solution 


\section{CHAPTER 2}

\section{EXPER IMENTAL PROCEDURES}

\subsection{APPARATUS AND TECHNIQUES}

The experiments have been carried out in a single stage, solid media, piston-cylinder apparatus of Boyd and England (1960, 1963) design. All experimental runs have been carried out in graphite capsules, ${ }^{1}$ ) unless otherwise indicated in the tables. The use of graphite capsules has the following advantages over the use of platinum and other sample containers:

1. The problem of Fe-loss to the capsule walls occurring in runs in Pt capsules is eliminated.

2. Conditions of low oxygen fugacity during the experiments are assured (see section 2.5).

3. Partial melting in long duration experiments is kept to a minimum compared to non-sealed Pt, Au or Ag-Pd capsules. 2)

Above $800^{\circ} \mathrm{C}$, dried furnace assemblies with inner boron nitride sleeves, identical to those described by Green and

1) The thermocouple bead is separated from the graphite capsule by a ceramic disc.

2) This may be due to the predominance of $\mathrm{CO}$ and $\mathrm{CO}_{2}$ over $\mathrm{H}_{2} \mathrm{O}$ in any vapour phase present. 
Ringwood (1967), have been used. By this method essentially dry conditions are maintained during the runs, preventing hydration or partial melting. At $800^{\circ} \mathrm{C}$ assemblies with talc sleeves only have been used.

Temperatures have been controlled by Pt/Pt-10\% Rh thermocouples at $1100^{\circ} \mathrm{C}$ and above, and with Chromel-Alumel at $1000^{\circ} \mathrm{C}$ and below. The pressure effect on the EMF of the thermocouples has been ignored. Precision in temperature control is considered to be $\pm 10^{\circ} \mathrm{C}$. The possible effect of contamination on the Chromel-Alumel thermocouples in long duration experiments at $1000^{\circ} \mathrm{C}$ has been checked by running several experiments with two thermocouples. These experiments indicate that the relative difference between the chromelAlumel and Pt/Pt-10\% Rh thermocouples at pressures up to $10 \mathrm{~kb}$ is within experimental precision.

All experiments were carried out by the "piston in" method and a $-10 \%$ pressure correction has been applied to the nominal pressures (Green et al., 1967). The pressure uncertainty is believed to be $\pm 0.4 \mathrm{~kb}$. The usual $-10 \%$ correction has been applied since accurate data for the variation of the pressure correction as a function of pressure and temperature are not available as yet.

Edmond and Patterson (1970, in press) have studied the strength of materials used as solid pressure media in piston-cylinder apparatus at elevated temperatures and 
pressures. On the basis of their experimental evidence and theoretical considerations they conclude that a constant pressure correction of approximately - 2 kb may be required for experiments carried out in 0.5 inch diameter pressure vessels.

As part of the present project a number of calibration experiments have been carried out on the olivine-spinel transition in $\mathrm{Mg}_{2} \mathrm{GeO}_{4}$, directly comparing piston cylinder and gas apparatus techniques. ${ }^{1}$ ) The results indicate that at low pressures and temperatures a correction greater than - 10\% of the nominal pressure may be necessary. At $900^{\circ} \mathrm{C}$ - $5 \mathrm{~kb}$ (nominal) a ca. - 30\% correction is needed to bring a piston cylinder reversal into agreement with a gas apparatus reversal. This correction is $0.5 \mathrm{~kb}$ short of the constant correction suggested by the above authors. On the other hand experimental results at $900^{\circ} \mathrm{C}$ to $1050^{\circ} \mathrm{C}$ on the $\mathrm{B} O$ and $\mathrm{Al}+\mathrm{Qz}$ compositions (Chapter 5.5) suggest that a - $10 \%$ correction is sufficient even at low pressures. A larger correction would cause an inconsistency between the present data and hydrothermal experiments on the system $\mathrm{FeO}_{-} \mathrm{Al}_{2} \mathrm{O}_{3}-\mathrm{SiO}_{2}$ (Hsu, 1968$)$.

In the relatively long duration experiments used in the present study, during which the pressure has been

1) Chromel-Alumel thermocouples were used in both types of apparatus. 
repeatedly readjusted on the compression stroke, the magnitude of the necessary pressure correction may be reduced compared to short duration experiments. From the above it is clear that the magnitude of the pressure correction will be a function of a large number of variables e.g. P. T, time, combination of pressure media, dimensions of the pressure cell, condition of the pressure vessel etc. For this reason the exact value of the necessary pressure correction remains unknown, however most of the conclusions reached in this thesis will not be basically affected by any possible change in the magnitude of the pressure correction.

\subsection{PREPARATION OF GLASSES}

Synthetic oxide mixes were prepared from analytical reagent chemicals. The starting compounds are listed in Table 2.1. These compounds were thoroughly mixed by grinding, pellitised, and fired at $1100^{\circ} \mathrm{C}$ to 8 hours to produce the oxide mix. Iron was added as ferric iron prior to firing. Subsequently $\mathrm{Fe}$-powder was added in the right proportion to produce FeO after melting, and mixed in by prolonged grinding under acetone. The resulting mix was pelletised, melted and quenched to a glass under reducing conditions.

Most glasses were melted in platinum crucibles ${ }^{1}$ )

1) To the oxide mix melted in platinum crucibles an empirically determined amount of extra Fe-powder, approximately 0.005 gms per 2 grams of mix, was added to make up for the loss of Fe to the platinum during the melting procedure. 
Analytical reagent chemical compounds used in preparing the synthetic rock compositions

silicic acid

aluminium sulphate hydrate

hematite) mixed in proportions

iron f f Feo content

magnesium oxide

calcium carbonate

sodium carbonate

potassium carbonate
$\mathrm{SiO}_{2}$

$\mathrm{Al}_{2} \mathrm{O}_{3}$

$\mathrm{FeO}$

$\mathrm{MgO}$

$\mathrm{CaO}$

$\mathrm{Na}_{2} \mathrm{O}$

$\mathrm{K}_{2} \mathrm{O}$

1) The weight loss on firing of each of the individual compounds (due to the escape of volatiles) was determined prior to use. 
suspended in a graphite cylinder acting as the susceptor within the coil of an induction heater. Argon was passed through the graphite cylinder. While raising the temperature, the sample was observed and the temperature measured with an optical pyrometer. The temperature was raised until complete melting occurred (usually between 1300 and $1500^{\circ} \mathrm{C}$ ). After 1-2 minutes the sample was quenched in water.

The resulting glass was ground to $<20 \mu$ and checked optically for homogeneity. The glasses have been analysed for ferrous and ferriciron and, in a few selected cases, for $\mathrm{Na}_{2} \mathrm{O}$ and $\mathrm{K}_{2} \mathrm{O}$ (E. Kiss, analyst). These analyses showed that that glasses contain $>90 \%$ ferrous iron and have not lost a significant amount of the more volatile elements (Na and K) during preparation .

Some mixes have been fused in molybdenum crucibles using a strip heater in an argon atmosphere. The resulting glasses show no differences from those prepared in the way described above.

\subsection{THE SEEDED GLASS METHODS: STARTING MATERIALS}

As the use of glass as starting material has proved unreliable owing to the appearance and persistence of metastable low pressure phases (e.g. cordierite) and extremely low nucleation rates of high pressure phases (e.g. garnet), a seeding technique has been used. Finely 
ground crystalline material, ${ }^{1}$ ) containing both the high and the low pressure assemblages, obtained from large capacity runs on glass, is mixed with glass in a 1:4 ratio. It has been found that the glass shards crystallize in a short time (5-10 minutes) to the low pressure assemblage up to pressures we11 beyond its stability limit. Therefore any increase in the high pressure assemblage takes place at the cost of the low pressure assemblage (and not of the glass). A few reversals using crystalline phases only as starting materials have been carried out. For this purpose runs containing the required assemblages were mixed in various proportions to serve as starting material. The results of the reversals are in most cases in agreement with the seeded glass runs. Individual starting materials are described at the beginning of each chapter or section.

\subsection{ATTAINMENT OF EQUILIBRIUM}

The best indication that equilibrium has been approached, if not reached, in a large proportion of the experimental runs, is provided by the microprobe analyses of the experimental phases. These analyses show that garnets and

1) The material was ground in an agate vial with a spex MIXER MILL. The resulting minor contamination of $\mathrm{SiO}_{2}$ does not affect the experimental results in any way. 
cordierites within each experimental run are remarkably uniform in composition. Agreement between experiments using different starting materials is also good and distribution coefficients between coexisting garnet and cordierite, for example, in the $\mathrm{B}_{70}$ and $\mathrm{C}_{70}$ compositions agree, within experimental error.

On the other hand the persistence of garnet seeds with virtually unchanged composition as cores in more iron-rich garnets at $900^{\circ} \mathrm{C}$, and sometimes also at $1000^{\circ} \mathrm{C}$, indicates that diffusion rates in the solid phases are very low and that complete chemical equilibrium has not been reached. Similarly, close to equilibrium boundaries, reaction rates are low and as a result equilibrium is not reached. In most of such cases, however, it has been possible to determine the direction in which reaction is proceeding.

Because reaction rates are strongly temperature dependent, run duration has been increased with decreasing temperature. Run times vary from around 15 hours at $1100^{\circ} \mathrm{C}$ to 96 hours at $800^{\circ} \mathrm{C}$. These durations have proved to be adequate for the purpose of this investigation.

\subsection{OXYGEN FUGACITY}

The experiments have been carried out in graphite sample capsules. The capsules and samples were kept under 
atmospheric conditions until use. As a result a small amount of atmospheric contamination, mainly in the form of $\mathrm{H}_{2} \mathrm{O}$, is introduced into the charge and the graphite directly in contact with it. Thus a gas phase consisting largely of C-O-H probably coexists with the solid phases in the charge. This knowledge allows an approximate evaluation of the oxygen fugacity under the present experimental conditions. The oxygen fugacity in an atmosphere in equilibrium with graphite in the presence of water (i.e. in the system C-O-H), is not fixed unless the fugacity of one of the other gas species is independently buffered (Eugster and skippen, 1967). It seems likely that in the present case, the equilibrium will be dominated by graphite, and therefore it is reasonable to assume that the oxygen fugacity is close to that of the C-O system (French and Eugster, 1965). Their data show that the oxygen fugacity at $900-1100^{\circ} \mathrm{C}$ is below the $\mathrm{fO}_{2}$ of the quartz-fayalite-magnetite buffer and approximately between that of the magnetite-wüstite and wüstite-iron buffers $\left(\mathrm{fO}_{2}=10^{-12}-10^{-18}\right.$ bars). As $\mathrm{fO}_{2}$ in this system is relatively pressure dependent, it is possible that at high total pressure it will be greater than $10^{-12}$ bars at $1000-1100^{\circ} \mathrm{C}$ (i.e. close to the QFM buffer).

Independent evidence of low oxygen fugacity under the present experimental conditions has been obtained from 
the work on the iron endmember compositions ${ }{ }_{O}$ and almandine-quartz (Chapter 5.5). In these compositions the following data provide clear proof for low oxygen fugacity:

1. the coexistence of fayalite and quartz (with minor hercynite ${ }_{\text {s }}$ ) at 1000 and $1050^{\circ} \mathrm{C}, 1.8$ and $3.6 \mathrm{~kb}$.

2. the stability of almandine + quartz (+ minor hercynite ${ }_{\mathrm{ss}}$ ) at $1100^{\circ} \mathrm{C}-10 \mathrm{~kb}$.

3. the very low ferric iron content of the hercynite ss coexisting with quartz at $1050^{\circ} \mathrm{C}-$ $3.6 \mathrm{~kb}$ (run no. 1792). It contains only $8 \pm 2$ mole \% magnetite ss (Chapter 3.5).

The coexistence of fayalite and quartz and the fact that spinel has only $8 \pm 2$ mole $\%$ magnetite solid solution show that conditions are more reducing than those of the quartz-fayalite-magnetite buffer. The data of Turnock and Eugster (1962) indicate that at $900^{\circ} \mathrm{C}$ hercynite with

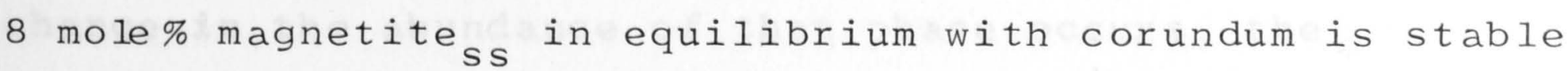
at $\mathrm{fO}_{2} \approx 10^{-13}$ bar. The same hercynite ss coexisting with quartz and fayalite will be stable at lower $\mathrm{fO}_{2}$. The lower limit of oxygen fugacity under the same conditions lies at $\mathrm{fO}_{2} \approx 10^{-17}-10^{-18}$, where the hercynite coexists with wüstite, Fe-metal and vapour. Formation of Fe-metal has not been observed in the experimental runs, therefore 
this limit can also be regarded as a lower limit for the experimental conditions.

In conclusion, it can be stated that in the present experiments oxygen fugacity is kept at a low value by the fact that the system is quasi-buffered by the presence of graphite. The $\mathrm{fO}_{2}$ could range from $10^{-18}$ to $10^{-13}$ bars for the temperatures from 900 to $1000^{\circ} \mathrm{C}$, but is more likely to have a value near the lower or middle part of this range (i.e. $10^{-18}$ to $10^{-15}$ bars).

\subsection{EXAMINATION OF THE SAMPLE}

All runs have been examined optically (as grain mounts) and by $\mathrm{X}-\mathrm{ray}$ powder photography. Polished sections of selected samples have enabled a check on the homogeneity of the runs and on abundance, size and shape of the mineral grains. Changes in the relative abundance of mineral phases have been determined principally by the $\mathrm{x}-\mathrm{ray}$ powder method. In the case of the incoming of garnet, where only a small change in the abundance of that phase occurs, the interpretation of the $x-r a y$ data has been confirmed by the examination of polished sections of the runs in question. When a decrease of garnet had been interpreted from the X-ray data, irregular, resorbed grains (seeds) of garnet were observed optically. Rounded grains with increased grain size were found in the runs in which garnet had been growing. 
In addition, analyses of the experimentally produced phases by electron probe microanalyser have been made for a large number of runs. The methods used to obtain the analytical data are described in the next section.

\subsection{PROCEDURE FOR QUANTATIVE ELECTRON PROBE ANALYSIS}

\section{OF EXPER IMENTAL PHASES}

An electron probe $\mathrm{X}-\mathrm{ray}$ micro analyser (Applied Research Laboratories, EMX model) has been used for the quantative analyses of the experimentally produced phases. ${ }^{1}$ ) Partial analyses for the elements $\mathrm{Fe}, \mathrm{Ca}$, and $\mathrm{Mg}$ were made in most cases. These three elements can be measured simultaneously.

Although the spot size (diameter) of the electron beam can be brought down to 1-2 microns, the actual area (or rather volume) from which $x$-rays are being generated is larger. Therefore grains smaller than 5-8 $\mu$ cannot be accurately analysed by this method.

\section{Garnet analysis}

The most important phase of interest is garnet. This phase forms porphyroblasts which range up to $30 \mu$ in size in some runs. However, garnet is commonly finer-grained (3-15 M)and has small inclusions of other phases. In polished mounts garnet, being much harder than the surrounding phases,

1) Settings used are given at the end of this section. 
stands out in relief and can be easily identified.

To obtain the garnet analyses the following method was used. A grain is located under the electron beam by manual control. Then the electron beamis slowly moved over the grain by electronic controls which allow one to change the position of the spot by very small increments with relative ease. The $x-r a y$ intensities of the three elements being analysed can be watched on the count rate meters during this procedure. In this manner, zoning of the crystal or the presence of inclusions can be detected, even in very small grains.

Usually, one 20-second measurement per grain was made on that part of the grain which simultaneously produced the highest intensities for the three elements. Where zoning was apparent, both cores and rims were measured separately. For each run, a large number of grains were measured in this fashion.

All analyses have been carried out using the same garnet standard. The garnet is from a Norwegian eclogite (Green, 1969). It is not entirely homogeneous and therefore a large number (10-15) of grains were measured in each run and the average was taken.

The analytical precision is $\pm 1.5 \%$ of the amount present for the elements $\mathrm{Fe}$ and $\mathrm{Mg}$ and $\pm 4 \%$ for Ca. These maximum errors in reproducibility have been established by 
averaging the error in the analysis of another more homogeneous and more magnesian garnet standard in 22 separate runs.

Because the unknown garnets were analysed only for three elements, itwas not possible to use a normal (direct) correction procedure. A computer program has been devised $^{1}$ ) that processes the data in such a way that corrections can be made. The output also provides information on whether the analysed mineral is pure garnet or not.

The following steps have been taken in the treatment of the raw data:

1. corrections are made for beam current drift, background and where necessary, dead time.

2. the equivalent weights of almandine, grossular and pyrope from the $\mathrm{Fe}, \mathrm{Ca}$ and $\mathrm{Mg}_{\mathrm{g}}$ values are calculated.

3. the calculated ( 3 component) garnet analysis is used to obtain corrected values for Fe, Ca and $\mathrm{Mg}$. The following corrections have been made:

a. absorption correction as proposed by Philibert (1963) and modified by Duncumb and Shields $(1966)$

b. fluorescence correction as proposed by Reed (1965), except that a constant of 11.6 was used

1) The program was kindly written by N.G. Ware, A.N.U. 
for the J-values.

c. atomic number correction as proposed by Duncumb and Reed (1968).

4. the corrected values of Fe, Ca, Mg are calculated in total weight of almandine + grossular + pyrope end members.

5. the endmembers are expressed in mole \%.

6. the information obtained in (5) is printed out on a triangular garnet diagram. Analyses with totals (as obtained in 4) outside the limits 95-102 are automatically rejected.

The output allows one to evaluate the amount of contamination by other phases. The total weight of the garnet end members calculated in (4) should be equal to 100 , if the analysis represents pure garnet. ${ }^{1)}$ The total is lowered by contamination of all other phases except hypersthene and spinel, these increase the total to >100.

The totals obtained have the general tendency to be low owing to contamination. Because the scatter in data points in the triangular diagrams does not appreciably change when analyses with totals down to 80 are included, the contamination is evidently mainly due to inclusions of

1) It is assumed that the garnet contains no ferric iron. The totals obtained suggest this assumption is valid within the limits of error. 
quartz. This provides indirect evidence that the scatter observed is not due to varying amounts of contamination by other ferromagnesian phases (e.g. cordierite, hypersthene, spinel, sapphirine), but reflects actual differences in garnet composition.

\section{Cordierite analysis}

Cordierite cannot be recognized in polished sections. It can only be found by moving the sample under the electron beam, while watching the $x-r a y$ intensities of the three elements (Fe, Ca, Mg). Analyses of small areas of only a few microns in size, which are very low in Ca and have intermediate amounts of $\mathrm{Fe}$ and $\mathrm{Mg}$ and which were thought to represent cordierite, do give calculated cordierite totals of close to 100 per cent.

The $\mathrm{Mg} / \mathrm{Mg}+\mathrm{Fe}^{2+}$ ratios of these analyses generally fall in a restricted range for each run, as do the garnet analyses. They are therefore believed to represent the actual range in cordierite compositions. Because of the amount of time involved in obtaining these data, the number of analyses is small for most runs. Uncorrected values for $\mathrm{Fe}$ and $\mathrm{Mg}$ were used for the calculation of the $\mathrm{Mg} / \mathrm{Mg}+\mathrm{Fe}^{2+}$ ratio of the cordierite. It was found empirically from total analyses of natural cordierites that the omission of the correction procedure did not significantly affect the values obtained for this ratio. 
Hypersthene analysis

Hypersthene has a very low relief and is recognizable only when it occurs as large $(>5 \mu)$ grains. In general however, it is very fine grained and analysis is extremely difficult. Only in a few runs has it been possible to obtain analyses, usually with rather low totals. This may be partly due to the fact that the hypersthene is very aluminous.

Sapphirine analysis

Only one run contained crystals of sapphirine large enough for analysis. A total analysis for the elements Fe, Mg, Al, Si has been made in this case (Chapter 4.1).

Settings used for analyses

Accelerating voltage - 10-12 Kilo Volts

Emission current - 80-100 miliamps

Sample current - . .035-.045 microamps

Counting time - $\quad 20$ seconds 


\section{CHAPTER 3}

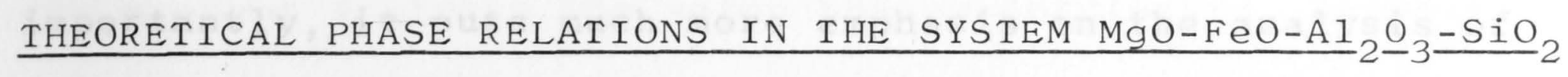

In order to interpret the experimental results on the complex compositions studied, it has proved helpful to analyse the theoretical phase relationships of the system $\mathrm{MgO}-\mathrm{FeO}-\mathrm{Al}_{2} \mathrm{O}_{3}-\mathrm{SiO}_{2}$ by the Phase Rule and Schreinemakers methods. 1 )

Although the theoretical analysis was developed chiefly as an aid in deducing the experimentally observed phase relations, it is presented at the outset to introduce the reader to the various types of equilibria to be discussed in later chapters. The proposed model phase diagrams in which the relative stabilities of the ferromagnesian phases occurring in the system are represented as a function of pressure, temperature and composition, could not have been constructed on the basis of theoretical considerations only. The information obtained from the experiments has been essential in selecting the significant phase equilibria from a larger number of mathematically possible ones. The treatment given in this chapter differs from that of previous authors (e.g. Hess, 1969; Grant, 1968) in two

\footnotetext{
1) For a discussion of the methods of Schreinemakers the reader is referred to Schreinemakers (1965) and Zen (1966).
} 
ways. It deals only with anhydrous equilibria and more importantly, it puts much more emphasis on the analysis of divariant equilibria, which are believed to be of particular relevance to mineral assemblages occurring in natural rocks. The importance of divariant equilibria in natural processes was first emphasized by Goldschmidt (1911), who argued that the occurrence of invariant and univariant mineral assemblages in natural rocks has a very low probability (Goldschmidt's mineralogical Phase Rule). Ramberg (1959, 1964) has drawn attention to the potential of divariant reactions as geothermo-barometers.

A theoretical analysis of part of the system $\mathrm{MgO}-\mathrm{FeO}-\mathrm{Al}_{2} \mathrm{O}_{3}-\mathrm{SiO}_{2}$ has been given by Khlestov (1964) and Marakushev and Kudryavtsev (1965). These authors present a treatment of the reactions involving the minerals garnet, cordierite, hypersthene, sillimanite and quartz. Based on natural rock observations, the approach followed by these Russian workers evaluates the interaction of divariant and univariant reactions as a function of temperature, pressure and compositions of the phases. These papers will be further discussed in Chapter 10 on the application of experimental results to natural rocks.

Phase analysis

In order to analyse the phase equilibria in a multicomponent system, the chemographic relationships of 
the phases occurring in the system have to be known. In the present analysis the seven phases cordierite, sapphirine, hypersthene, spinel, garnet, sillimanite and quartz have been considered. The relative compositions of the ferromagnesian phases (in terms of their $\mathrm{Mg} / \mathrm{Mg}+\mathrm{Fe}^{2+}$ ratios (X)) can be derived from the experimental results obtained in this study and from natural rock data. The observed relative values

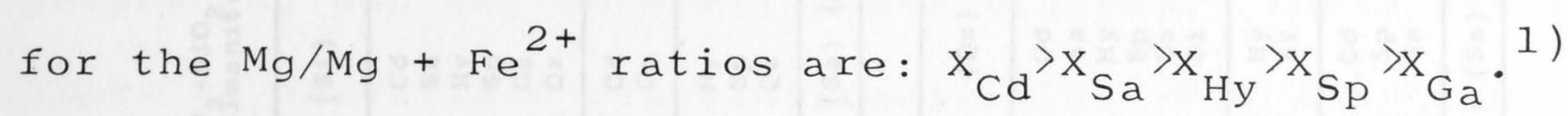
(Note that spinel is $\mathrm{MgAl}_{2} \mathrm{O}_{4}-\mathrm{FeAl}_{2} \mathrm{O}_{4}$ solid solution only.)

\subsection{INVAR IANT POINTS AND UNIVARIANT CURVES}

In a 4-component system with 7 phases there are 7 invariant points each involving 6 phases (one phase being absent in each case). The invariant points are generally identified by the missing phase e.g. ( $Z$ ) is the invariant point from which the phase $Z$ is absent. A maximum of 6 univariant reactions pass through every invariant point. A list of all possible invariant points and univariant equilibria is given in Table 3.1. At an invariant point, pressure, temperature and the compositions of all phases are uniquely fixed. In the case of univariant equilibrium one variable can be chosen ( $P$, $T$ or the composition of one

1) Evidence supporting the proposed order of $\mathrm{X}$-values is reviewed in Chapter 9. The alternative with $\mathrm{x}_{\mathrm{Sp}}<\mathrm{X}_{\mathrm{Ga}}$ is
considered in Appendix 2 of this Chapter. 
TABLE 3.1

Invariant points and univariant reactions in the system $\mathrm{MgO}-\mathrm{FeO}-\mathrm{Al}_{2} \mathrm{O}_{3}-\mathrm{SiO}_{2}$

involving the phases cordierite, garnet, hypersthene, sapphirine, spinel, silimanite and quartz

\begin{tabular}{|c|c|c|c|c|c|c|c|c|c|c|c|c|c|c|c|c|c|c|c|c|c|c|c|}
\hline Invariant & oint & trat & & $(s p)$ & & & & 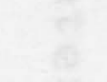 & tat & (Hy) & & I & cas & 9 & $(\mathrm{Si})$ & & & & 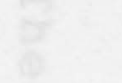 & $(\mathrm{Sa})$ & & & \\
\hline $\begin{array}{r}\text { Phases } \\
\text { invariant }\end{array}$ & int & $y$ & 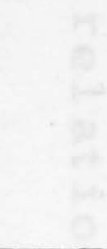 & $\begin{array}{l}\mathrm{Cd} \\
\mathrm{Sa} \\
\mathrm{Hy} \\
\mathrm{Ga} \\
\mathrm{Si} \\
\mathrm{Qz}\end{array}$ & ter & 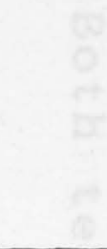 & 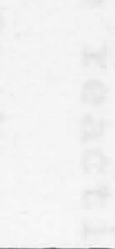 & 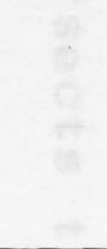 & 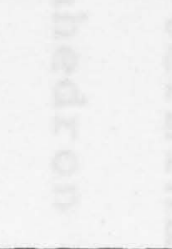 & $\begin{array}{l}\mathrm{Cd} \\
\mathrm{Sa} \\
\mathrm{Sp} \\
\mathrm{Ga} \\
\mathrm{Si} \\
\mathrm{Qz}\end{array}$ & & $\sqrt{2}$ & 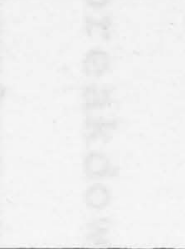 & $\frac{5}{2}$ & $\begin{array}{l}\mathrm{Cd} \\
\mathrm{Sa} \\
\mathrm{Hy} \\
\mathrm{SP} \\
\mathrm{Ga} \\
\mathrm{Qz}\end{array}$ & $x^{2}$ & 5 & 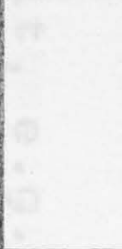 & 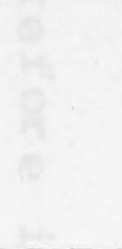 & $\begin{array}{l}\mathrm{Cd} \\
\mathrm{Hy} \\
\mathrm{SP} \\
\mathrm{Ga} \\
\mathrm{Si} \\
\mathrm{Qz}\end{array}$ & 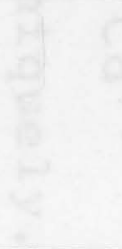 & $\sqrt{2}$ & \\
\hline \multirow{2}{*}{$\begin{array}{l}\text { Univariant } \\
\text { reaction }\end{array}$} & join & $\begin{array}{l}\mathrm{Hy} \\
\mathrm{Si}\end{array}$ & $\begin{array}{l}\mathrm{Hy} \\
\mathrm{Si}\end{array}$ & $\begin{array}{l}\mathrm{Sa} \\
\mathrm{Qz}\end{array}$ & $\begin{array}{l}\mathrm{Sa} \\
\mathrm{Qz}\end{array}$ & $\begin{array}{l}\mathrm{Cd} \\
\mathrm{Ga}\end{array}$ & $\begin{array}{l}\mathrm{Cd} \\
\mathrm{Ga}\end{array}$ & $\begin{array}{l}\mathrm{Sa} \\
\mathrm{Qz}\end{array}$ & $\begin{array}{l}\mathrm{Sa} \\
\mathrm{Qz}\end{array}$ & $\begin{array}{l}\mathrm{SP} \\
\mathrm{Qz}\end{array}$ & $\begin{array}{l}\mathrm{Sp} \\
\mathrm{Qz}\end{array}$ & $\begin{array}{l}\mathrm{Cd} \\
\mathrm{Sp}\end{array}$ & $\begin{array}{l}\mathrm{Sa} \\
\mathrm{Qz}\end{array}$ & $\begin{array}{l}\mathrm{Cd} \\
\mathrm{Ga}\end{array}$ & $\begin{array}{l}\mathrm{Cd} \\
\mathrm{Ga}\end{array}$ & $\begin{array}{l}\text { Sa } \\
\text { Ga }\end{array}$ & $\begin{array}{l}\mathrm{Sa} \\
\mathrm{Ga}\end{array}$ & $\begin{array}{l}\mathrm{Cd} \\
\mathrm{Ga}\end{array}$ & $\begin{array}{l}S p \\
Q z\end{array}$ & $\begin{array}{l}\mathrm{Cd} \\
\mathrm{Ga}\end{array}$ & $\begin{array}{l}\mathrm{Hy} \\
\mathrm{Si}\end{array}$ & $\begin{array}{l}\mathrm{Hy} \\
\mathrm{Si}\end{array}$ & $\begin{array}{l}\mathrm{SP} \\
\mathrm{Qz}\end{array}$ \\
\hline & plane & $\begin{array}{l}\mathrm{Sa} \\
\mathrm{Ga} \\
\mathrm{Qz}\end{array}$ & $\begin{array}{l}\mathrm{Cd} \\
\mathrm{Sa} \\
\mathrm{Ga}\end{array}$ & $\begin{array}{l}\mathrm{Cd} \\
\mathrm{Ga} \\
\mathrm{Si}\end{array}$ & $\begin{array}{l}\mathrm{Cd} \\
\mathrm{Hy} \\
\mathrm{Si}\end{array}$ & $\begin{array}{l}\mathrm{Hy} \\
\mathrm{Si} \\
\mathrm{Qz}\end{array}$ & $\begin{array}{l}\mathrm{Sa} \\
\mathrm{Hy} \\
\mathrm{Qz}\end{array}$ & $\begin{array}{l}\mathrm{Cd} \\
\mathrm{Ga} \\
\mathrm{Si}\end{array}$ & $\begin{array}{l}\mathrm{Cd} \\
\mathrm{Sp}\end{array}$ & $\begin{array}{l}\mathrm{Cd} \\
\mathrm{Ga} \\
\mathrm{Si}\end{array}$ & $\begin{array}{l}\mathrm{Sa} \\
\mathrm{Ga} \\
\mathrm{Si}\end{array}$ & $\begin{array}{l}\mathrm{Sa} \\
\mathrm{Ga} \\
\mathrm{Si}\end{array}$ & $\begin{array}{l}\mathrm{Cd} \\
\mathrm{Sp}\end{array}$ & $\begin{array}{l}\mathrm{Sa} \\
\mathrm{Hy} \\
\mathrm{Qz}\end{array}$ & $\begin{array}{l}\text { Hy } \\
\text { Sp } \\
\text { Qz }\end{array}$ & $\begin{array}{l}\mathrm{Hy} \\
\mathrm{Sp} \\
\mathrm{Qz}\end{array}$ & $\begin{array}{l}\mathrm{Cd} \\
\mathrm{Hy} \\
\mathrm{SP}\end{array}$ & $\begin{array}{l}\mathrm{Hy} \\
\mathrm{SP} \\
\mathrm{Qz}\end{array}$ & $\begin{array}{l}\mathrm{Cd} \\
\mathrm{Ga} \\
\mathrm{Si}\end{array}$ & $\begin{array}{l}\mathrm{Hy} \\
\mathrm{Si} \\
\mathrm{Qz}\end{array}$ & $\begin{array}{l}\mathrm{Cd} \\
\mathrm{Sp} \\
\mathrm{Ga}\end{array}$ & $\begin{array}{l}\mathrm{Cd} \\
\mathrm{Sp} \\
\mathrm{Qz}\end{array}$ & $\begin{array}{l}\mathrm{Hy} \\
\mathrm{Ga} \\
\mathrm{Si}\end{array}$ \\
\hline \multicolumn{2}{|c|}{ Missing phase (s) $\left.{ }^{1}\right)$} & (cd) & $(Q z)$ & ( $\mathrm{Hy})$ & $(G a)$ & (Sa) & (Si) & $(S p)$ & $(\mathrm{Ga}, \mathrm{Si})$ & $(\mathrm{Sa})$ & (Cd) & $(Q z)$ & $(\mathrm{Ga}, \mathrm{Hy})$ & $(\mathrm{sp})$ & $(\mathrm{Sa})$ & $(\mathrm{Cd})$ & $(Q z)$ & $(\mathrm{Si})$ & (Hy) & $\left(S_{p}\right)$ & $(\mathrm{Q} z)$ & (Ga) & (cd) \\
\hline
\end{tabular}

\begin{tabular}{|c|c|c|c|c|c|c|c|c|c|c|c|c|c|c|c|c|c|c|}
\hline \multicolumn{2}{|c|}{ Invariant point } & & & (Cd) & & & & \multicolumn{5}{|c|}{$(G a)$} & \multicolumn{6}{|c|}{$(\mathrm{Qz})$} \\
\hline \multicolumn{2}{|c|}{$\begin{array}{l}\text { Phases at } \\
\text { invariant point }\end{array}$} & & & $\begin{array}{l}\mathrm{Sa} \\
\mathrm{Hy} \\
\mathrm{Sp} \\
\mathrm{Ga} \\
\mathrm{Si} \\
\mathrm{Qz}\end{array}$ & & & & & & $\begin{array}{l}\mathrm{Cd} \\
\mathrm{Sa} \\
\mathrm{Hy} \\
\mathrm{Sp} \\
\mathrm{Si} \\
\mathrm{Qz}\end{array}$ & & & & & & $\begin{array}{l}\mathrm{Cd} \\
\mathrm{Sa} \\
\mathrm{Hy} \\
\mathrm{Sp} \\
\mathrm{Ga} \\
\mathrm{Si}\end{array}$ & & \\
\hline \multirow[b]{2}{*}{$\begin{array}{c}\text { Univariant } \\
\text { reaction }\end{array}$} & join & $\begin{array}{l}\mathrm{Sa} \\
\mathrm{Ga}\end{array}$ & $\begin{array}{l}\mathrm{Sp} \\
\mathrm{Qz}\end{array}$ & $\begin{array}{l}\mathrm{Hy} \\
\mathrm{Si}\end{array}$ & $\begin{array}{l}\mathrm{Sa} \\
\mathrm{Ga}\end{array}$ & $\begin{array}{l}\mathrm{Sp} \\
\mathrm{Qz}\end{array}$ & $\begin{array}{l}\mathrm{Hy} \\
\mathrm{Si}\end{array}$ & $\begin{array}{l}\mathrm{Hy} \\
\mathrm{Si}\end{array}$ & $\begin{array}{l}\mathrm{Sa} \\
\mathrm{Qz}\end{array}$ & $\begin{array}{l}\mathrm{Sa} \\
\mathrm{Qz}\end{array}$ & $\begin{array}{l}\mathrm{Cd} \\
\mathrm{Sp}\end{array}$ & $\begin{array}{l}\mathrm{Hy} \\
\mathrm{Si}\end{array}$ & $\begin{array}{l}\mathrm{Hy} \\
\mathrm{Si}\end{array}$ & $\begin{array}{l}\mathrm{Cd} \\
\mathrm{Sp}\end{array}$ & $\begin{array}{l}\mathrm{Sa} \\
\mathrm{Ga}\end{array}$ & $\begin{array}{l}\mathrm{Hy} \\
\mathrm{Si}\end{array}$ & $\begin{array}{l}\mathrm{Sa} \\
\mathrm{Ga}\end{array}$ & $\begin{array}{l}\mathrm{Cd} \\
\mathrm{Sp}\end{array}$ \\
\hline & plane & $\begin{array}{l}\text { Hy } \\
\text { Sp } \\
\text { Qz }\end{array}$ & $\begin{array}{l}\mathrm{Sa} \\
\mathrm{Ga} \\
\mathrm{Si}\end{array}$ & $\begin{array}{l}\mathrm{Sa} \\
\mathrm{Ga} \\
\mathrm{Qz}\end{array}$ & $\begin{array}{l}\mathrm{Hy} \\
\mathrm{Sp} \\
\mathrm{Si}\end{array}$ & $\begin{array}{l}\mathrm{Hy} \\
\mathrm{Ga} \\
\mathrm{Si}\end{array}$ & $\begin{array}{l}\mathrm{Sa} \\
\mathrm{SP} \\
\mathrm{Qz}\end{array}$ & $\begin{array}{l}\mathrm{Sa} \\
\mathrm{Sp} \\
\mathrm{Qz}\end{array}$ & $\begin{array}{l}\mathrm{Cd} \\
\mathrm{Sp}\end{array}$ & $\begin{array}{l}\mathrm{Cd} \\
\mathrm{Hy} \\
\mathrm{Si}\end{array}$ & $\begin{array}{l}\mathrm{Hy} \\
\mathrm{Sa} \\
\mathrm{Si}\end{array}$ & $\begin{array}{l}\mathrm{Cd} \\
\mathrm{Sp} \\
\mathrm{Qz}\end{array}$ & $\begin{array}{l}\mathrm{Cd} \\
\mathrm{Sa} \\
\mathrm{Ga}\end{array}$ & $\begin{array}{l}\mathrm{Sa} \\
\mathrm{Ga} \\
\mathrm{Si}\end{array}$ & $\begin{array}{l}\mathrm{Cd} \\
\mathrm{Hy} \\
\mathrm{SP}\end{array}$ & $\begin{array}{l}\mathrm{Cd} \\
\mathrm{Sp} \\
\mathrm{Ga}\end{array}$ & $\begin{array}{l}\text { Hy } \\
\text { Sp } \\
\text { Si }\end{array}$ & $\begin{array}{l}\mathrm{Hy} \\
\mathrm{Sa} \\
\mathrm{Si}\end{array}$ \\
\hline Missing & $(s)^{1}$ & (Si) & (Hy) & $(\mathrm{Sp})$ & ( $Q z)$ & (Sa) & ( $G a)$ & $(c d)$ & $y, S_{i}$ & $(s p)$ & $(Q z)$ & (Sa) & $(S p)$ & ( $\mathrm{Hy})$ & (Si) & $(\mathrm{Sa})$ & (Cd) & $(G a)$ \\
\hline
\end{tabular}

1) In addition to the phase missing from the invariant point.

A univariant, non degenerate equilibrium is characterised by two non participating phases. 
phase, e.g. $\mathrm{x}_{\mathrm{Cd}}$ ), whereby all other variables are determined uniquely.

A nondegenerate univariant reaction involves five phases. Therefore it can be characterized by the phases absent from it, e.g. $(X, Z)$ is the univariant equilibrium not involving phases $x$ and $Z$ and connecting invariant points $(X)$ and $(Z)$ on a P-T phase diagram. There are two types of univariant reactions possible. For a system having seven phases A, B, C, D, E, F, G we can have:

1. The breakdown of a phase: $A \rightleftharpoons B+C+D+E(F, G)$ terminal reaction, Hess (1969). Chemographically A lies inside the tetrahedron BCDE.

2. The breakdown of a join: $A+B \rightleftharpoons C+D+E(F, G)$ (non-terminal reaction). A lies outside the tetrahedron BCDE and a line through $A$ and $B$ intersects the side CDE.

In degenerate reactions the number of participating phases is reduced. Both terminal and non-terminal types can occur. In order to predict the type of reaction ( 1 or 2 ) for each of the univariant assemblages listed in Table 2.1 , the chemographic relations (or relative positions of the phases in compositional space) have to be known. This knowledge is also required for the detection of degenerate equilibria. From the relative values for the $\mathrm{Mg} / \mathrm{Mg}+\mathrm{Fe}^{2+}$ ratio of the ferromagnesian phases as given above, it has been 
deduced that all the univariant reactions in Table 3.1 are of the second type and that only one degenerate reaction occurs. Therefore, all univariant reactions mark the breakdown of a join, prohibiting the coexistence of two phases, in favour of a triangular plane, allowing the coexistence of the three phases forming the apices of the triangle. The only degenerate reaction (Hy, Ga, Si) is represented by the intersection of two co-planar joins (i.e. Cd-Sp and $S a-Q z)$.

The fact that no terminal univariant reactions (reactions marking the breakdown of a single phase) occur in the system, means that the stability of the individual phases is not limited by any of the univariant boundaries. ${ }^{1}$ ) As will be shown later, the stability of several phases (e.g. Cd, Ga, Sa and $\mathrm{Sp}$ ) is limited by divariant reactions. Since the possible invariant points and univariant reactions are known, it is feasible to construct a pressure-temperature phase diagram. The relative positions of the invariant points and univariant lines in the P-T plane have to comply with Schreinemakers principles. These restrictions alone do not

1) Excepting the kyanite $\rightleftharpoons$ sillimanite, phase boundary which has been disregarded here. The experimental evidence indicates that this reaction does not affect the proposed phase relations. Its intersection with the univariant curve ( $\mathrm{Sa}, \mathrm{Sp}$ ) gives rise to the univariant boundary Cd $+\mathrm{Ga} \rightleftharpoons$ $\mathrm{Hy}+\mathrm{Ky}+\mathrm{Qz}$ (Chapter 9). 
provide a unique solution for a P-T diagram. However, by using evidence obtained in the experimental investigation, a model phase diagram can be constructed that is consistent with both experimental and theoretical constraints.

The model P-T diagram is shown in Figure 3.1. It is apparent from this diagram that some of the invariant points listed in Table 3.1 have been deduced to be metastable. The reasons for choosing the stable and metastable invariant points, the relative positions of the stable invariant points and the slopes of univariant curves emanating from them, are discussed below.

The invariant point ( $S p)$ has been inferred to be stable from the experimental evidence ( $B_{70}$ composition, Chapter 5.1). The negative slope of the reaction ( $\mathrm{Sa}, \mathrm{Sp}$ ) and the positive slope of (Cd, $\mathrm{Sp})$, both passing through ( $\mathrm{Sp}$ ), have also

been deduced from the experimental data.

As can be seen from the diagram, assemblages containing cordierite occur at the low pressure (high volume) side of all but one of the univariant reactions. ${ }^{1}$ ) This is due to the relatively large molar volume (low density) of cordierite compared to all other ferromagnesian phases. Similarly,

1) Experimental evidence indicates that the reaction (Si, Sa) shown with a negative slope in Fig. 4.1 actually has a positive slope with Cd and Ga occurring at the high pressure side (see Chapter 9 for discussion). 


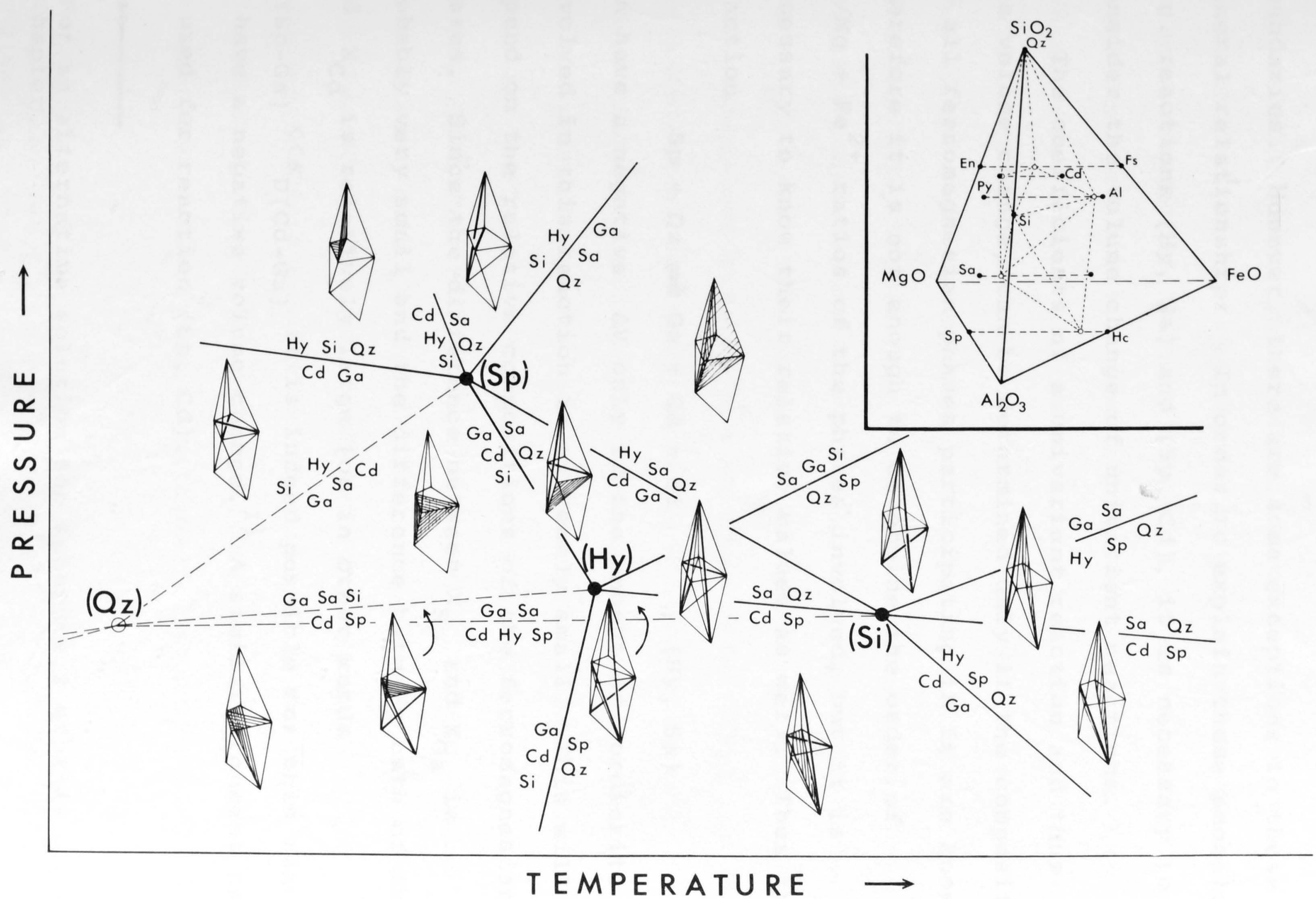

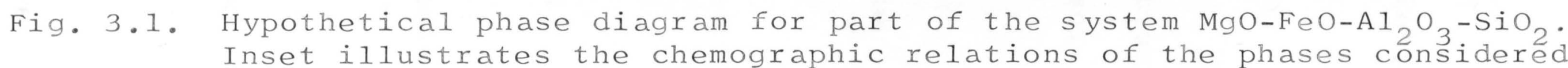
in the analysis. 
garnet occurs at the high pressure side of most phase boundaries. However, there are some exceptions to these general relationships. In order to explain these anomalies, e.g. reactions ( $\mathrm{Hy}, \mathrm{Sa}$ ) and ( $\mathrm{Sp}, \mathrm{Cd})$, it is necessary to consider the volume change of univariant reactions.

The coefficients of a univariant reaction and thus its volume change, can be determined only if the compositions of all ferromagnesian phases participating in it are known. Therefore it is not enough to determine the order of $\mathrm{Mg} / \mathrm{Mg}+\mathrm{Fe}^{2+}$ ratios of the phases involved, but it is necessary to know their relative values as well. Thus the reaction

$$
\mathrm{Sp}+\mathrm{Qz} \rightleftharpoons \mathrm{Ga}+\mathrm{Cd}+\mathrm{Si} \quad(\mathrm{Hy}, \mathrm{Sa})
$$

can have a negative $\Delta V$ only if the amount of cordierite involved in this reaction is extremely small. This will depend on the relative compositions of the ferromagnesian phases. Since the difference between $X_{S p}$ and $X_{G a}$ is probably very small and the difference between both of these and $\mathrm{x}_{\mathrm{Cd}}$ is relatively large (or in other words $\mathrm{K}_{\mathrm{D}(\mathrm{Sp}-\mathrm{Ga})}<\mathrm{K}_{\mathrm{D}(\mathrm{Cd}-\mathrm{Ga})}$ it is indeed possible for this reaction to have a negative volume change. ${ }^{1)}$ A similar argument can be used for reaction ( $\mathrm{Sp}, \mathrm{Cd})$.

1) For an alternative solution see Appendix 2 of this Chapter. 
As the composition of each phase changes continuously along a univariant phase boundary and since as a result the coefficients for the reaction will vary, the volume and entropy changes of the reaction will also vary. It is therefore possible that some of the univariant boundaries are curved. In extreme cases a change in sign of the $\Delta \mathrm{V}$ could occur by which the low volume side of a reaction becomes the high volume side. The negative slope of the reactions ( $\mathrm{Ga}, \mathrm{Sp}$ ) has not been determined experimentally, but can be deduced by a combination of evidence from the $\mathrm{B}_{70}$ and $\mathrm{B}_{100}$ compositions (Chapters 5.1 and 5.4). The existence and relative position of the invariant points (Hy) and (Si) are inferred by combining experimental evidence with restrictions imposed by schreinemakers rules.

Assuming the above deductions to be correct, the invariant points ( $\mathrm{Ga}$ ) and ( $\mathrm{Sa}$ ) and ( $\mathrm{Cd}$ ) have to be metastable for the following reasons. The invariant point (Ga) must be co-linear with the points (Hy) and (Si) because it shares with them the degenerate reaction (Ga, Hy, Si). ${ }^{1}$ ) It has to occur at the intersection of (Hy, Si) with the metastable extension of (Sp, Ga). As can be seen from Figure 3.1, this intersection can only occur outside the stability field of

1) $(\mathrm{Hy}),(\mathrm{Ga})$ and ( $\mathrm{Si}$ ) are not necessarily co-linear in the sense that they lie on a straight line, because the univariant phase boundaries may be curved. 
Hy-Si. Therefore (Ga) which involves Hy and Si must be metastable.

The invariant point ( $\mathrm{Sa}$ ) has to occur at the intersection of the phase boundaries ( $\mathrm{Sp}, \mathrm{Sa}),(\mathrm{Si}, \mathrm{Sa}$ ) and (Hy, Sa). This intersection lies outside the stability field of Hy-si (Fig. 3.1), and as a result (Sa) which involves Hy and Si is necessarily metastable.

(cd) could be a stable invariant point if the curves $(\mathrm{Sp}, \mathrm{Cd}),(\mathrm{Hy}, \mathrm{Cd})$ and (Si, Cd) intersect at high pressure. It is believed to be more likely that these curves diverge rather than converge towards higher pressure and thus a metastable point (Cd) at low pressure is required (Fig. 3.1). Another possibility is that the three curves are almost parallel, whereby (Cd) would loose any significance.

By the present criteria, the invariant point ( $Q z$ ) could be stable. It may be rendered metastable by reactions involving another phase (e.g. corundum), not considered in the present analysis. In Figure 3.1 only those curves which pass through one of the stable, silica-saturated points (Hy), (Si) and (Sp) have been represented.

The univariant reactions in the phase diagram apply for all bulk compositions within the system $\mathrm{MgO}_{-} \mathrm{FeO}-\mathrm{Al}_{2} \mathrm{O}_{3}-\mathrm{SiO}_{2}$. The composition of the ferromagnesian phases in univariant equilibrium is uniquely fixed by pressure (or temperature), and change along the phase boundaries so as to become more 
magnesian with increasing pressure. For a particular bulk composition, the phase assemblages will be bounded partly by portions of the univariant reactions and partly by divariant reactions (to be discussed in following sections). As pointed out before, no terminal reactions occur in the system as considered. Therefore, none of the phase boundaries in Fig. 3.1 delimit the stability of a single phase. However, appropriate parts of the diagram must be entirely within the stability limits of the end member phases. For example the boundary of reaction (Ga, Sp) in Fig. 3.1 has a relatively short length because the upper stability limit of magnesian cordierite is reached at a pressure only slightly in excess of the invariant point ( $\mathrm{sp}$ ).

\subsection{DIVARIANT REACTIONS}

Five divariant reactions (involving 4 phases) can be derived from each nondegenerate, univariant reaction (involving 5 phases). In Table 3.2 all possible divariant reactions related to the three invariant points of interest (Sp), (Hy) and (Si) have been listed. A number of these have been found experimentally. ${ }^{1)}$

1) The numbers following the reactions in Table 3.2 refer to those used in the Chapters dealing with the experimental study. 
TABLE 3.2

Divariant reactions related to univariant equilibria

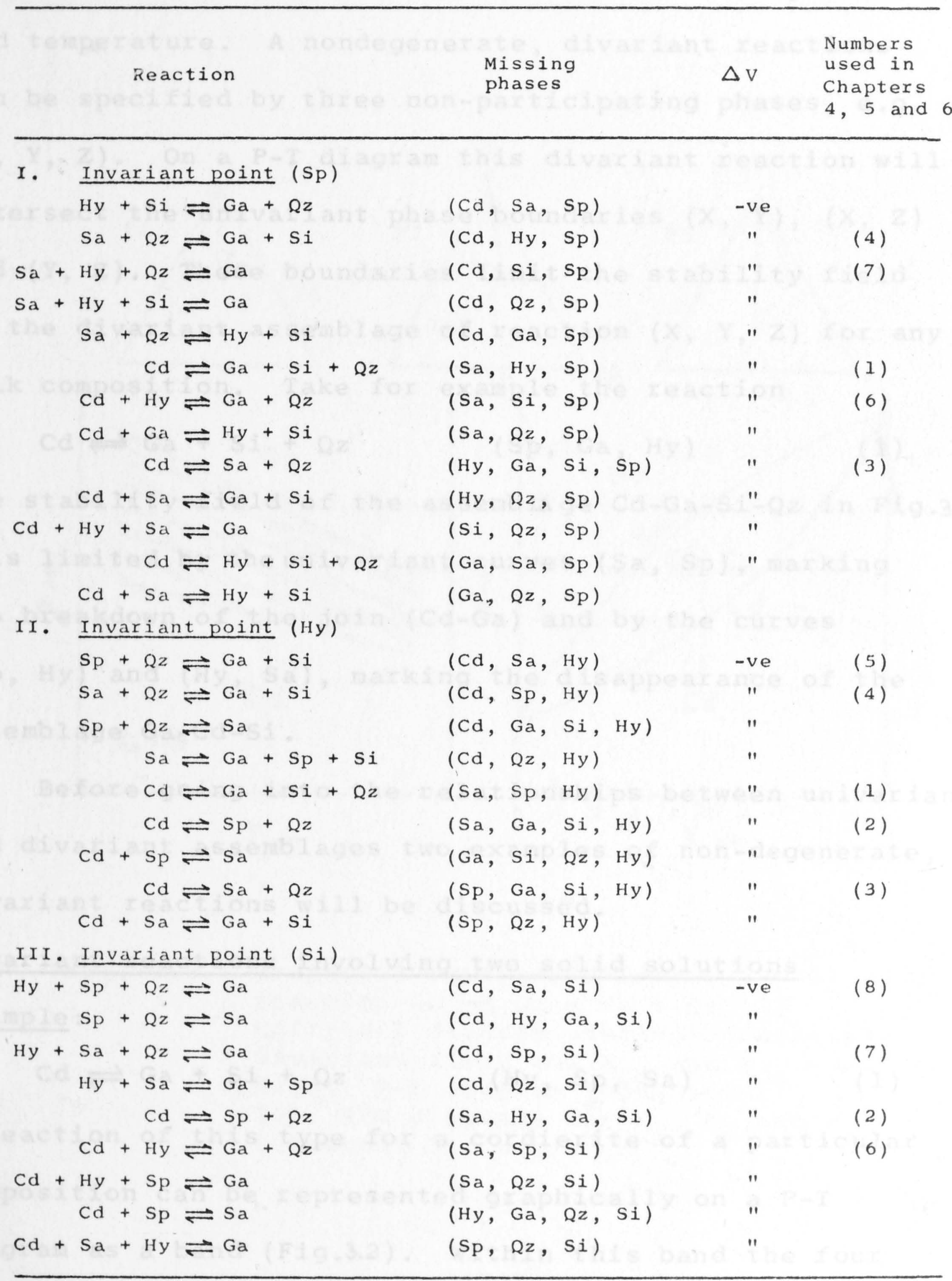


The four phases in divariant equilibrium form a tetrahedron in compositional space. The compositions of the coexisting phases are a function of both pressure and temperature. A nondegenerate, divariant reactions can be specified by three non-participating phases, e.g. $(X, Y, Z)$. On a P-T diagram this divariant reaction will intersect the univariant phase boundaries (X, Y), (X, Z) and $(Y, Z)$. These boundaries limit the stability field of the divariant assemblage of reaction (X, Y, Z) for any bulk composition. Take for example the reaction

$$
\mathrm{Cd} \rightleftharpoons \mathrm{Ga}+\mathrm{Si}+\mathrm{Qz} \quad(\mathrm{Sp}, \mathrm{Ga}, \mathrm{Hy})
$$

The stability field of the assemblage Cd-Ga-Si-Qz in Fig.3. 1 is limited by the univariant curves ( $\mathrm{Sa}$, $\mathrm{Sp}$ ), marking the breakdown of the join (Cd-Ga) and by the curves ( $\mathrm{Sp}, \mathrm{Hy}$ ) and (Hy, Sa), marking the disappearance of the assemblage Ga-Cd-Si.

Before going into the relationships between univariant and divariant assemblages two examples of non-degenerate, divariant reactions will be discussed.

Divariant reactions involving two solid solutions

Example:

$$
\mathrm{Cd} \rightleftharpoons \mathrm{Ga}+\mathrm{Si}+\mathrm{Qz} \quad(\mathrm{Hy}, \mathrm{Sp}, \mathrm{Sa})
$$

A reaction of this type for a cordierite of a particular composition can be represented graphically on a P-T diagram as a band (Fig.3.2). Within this band the four 


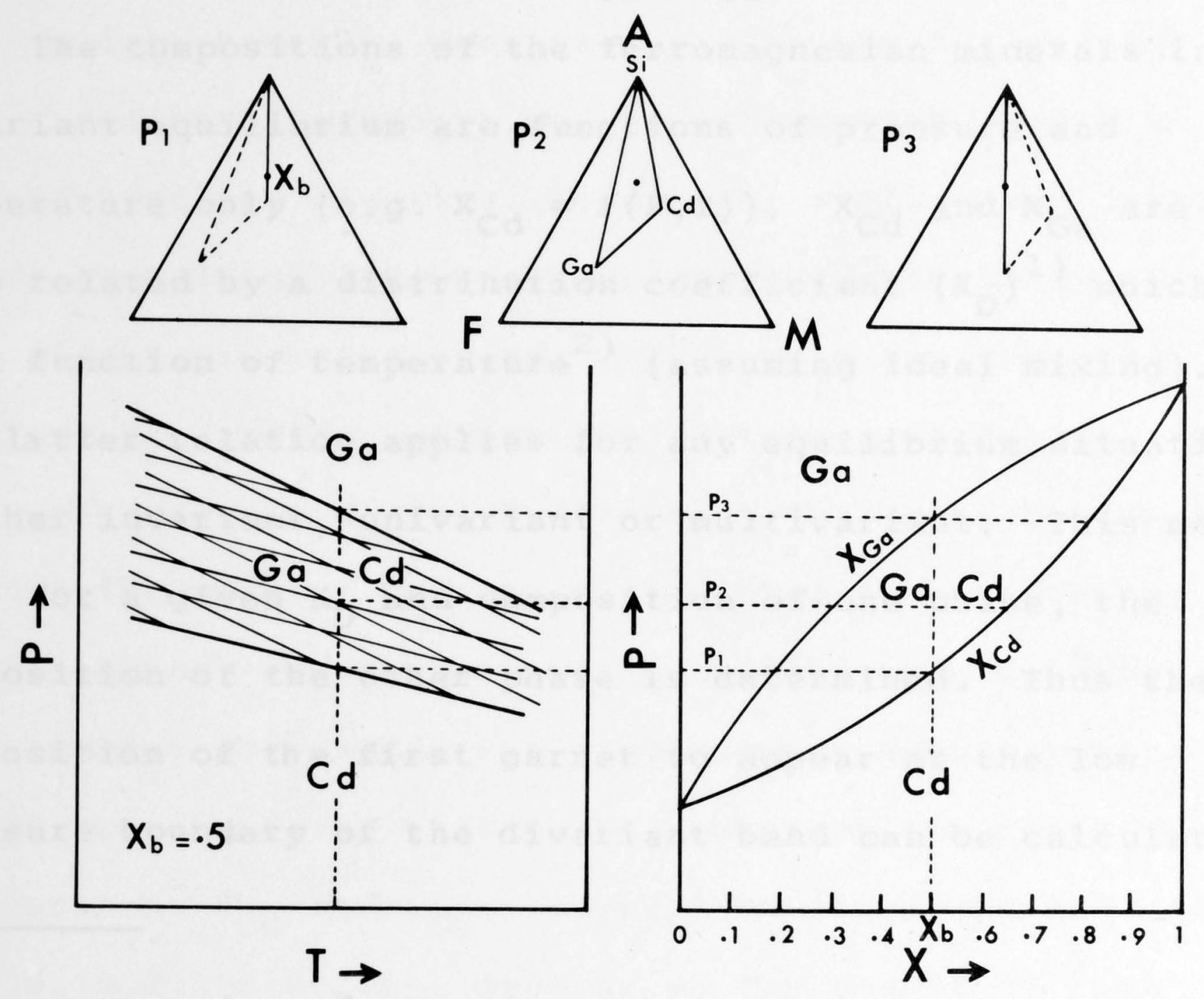

Fig. 3.2. Graphical representation of the divariant reaction $\mathrm{Cd} \rightleftharpoons \mathrm{Ga}+\mathrm{Si}+\mathrm{Qz}$ (1)

Left: P-T diagram showing boundaries of divariant field and $X_{\mathrm{Cd}}$ and $\mathrm{X}_{\mathrm{Ga}}$ contours. Right: P-X diagram (constant Ga) Top: AFM diagrams for $\mathrm{P}_{1}, \mathrm{P}_{2}$ and $\mathrm{P}_{3}$ (constant $T$ ). 
phases (Cd-Ga-Si-Qz) coexist. Both from experimental

evidence and from natural rock data it is well established that Mg distributes in favour of cordierite with respect to garnet and therefore at any point within the divariant field of Figure 3.2 we have $\mathrm{X}_{\mathrm{Cd}}>\mathrm{X}_{\mathrm{Ga}}$.

The compositions of the ferromagnesian minerals in divariant equilibrium are functions of pressure and temperature only $\left(\mathrm{e} \cdot \mathrm{g} \cdot \mathrm{x}_{\mathrm{Cd}}=\mathrm{f}(\mathrm{P}, \mathrm{T})\right) \cdot \mathrm{x}_{\mathrm{Cd}}$ and $\mathrm{X}_{\mathrm{Ga}}$ are also related by a distribution coefficient $\left(K_{D}\right)^{1}$ which is a function of temperature ${ }^{2}$ ) (assuming ideal mixing). The latter relation applies for any equilibrium situation, whether invariant, univariant or multivariant. This means that for a given $K_{D}$ and composition of one phase, the composition of the other phase is determined. Thus the composition of the first garnet to appear at the low pressure boundary of the divariant band can be calculated

1) The expression of the distribution coefficient $K_{D}$ is $\mathrm{K}_{\mathrm{D}(\mathrm{Cd}-\mathrm{Ga})}=\frac{\mathrm{X}_{\mathrm{Cd}}\left(1-\mathrm{X}_{\mathrm{Ga}}\right)}{\mathrm{X}_{\mathrm{Ga}}\left(1-\mathrm{X}_{\mathrm{Cd}}\right)}=\frac{(\mathrm{Mg} / \mathrm{Fe}) \mathrm{Cd}}{(\mathrm{Mg} / \mathrm{Fe}) \mathrm{Ga}}$ where $\mathrm{X}=\mathrm{Mg} / \mathrm{Mg}+\mathrm{Fe}^{2+}$. Because $\mathrm{x}_{\mathrm{Cd}}>\mathrm{X}_{\mathrm{Ga}}$, we have $\mathrm{K}_{\mathrm{D}}>1$.

2) The effect of pressure on $K_{D}$ is probably small. This effect is a function of the volume change resulting from the exchange of $\mathrm{Fe}$ and $\mathrm{Mg}$ between the two minerals. The $\Delta \mathrm{V}$ is very small (for further discussion see appendix). 
for each chosen $K_{D}$ and initial cordierite composition. ${ }^{1}$ ) Similarly $\mathrm{X}_{\mathrm{Cd}}$ at the upper boundary of the band is determined for a given $K_{D}$. As a result, the change in the composition of both minerals across the divariant field is determined for a chosen $K_{D}$ (i.e. fixed $T$ ). ${ }^{2}$ ) This information, however, does not tell us how $\mathrm{X}_{\mathrm{Cd}}$ changes as a function of pressure or, in other words, what is the width of the divariant band. The width shown on the P-T diagram (Fig. 3.2) has been chosen arbitrarily.

Also represented on the P-T diagram are contours of constant $x_{C d}$ and $x_{G a}$. From the foregoing it follows, that lines of constant $\mathrm{X}_{\mathrm{Ga}}$ will intersect the phase boundary for the incoming of garnet, giving rise to a different initial garnet composition for each temperature. The same applies for cordierite at the upper boundary marking the disappearance of that phase. Whether the contours for constant $X_{\mathrm{Cd}}$ and $\mathrm{X}_{\mathrm{Ga}}$ are straight lines (as represented in Fig. 3.2) or curves, depends on the amount of reaction as a function of pressure and on the variation of $K_{D}$ as a function of temperature. ${ }^{3}$ )

1) $\mathrm{X}_{\mathrm{b}}=\mathrm{Mg} / \mathrm{Mg}+\mathrm{Fe}^{2+}$ ratio of the bulk composition as used
in Fig. 3.2. 2) See also section 3.4 on mathematical treatment. 3) See also section 3.4 on mathematical treatment. 
The change in composition of cordierite and garnet for any bulk composition $\left(\mathrm{X}_{\mathrm{b}}\right)$ as a function of pressure (at constant temperature) is conveniently represented in a P-X diagram. This type of diagram is an isothermal section through $P, T, X$ space, whereas a $P-T$ diagram is an iso-compositional section. The P-X diagram presented here is a simplified case in that the reaction for the breakdown of cordierite involves the same phases (i.e. garnet, sillimanite and quartz) over the complete range of $\mathrm{Mg} / \mathrm{Mg}+\mathrm{Fe}^{2+}$ ratios. In reality this does not occur because other reactions interfere near the iron and magnesian ends of the diagram.

As can be seen from the P-X diagram, the pressure interval over which the four phases coexist (the divariant band) shifts to higher pressure from Fe-rich to Mg-rich compositions. The divariant pressure interval is largest for intermediate compositions. It can be determined from the P-X diagram whether or not the divariant fields for two different bulk compositions will overlap on the P-T diagram. This overlap is a function of the distribution coefficient (and thus of temperature), which is demonstrated graphically by a widening of the loop that limits the divariant field with increasing $K_{D}$ (decreasing temperature). The Mg and Fe endpoints are also displaced with changing temperature, and may accentuate or counteract the widening effect. 
As $\mathrm{K}_{\mathrm{D}}$ increases with decreasing temperature, and the first garnet to appear becomes more Fe-rich and the last (disappearing) cordierite more Mg-rich, the width of the divariant band may increase with decreasing temperature. The following observations support this suggestion:

1. If the upper and lower boundaries of the divariant band in a P-T diagram were parallel, the pressure interval of the band would be the same for all temperatures. Because $\mathrm{K}_{\mathrm{D}}$ increases with decreasing temperatures, the slope of the loop on the P-X diagram therefore must become less steep. This also requires that the phase boundaries of the end member reactions ${ }^{1}$ ) converge towards low temperature, unless the approximately symmetrical, lenticular shape of the divariant loops is drastically changed. It seems more likely that the end member reactions converge towards high temperature or are parallel.

2. Because of the common occurrence of the Cd-Ga-Si-Qz assemblage in natural rocks, it is improbable that the divariant fields would narrow towards low temperature, since this would

1) The Mg-endmember reaction (Mg-cordierite $\rightleftharpoons$ pyrope + sillimanite + quartz is almost certainly metastable with respect to Mg-cordierite $\rightleftarrows$ enstatite + kyanite + quartz (see Chapter 8). 
decrease the probability of this assemblage occurring in nature. By narrowing, the bands would become so thin as to be quasi-univariant.

The change in composition of garnet and cordierite with pressure (at constant temperature) for a bulk composition with $\mathrm{x}_{\mathrm{b}}=0.5$ has also been shown in Figure 3.2 in AFM triangular diagrams, ${ }^{1)}$ which can be used conveniently for quartz-saturated assemblages when undersaturated phases like sapphirine and spinel do not occur. In these diagrams the slope of the Cd-Ga tie line for a fixed composition of one of the phases is a function of the $\mathrm{K}_{\mathrm{D}}$.

Divariant reactions involving three solid solutions

Example:

$$
\mathrm{Cd}+4 \mathrm{Hy} \rightleftharpoons 2 \mathrm{Ga}+3 \mathrm{Qz} \quad(\mathrm{Sa}, \mathrm{Sp}, \mathrm{Si})
$$

Reactions of this type, although basically similar to those involving two solid solutions, differ in some important aspects. The appearance of garnet from the reaction between cordierite and hypersthene is no longer a unique function of pressure, temperature and $\mathrm{Mg} / \mathrm{Mg}+\mathrm{Fe}^{2+}$ ratio of the bulk composition. It is also determined by the relative amounts of cordierite and hypersthene present

1) The AFM triangle represents a planar section through the $\mathrm{MgO}-\mathrm{FeO}-\mathrm{Al}_{2} \mathrm{O}_{3}-\mathrm{SiO}_{2}$ tetrahedron. It phl一as'es through hypersthene and sillimanite (see index of Fig.3.1). Cordierite (spatially above the plane) and garnet (below it) are projected onto the plane from the sion corner of the tetrahedron. An AFM diagram represents the phase relations in the system at constant $P$ and $T$. 
which are given by the $\mathrm{Al}_{2} \mathrm{O}_{3} / \mathrm{MgO}+\mathrm{FeO}$ ratio of the bulk composition $(\mathrm{A} / \mathrm{F}+\mathrm{M})_{\mathrm{b}}$. This ratio ranges from 1 for cordierite to $\frac{1}{3}$ for garnet and $O$ for hypersthene. For bulk compositions with the same $\mathrm{Mg} / \mathrm{Mg}+\mathrm{Fe}^{2+}$ ratio $\left(\mathrm{X}_{\mathrm{b}}\right)$ but with different $A / F+M$ ratios, the cordierite and hypersthene will have different compositions for the same temperature (or $\mathrm{K}_{\mathrm{D}}$ ), as shown in Figures 3.3 and 3.4

Consequently, the composition of the first garnet ( $\left.\mathrm{X}_{\mathrm{Ga}}\right)$ that can coexist with cordierite and hypersthene at a constant temperature and $\mathrm{x}_{\mathrm{b}}$, will be a function of $(A / F+M)_{b} \cdot$ Because the compositions of the three coexisting phases (at constant $T$ ) are unique functions of pressure, it follows that garnet must appear at different pressures depending on the $(\mathrm{A} / \mathrm{F}+\mathrm{M})_{\mathrm{b}}$ ratio. This has been shown graphically in Fig. 3.3, where the $\mathrm{A} / \mathrm{F}+\mathrm{M}$ ratio is plotted against pressure. The pressure for the incoming of garnet increases with decreasing $\mathrm{A} / \mathrm{F}+\mathrm{M}$ ratio. ${ }^{1}$ )

On a P-T diagram the divariant reaction is represented by a band (Fig. 3.4). Only if cordierite and hypersthene

1) For simplicity the effect of $\mathrm{Al}_{2} \mathrm{O}_{3}$ in the orthopyroxene has been disregarded. At high temperature (around $1000^{\circ} \mathrm{C}$ ) hypersthene may have up to $10-15$ mole $\% \mathrm{Al}_{2} \mathrm{O}_{3}$ in solid solution. 

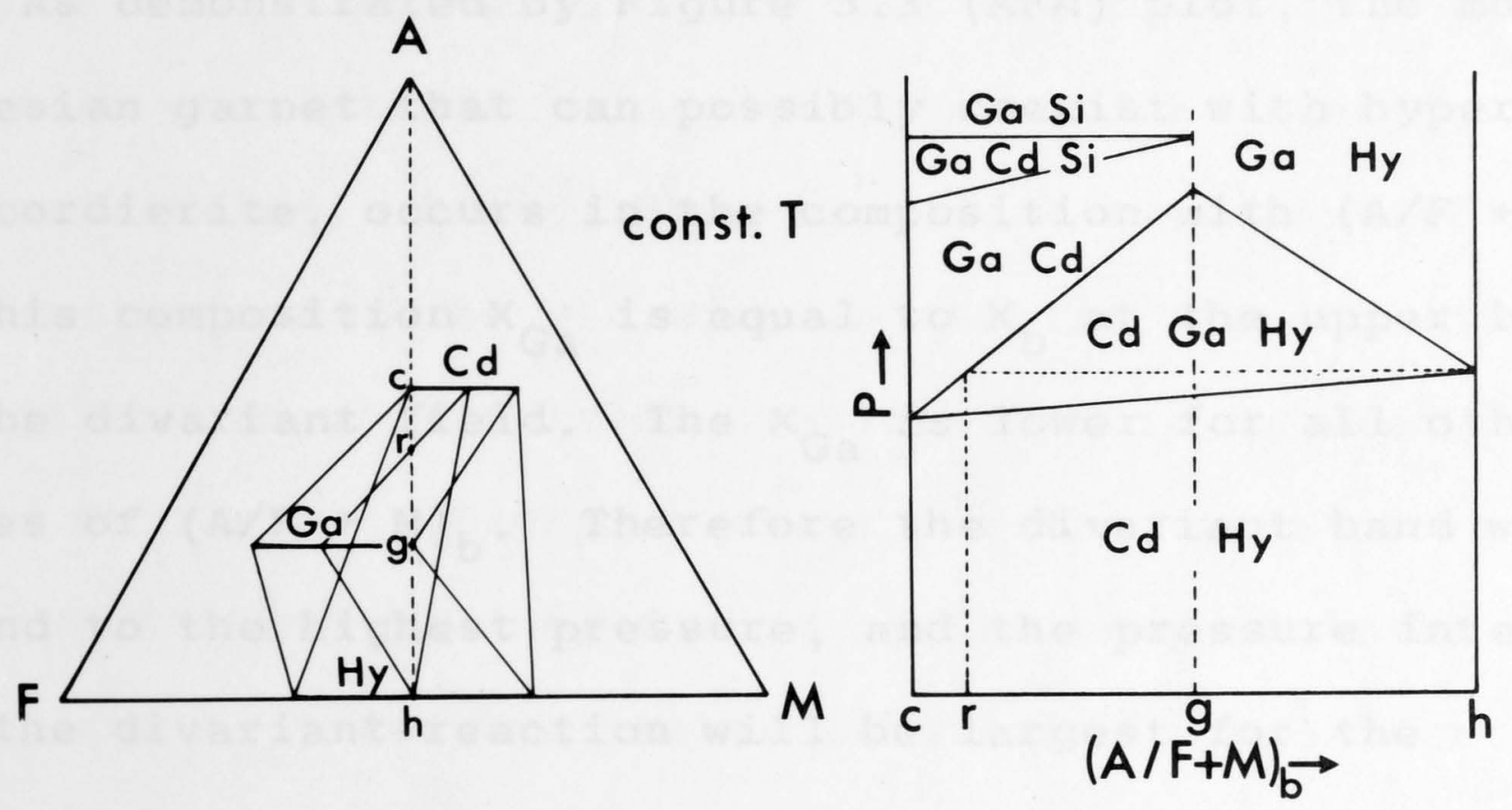

Fig. 3.3. AFM and $\mathrm{P}-(\mathrm{A} / \mathrm{F}+\mathrm{M})$ diagrams (constant $\mathrm{T}$ ) for the divariant reaction $\mathrm{Cd}+\mathrm{Hy} \rightleftharpoons$ $\mathrm{Ga}+\mathrm{Qz}$ (6). The points $\mathrm{c}, \mathrm{g}$ and h have a $(\mathrm{A} / \mathrm{F}+\mathrm{M})_{\mathrm{b}}$ ratio of $1, \frac{1}{3}$ and $\mathrm{O}$ respectively. 
are in the proper molecular proportions (i.e. 1:4) does garnet alone occur above the upper boundary of the divariant band. When $\mathrm{A} / \mathrm{F}+\mathrm{M}<\frac{1}{3}$ hypersthene persists to higher pressure and when $\mathrm{A} / \mathrm{F}+\mathrm{M}>\frac{1}{3}$ cordierite coexists with garnet above the divariant band. The pressure at which either cordierite or hypersthene (or both) disappear, is again determined by $(A / F+M) b$.

As demonstrated by Figure 3.3 (AFM) plot, the most magnesian garnet that can possibly coexist with hypersthene and cordierite, occurs in the composition with $(\mathrm{A} / \mathrm{F}+\mathrm{M}) \mathrm{b}=\frac{1}{3}$. In this composition $\mathrm{x}_{\mathrm{Ga}}$ is equal to $\mathrm{x}_{\mathrm{b}}$ at the upper boundary of the divariant field. The $\mathrm{X}_{\mathrm{Ga}}$ is lower for all other values of $(A / F+M) b$. Therefore the divariant band will extend to the highest pressure, and the pressure interval for the divariant reaction will be largest for the composition with the $\mathrm{A} / \mathrm{F}+\mathrm{M}$ ratio of garnet. On the $(A / F+M)_{b}-P$ diagram (Fig. 3.3) this is expressed by a maximum in the upper boundary. The position of this maximum is restricted by the point $(A / F+M)_{b}=r$. In a composition at point $r$, the position of which is fixed by $K_{D}$, hypersthene disappears at the $s$ ame pressure as garnet (theoretically) appears in a composition at point h (see Fig. 3.3). Given the slope of the lower boundary as a function of pressure and $(A / F+M) b$ ratio, the position of the maximum in the upper boundary at 
$(\mathrm{A} / \mathrm{F}+\mathrm{M})_{\mathrm{b}}=\frac{1}{3}$ can be constructed, assuming that the phase boundaries are represented by straight lines on this diagram.

A final point about the $\mathrm{P}-(\mathrm{A} / \mathrm{F}+\mathrm{M})_{\mathrm{b}}$ diagram is, that the cordierite persisting above the upper phase boundary of the divariant band for compositions with $(\mathrm{A} / \mathrm{F}+\mathrm{M})_{\mathrm{b}}>\frac{1}{3}$ will eventually break down as shown in Figure 3.3. This will be further explained in the next section where the interaction of divariant reactions will be considered. First, however, it is necessary to turn our attention to the P-X diagram for the type of divariant reaction under discussion, represented in Figure 3.4.

On the $\mathrm{P}-\mathrm{X}$ diagram a curve for the variation in $\mathrm{X}_{\mathrm{H} y}$ occurs inside the loop formed by the compositional curves $\left(\mathrm{X}_{\mathrm{Cd}}\right.$ and $\left.\mathrm{X}_{\mathrm{Ga}}\right)$ for the phases cordierite and garnet. The curves delineating the stability field of the divariant assemblage Cd-Hy-Ga-Qz, for a particular value of $(\mathrm{A} / \mathrm{F}+\mathrm{M})_{\mathrm{b}}$, i.e. composition $\left.\mathrm{x}_{\mathrm{b}_{1}},{ }^{1}\right)$ as a function of pressure, do not coincide with the $\mathrm{X}_{\mathrm{Cd}}$ and $\mathrm{X}_{\mathrm{Ga}}$ curves. The lenticular stability field for such a bulk composition is located inside the loop formed by $\mathrm{X}_{\mathrm{Cd}}$ and $\mathrm{X}_{\mathrm{Ga}}$. The reason for this relationship is as follows: at the point where garnet appears in composition $\mathrm{x}_{\mathrm{b}_{1}}\left(\mathrm{~T}_{1}, \mathrm{P}_{1}\right)$ in $\mathrm{Fig}$. 3.4, cordierite is more magnesian and hypersthene is more iron-rich than the bulk composition $\left(\mathrm{K}_{\mathrm{D}}(\mathrm{Cd}-\mathrm{Hy})=2 \mathrm{was}\right.$ ${ }^{1)} \mathrm{X}_{\mathrm{b}_{1}}$ stands for a bulk composition with a fixed value for $\mathrm{X}$;
${ }_{1}$ the subscript 1 refers to a particular A/F + M ratio. 


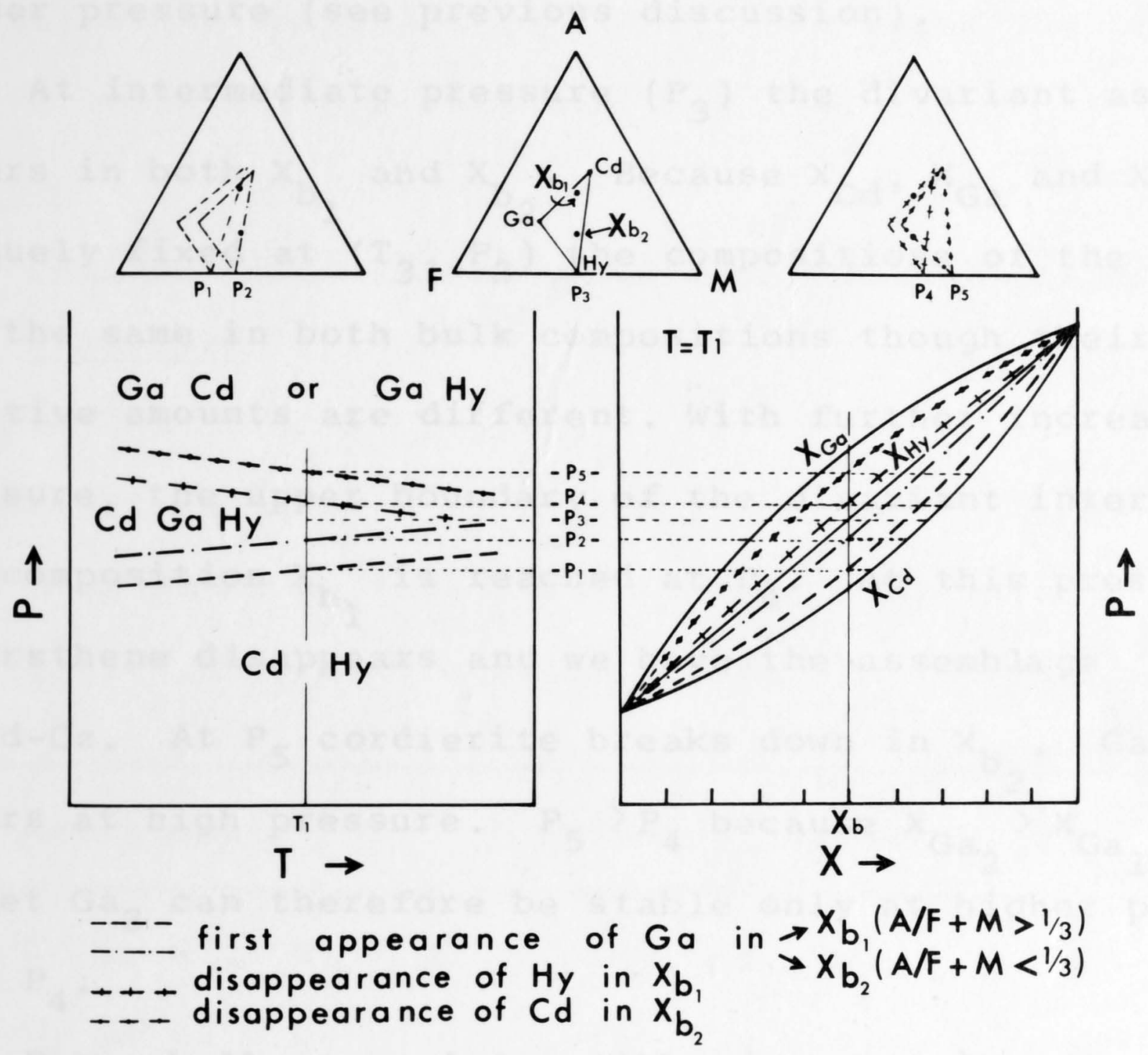

Fig. 3.4. Graphical representation of the divariant reaction $\mathrm{Cd}+\mathrm{Hy} \rightleftharpoons \mathrm{Ga}+\mathrm{Qz}$ (6).

Left: P-T diagram. Right: P-X diagram. Top: AFM diagrams. Phase relations are given for two bulk compositions ( $X_{b}$ and $\mathrm{X}_{\mathrm{b}}$ ) with the same $\mathrm{Mg} / \mathrm{Mg}+\mathrm{Fe}^{2+} \mathrm{ratiol}$ 2 but with different $(\mathrm{A} / \mathrm{F}+\mathrm{M})$ ratios. 
used for the construction of the diagram. ${ }^{1}$ ) The garnet ${ }^{2}$ ) that first appears in $\mathrm{X}_{\mathrm{b}_{2}}$ will be more magnesian than the garnet in $\mathrm{x}_{\mathrm{b}_{1}}$ (compare upper left hand AFM diagram in Fig. 3.4). Therefore the garnet in $x_{b_{2}}$ has to occur at the higher pressure (see previous discussion).

At intermediate pressure $\left(\mathrm{P}_{3}\right)$ the divariant assemblage occurs in both $\mathrm{x}_{\mathrm{b}_{1}}$ and $\mathrm{x}_{\mathrm{b}_{2}}$. Because $\mathrm{x}_{\mathrm{Cd}}, \mathrm{x}_{\mathrm{Ga}}$ and $\mathrm{x}_{\mathrm{H} y}$ are uniquely fixed at $\left(\mathrm{T}_{3}, \mathrm{P}_{3}\right)$ the compositions of the phases are the same in both bulk compositions though their relative amounts are different. With further increase in pressure, the upper boundary of the divariant interval for composition $\mathrm{x}_{\mathrm{b}_{1}}$ is reached at $\mathrm{P}_{4}$. At this pressure hypersthene disappears and we have the assemblage Ga-Cd-Qz. At $\mathrm{P}_{5}$ cordierite breaks down in $\mathrm{X}_{\mathrm{b}_{2}} \cdot \mathrm{Ga}-\mathrm{Hy}-\mathrm{Qz}$ occurs at high pressure. $\mathrm{P}_{5}>\mathrm{P}_{4}$ because $\mathrm{X}_{\mathrm{Ga}_{2}}>\mathrm{X}_{\mathrm{Ga}_{1}}$, and garnet $\mathrm{Ga}_{2}$ can therefore be stable only at higher pressure than $\mathrm{P}_{4}$.

For a bulk composition with $\mathrm{A} / \mathrm{F}+\mathrm{M}=\frac{1}{3}$, garnet will appear at a pressure intermediate between those at which garnet appears in $\mathrm{x}_{\mathrm{b}_{1}}$ and $\mathrm{x}_{\mathrm{b}_{2}}$ (Fig. 3.3 and 3.4 ), while

1) The diagram is not precisely constructed; $K_{D}$ changes slightly from the middle of the diagram towards both ends. This, however, does not affect the discussion in any way.

2) $\mathrm{K}_{\mathrm{D}(\mathrm{Cd}-\mathrm{Ga})}=4$ in the diagram. 
cordierite and hypersthene will simultaneously break down at the point where the line for constant $x_{b}$ intersects the $\mathrm{X}_{\mathrm{Ga}}$ curve. Only in this particular case does the $\mathrm{X}_{\mathrm{Ga}}$ curve limit the divariant field for the assemblage Cd-Hy-Ga-Qz. For all other values of $(A / F+M)_{b}$ the upper boundary occurs below the $x_{G a}$ curve in Fig. 3.4 .

\subsection{RELATIONSHIPS BETWEEN DIVARIANT AND UNIVARIANT REACTIONS}

Example:

Univariant reaction

$$
\mathrm{Cd}+\mathrm{Ga} \rightleftharpoons \mathrm{Hy}+\mathrm{Si}+\mathrm{Qz} \quad(\mathrm{Sa}, \mathrm{Sp})
$$

The related divariant equilibria are:

Reactions

$\mathrm{Cd} \rightleftharpoons \mathrm{Ga}+\mathrm{Si}+\mathrm{Qz}$

$\mathrm{Cd}+\mathrm{Hy} \rightleftharpoons \mathrm{Ga}+\mathrm{Qz}$

$\mathrm{Cd} \rightleftharpoons \mathrm{Hy}+\mathrm{Si}+\mathrm{Qz}$

$\mathrm{Hy}+\mathrm{Si} \rightleftharpoons \mathrm{Ga}+\mathrm{Qz}$

$\mathrm{Cd}+\mathrm{Ga} \rightleftharpoons \mathrm{Hy}+\mathrm{Si}$
Missing phases

( $\underline{\mathrm{H}} \underline{\mathrm{y}}, \mathrm{Sa}, \mathrm{Sp})$

- ve

( $\underline{\text { i }}, \mathrm{sa}, \mathrm{sp}$ )

( $\mathrm{Ga}, \mathrm{Sa}, \mathrm{Sp})$

$(\underline{\mathrm{Cd}}, \mathrm{Sa}, \mathrm{sp})$

$(\underline{\mathrm{Q}} \underline{\mathrm{S}}, \mathrm{Sa}, \mathrm{Sp})$
11

it

11 i

Firstly, the relationship of divariant and univariant reactions will be illustrated on P-X diagrams. For arguments' sake it has been assumed that at low temperature a univariant 
curve does not exist. 1 ) The graphical representation of this situation is presented in Figure 3.5 (left hand side, $\left.\mathrm{T}_{1}\right)$. In this diagram reactions (1) and (6), discussed previously, have been represented. Three isothermal-isobaric sections $\left(P_{1}, P_{2}, P_{3}\right)$ are given in the form of AFM diagrams in Figure 3.6. These exhibit the phase assemblages occurring for all silica-saturated compositions at a specified pressure and temperature. Divariant assemblages are represented by triangles. For all compositions within such a triangle the $\mathrm{Mg} / \mathrm{Mg}+\mathrm{Fe}^{2+}$ ratios of the coexisting phases are fixed. Trivariant fields havebeen contoured for constant $K_{D}$. The compositions of coexisting phases in these fields are determined by bulk composition and temperature $\left(K_{D}\right)$. The distribution coefficients used for $\mathrm{T}_{1}$ in Fig. 3.5 and 3.6 are $\mathrm{K}_{\mathrm{D}(\mathrm{Cd}-\mathrm{Ga})}=6$ and $\mathrm{K}_{\mathrm{D}(\mathrm{Cd}-\mathrm{Hy})}=2.5$

For all compositions in which cordierite persists to pressures above the upper limit of the divariant band (i.e. compositions with $\left.\frac{1}{3}<(A / F+M)_{b}<1\right)$, the cordierite will eventually disappear with increasing pressure due to reaction (1). In the pressure interval between the upper

1) In actual fact the reaction $\mathrm{Cd}+\mathrm{Ga} \rightleftharpoons \mathrm{Hy}+\mathrm{Si}+\mathrm{Qz}$ is replaced at low temperature by the reaction $\mathrm{Cd}+\mathrm{Ga} \rightleftharpoons \mathrm{Hy}+\mathrm{Ky}+\mathrm{Qz}$, due to the intersection of the former with the Ky $\rightleftharpoons$ Si phase boundary (Chapter 4.3). As a result the stable coexistence of pyrope and Mgcordierite in the presence of quartz is prohibited. 

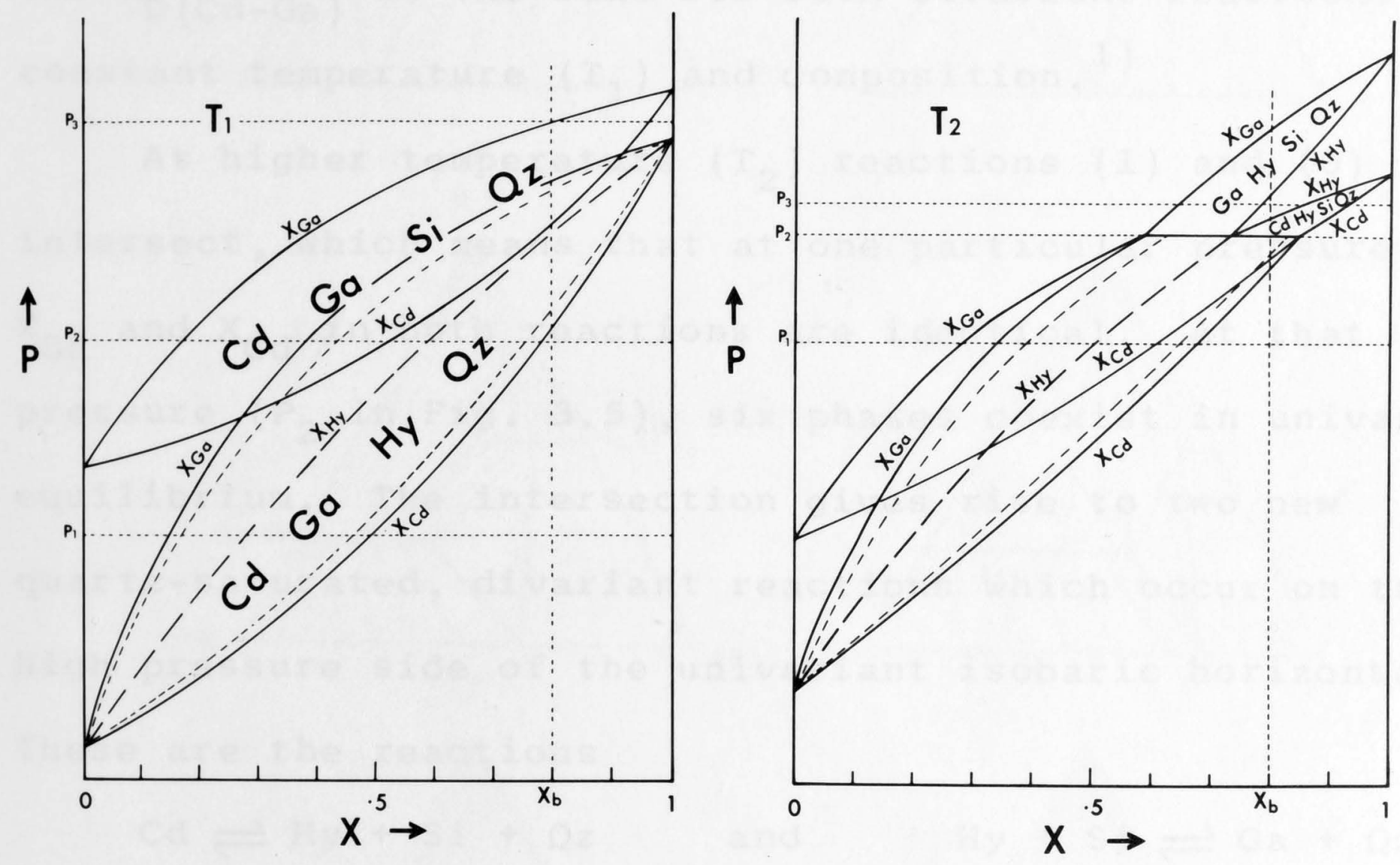

Fig. 3.5. P-X diagrams for reactions $\mathrm{Cd} \rightleftharpoons$ $\mathrm{Ga}+\mathrm{Si}+\mathrm{Qz}$ (1) and $\mathrm{Cd}+\mathrm{Hy} \rightleftharpoons$ $\mathrm{Ga}+\mathrm{Qz}$ (6). Left: $\mathrm{T}_{1}$, reactions do not intersect (hypothetical). Right: $\mathrm{T}_{2}$, reactions intersect on a univariant boundary giving rise to two more divariant reactions, i.e. $\mathrm{Ga}+\mathrm{Qz} \rightleftharpoons \mathrm{Hy}+\mathrm{Si}$ and $\mathrm{Cd} \rightleftharpoons \mathrm{Hy}+\mathrm{Si}+\mathrm{Qz}$. Dashed lines mark the appearance of $\mathrm{Ga}$ and the disappearance of Hy in reaction (6). 
boundary of reaction (1) $\mathrm{X}_{\mathrm{Cd}}$ and $\mathrm{X}_{\mathrm{Ga}}$ remain unchanged. On the P-X diagram $X_{C d}$ and $X_{G a}$ move vertically up from the loop of reaction (6) until both of them simultaneously reach the curves for reaction (1). $x_{\mathrm{Cd}}$ and $\mathrm{X}_{\mathrm{Ga}}$ will reach their respective curves at the same pressure because the $\mathrm{K}_{\mathrm{D}(\mathrm{Cd}-\mathrm{Ga})}$ is the same for both divariant reactions at constant temperature $\left(T_{1}\right)$ and composition. $\left.{ }^{1}\right)$

At higher temperature $\left(\mathrm{T}_{2}\right)$ reactions (1) and (6) intersect, which means that at one particular pressure the $\mathrm{X}_{\mathrm{Ga}}$ and $\mathrm{X}_{\mathrm{Cd}}$ in both reactions are identical. At that pressure ( $\mathrm{P}_{2}$ in Fig. 3.5), six phases coexist in univariant equilibrium. The intersection gives rise to two new quartz-saturated, divariant reactions which occur on the high pressure side of the univariant isobaric horizontal.

These are the reactions

$$
\mathrm{Cd} \rightleftharpoons \mathrm{Hy}+\mathrm{Si}+\mathrm{Qz} \text { and } \mathrm{Hy}+\mathrm{Si} \rightleftharpoons \mathrm{Ga}+\mathrm{Qz}
$$

AFM plots for three isobaric sections are shown in Fig. $3.6 .2)$

A P-T diagram (Fig. 3.7) incorporating the $T_{1}$ and $\mathrm{T}_{2}$ isothermal sections shows the phase relationships for $\mathrm{a}$ chosen bulk composition $\left(\mathrm{X}_{\mathrm{b}}=0.8\right.$ and $\left.\frac{1}{3}<(\mathrm{A} / \mathrm{F}+\mathrm{M})_{\mathrm{b}}<1\right)$

1) Assuming $K_{D}$ is independent of pressure.

2 ) Distribution coefficients used for $\mathrm{T}_{2}$ in Figs. 3.5 and 3.6 are: $\mathrm{K}_{\mathrm{D}(\mathrm{Cd}-\mathrm{Ga})}=4$ and $\mathrm{K}_{\mathrm{D}(\mathrm{Cd}-\mathrm{Hy})}=2$. 

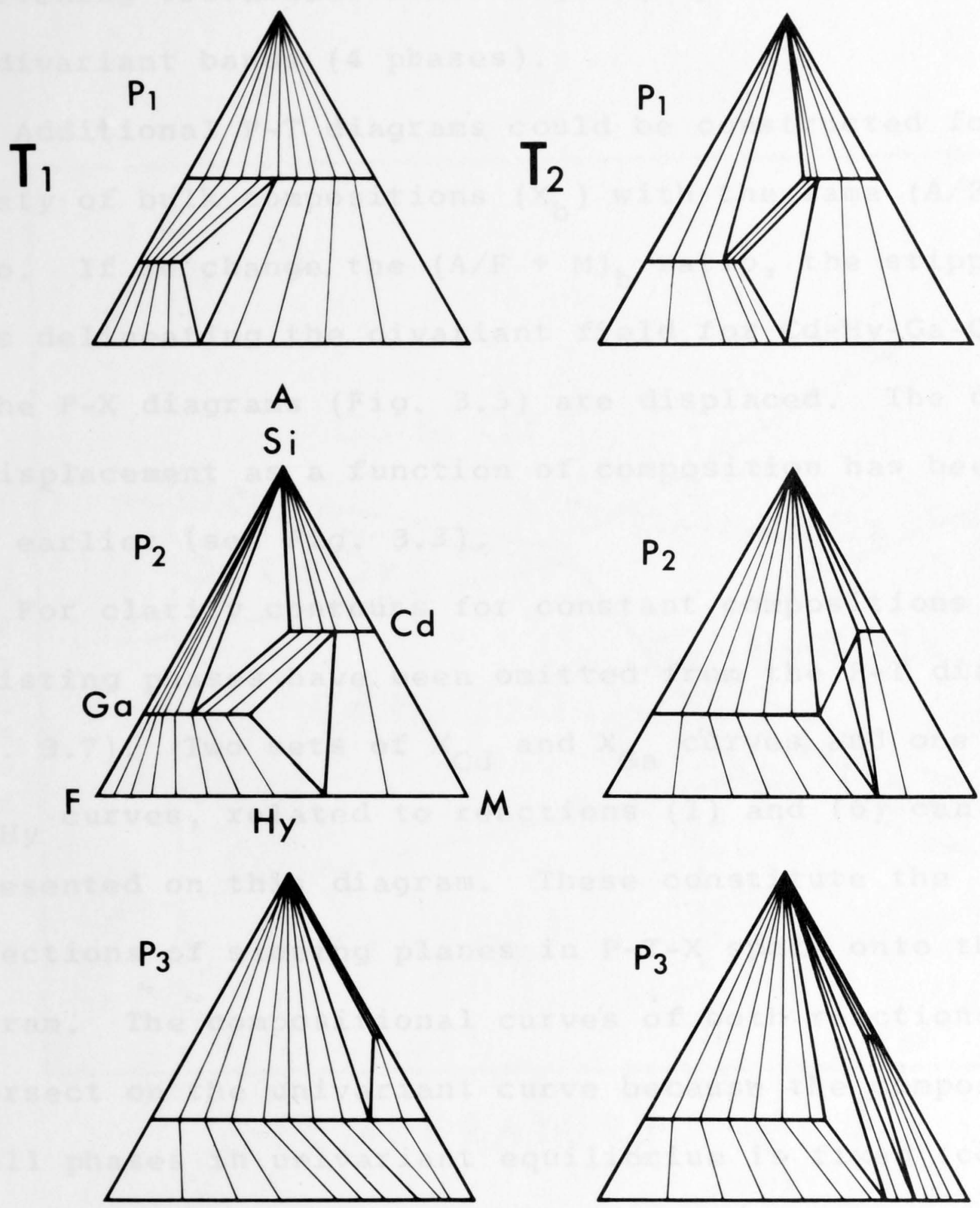

Fig. 3.6. AFM diagrams at $\mathrm{T}_{1}\left(\mathrm{P}_{1}, \mathrm{P}_{2}, \mathrm{P}_{3}\right)$ and

$\mathrm{T}_{2}\left(\mathrm{P}_{1}, \mathrm{P}_{2}, \mathrm{P}_{3}\right)$ showing shifting of tie tines as a function of $P$ at constant $T$. Compare Figs. 3.5 and 3.7 . 
as a function of pressure and temperature. Note the intervening trivariant assemblages ( 3 phases) between the divariant bands ( 4 phases).

Additional P-T diagrams could be constructed for a variety of bulk compositions $\left(\mathrm{X}_{\mathrm{b}}\right)$ with the same $(\mathrm{A} / \mathrm{F}+\mathrm{M})_{\mathrm{b}}$ ratio. If we change the $(\mathrm{A} / \mathrm{F}+\mathrm{M})_{\mathrm{b}}$ ratio, the stippled lines delineating the divariant field for Cd-Hy-Ga-Qz in the P-X diagrams (Fig. 3.5) are displaced. The direction of displacement as a function of composition has been dealt with earlier (see Fig. 3.3).

For clarity contours for constant compositions of the coexisting phases have been omitted from the P-T diagram (Fig. 3.7). Two sets of $x_{C d}$ and $X_{G a}$ curves and one set of $\mathrm{x}_{\mathrm{Hy}}$ curves, related to reactions (1) and (6) can be represented on this diagram. These constitute the projections of sloping planes in P-T-X space onto the P-T diagram. The compositional curves of both reactions intersect on the univariant curve because the composition of all phases in univariant equilibrium is fixed (compare Fig. 3.6, $\left.\mathrm{T}_{2}, \mathrm{P}_{2}\right)$. Further discussion will be given in later chapters, dealing with the interpretation of the experimental data. 


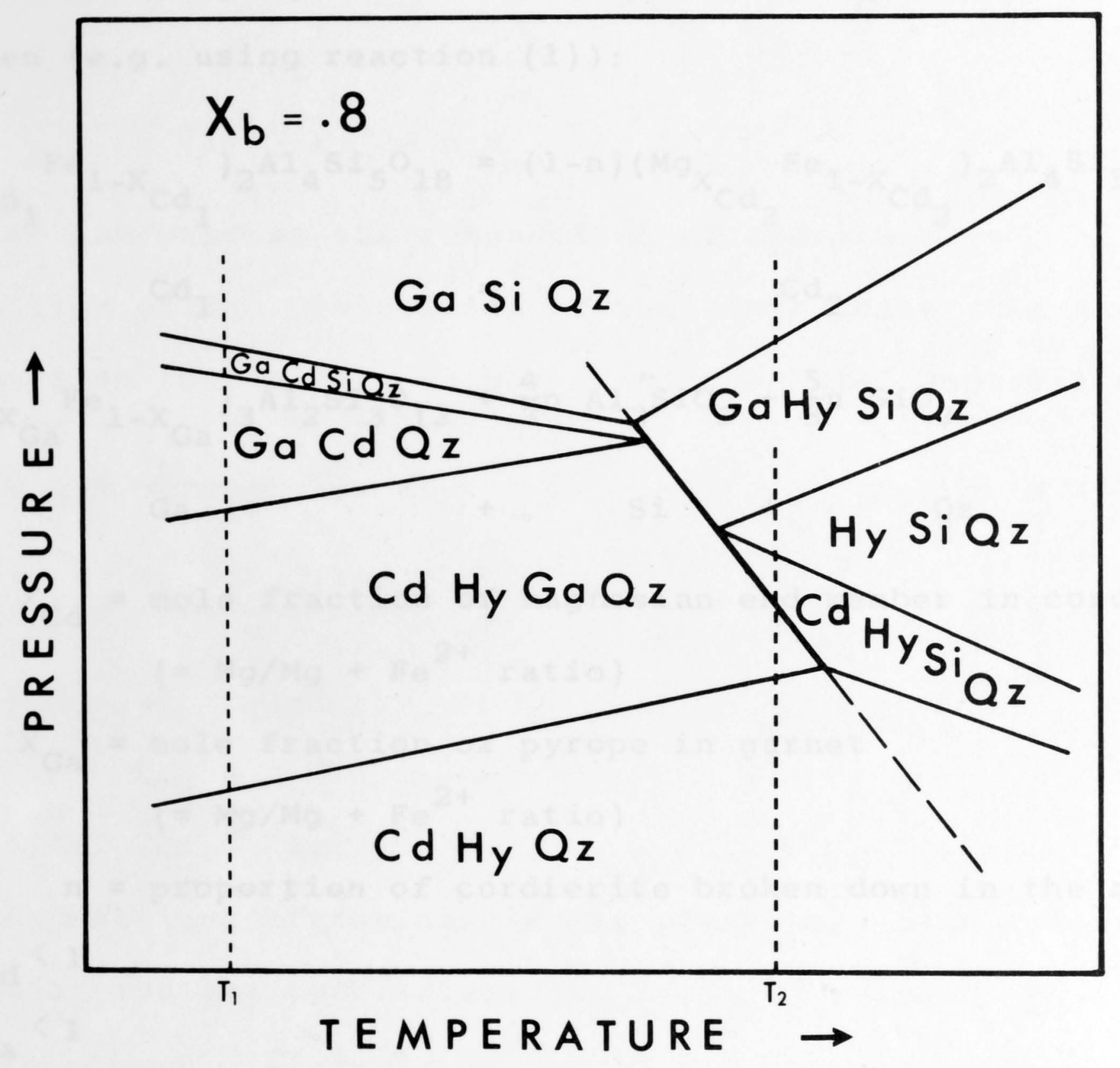

Fig. 3.7. P-T diagram illustrating phase relations for a composition with $\mathrm{X}_{\mathrm{b}}=.8$ and $\frac{1}{3}<(\mathrm{A} / \mathrm{F}+\mathrm{M}){ }_{\mathrm{b}}<1 . \mathrm{T}_{1}$
Figs. 3.5 and 3.6 . $\mathrm{T}_{2}$ refer to 


\subsection{MATHEMATICAL AND GRAPHICAL ANALYSIS OF DIVARIANT}

\section{REACTIONS}

For each simple divariant equilibrium involving two solid solutions, equation of the following type can be written (e.g. using reaction (1)):

$$
\begin{aligned}
& \left({ }^{\mathrm{Mg}} \mathrm{X}_{\mathrm{Cd}}{ }^{\mathrm{Fe}}{ }_{1-\mathrm{X}_{\mathrm{Cd}}}\right){ }_{2} \mathrm{Al}_{4} \mathrm{Si}_{5} \mathrm{O}_{18}=(1-\mathrm{n})\left(\mathrm{Mg}_{\mathrm{X}_{\mathrm{Cd}}} \mathrm{Fe}_{1-\mathrm{X}_{\mathrm{Cd}}}\right){ }_{2} \mathrm{Al}_{4} \mathrm{Si}_{5} \mathrm{O}_{18}+ \\
& \mathrm{Cd}_{1} \quad=\quad \mathrm{Cd}_{2} \\
& \frac{2}{3} n\left(\mathrm{Mg}_{\mathrm{Xa}} \mathrm{Fe}_{1-\mathrm{X}_{\mathrm{Ga}}}\right)_{3} \mathrm{Al}_{2} \mathrm{Si}_{3} \mathrm{O}_{12}+\frac{4}{3} n \mathrm{Al}_{2} \mathrm{SiO}_{5}+\frac{5}{3} n \mathrm{SiO}_{2} \\
& \mathrm{Ga}+\mathrm{Si}+\mathrm{Qz}
\end{aligned}
$$

where $\mathrm{X}_{\mathrm{Cd}}=$ mole fraction of magnesian end member in cordierite

$$
\begin{aligned}
& \left(=\mathrm{Mg} / \mathrm{Mg}+\mathrm{Fe}^{2+} \text { ratio }\right) \\
\mathrm{X}_{\mathrm{Ga}}= & \text { mole fraction of pyrope in garnet } \\
& \left(=\mathrm{Mg} / \mathrm{Mg}+\mathrm{Fe}^{2+} \text { ratio }\right) \\
\mathrm{n}= & \text { proportion of cordierite broken down in the reaction. }
\end{aligned}
$$$$
0<x_{C d}<1
$$$$
0<x_{\mathrm{Ga}}<1
$$$$
\mathrm{O}<\mathrm{n}<1
$$

In the case where cordierite is the only ferromagnesian phase present, $\mathrm{Cd}_{1}$ has the same $\mathrm{Mg} / \mathrm{Mg}+\mathrm{Fe}^{2+}$ ratio as the bulk composition. Therefore

$\mathrm{x}_{\mathrm{Cd}_{1}}=\mathrm{x}_{\mathrm{b}}$ (where $\mathrm{x}_{\mathrm{b}}$ is the $\mathrm{x}$ value for the bulk composition) Consequently we can relate the composition of the initial 
cordierite to that of the phases produced by the reaction. From element balance requirements for Mg in the equation for reaction (1) we can write

$$
\begin{gathered}
2\left(x_{b}\right)=(1-n) 2\left(x_{C d}\right)+\frac{2}{3} 3\left(x_{G a}\right) \\
\text { or } \\
x_{b}=(1-n) x_{C d}+n x_{G a}
\end{gathered}
$$

Thus we can express the composition of one phase as a function of the composition of the other phase, the amount of reaction that has taken place and the bulk composition.

$$
\begin{aligned}
x_{C d} & =\frac{x_{b}-n x_{G a}}{1-n} \\
x_{G a} & =\frac{x_{b}-x_{C d}(1-n)}{n} \\
n & =\frac{x_{C d}-x_{b}}{x_{C d}-x_{G a}}
\end{aligned}
$$

The compositions of the coexisting phases are also related by a distribution coefficient $\left(K_{D}\right)$

$$
\begin{aligned}
& K_{D(C d-G a)}=\frac{X_{C d}\left(1-X_{G a}\right)}{X_{G a}\left(1-X_{C d}\right)}=\frac{(M g / F e) C d}{(M g / F e) G a} \\
& \text { or } \\
& x_{C d}=\frac{K_{D} \cdot x_{G a}}{1+\left(K_{D}-1\right) x_{G a}} \\
& \text { and } \\
& X_{G a}=\frac{x_{C d}}{K_{D}\left(1-X_{C d}\right)+X_{C d}}
\end{aligned}
$$


Therefore, it is possible to express the composition of a phase in terms of $\mathrm{x}_{\mathrm{b}}, \mathrm{n}$ and $\mathrm{K}_{\mathrm{D}}$. This relationship is best illustrated graphically (Fig.3.8)。 In this diagram, having $\mathrm{X}_{\mathrm{Cd}}$ and $\mathrm{X}_{\mathrm{Ga}}$ as perpendicular axes, one can represent:

1. the composition of two coexisting phases by a point on the diagram,

2. a constant distribution coefficient between two phases by a curve,

3. the amount of reaction that has taken place, by the slope of the straight line passing through the compositional point (1) and $x_{b}$, the initial composition of the cordierite.

If ideal mixing ${ }^{1}$ ) is assumed, implying that the $\mathrm{K}_{\mathrm{D}}$ is independent of composition and thus is a function of temperature only, then the change in composition of the coexisting phases with increasing pressure (and increasing n) at constant temperature (and $\mathrm{K}_{\mathrm{D}}$ ) can be illustrated as in Fig. 3.8. For each "bulk composition" $\left(\mathrm{X}_{\mathrm{b}}\right)$ and chosen $\mathrm{K}_{\mathrm{D}}$ (i.e. temperature) the compositional point giving $\mathrm{X}_{\mathrm{Cd}}$ and $\mathrm{X}_{\mathrm{Ga}}$ moves a corresponding distance along a constant $\mathrm{K}_{\mathrm{D}}$ curve on the diagram. The intercept on the $\mathrm{K}_{\mathrm{D}}$ curve is bounded by a horizontal line $(n=0 ; i$.e. no garnet present) and a vertical line ( $n=1$; i.e. no cordierite present).

1) The assumption of ideality can be used as a first approximation only, but may be approximately correct over a relatively small compositional range. 


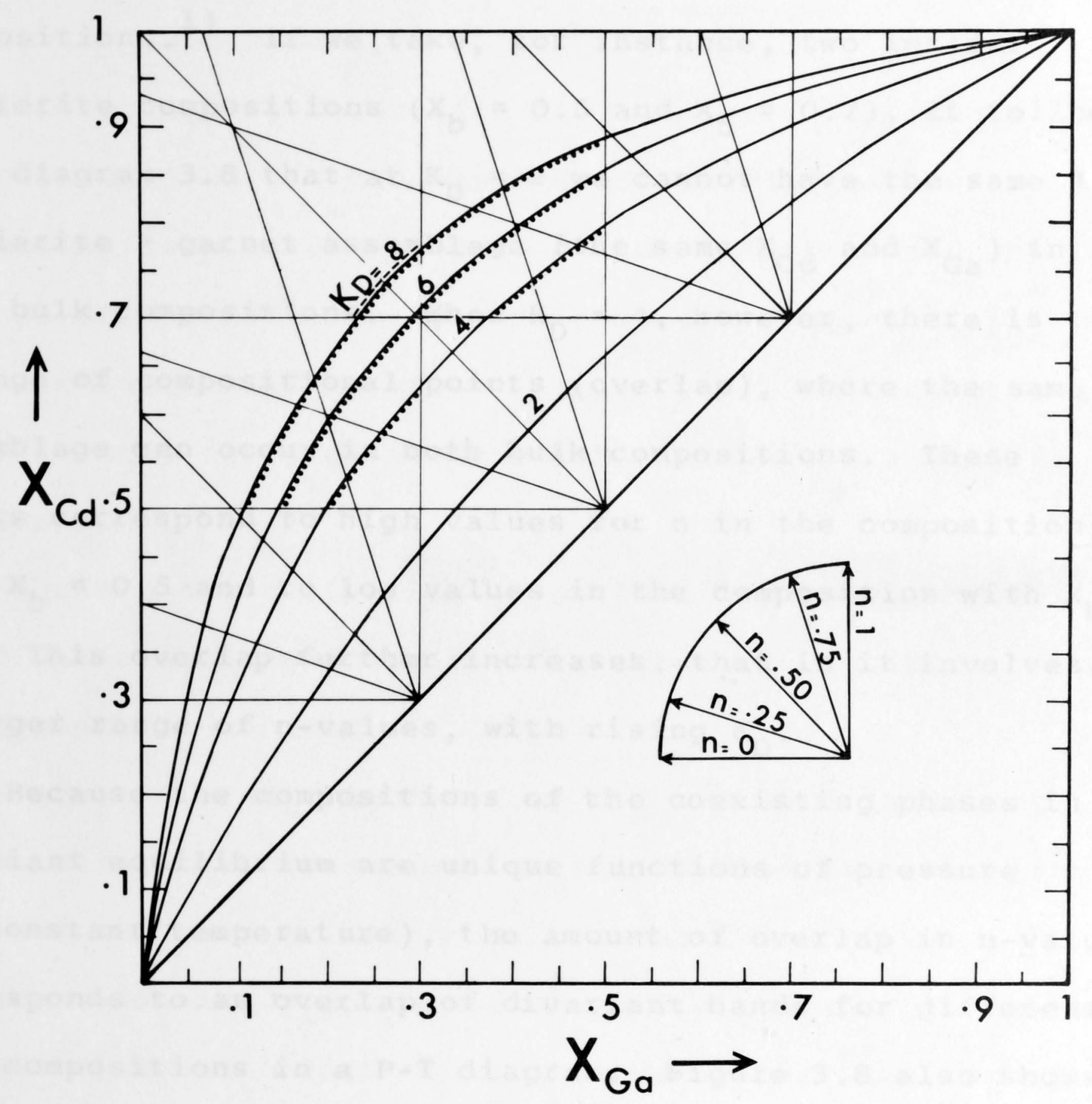

Fig. 3.8. Graphical representation of the relation between the amount of reaction ( $n)$, the composition of the ferromagnesian phases ( $\mathrm{X}_{\mathrm{C} \text { and }} \mathrm{X}_{\mathrm{Ga}}$ ) and the distribution $\mathrm{Cd} \rightleftharpoons \mathrm{Ga}+\mathrm{Si}+\mathrm{Qz}$ (1). The overlap of $\mathrm{n}$ between different bulk compositions as a function of $K_{D}$ is dotted (for $x_{\text {p }}=0.3$ and 0.5 , and for $x_{b}=0.5$ and 0.7 ? and dashed ( for $x_{b}=0.3$ and 0.7 ). 
An interesting aspect to emerge from this treatment is the graphical demonstration of the effect of $K_{D}$ on the overlapping of divariant assemblages for different bulk compositions. ${ }^{1)}$ If we take, for instance, two initial cordierite compositions $\left(x_{b}=0.5\right.$ and $\left.x_{b}=0.7\right)$, it follows from diagram 3.8 that at $K_{D}=2$ we cannot have the same cordierite + garnet assemblage (the same $\mathrm{x}_{\mathrm{Cd}}$ and $\mathrm{X}_{\mathrm{Ga}}$ ) in both bulk compositions. When $\mathrm{K}_{\mathrm{D}}=4$, however, there is a range of compositional points (overlap), where the same assemblage can occur in both bulk compositions. These points correspond to high values for $n$ in the composition with $\mathrm{x}_{\mathrm{b}}=0.5$ and to low values in the composition with $\mathrm{x}_{\mathrm{b}}=$ 0.7. This overlap further increases, that is it involves a larger range of $\mathrm{n}$-values, with rising $\mathrm{K}_{\mathrm{D}}$.

Because the compositions of the coexisting phases in divariant equilibrium are unique functions of pressure (at constant temperature), the amount of overlap in n-values corresponds to an overlap of divariant bands for different bulk compositions in a P-T diagram. Figure 3.8 also shows that, for low values of $\mathrm{K}_{\mathrm{D}}$, the divariant bands for certain bulk compositions cannot possibly overlap, whatever the value of $n$. Therefore this type of approach can provide criteria for equilibrium in the experimental study of

1) The same relationships are also illustrated by P-X
diagrams (sections 3.2 and 3.3 ). 
divariant reactions where the Phase Rule is of restricted use. The amount of reaction ( $n$ ) for each bulk composition $\left(x_{b}\right)$ is some unknown function of pressure for each particular temperature.

The preceding discussion indicates that the width (in pressure) of the divariant bands may increase with decreasing temperature because of the effect of the distribution coefficient on the compositional overlap. This increase could only be offset if the end member reactions significantly converge towards lower temperature (see section 3.2).

Equations for divariant reactions involving three solid solutions are somewhat more complicated. If we take the example:

$\mathrm{Cd}_{1}+4 \mathrm{Hy}_{1}=(1-\mathrm{n}) \mathrm{Cd}_{2}+4(1-\mathrm{n}) \mathrm{Hy}_{2}+2 \mathrm{nGa}+3 \mathrm{n} \mathrm{Qz}$ we can only treat this equation in the same fashion as the previous one when we take a bulk composition with the correct molecular proportions of cordierite and hypersthene (i.e. 1:4) as our starting point. Using the same symbols as previously, the above reaction reads:

$$
\begin{aligned}
& 2\left(\mathrm{X}_{\mathrm{Cd}_{1}}\right)+4\left(\mathrm{x}_{\mathrm{Hy}_{1}}\right)=2(1-\mathrm{n}) \mathrm{x}_{\mathrm{Cd}_{2}}+4(1-\mathrm{n})\left(\mathrm{x}_{\mathrm{H}_{2}}\right)+2 \mathrm{n} 3\left(\mathrm{x}_{\mathrm{Ga}}\right) \\
& \text { If } \mathrm{n}=1 \\
& 2\left(\mathrm{x}_{\mathrm{Cd}_{1}}\right)+4\left(\mathrm{x}_{\mathrm{Hy}_{1}}\right)=6\left(\mathrm{x}_{\mathrm{Ga}}\right)
\end{aligned}
$$

Because, when garnet is the only ferromagnesian phase, 


$$
\begin{aligned}
x_{G a}= & x_{b} \text {, and dividing by two we have } \\
& x_{\mathrm{Cd}}+2 x_{\mathrm{Hy}_{1}}=3 \mathrm{x}_{\mathrm{b}}
\end{aligned}
$$

If we substitute this in the general equation above we get

$$
\begin{aligned}
3 x_{b} & =(1-n) x_{C d}+2(1-n) x_{H y}+3 n x_{G a} \\
n & =\frac{x_{C d}+2 x_{H y}-3 x_{b}}{x_{C d}+2 x_{H y}-3 x_{G a}} \\
x_{G a} & =\frac{3 x_{b}-(1-n)\left(x_{C d}+2 x_{H y}\right)}{3 n} \\
x_{C d} & =\frac{3 x_{b}-2(1-n) x_{H y}-3 n x_{G a}}{1-n} \\
x_{H y} & =\frac{3 x_{b}-(1-n) x_{C d}-3 n x_{G a}}{2(1-n)} \\
x_{b} & =\frac{(1-n) x_{C d}+2(1-n) x_{H y}+3 n x_{G a}}{3}
\end{aligned}
$$

The compositions of the three phases are also related by three distribution coefficients, two of which can be chosen independently. A two-dimensional graphical illustration of the relations between $\mathrm{K}_{\mathrm{D}}, \mathrm{n}, \mathrm{x}_{\mathrm{b}}$ etc. is not practicable. However, the same general rules as in the previous example apply in this case and the amount of overlap between divariant bands for different compositions $\left(\mathrm{x}_{\mathrm{b}}\right)$ will probably tend to increase with decreasing temperature. 


\section{APPENDIX 1}

Note on the influence of pressure on the $K_{D}$ (Cd-Ga)

Using the volume data of Robie et al. (1967), the volume change for the exchange reaction between garnet and cordierite, given below, can be calculated.

$3 \mathrm{Mg}-$ cordierite +2 almandine $\rightleftharpoons 3 \mathrm{Fe}-$ cordierite +2 pyrope

Using the following molar volumes at room temperature

\section{$\underline{\text { Phase }}$}

almandine

Fe-indialite

Mg-indialite pyrope

$\Delta \mathrm{V}\left(\mathrm{Cm}^{3}\right)$

$$
\begin{aligned}
115.27 & \pm 0.04 \\
113.27 & \pm 0.04 \\
235.40 & \pm 0.54 \\
232.78 & \pm 0.16
\end{aligned}
$$

we obtain $\Delta v_{1}=+3.86 \pm 2.26 \mathrm{~cm}^{3}$.

Assuming this $\Delta v$ to be significant, it means that the left hand side of reaction (1) is favoured by increasing pressure, i.e. contours for constant $K_{D}$ on a P-T diagram have positive slopes and thus $K_{D}$ increases with increasing pressure. If we use the volume data for low Mg-cordierite and Fe-cordierite:

$$
\begin{array}{ll}
\text { low Mg-cordierite } & 233.22 \pm 0.13\left(\mathrm{~cm}^{3}\right) \\
\text { Fe-cordierite } & 232.08 \pm 0.37(")
\end{array}
$$

we obtain $\Delta v=-7.42 \pm 1.66 \mathrm{~cm}^{3}$,

i.e. the $\Delta v$ is larger and has changed sign. This is due to the anomalous relative values for the cordierite end members given above. The molar volume of the Fe-cordierite 
is smaller than that of the Mg-cordierite, which is the opposite of what would be expected (the Fe-end members in most solid solution series being more voluminous than the Mg-end members).

It seems reasonable to assume that the small $\Delta \mathrm{V}$, obtained using the indialite values, is more representative for the actual volume change of the exchange reaction (1). However, the small volume change with a relatively large uncertainty, which is moreover obtained as a difference between large numbers, is not necessarily relevant at elevated temperature. Thermal expansion data for all phases are required to ensure the sign of $\Delta V$ does not change at high temperature, but these data are not available as yet. 
APPENDIX 2

Alternative solution for univariant curves involving

garnet and spinel with $x_{S p}<x_{G a}$

Although evidence has been found supporting the assumption that $\mathrm{X}_{\mathrm{Sp}}>\mathrm{X}_{\mathrm{Ga}}$ (Chapter 5), there remains some uncertainty about the relative composition of coexisting garnet and spinel (compare Hsu and Burnham, 1969).

If we take $x_{S p}<x_{G a}$, the following changes are required in two of the four univariant reactions simultaneously involving garnet and spinel.

These are:

1. $\mathrm{Cd}+\mathrm{Ga}+\mathrm{Si} \rightleftharpoons \mathrm{Sp}+\mathrm{Qz} \quad \Delta \mathrm{V}=+\mathrm{ve}$ (?)

becomes

$\mathrm{Ga}+\mathrm{Si} \rightleftharpoons \mathrm{Cd}+\mathrm{Sp}+\mathrm{Qz} \quad \Delta \mathrm{V}=+\mathrm{ve}$

2. $\mathrm{Ga}+\mathrm{Sa}+\mathrm{Si} \rightleftharpoons \mathrm{Sp}+\mathrm{Qz} \quad \Delta \mathrm{V}=+\mathrm{ve}$

becomes

$(\mathrm{Hy}, \mathrm{Cd})$

$$
\mathrm{Ga}+\mathrm{Si} \rightleftharpoons \mathrm{Sa}+\mathrm{Sp}+\mathrm{Qz} \quad \Delta \mathrm{V}=+\mathrm{ve}
$$

However, the two remaining univariant reactions (Si,

$\mathrm{Sa}$ ) and ( $\mathrm{Si}, \mathrm{Cd}$ ), do not necessarily change when the relative compositions of garnet and spinel are reversed. In fact no change can occur unless the $\mathrm{K}_{\mathrm{D}}(\mathrm{Hy}-\mathrm{Ga})$ is very small and the $K_{D(G a-S p)}$ relatively large.

Considering the reaction:

$\mathrm{Cd}+\mathrm{Ga} \rightleftharpoons \mathrm{Hy}+\mathrm{Sp}+\mathrm{Qz}$ 
and taking the extreme case where $x_{H y}=0.5 ; x_{S p} \rightarrow 0$; $\mathrm{x}_{\mathrm{Cd}}=0.66$, as an example, then this reaction will remain non-terminal unless $\mathrm{x}_{\mathrm{Ga}}>0.33$ (i.e. if $\mathrm{K}_{\mathrm{D}(\mathrm{Hy}-\mathrm{Ga})}<2$ ), since only in that case will the garnet be situated inside the tetrahedron formed by the phases Cd-Hy-Sp-Qz. The reaction

$$
\mathrm{Cd}+\mathrm{Ga} \rightleftharpoons \mathrm{Hy}+\mathrm{Sp}+\mathrm{Qz}
$$

$$
\Delta v=+v e(?)
$$

will therefore change to

$$
\mathrm{Ga} \rightleftharpoons \mathrm{Cd}+\mathrm{Hy}+\mathrm{Sp}+\mathrm{Qz} \quad \Delta \mathrm{V}=+\mathrm{ve}
$$

However, this alternative solution requires a relatively small difference between $X_{\mathrm{Hy}}$ and $\mathrm{X}_{\mathrm{Ga}}$, as well as a large difference between $\mathrm{X}_{\mathrm{Ga}}$ and $\mathrm{X}_{\mathrm{SP}}$. This is a very unlikely situation. Therefore the reactions (Si, Sa) and (Si, Cd) which theoretically could be terminal reactions representing the breakdown of a single phase (i.e. garnet), are most likely non-terminal and represent the breakdown of two joins (i.e. the Cd-Ga and Sa-Ga joins respectively. 


\section{CHAPTER 4}

\section{EXPERIMENTAL STUDY OF THE C-SERIES OF COMPOSITIONS}

\section{Introduction}

The C-series, the most aluminous of the compositions studied, is modelled on a sillimanite-bearing metapelite, both sillimanite and quartz being excess phases. The chemographic position of the $C_{70}$ and $C_{30}$ compositions in the various compositional diagrams is given in Figure 1.1.

Since most experiments were carried out at temperatures well in excess of those required for the breakdown of hydrous phases (e.g. biotite, amphibole), the present experiments deal almost exclusively with anhydrous phase relationships. The ferromagnesian phases found to be of interest are cordierite, garnet, hypersthene, sapphirine and spinel. The relative stabilities of these minerals as a function of pressure, temperature and composition, i.e. $\mathrm{Mg} / \mathrm{Mg}+\mathrm{Fe}^{2+}$ ratio, have been investigated for two members of this series, $\mathrm{C}_{70}$ and $\mathrm{C}_{30}$, which have $100 \mathrm{Mg} / \mathrm{Mg}+\mathrm{Fe}^{2+}$ ratios of 70 and 30 respectively. For a discussion of the experimental methods used in this study the reader is referred to chapter 2 . 


\subsection{PHASE RELATIONSHIPS IN THE C 70 COMPOSITION}

The chemical composition of $\mathrm{C}_{70}$ is:

SiO $\quad-\quad 52.15$

$\mathrm{Al}_{2} \mathrm{O}_{3} \quad-\quad 33.26$

$\mathrm{FeO} \quad-\quad 4.49$

$\mathrm{MgO} \quad 5.86 \quad$ Normative plagioclase : $\mathrm{An}_{44.2}$

$\mathrm{CaO} \quad 1.69 \quad 100 \mathrm{Mg} / \mathrm{Mg}+\mathrm{Fe}^{2+}=70$

$\mathrm{K}_{2} \mathrm{O} \quad-\quad 1.18$

$\mathrm{Na}_{2} \mathrm{O} \quad 1.35$

99.98

Three "seeded" starting materials, listed below, were prepared for the present study. Starting material. (I) was used for most experiments, investigating the relative stability of garnet and cordierite, while (II) and (III) were made up to evaluate the stability of hypersthene and sapphirine.

I. 10\% low pressure assemblage, crystallized from glass at $1000^{\circ} \mathrm{C}-3.6 \mathrm{~kb}$, containing cordierite, minor sillimanite, trace of quartz and feldspars. 10\% high pressure assemblage crystallized from glass at $1125^{\circ} \mathrm{C}-18 \mathrm{~kb}$, containing garnet, sillimanite and traces of feldspars and quartz. $80 \%$ glass.

II. $\quad 83.3 \%$ starting material I.

$16.6 \%$ high temperature run $1200^{\circ} \mathrm{C}-8.1 \mathrm{~kb}$ containing sapphirine, sillimanite, quartz and 
feldspars.

III. 95\% starting material II.

5\% runs 1753 and 1731 , both containing garnet, hypersthene, sillimanite, quartz and

feldspars.

Experimental results

The experimental data are given in Table 4.1 and the deduced phase relations are represented in Figure 4.1.1) At low pressure the as semblage

cordierite-sillimanite-quartz-feldspars

is found over the temperature range covered by the experiments, i.e. $800-1150^{\circ} \mathrm{C}$.

At temperatures below $1100^{\circ} \mathrm{C}$ this assemblage is replaced towards higher pressure by

garnet-cordierite-sillimanite-quartz-feldspars

The boundary for the incoming of garnet has a negative slope. Its position has been determined using the following criteria:

1. On the high pressure side of the boundary the amount of garnet has markedly increased. (Figs. 4.2 and 4.4). It has been determined by electron microprobe that the composition of the garnet

1) The overlay on Fig. 4.1 shows the univariant reactions which have been constructed such as to be consistent with all experimental data on the B- and C-series of compositions. (See Chapter 9) 
TABLE 4.1

Experimental results for $c_{70}$ composition

\begin{tabular}{|c|c|c|c|c|c|c|c|c|c|c|c|c|c|}
\hline \multirow{2}{*}{$\begin{array}{l}\text { Run } \\
\text { No. }\end{array}$} & \multirow{2}{*}{$\begin{array}{l}\text { Temp } \\
{ }_{\mathrm{O}}\end{array}$} & \multirow{2}{*}{$\begin{array}{l}\text { Press } \\
\mathrm{Kb}\end{array}$} & \multirow{2}{*}{$\begin{array}{r}\text { Time } \\
\text { hrs }\end{array}$} & \multicolumn{9}{|c|}{ Phases present } & \multirow[b]{2}{*}{ Glass } \\
\hline & & & & $\mathrm{cd}$ & Ga & $\mathrm{Hy}$ & Si & $Q z$ & $\mathrm{sp}_{\mathrm{p}}$ & Sa & $\mathbf{B i}$ & Fsp & \\
\hline $\begin{array}{l}\text { Starffjng } \\
2133\end{array}$ & $\begin{array}{l}\text { material } \\
1200\end{array}$ & $\begin{array}{l}\text { I } \\
13.5\end{array}$ & 15 & & H & & M & tr & & $\mathbf{L}$ & & & $\mathrm{L} / \mathrm{M}$ \\
\hline $\begin{array}{l}1894 \\
1899 \\
2137\end{array}$ & $\begin{array}{c}1150 \\
" \\
"\end{array}$ & $\begin{array}{l}7.2 \\
9 \\
9.9\end{array}$ & $\begin{array}{l}17 \\
14 \\
15\end{array}$ & $\mathrm{H}$ & & & $\begin{array}{l}\mathrm{L} / \mathrm{M} \\
\mathrm{L} \\
\mathrm{L}\end{array}$ & $\begin{array}{l}M \\
M\end{array}$ & $\mathrm{M} / \mathrm{H}$ & $\begin{array}{l}\mathrm{H} \\
\mathrm{H}\end{array}$ & & $\begin{array}{l}\text { L } \\
\text { L }\end{array}$ & $\begin{array}{l}\mathrm{L} / \mathrm{M} \\
\mathrm{L} \\
\mathrm{L}\end{array}$ \\
\hline 1730 & 1100 & 6.3 & 16 & $\mathrm{H}$ & & & L & & & & & $\mathrm{L}$ & L \\
\hline 17322$)$ & $"$ & 7.2 & 16 & $\mathbf{H}$ & & & L & & L & & & L & $\mathrm{L}$ \\
\hline $1737^{21}$ & $"$ & $\begin{array}{l}8.1 \\
8.1\end{array}$ & $\begin{array}{l}16 \\
23\end{array}$ & $M$ & $\begin{array}{l}\operatorname{tr} / L \\
\operatorname{tr} / L\end{array}$ & & L & L & $M$ & $\operatorname{tr}(o p t \cdot)$ & & L & $\mathrm{L}$ \\
\hline $\begin{array}{l}1875 \\
1734^{3}\end{array}$ & $"$ & $\begin{array}{l}8.1 \\
9\end{array}$ & $\begin{array}{l}23 \\
16\end{array}$ & $M$ & $\begin{array}{l}t r / L \\
L\end{array}$ & $\begin{array}{l}\operatorname{tr} \\
M\end{array}$ & $\begin{array}{l}\mathrm{L} \\
M\end{array}$ & $\begin{array}{l}L \\
M\end{array}$ & M & 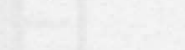 & & $\begin{array}{l}\mathrm{L} \\
\mathrm{L}\end{array}$ & $\begin{array}{l}\mathrm{L} \\
\mathrm{L}\end{array}$ \\
\hline $1744_{4}$ & $"$ & 10.8 & 13 & & м & м & м & M & & & & L & L \\
\hline $2132^{4)}$ & $"$ & 11.7 & 24 & & $\mathrm{M} / \mathrm{H}$ & L & м & $\mathbf{M}$ & & & & L & $\mathrm{L}$ \\
\hline 1735 & 1000 & 5.4 & 49 & H & & & L & tr & & & & L & L \\
\hline $1921_{51}$ & " & 6.3 & 62 & $\mathrm{H}$ & & & L & tr & & & & L & L \\
\hline 1747.5$)$ & $"$ & 7.2 & 49 & H & $t r / L$ & & L & L & & & & L & L \\
\hline $1884^{6)}$ & $"$ & 8.1 & 75 & H & $\mathrm{L} / \mathrm{M}$ & & M & tr & & & & L & L \\
\hline 1723 & $"$ & 9 & 45 & $\mathbf{M}$ & M & & м & L & & & & $t r / L$ & $\mathrm{~L} / \mathrm{M}$ \\
\hline 1753 & $"$ & 9.9 & 48 & & $\mathrm{H}$ & L & $\mathrm{H}$ & M & & & & L & $\mathrm{L}$ \\
\hline $\begin{array}{l}2445 \\
1731\end{array}$ & $"$ & $\begin{array}{r}9.9 \\
10.8\end{array}$ & $\begin{array}{r}140 \\
46\end{array}$ & & $\begin{array}{l}\mathrm{H} \\
\mathrm{H}\end{array}$ & L & ${ }_{\mathrm{H}}^{\mathrm{M}}$ & $\stackrel{M}{M}$ & & & & ${ }_{\mathrm{L}}^{\mathrm{L}}$ & $\begin{array}{l}\mathrm{L} \\
\mathrm{L}\end{array}$ \\
\hline $\left.1927^{7}\right)$ & 900 & 6.3 & 90 & H & $\operatorname{tr}$ & & & L & & & & L & $\mathrm{tr} / \mathrm{L}$ \\
\hline $\left.1908^{5}\right)$ & $"$ & 7.2 & 113 & $\mathrm{H}$ & $\mathrm{tr} / \mathrm{L}$ & & & L & & & & $\mathrm{L}$ & $\mathrm{tr} / \mathrm{L}$ \\
\hline $1898^{8)}$ & $"$ & 8.1 & 92 & H & L & & L & L & & & & L & $t r / L$ \\
\hline $2459^{61}$ & $"$ & 9 & 96 & M & M & & $L / M$ & M & & & & L & $\operatorname{tr} / \mathrm{L}$ \\
\hline 1809 & $"$ & 9.9 & 94 & M & M & & M & M & & & & L & $\mathrm{tr} / \mathrm{L}$ \\
\hline 1777 & $"$ & 10.8 & 95 & & H & $t r$ & м & M & & & & L & $\mathrm{tr} / \mathrm{L}$ \\
\hline 1999 & 800 & 7.2 & 96 & H & & & L & L & & & & L & L \\
\hline 2025 & $"$ & 8.1 & 96 & $\mathrm{H}$ & $\operatorname{tr}$ & & L & L & & & & L & L \\
\hline $2018^{8)}$ & $"$ & 9 & 99 & H & $t r / L$ & & L & tr & & & $\operatorname{tr}\left(o p t_{.}\right)$ & $\operatorname{tr} / \mathrm{L}$ & L \\
\hline 2050 & $"$ & 10.8 & 95 & L & H & & $\mathrm{M} / \mathrm{H}$ & M & & & M & tr & $\mathrm{L}$ \\
\hline 1993 & $"$ & 11.7 & 90 & tr & $\mathrm{H}$ & & $\mathrm{M} / \mathrm{H}$ & M & & & $M$ & tr & L \\
\hline Starting & material & II & & & & & & & & & & & \\
\hline 2365 & 1100 & 8.1 & 54 & $\mathrm{H}$ & & & $L / M$ & & & $t r / L$ & & L & L \\
\hline 2377 & 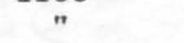 & 9 & 50 & & & & L & M & & H & & L & L \\
\hline 2378 & $"$ & 11.7 & 49 & & $\mathrm{H}$ & tr & M & $L / M$ & & & & L & $\mathrm{L} / \mathrm{M}$ \\
\hline Starting & material & I I I & & & & & & & & & & & \\
\hline 2392 & 1050 & 10.35 & 50 & & H & & M & tr & & $t r / L$ & & tr & $\mathrm{L} / \mathrm{M}$ \\
\hline 2395 & 1000 & $9-9.5$ & 72 & $L / M$ & $\mathrm{H}$ & & M & L & & & & L & L \\
\hline
\end{tabular}

1) Melting resulting in formation of corundum

2) Sapphirine optically

3) Compare reversal (no. 2377)

4 ) Compare reversal (no. 2378)

5) Garnet decreased

6) Garnet increased

7) Trace of garnet

8) Garnet unchanged

Relative proportions of the phases are indicated by: $\mathrm{H}=\mathrm{high}$ 


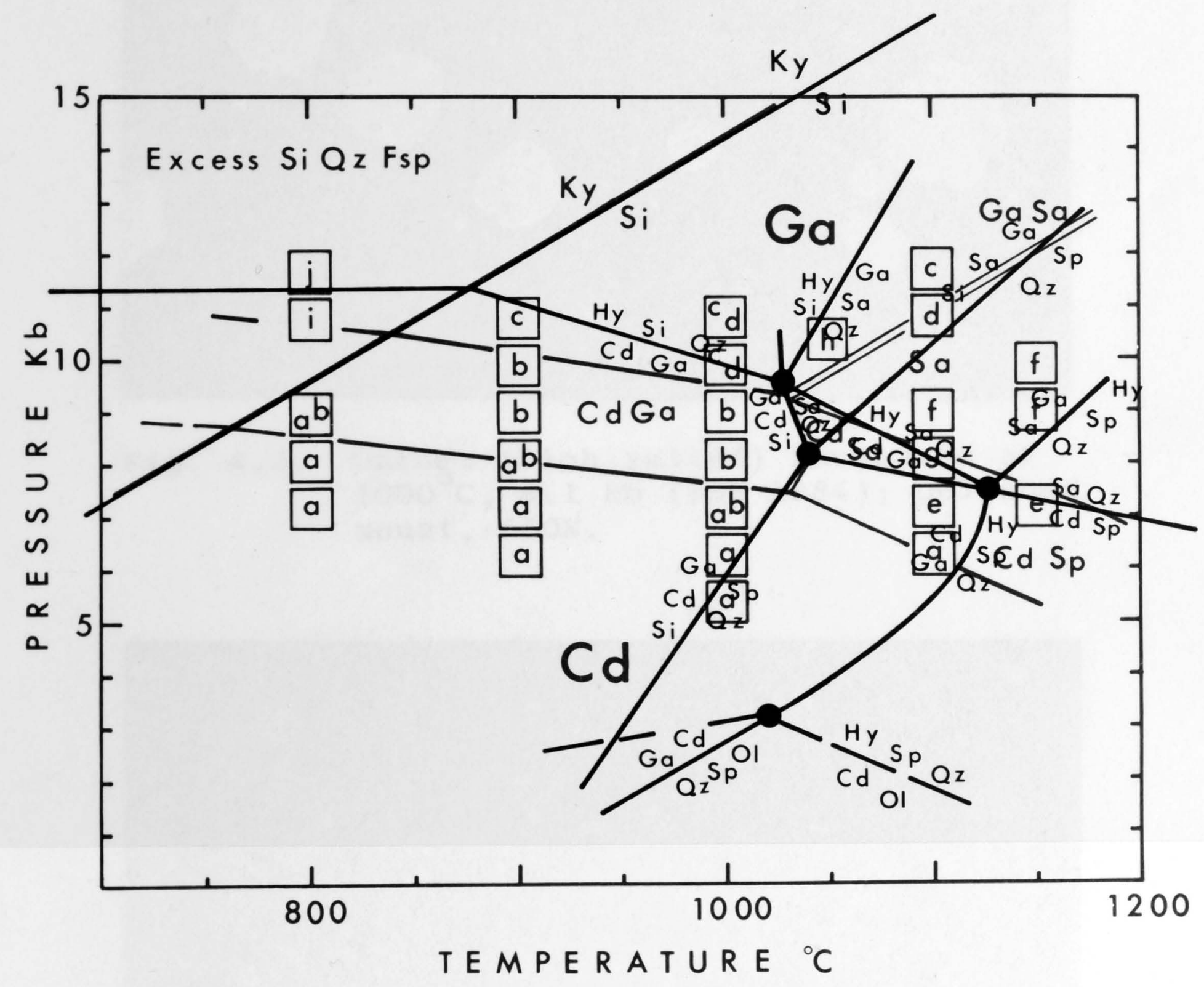

Fig. 4.1. P-T diagram for C 70 composition. Mineral assemblages are indicated by letters also used in the text. The overlay shows the relationship of the derived phase boundaries to the quasi-univariant boundaries of the general phase diagram (Fig. 9.1). 


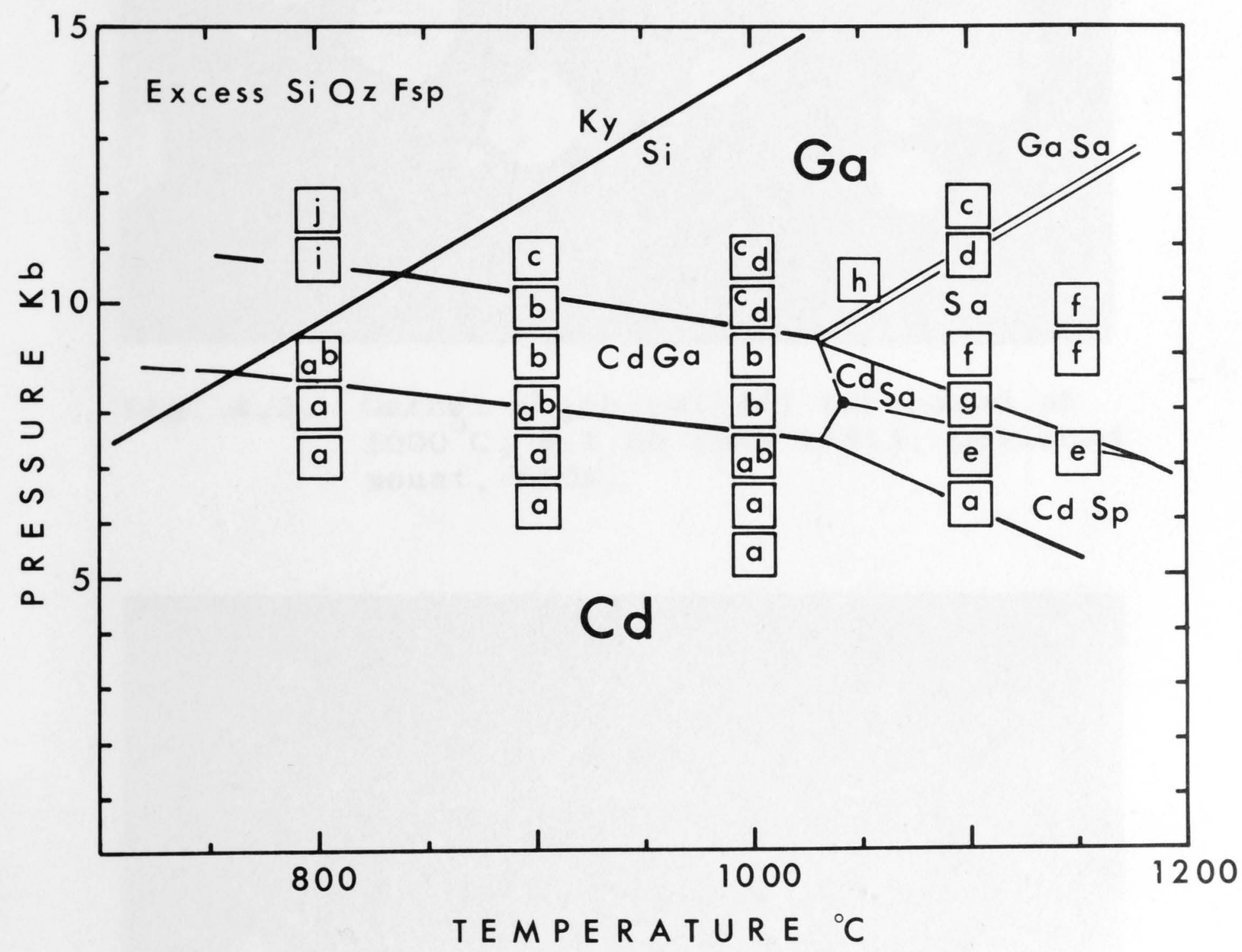

Fig. 4.1. P-T diagram for $\mathrm{C}_{70}$ composition. Mineral assemblages are indicated by letters also used in the text. The overlay shows the relationship of the derived phase boundaries to the quasi-univariant boundaries of the general phase diagram (Fig. 9.1). 


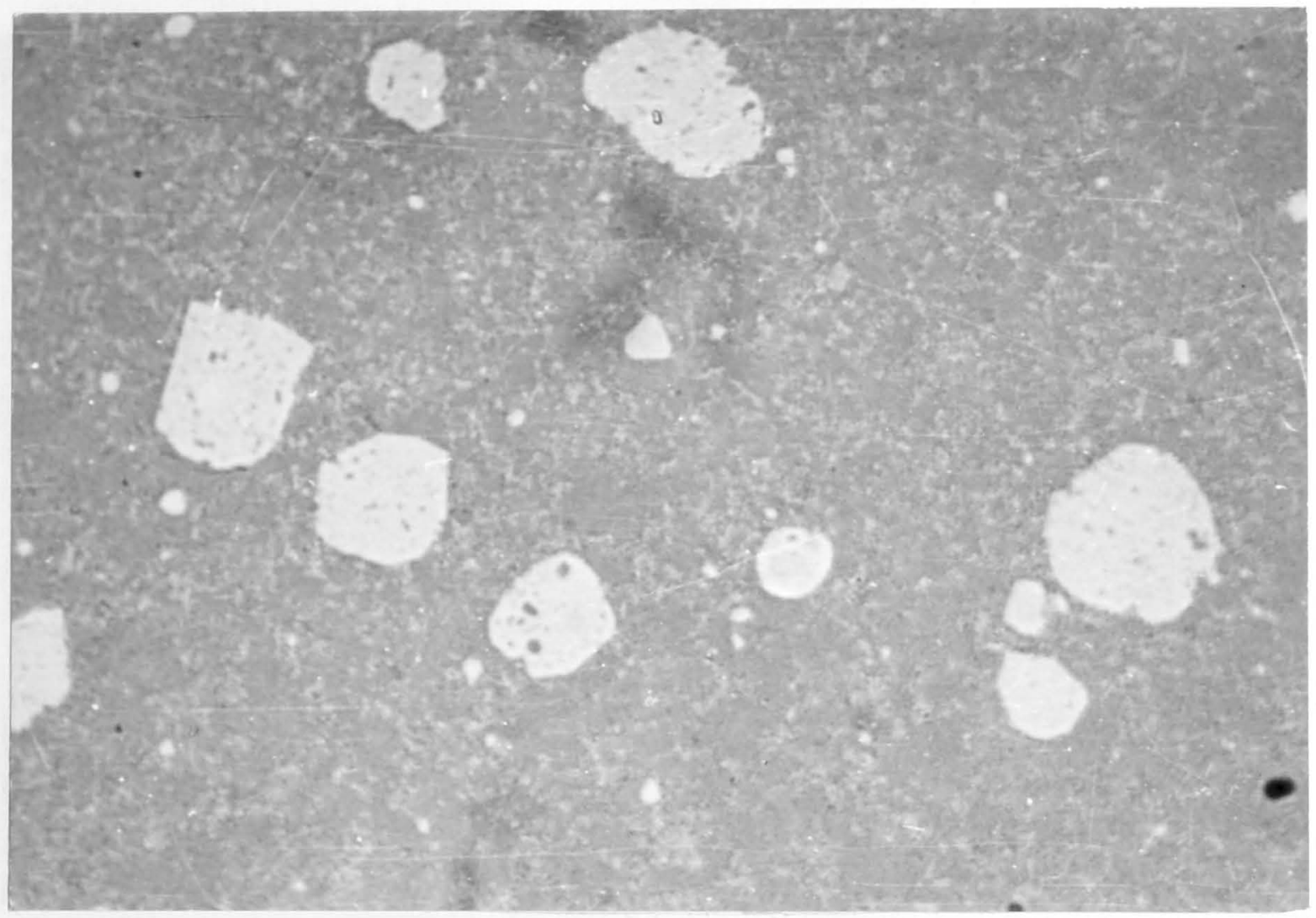

Fig. 4.2. Garnet (high relief) increased at $1000^{\circ} \mathrm{C}, 8.1 \mathrm{~kb}$ (run 1884); polished mount, $650 x$.

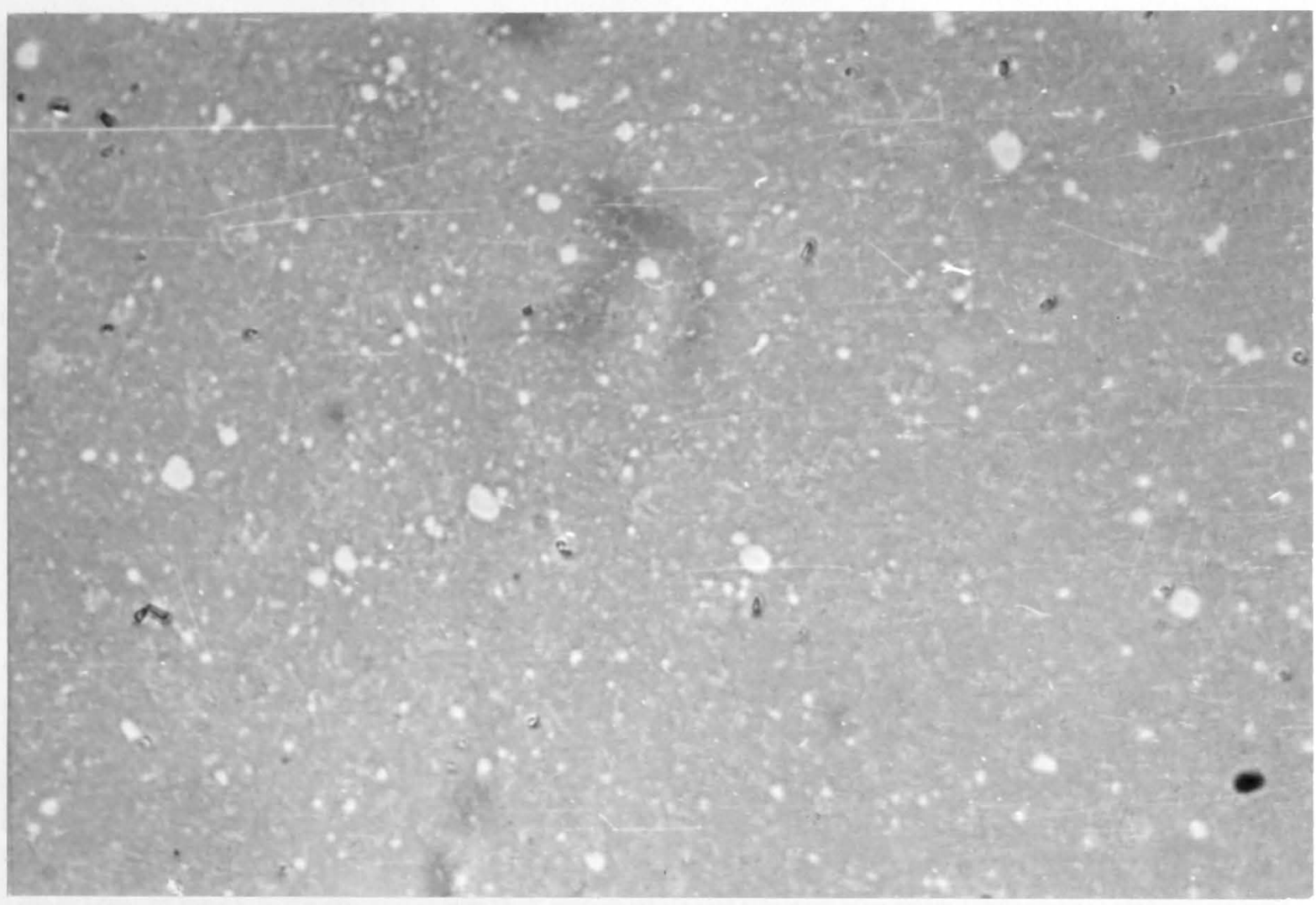

Fig. 4.3. Garnet (high relief) decreased at $1000^{\circ} \mathrm{C}, 7.2 \mathrm{~kb}$ ( r un 1747) ; polished mount, $650 x$. 


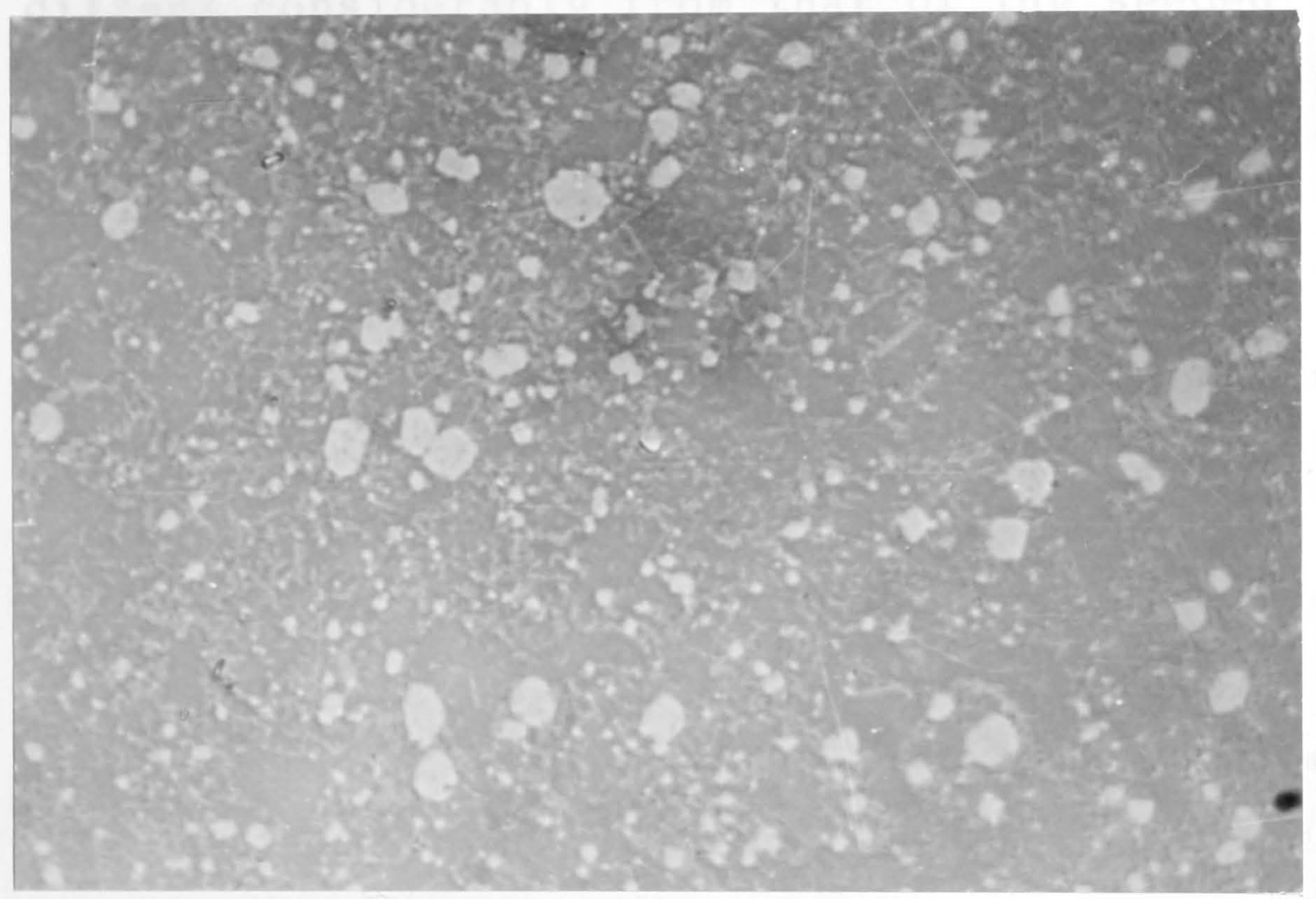

Fig. 4.4. Garnet (high relief) increased at $900^{\circ} \mathrm{C}, 9 \mathrm{~kb}$ (run 2459); polished mount, $650 x$.

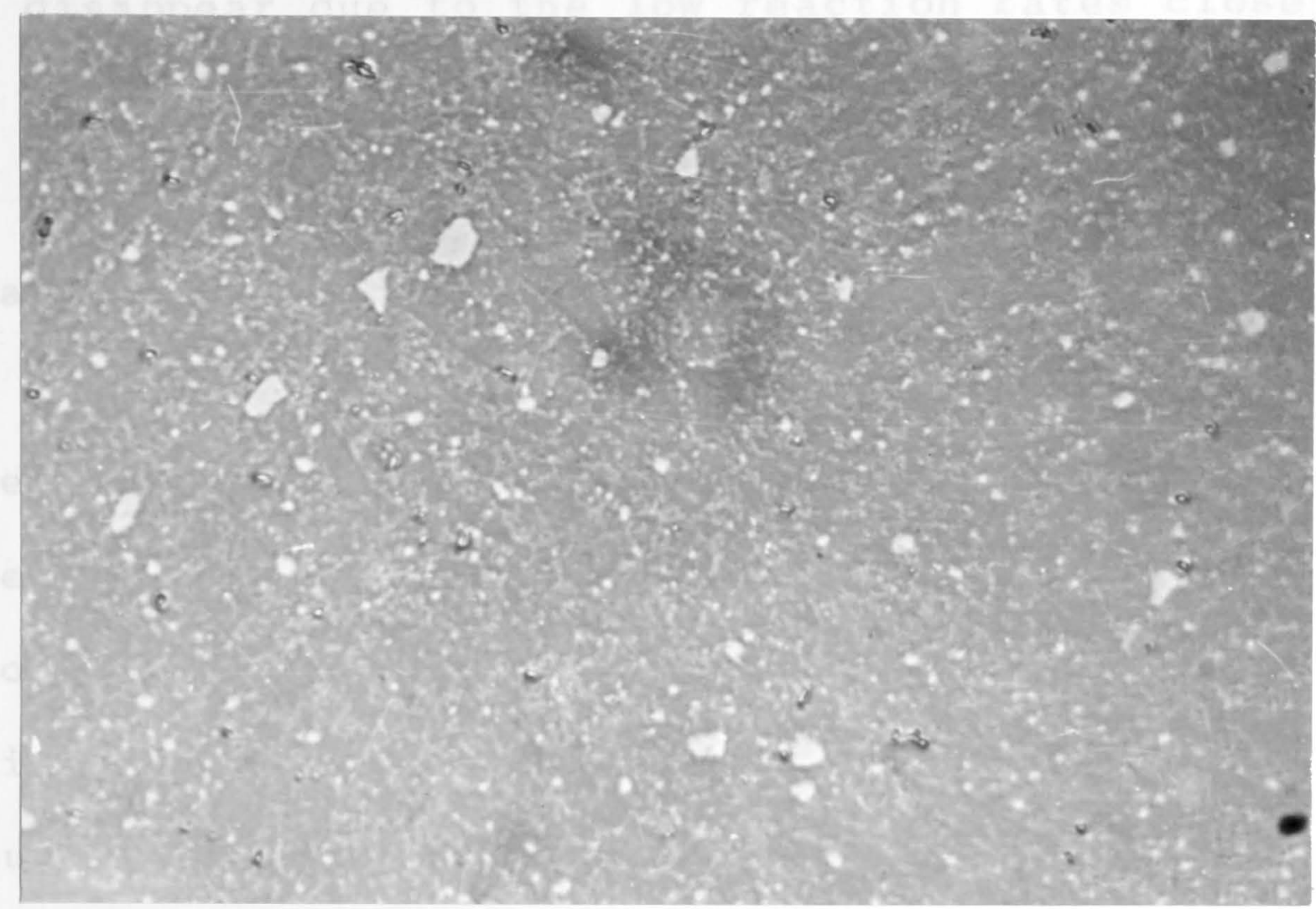

Fig. 4.5. Garnet unchanged (note angular shapes) at $900^{\circ} \mathrm{C}, 8.1 \mathrm{~kb}$ (run 1898); polished mount, $650 \mathrm{X}$. 
differs considerably from that of the seeded garnet which has $100 \mathrm{x}_{\mathrm{Ga}}=70$ (i.e. the $\mathrm{Mg} / \mathrm{Mg}+\mathrm{Fe}^{2+}$ ratio of the bulk composition; see next section for chemical data).

2. On the low pressure side of the boundary garnet either disappears, or its amount decreases or remains unchanged. The garnets are small and have irregular shapes (see Figs. 4.3 and 4.5 ). Analyses of the small grains indicate that these garnets invariably have the same $\mathrm{Mg} / \mathrm{Mg}+\mathrm{Fe}^{2+}$ ratio as the bulk composition (i.e. of the garnet seeds), and therefore they are regarded as non-equilibrated relics which failed to disappear due to the low reaction rates close to the equilibrium boundary for the incoming of garnet.

At 900 and $1000^{\circ} \mathrm{C}$ cordierite and garnet are found to coexist over a restricted pressure interval. The high pressure boundary of this interval, which also has a negative slope, marks the disappearance of cordierite. Since no experiments have been carried out in which cordierite grew on the low pressure side of the boundary, this boundary can be regarded only as a high pressure limit for the stability of cordierite. It is believed however, that it represents the equilibrium boundary 
for the stability of cordierite for the following reasons:

1. The results are in close agreement with those on the $B_{70}$ composition (Chapter 5.1) in which

a reversal was carried out at $900^{\circ} \mathrm{C}$ showing the phase boundary inferred on the basis of seeded glass experiments to be correct.

2. The disappearance of cordierite is sharply defined in the sense that cordierite is still a major phase in runs below the boundary (at 900 and $1000^{\circ} \mathrm{C}$ ) and is entirely absent or reduced to the merest trace in runs above it. If a rate dependent breakdown of cordierite were operative, one would expect the breakdown to extend over a larger pressure interval. At $900^{\circ} \mathrm{C}-10.8 \mathrm{~kb}$ the assemblage garnet-sillimanite-quartz-feldspar

is found. However, at $1000^{\circ} \mathrm{C}$ hypersthene appears as an additional phase above the breakdown of cordierite.

Because work on $\mathrm{B}_{70}$ and $\mathrm{B}_{70} \mathrm{~S}$ raised doubts regarding the stability of hypersthene under these conditions, an attempt has been made to verify the observed field of coexistence of

garnet-hypersthene-sillimanite-quartz-feldspars

A 140 hour run at $1000^{\circ} \mathrm{C}, 9.9 \mathrm{~kb}$ in a sealed $\mathrm{Au}-\mathrm{c}$ apsule (to prevent excessive melting) using starting material 
still contained assemblage (d). However, in a run at $1050^{\circ} \mathrm{C}, 10.35 \mathrm{~kb}$, in the middle of the originally deduced stability field of assemblage (d) a markedly different result was obtained. In this run, using a starting material containing seeds of both hypersthene and sapphirine, in addition to garnet and cordierite, hypersthene disappeared and the assemblage

$$
\begin{array}{r}
\text { garnet-minor sapphirine-sillimanite-feldspars- } \\
\text {-trace of quartz }
\end{array}
$$

was encountered. This result indicates that assemblage (d) is metastable with respect to (h) at $1050^{\circ} \mathrm{C}, 10.35 \mathrm{~kb}$, and probably also with respect to (c) at $1000^{\circ} \mathrm{C}$. The resulting phase relationships $^{1}$ ) shown in Fig. 4.1 are consistent with those found in the ${ }_{70}$ composition (Chapter 5.1).

At $1100^{\circ} \mathrm{C}$ the sequence of assemblages is complicated, especially since different results have been obtained from different starting materials. In the runs with starting material (I), spinel first appears at $7.2 \mathrm{~kb}$ (Fig. 4.6). At $8.1 \mathrm{~kb}$ spinel is abundant and some garnet grains also seem to have increased in size compared to the seeds. Two runs carried out under the same conditions gave virtually identical results. In a polished mount of one of these runs, some crystals of sapphirine occur, recognizable

1) See discussion. 


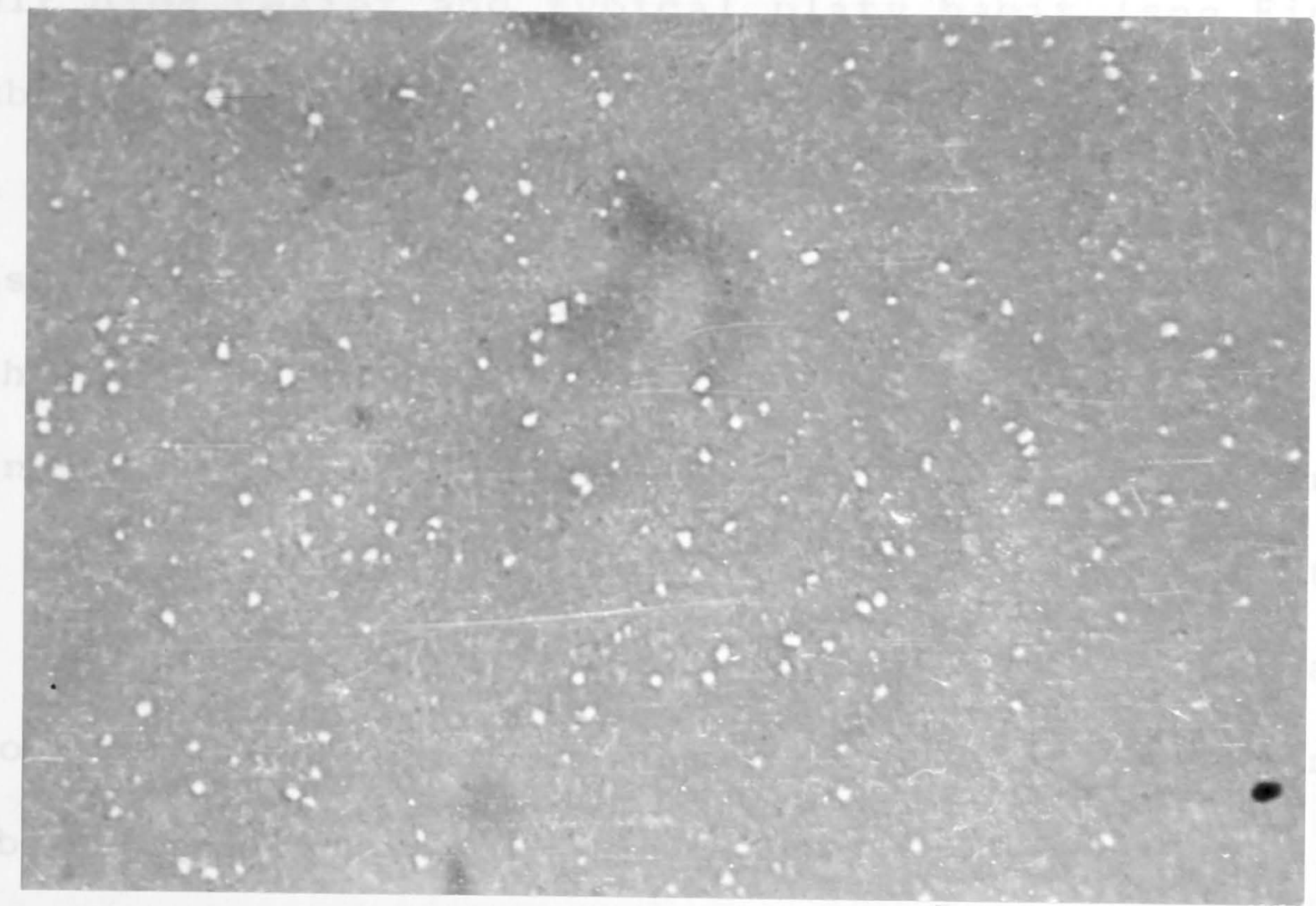

Fig. 4.6. Spinel (high relief) at $1100^{\circ} \mathrm{C}, 7.2$ kb (run 1732); polished mount, 650X.

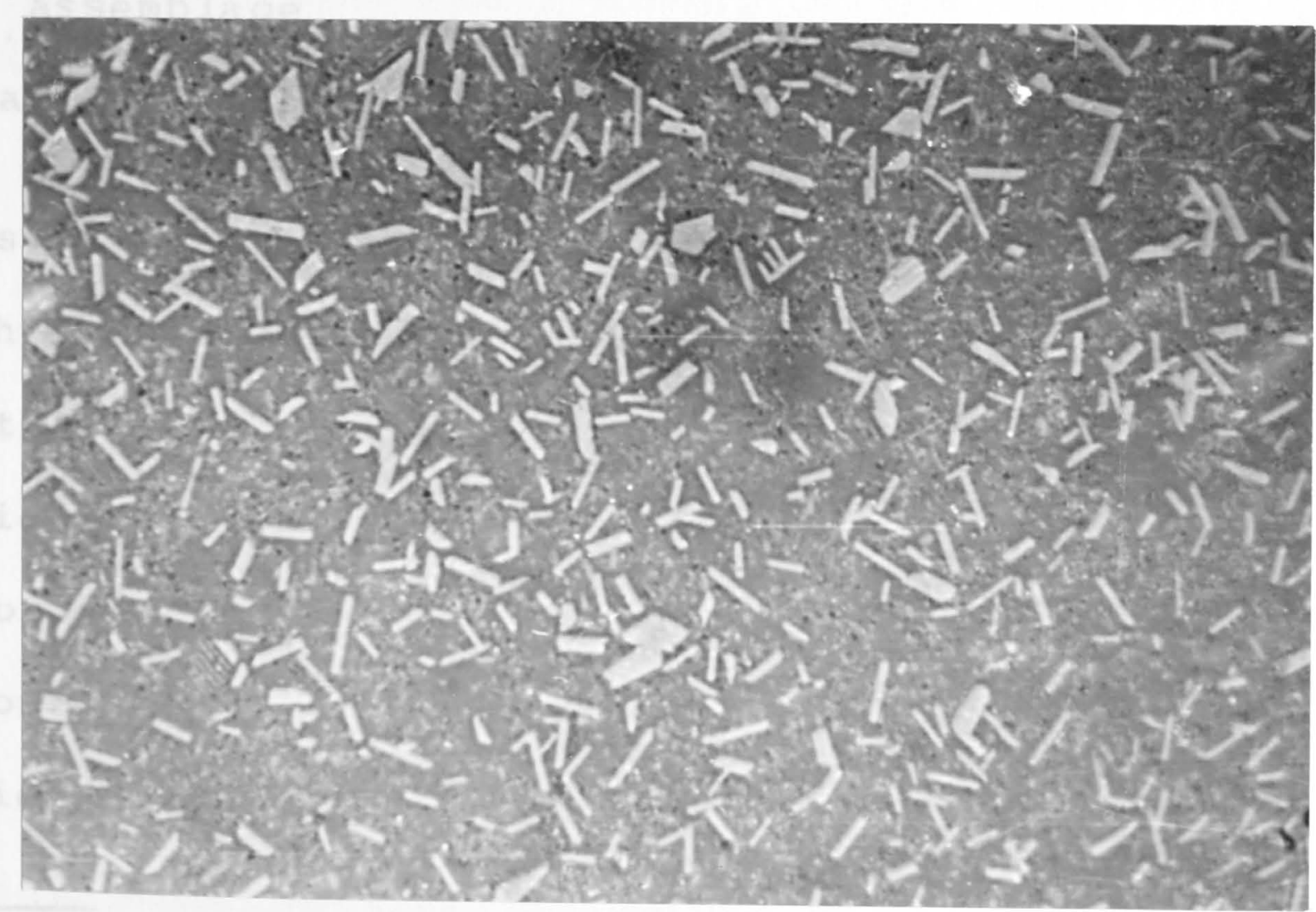

Fig. 4.7. Sapphirine (high relief) at $1150^{\circ} \mathrm{C}$, $9.9 \mathrm{~kb}$ (run 2137); polished mount, $650 x$. 
by their high relief and typical platy habit (see Fig. 4.7)。 At $9 \mathrm{~kb}$ and $10.8 \mathrm{~kb}$ abundant hypersthene appears and the amount of garnet is relatively 1ow. At $11.7 \mathrm{~kb}$ garnet has increased and hypersthene decreased in amount.

Three runs were carried out with starting material (II) containing sapphirine seeds. At $8.1 \mathrm{~kb}$ major cordierite occurs with only a small amount of sapphirine present. No spinel could be detected in this run and the assemblage is cordierite-sillimanite-sapphirine-feldspars-quart $z^{1}$ (g) At $9 \mathrm{~kb}$ both garnet and cordierite have disappeared. Instead the assemblage

$$
\text { sapphirine-quartz-minor sillimanite-feldspar }
$$

is found. At $11.7 \mathrm{~kb}$ the same starting material gives rise to the assemblage

$$
\begin{array}{r}
\text { garnet-sillimanite-quartz-feldspars-trace of } \\
\text { hypersthene }
\end{array}
$$

In this run (2378) the amount of hypersthene is considerably less than in an experiment of shorter duration (2132) suggesting that hypersthene is not stable under these conditions. At $1150^{\circ} \mathrm{C}, 7.2 \mathrm{~kb}$

$$
\text { cordierite-spinel-sillimanite-quartz-feldspars }
$$
is encountered, and at 9 and $9.9 \mathrm{~kb}$ (using starting material (I) which does not contain sapphirine seeds)

1) Quartz below X-ray detection limit. 
sapphirine-quartz-sillimanite-feldspars

occurs.

At $800^{\circ} \mathrm{C}$, where long duration experiments were necessary because of low reaction rates, the stability relations of garnet and cordierite were obscured by the appearance of abundant biotite giving rise to the assemblages

$$
\begin{array}{r}
\text { cordierite-garnet-biotite-sillimanite-quartz- } \\
\text {-feldspars }
\end{array}
$$

and

garnet-biotite-sillimanite-quartz-feldspars

at 10.8 and $11.7 \mathrm{~kb}$ respectively. Apparently, enough water has access to the sample for the formation of biotite. Biotite does not appear at pressures below 9 - $10 \mathrm{~kb}$ at this temperature. Both runs at 10.8 and $11.7 \mathrm{~kb}$ are outside the sillimanite stability field as determined by Richardson et al. (1968), and the persistence of sillimanite in these runs is therefore regarded as a metastable feature. The $\mathrm{Ky} \rightleftharpoons$ Si boundary in Figure 4.1 differs slightly from that proposed by the above authors. The exact position and slope of this boundary are given in chapter 8, where the reasons for choosing this particular position are discussed also.

Chemical analyses of experimentally produced phases

Microprobe analyses of garnet and cordierite are given in Table 4.2. Attention should be drawn to the 
TABLE 4.2

Microprobe analyses of experimentally produced phases $\left(C_{70}\right)$

\begin{tabular}{|c|c|c|c|c|c|c|c|c|c|c|c|c|c|}
\hline Garnet & analy & & & & & & Percentage of & & Maximum $1 i$ & its & & Cordierite & analyses \\
\hline $\begin{array}{l}\text { Run } \\
\text { No. }\end{array}$ & $\begin{array}{l}\text { Temp } \\
\text { oc }\end{array}$ & $\begin{array}{c}\text { Press } \\
\mathrm{Kb}\end{array}$ & 100 & $\mathrm{Mg} / \mathrm{Mg}+\mathrm{Fe}^{2+}$ & $\begin{array}{l}\text { Mole \% } \\
\text { gross }\end{array}$ & $\begin{array}{c}\text { No. of } \\
\text { analyses }\end{array}$ & $\begin{array}{c}\text { total falling } \\
\text { within these } \\
\text { limits }\end{array}$ & 100 & $\mathrm{Mg} / \mathrm{Mg}+\mathrm{Fe}^{2+}$ & $\begin{array}{l}\text { Mole } \% \\
\text { gross }\end{array}$ & 100 & $\mathrm{Mg} / \mathrm{Mg}+\mathrm{Fe}^{2+}$ & $\begin{array}{c}\text { No. of } \\
\text { analyses }\end{array}$ \\
\hline 2132 & 1100 & 11.7 & & $67.5 \pm 1.5$ & $6 \pm 1$ & 15 & 87 & & $64-69$ & $5-9$ & & & \\
\hline 2392 & 1050 & 10.35 & & $67 \pm 4$ & $6 \pm 1$ & 11 & 100 & & $63-71$ & $5-7$ & & & \\
\hline 1884 & 1000 & 8.1 & & $49+2$ & $6+1$ & 50 & 80 & & $47-53$ & $5-7$ & & $80+1$ & 12 \\
\hline 2395* & $"$ & $9-9.5$ & & $61 \mp 2$ & $6 \mp 1$ & 26 & 54 & & $57-72$ & $5-7$ & & $89 \mp 1$ & 6 \\
\hline 1753 & $"$ & 9.9 & & $68 \quad \mp 2$ & $6 \mp 2$ & 13 & 85 & & $65-71$ & $4-8$ & & & \\
\hline 1731 & $"$ & 10.8 & & $68 \mp 2$ & $7 \mp 1$ & 12 & 67 & & $65-71$ & $6-8$ & & & \\
\hline 2459 & 900 & 9 & & $49 \pm 2$ & $6 \pm 1$ & 28 & 43 & & & & & $81 \pm 1$ & 4 \\
\hline 1809 & $"$ & 9.9 & & & & 6 & & & $55-58$ & $6-9$ & & & \\
\hline 1777 & $"$ & 10.8 & & & & 10 & & & $67-72$ & $7-9$ & & & \\
\hline
\end{tabular}

* Zoned garnets 
remarkably uniform composition of the garnets formed within each experimental run. This uniformity of composition indicates that equilibrium has been closely approached in these experiments and justifies the use of the analytical data for the deduction of the P, T, X relationships for this series (see section 3 of this chapter).

The analyses show that the $\mathrm{Mg} / \mathrm{Mg}+\mathrm{Fe}^{2+} \mathrm{ratio}$ of the garnet varies as a function of pressure and temperature. Garnet is most iron-rich at low pressure and becomes progressively more magnesian with increasing pressure. The $\mathrm{Mg} / \mathrm{Mg}+\mathrm{Fe}^{2+}$ ratio decreases with decreasing temperature, at constant pressure, indicating that contours for constant garnet composition will have negative slopes on a $\mathrm{P}-\mathrm{T}$ diagram. The garnet contains a small amount of grossularss i.e. $6 \pm 1$ mole $\%$. There is no detectable change in this amount as a function of either pressure or temperature. In runs at $900^{\circ} \mathrm{C}$ and in one case $1000^{\circ} \mathrm{C}$ (run 2395) Fe-rich garnets have Mg-rich cores. The difference between core and rim in these garnets can be considerable, as shown in Figure 4.8 (run 2459). The Mg-rich cores are believed to be the result of the persistence of nonequilibrated garnet seeds. These seeds have the same $\mathrm{Mg}_{\mathrm{g}} / \mathrm{Mg}+\mathrm{Fe}^{2+}$ ratio as the bulk composition. The disequilibrium between core and rim will not significantly affect the overall chemistry of the run since the seeds only constitute 

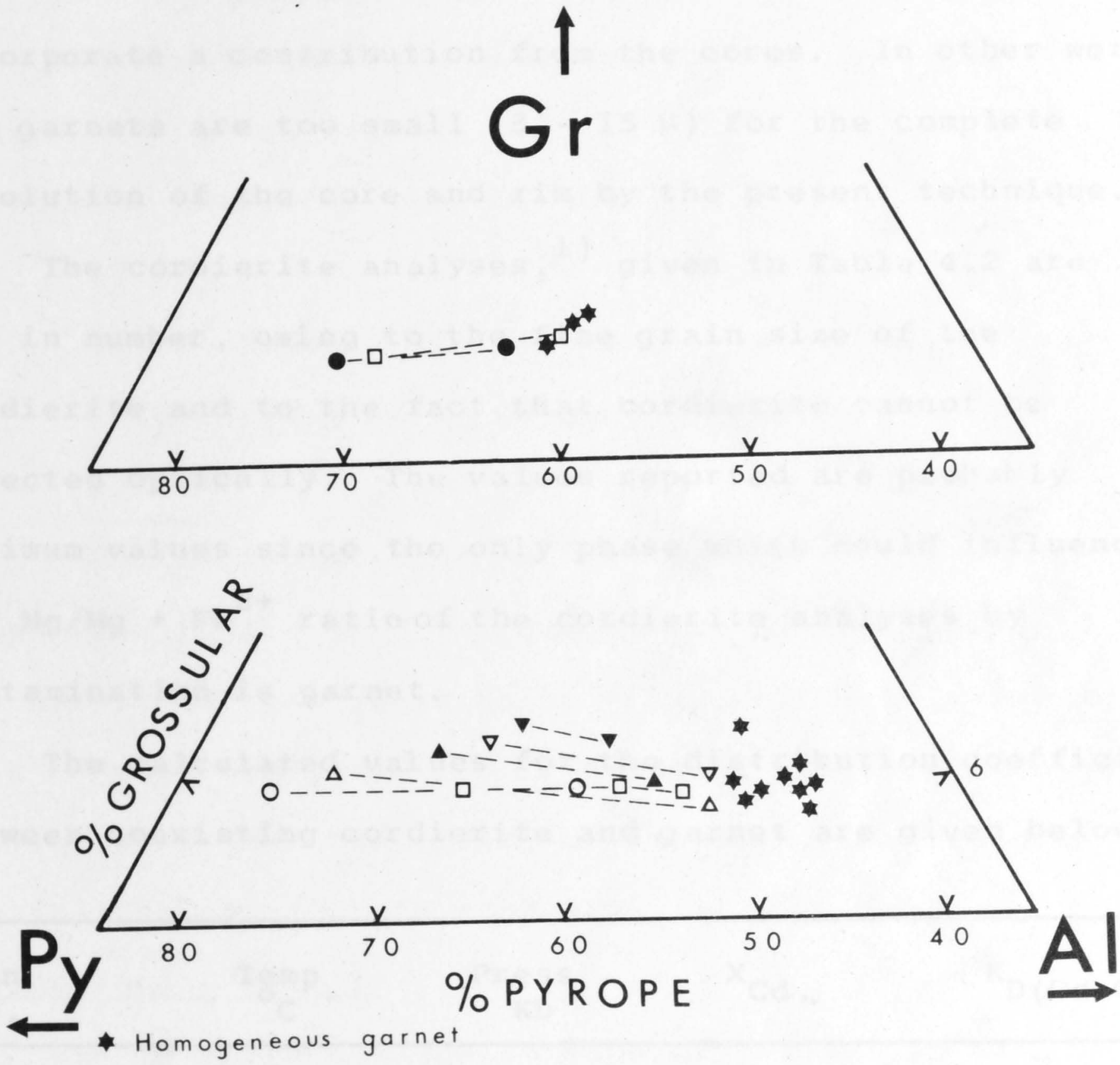

Fig. 4.8. Garnet endmember diagram (A1-Py-Gr) showing zoning in garnets. Top: run $2395 ; 1000^{\circ}, 9-9.5 \mathrm{~kb}$. Bottom: run 2459; $900^{\circ}, 9 \mathrm{~kb}$. 
a very small weight fraction of each run. In addition to zoned garnets, homogeneous grains also occur in run 2459. These have a distinctly lower $\mathrm{Mg} / \mathrm{Mg}+\mathrm{Fe}^{2+}$ ratio than the rims of zoned garnets suggesting that the analyses of rims incorporate a contribution from the cores. In other words the garnets are too $\operatorname{smal}(3-15 \mu)$ for the complete resolution of the core and rim by the present technique. The cordierite analyses, ${ }^{1}$ ) given in Table 4.2 are few in number, owing to the fine grain size of the cordierite and to the fact that cordierite cannot be detected optically. The values reported are probably minimum values since the only phase which could influence the $\mathrm{Mg} / \mathrm{Mg}+\mathrm{Fe}^{2+}$ ratio of the cordierite analyses by contamination is garnet.

The calculated values for the distribution coefficients between coexisting cordierite and garnet are given below

\begin{tabular}{lcccc}
\hline $\begin{array}{l}\text { Run } \\
\text { No. }\end{array}$ & $\begin{array}{c}\text { Temp } \\
\mathrm{C}_{\mathrm{C}}\end{array}$ & $\begin{array}{c}\text { Press } \\
\mathrm{Kb}\end{array}$ & $\mathrm{X}_{\mathrm{Cd}}$ & $\mathrm{K}_{\mathrm{D}(\mathrm{Cd}-\mathrm{Ga})}$ \\
\hline 1884 & 1000 & 8.1 & $80 \pm 1$ & $4.2 \pm 0.6$ \\
2395 & 1000 & 9 & $89 \pm 1$ & $5.2 \pm 1.1$ \\
2459 & 900 & 9 & $81 \pm 1$ & $4.5 \pm 0.6$ \\
\hline
\end{tabular}

1) For technique used see chapted 2.7 . 
There is no detectable change in the value of $K_{D}$ between 900 and $1000^{\circ} \mathrm{C}$. An increase of $K_{D}$ at constant temperature with increasing $\mathrm{X}_{\mathrm{Cd}}$ and $\mathrm{X}_{\mathrm{Ga}}$ is suggested by the difference between runs 1884 and 2395.

Sapphirine has been analysed in one run. The analysis is given below.

Sapphirine analysis (run no. 1899)
$\mathrm{SiO}_{2}$
17.47
Si
1. 04

$\mathrm{Al}_{2} \mathrm{O}_{3}$

56.40

Numbers of ions on the

A 1

3. 97

$\mathrm{FeO}$

8. 57

basis of 10 Oxygens

$\mathrm{Fe}^{2+}$

$.43)$

$\mathrm{MgO}$

17.27

$\mathrm{Mg}$

$1.54)$

1.97

$\overline{99.71} 100 \mathrm{Mg} / \mathrm{Mg}+\mathrm{Fe}^{2+}=78$

Sapphirine is the only ferromagnesian mineral present in run 1899. The change in $\mathrm{Mg} / \mathrm{Mg}+\mathrm{Fe}^{2+}$ ratio relative to the bulk composition (with $100 \mathrm{x}_{\mathrm{b}}=70$ ) is attributed to partial melting which has the effect of enriching the residual crystalline material in magnesium.

\section{Discussion of results}

The observed changes in mineral assemblage have been interpreted in terms of reactions, which are listed in Table 4.3. Themost important feature of the phase diagram cordierite-garnet-sillimanite-quartz-feldspars

This assemblage corresponds to the following divariant reaction in the system $\mathrm{MgO}-\mathrm{FeO}-\mathrm{Al}_{2} \mathrm{O}_{3}-\mathrm{SiO}_{2}:^{1}$ )

\footnotetext{
1) See Chapter 3.2 .
} 
TABLE 4.3

Divariant and univariant reactions

a) Divariant reactions

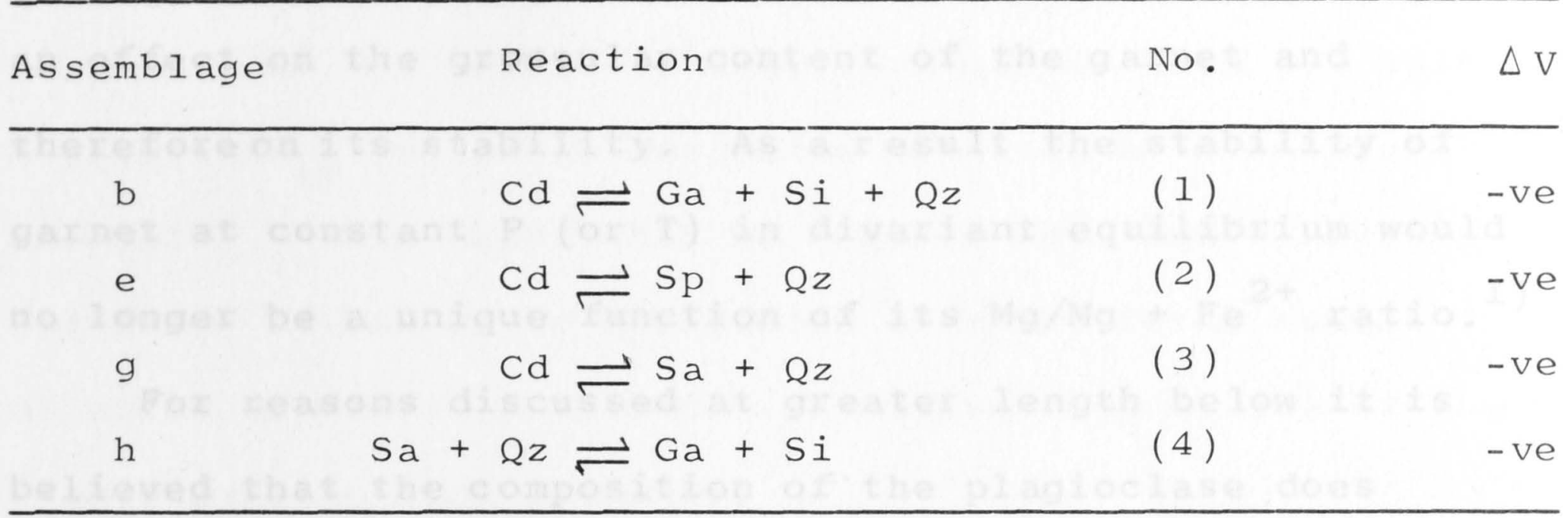

b) Univariant reactions

\begin{tabular}{lcll}
\hline $\begin{array}{l}\text { From assemblage } \\
\text { to assemblage }\end{array}$ & Reaction & No & $\Delta V$ \\
\hline $\mathrm{e} \rightleftharpoons \mathrm{b}$ & $\mathrm{Sp}+\mathrm{Qz} \rightleftharpoons \mathrm{Cd}+\mathrm{Ga}+\mathrm{Si}$ (I) & -ve \\
$\mathrm{e} \rightleftharpoons \mathrm{g}$ & $\mathrm{Cd}+\mathrm{Sp} \rightleftharpoons \mathrm{Sa}+\mathrm{Qz}$ & (II) & -ve \\
$\mathrm{b} \rightleftharpoons \mathrm{g}$ & $\mathrm{Cd}+\mathrm{Ga}+\mathrm{Si} \rightleftharpoons \mathrm{Sa}+\mathrm{Qz}$ & (III) & -ve
\end{tabular}


Cd $\mathrm{Ga}+\mathrm{Si}+\mathrm{Qz}$

The garnet contains 5 - 7 mole \% grossular component, and therefore this assemblage is not strictly divariant. The composition of the coexisting plagioclase could have an effect on the grossular content of the garnet and thereforeonits stability. As a result the stability of garnet at constant $\mathrm{P}$ (or $\mathrm{T}$ ) in divariant equilibrium would no longer be a unique function of its $\mathrm{Mg} / \mathrm{Mg}+\mathrm{Fe}^{2+} \mathrm{ratio.}^{1}$ )

For reasons discussed at greater length below it is believed that the composition of the plagioclase does not significantly influence the grossular content of the garnet. Therefore, the equilibria involving garnet are referred to as quasi-divariant indicating they are not divariant in a strict sense but can, for all practical purposes, be treated as such.

The total change in composition of the plagioclase from low pressure, where no garnet is present, to high pressure, where garnet is the only ferromagnesian phase, can be calculated for a given garnet composition. Since the grossular content of the garnet is known from the micro-analytical work (previous section), the change in normative plagioclase composition for this bulk composition $\left(\mathrm{C}_{70}\right)$ can be calculated as follows.

1) A theoretical discussion of the influence of the components $\mathrm{CaO}, \mathrm{Na}_{2} \mathrm{O}$ and $\mathrm{K}_{2} \mathrm{O}$ on the phase equilibria is given in an appendix at the end of this chapter. 
The number of moles of garnet present at high pressure, when garnet is the only ferromagnesian phase, is equal to the total number of moles $\mathrm{FeO}+\mathrm{MgO} / 3$ inthe bulk composition. For every mole of (pyrope-almandine) garnet, 0.0695 moles of grossular are needed to make up a garnet with 6.5 mole \% grossular ss (which is the value obtained by microprobe analysis). This means that we require $\mathrm{FeO}+\mathrm{MgO} / 3 \times 0.0695$ $x 3$ moles of $\mathrm{CaO}$ to be subtracted from the total number of moles of CaO to obtain the normative composition of the plagioclase at high pressure.

By this calculation, it is found that the normative plagioclase composition must change from An 44.2 to An 29.2 across the divariant band in Figure 4.1. This constitutes a change of ca. $34 \%$ in anorthite content over the pressure interval of the divariant band, while the grossular content of the garnet remains constant (within analytical error). This by itself is not sufficient evidence to prove that the grossular content of the garnet is independent of the composition of the plagioclase because the $\mathrm{Mg} / \mathrm{Mg}+\mathrm{Fe}^{2+}$ ratio of the garnet increases over the pressure interval. The grossular content could be a function of the following variables: pressure, temperature, $\mathrm{Mg} / \mathrm{Mg}+\mathrm{Fe}^{2+} \mathrm{ratio}$ of the garnet and anorthite content of the plagioclase. It is worth noting that in $B_{70}$ the garnet contains the same amount of grossular ss over roughly the same 
pressure interval, although the plagioclase composition is different (it varies from $\mathrm{An}_{53.2}$ to $\mathrm{An}_{35.8}$; Chapter 5.1). This shows that within these admittedly restricted limits the grossular content of the garnet is not measurably influenced by the composition of the plagioclase.

At $1000^{\circ} \mathrm{C}$ hypersthene appears at pressures higher than the breakdown of cordierite. In terms of phase relations the appearance of hypersthene could mean that we have crossed the univariant curve marking the breakdown of the pair Cd-Ga to Hy-Si-Qz (reaction (Sa, Sp); Chapter 3.1). Above the boundary for this univariant reaction three different mineral assemblages can occur, depending on the bulk composition and the temperature (or pressure) at which the boundary is crossed. These are Cd-Hy-Si-Qz, Hy-Si-Qz and $\mathrm{Ga}-\mathrm{Hy}-\mathrm{Si}-\mathrm{Qz}$ in order of decreasing $\mathrm{Mg} / \mathrm{Mg}+\mathrm{Fe}^{2+} \mathrm{ratio}$ of the bulk composition ( see Chapter 3, Fig. 3.6). In the present composition the assemblage

$$
\text { garnet-hypersthene-sillimanite-quartz-feldspars }
$$

occurs which corresponds to the divariant reaction (Chapter 3.3 )

$$
\mathrm{Hy}+\mathrm{Si} \rightleftharpoons \mathrm{Ga}+\mathrm{Qz} \quad \text { (Cd, Sa, Sp) }
$$

Hypersthene disappears with increasing pressure giving rise to the assemblage

$$
\text { garnet-quartz-(sillimanite) }
$$

This interpretation showing the experimental results to be 
consistent with the theoretical model (Chapter 3) was adopted until it appeared from the data on the $B_{70}$ and ${ }_{70}{ }^{S}$ compositions (Chapters 5.1 and 6) that the occurrence of hypersthene is probably a metastable feature. The situation is best illustrated graphically by a P-X diagram (see Fig. 4.14).

At $1000^{\circ} \mathrm{C}-9.9 \mathrm{~kb}$ we are on the high pressure side of both the stable divariant field for the assemblage Cd-Ga-Si-Qz and the metastable field Cd-Hy-Si-Qz for this particular bulk composition. Cordierite, which crystallizes metastably from the glass at first (as demonstrated by short term experiments with glass only as starting material), probably breaks down metastably to hypersthene, sillimanite and quartz. The latter minerals fail to react to the stable assemblage Ga-Si-Qz in the available time. The free energy difference between the last two assemblages is probably very smal 1 and the reaction rates are correspondingly low.

At $1100^{\circ} \mathrm{C}$ and $1150^{\circ} \mathrm{C}$ the appearance of spinel instead of $\mathrm{g}$ arnet at $8.2 \mathrm{~kb}$ indicates that the reaction

$$
\mathrm{Cd} \rightleftharpoons \mathrm{Sp}+\mathrm{Qz}
$$

is stable with respect to reaction

$$
\mathrm{Cd} \rightleftharpoons \mathrm{Ga}+\mathrm{Si}+\mathrm{Qz}
$$

because the garnet seeds that were present in the starting material disappeared. The stability fields of the divariant 
assemblages $\mathrm{Cd}-\mathrm{Ga}-\mathrm{Si}-\mathrm{Qz}$ and $\mathrm{Cd}-\mathrm{Sp}-\mathrm{Qz}$ are separated by the univariant reaction

$$
\mathrm{Sp}+\mathrm{Qz} \rightleftharpoons \mathrm{Cd}+\mathrm{Ga}+\mathrm{Si}
$$

The experimental evidence obtained from the $\mathrm{C}_{30}$ composition (next section) suggests that this reaction has a positive slope, which requires the volume change of this reaction to be positive (i.e. Sp $+Q z$ is high temperature as well as on the low volume side). Although this may seem unlikely at first sight, since cordierite is a very voluminous phase, the coefficients for the reaction will be a function of the composition of the participating phases (Chapter 3.1 ). Because cordierite is much more magnesian than garnet and spinel, which have similar $\mathrm{Mg} / \mathrm{Mg}+\mathrm{Fe}^{2+}$ ratios (with $\left.\mathrm{X}_{\mathrm{Ga}}<\mathrm{x}_{\mathrm{Sp}}\right),{ }^{1)}$ the amount of cordierite involved in the reaction is likely to be very small. Since the reaction

$$
\mathrm{Ga}+\mathrm{Si} \rightleftharpoons \mathrm{Sp}+\mathrm{Qz}
$$

has a positive volume change, a small amount of cordierite participating in the reaction may not change the sign of the volume change. Further comment on the stability of spinel + quartz is given in the next section dealing with the $\mathrm{C}_{30}$ composition.

At higher pressure, above the field for Cd-Sp-Qz (e) we find the assemblage Cd-Sa-Qz (g) which corresponds to

\footnotetext{
1) See Chapter 3, Appendix 2 for alternative solution with $\mathrm{x}_{\mathrm{Ga}}>\mathrm{x}_{\mathrm{Sp}} \cdot$
} 
the divariant reaction

$$
\mathrm{Cd} \rightleftharpoons \mathrm{Sa}+\mathrm{Qz}
$$

Assemblages (e) and (g) are separated by the univariant boundary for the reaction

$$
\mathrm{Cd}+\mathrm{Sp} \rightleftharpoons \mathrm{Sa}+\mathrm{Qz}
$$

This is a degenerate univariant reaction, involving only four phases, owing to the fact that cordierite, sapphirine, spinel and quartz are co-planar in compositional space (see Chapter 3.1).

It has not been possible to analyse the very finegrained spinel. Since the oxygen fugacity in the experiments was probably very low (Chapter 2.5), it is assumed that the spinel is correspondingly poor in magnetite ss $^{*}$

Reaction (II) has not been reversed, i.e. sapphirine has not been broken down to cordierite and spinel. At $1150^{\circ} \mathrm{C}$, however, sapphirine forms very readily in this composition. Its absence at $7.2 \mathrm{~kb}$ at this temperature is therefore taken as a good indication that spinel-cordierite is the stable pair under these conditions. The boundary, required between the stability fields of the assemblages $\mathrm{Cd}-\mathrm{Ga}-\mathrm{Si}-\mathrm{Qz}$ (b) and Cd-Sa-Qz (g) (Fig. 4.1) must be

$$
\mathrm{Cd}+\mathrm{Ga}+\mathrm{Si} \rightleftharpoons \mathrm{Sa}+\mathrm{Qz} \quad \Delta \mathrm{V}=-\mathrm{ve}
$$

This again is a quasi-univariant boundary involving five phases. In contrast to reaction (II) the volume change of this reaction must be negative. This can be explained by 
the fact that the compositions of cordierite and sapphirine are similar (with $\left.\mathrm{x}_{\mathrm{Cd}}>\mathrm{x}_{\mathrm{Sa}}\right)$. However the $\mathrm{M}_{\mathrm{g}} / \mathrm{Mg}+\mathrm{Fe}{ }^{2+}$ ratio of the garnet is much lower than that of the other phases. As a result, the proportion of cordierite in the reaction will be relatively high and the volume change will be negative.

At $1100^{\circ} \mathrm{C}-9 \mathrm{~kb}$ no sapphirine was formed in the runs using the normal starting material. With a mix seeded with sapphirine, however, only sapphirine was found after the run. This result, together with the occurrence at $1050^{\circ} \mathrm{C}$, $10.35 \mathrm{~kb}$ of the assemblage

$$
\begin{array}{r}
\text { garnet-sapphirine-sillimanite-trace of quartz- } \\
\text { feldspars }
\end{array}
$$

indicate the existence of the quasi-divariant reaction

$$
\mathrm{Sa}+\mathrm{Qz} \rightleftharpoons \mathrm{Ga}+\mathrm{Si}
$$

As shown in Figure 4.1 this reaction intersects on the univariant curve (III) and has a positive slope (i.e. $\Delta \mathrm{V}=$-ve). At low temperature, around $800^{\circ} \mathrm{C}$, reaction must intersect the kyanite $\rightleftharpoons$ sillimanite phase boundary. As a result the stability field of cordierite is reduced towards lower temperature, but the reaction

$$
\mathrm{Cd} \rightleftharpoons \mathrm{Ga}+\mathrm{Ky}+\mathrm{Qz}
$$

probably still has a negative slope. In the experiments, however, kyanite did not form in the available running time, and biotite appears as an additional phase. The 
relationships between dehydration reactions and anhydrous equilibria will be dealt with in Chapter 9.

\subsection{PHASE RELATIONSHIPS IN THE $\mathrm{C}_{30}$ COMPOSITION}

The second member of the C-series that has been studied is $\mathrm{C}_{30^{*}}$. Its chemical composition is: ${ }^{1}$ )

$\begin{array}{lll}\mathrm{SiO}_{2} & - & 50.94 \\ \mathrm{Al}_{2} \mathrm{O}_{3} & - & 32.31 \\ \mathrm{FeO} & - & 10.13 \\ \mathrm{MgO} & - & 2.44 \\ \mathrm{CaO} & - & 1.63 \\ \mathrm{Na}_{2} \mathrm{O} & - & 1.18 \\ \mathrm{~K}_{2} \mathrm{O} & - & 1.35 \\ & & 99.98\end{array}$

The starting material consisted of:

$20 \%$ high pressure assemblage crystallised from glass at $950^{\circ} \mathrm{C}-8.1 \mathrm{~kb}$, containing major garnet, sillimanite, quartz and minor spinel.

$80 \%$ glass.

Experimental data

The experimental data are given in Table 4.4 and the deduced phase relations are illustrated in Fig. 4.9. At

1) See Fig. 1.1 for chemographic representation of $\mathrm{C}_{30}$. 
TABLE 4.4

Experimental results for $\mathrm{C}_{30}$ composition

\begin{tabular}{|c|c|c|c|c|c|c|c|c|c|c|c|}
\hline \multirow{2}{*}{$\begin{array}{l}\text { Run } \\
\text { No. }\end{array}$} & \multirow{2}{*}{$\underset{\mathrm{C}}{\text { Temp }}$} & \multirow{2}{*}{$\begin{array}{c}\text { Press } \\
\mathrm{Kb}\end{array}$} & \multirow{2}{*}{$\begin{array}{r}\text { Time } \\
\text { hrs }\end{array}$} & \multicolumn{8}{|c|}{ Phases present } \\
\hline & & & & $\mathrm{Cd}$ & $\mathrm{Ga}$ & $\mathrm{Si}$ & $Q z$ & $\mathrm{Sp}$ & Co & $\mathrm{Fsp}$ & Glass \\
\hline 1997 & 1100 & 5.4 & i3 & M & & $\mathrm{L} / \mathrm{M}$ & L & $\mathrm{M} / \mathrm{H}$ & & $\mathrm{L}$ & $\mathrm{L} / \mathrm{M}$ \\
\hline 1938 & $"$ & 6.3 & 17 & & & M & M & $\mathrm{H}$ & & $\mathbf{L}$ & $\mathrm{L}$ \\
\hline 1974 & $"$ & 7.2 & 20 & & & M & M & $\mathrm{H}$ & & tr & $\mathrm{L}$ \\
\hline 1995 & $"$ & 9 & 17 & & & $\mathrm{H}$ & $\operatorname{tr}$ & $\mathrm{H}$ & & $\operatorname{tr}$ & M \\
\hline 1960 & $"$ & 9.9 & 16 & & $\mathrm{H}$ & $\mathrm{H}$ & $?$ & $\operatorname{tr}$ & & $\operatorname{tr}$ & M \\
\hline 1966 & 1050 & 3.6 & 24 & $\mathrm{H}$ & & $\mathrm{L}$ & L & $\mathrm{M} / \mathrm{H}$ & & $\mathrm{L}$ & $L$ \\
\hline 1941 & " & 5.4 & 23 & $\mathrm{M} / \mathrm{H}$ & & $\mathrm{L}$ & M & $\mathrm{H}$ & & L & L \\
\hline 1951 & " & 6.3 & 22 & $\mathrm{~L} / \mathrm{M}$ & & L & M & $\mathrm{H}$ & & L & L \\
\hline 1959 & $"$ & 7.2 & 46 & & M & M & M & $M$ & & $\mathrm{~L}$ & $\mathrm{~L}$ \\
\hline 1953 & $"$ & 8.1 & 25 & & M & M & M & M & & $\mathrm{L}$ & $\mathbf{L}$ \\
\hline 2011 & 1000 & 7.2 & 65 & $\operatorname{tr}$ & $\mathrm{H}$ & M & M & $\operatorname{tr}$ & & $\mathrm{L}$ & L \\
\hline $1977^{1)}$ & 950 & 3.6 & 71 & $\mathrm{H}$ & $\mathrm{L}$ & M & M & $\mathrm{L}$ & & $\mathrm{L}$ & $\mathrm{L}$ \\
\hline 1964 & $"$ & 5.4 & 36 & M & $M$ & M & M & tr & & L & $\mathrm{L}$ \\
\hline 1952 & $"$ & 7.2 & 63 & M & $\mathrm{H}$ & $M$ & M & tr & & $\mathrm{L}$ & $\mathrm{L}$ \\
\hline 1985 & $"$ & 8.1 & 69 & $t r$ & $\mathrm{H}$ & M & M & tr & & $\mathrm{L}$ & $\mathrm{L}$ \\
\hline 1962 & 900 & 8.1 & 72 & & $\mathrm{H}$ & L & & & $L / M$ & & M \\
\hline $1987^{2)}$ & 800 & 3.6 & 94 & $\mathrm{H}$ & L & M & L & tr & & L & $\mathrm{L}$ \\
\hline 1970 & $"$ & 9 & 96 & $L / M$ & $\mathrm{H}$ & $M$ & M & tr & & $\operatorname{tr}$ & $\mathrm{L}$ \\
\hline 1982 & $"$ & 9.9 & 96 & & $\mathrm{H}$ & $M$ & M & tr & & tr & $\mathrm{L}$ \\
\hline$\left.H 8^{3}\right)$ & 750 & 3.8 & & $\mathrm{H}$ & $\operatorname{tr} / \mathrm{L}$ & $\mathrm{L}$ & tr & $\mathrm{L}$ & & tr & $\mathrm{L}$ \\
\hline
\end{tabular}

1) Garnet unchanged

2) Garnet slightly decreased

3) Hydrothermal experiment; $\mathrm{fO}_{2}$ between that of the iron-wustite and quartz-fayalite-magnetite buffers

Relative proportions of the phases are indicated by:

$$
\begin{aligned}
H & =\text { high } \\
M & =\text { medium } \\
L & =\text { low } \\
t r & =\text { trace }
\end{aligned}
$$




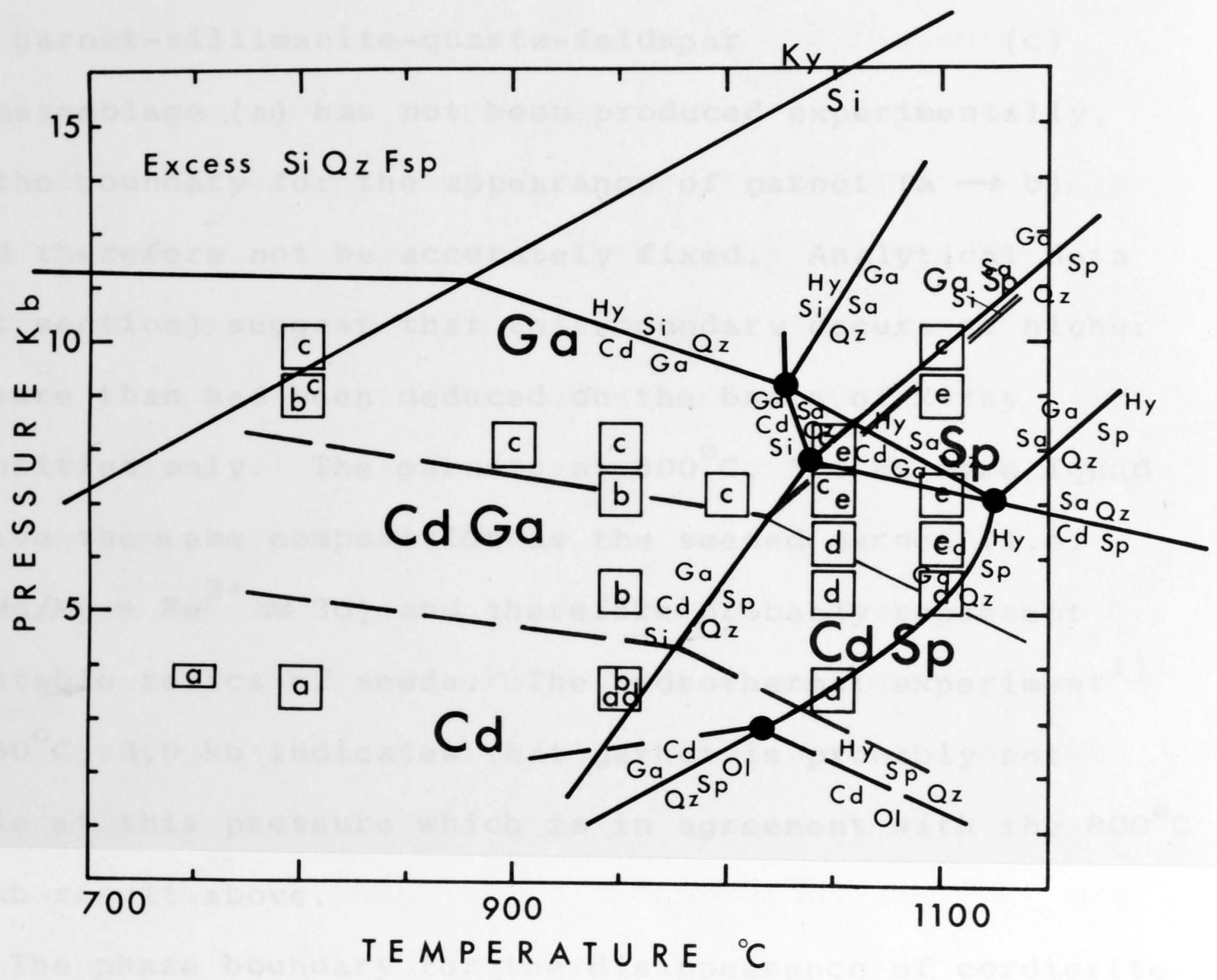

Fig. 4.9. P-T diagram for $\mathrm{C}_{30}$ composition. The observed mineral assemblages are indicated by letters also used in the text. The related quasi-univariant boundaries are shown on the overlay. 


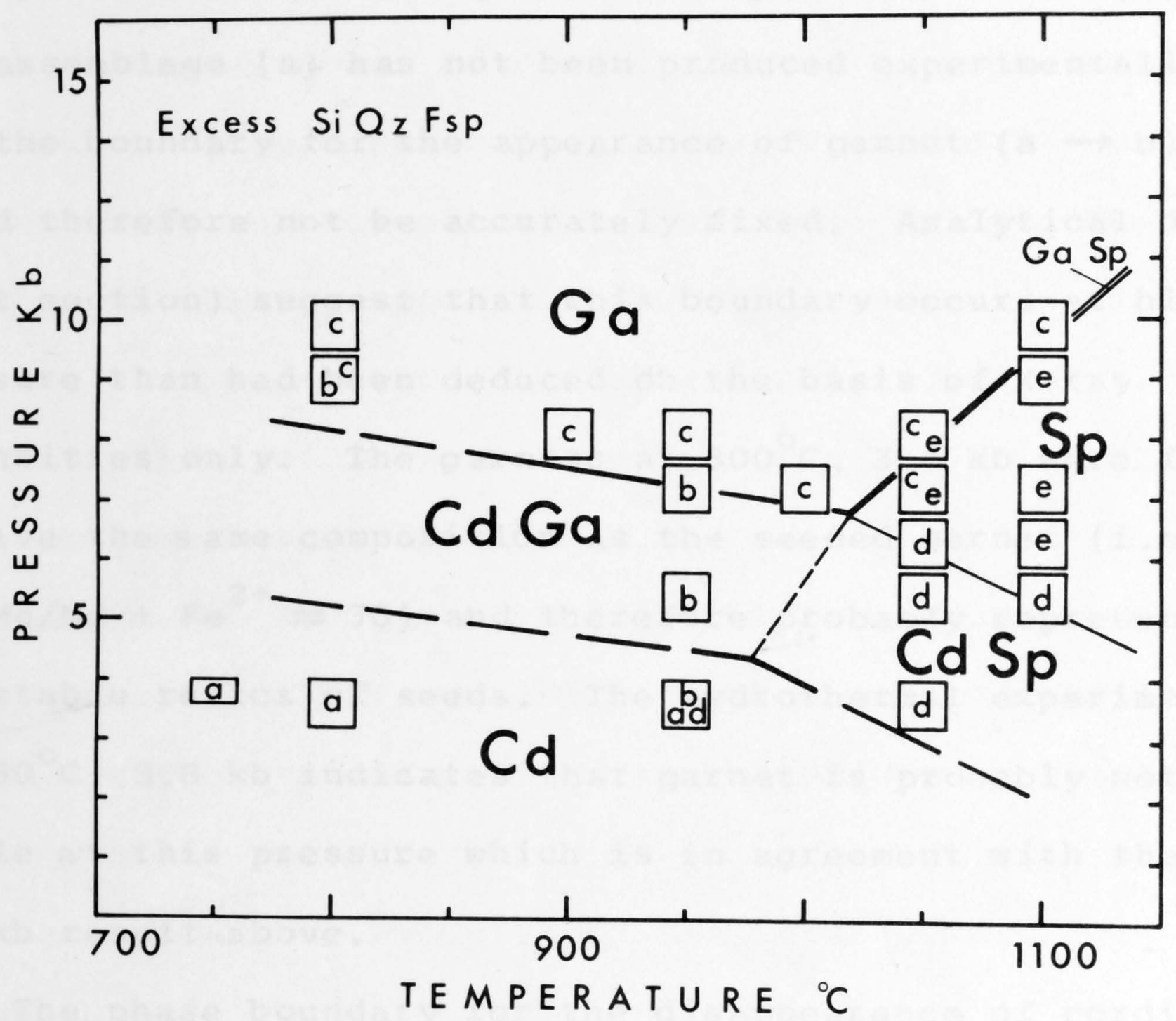

Fig. 4.9. P-T diagram for $\mathrm{C}_{30}$ composition. The observed mineral assemblages are indicated by letters also used in the text. The related quasi-univariant boundaries are shown on the overlay. 
low temperature, below $950^{\circ} \mathrm{C}$, the following three assemblages are found with increasing pressure:

$$
\begin{aligned}
& \text { cordierite-sillimanite-quartz-feldspar } \\
& \text { cordierite-garnet-sillimanite-quartz-feldspar } \\
& \text { garnet-sillimanite-quartz-feldspar }
\end{aligned}
$$

The assemblage (a) has not been produced experimentally, and the boundary for the appearance of garnet $(a \rightarrow b)$ could therefore not be accurately fixed. Analytical data (next section), suggest that this boundary occurs at higher pressure than had been deduced on the basis of X-ray intensities only. The garnets at $800^{\circ} \mathrm{C}, 3.6 \mathrm{~kb}$ were found to have the same composition as the seeded garnet (i.e. $100 \mathrm{Mg} / \mathrm{Mg}+\mathrm{Fe}^{2+} \approx 30$ ) and therefore probably represent metastable relics of seeds. The hydrothermal experiment ${ }^{1}$ ) at $750^{\circ} \mathrm{C}, 3.8 \mathrm{~kb}$ indicates that garnet is probably not stable at this pressure which is in agreement with the $800^{\circ} \mathrm{C}$ $3.6 \mathrm{~kb}$ result above.

The phase boundary for the disappearance of cordierite has a negative slope. Although an actual reversal (i.e. growing cordierite at the expense of garnet, sillimanite and quartz) on the low pressure side of the boundary has

1) The $\mathrm{fO}_{2}$ in this hydrothermal run was not fixed. The iron wustite buffer that was added had oxidized to magnetite at the completion of the run. It seems likely that the $\mathrm{fO}_{2}$ was close to that of the quartz, fayalite, magnetite buffer. 
not been carried out in this case, the upper limit in Fig. 4.9 is believed to represent the equilibrium boundary within experimental error. Two runs at $1000^{\circ} \mathrm{C}-7.2 \mathrm{~kb}$ of 13 and 65 hours duration demonstrate the effect of run duration on the amount of reaction. In the former run, a moderate amount of cordierite is still present while in the longer run only a trace of cordierite remains. In the longer run the garnet has the same $\mathrm{Mg} / \mathrm{Mg}+\mathrm{Fe}^{2+}$ ratio as the bulk composition $\left(100 \mathrm{x}_{\mathrm{Ga}}=30 \pm 2\right)$. These two runs also show that metastable cordierite crystallizes from the glass initially before reaction to the high pressure assemblage takes place.

Taking the run duration effect into account, the upper stability limit of cordierite has been drawn close to the lower pressure limit of the breakdown as bracketed by the present runs.

Towards higher temperature the intermediate pressure assemblage

$$
\text { cordierite-garnet-sillimanite-quartz-feldspars }
$$

becomes

$$
\text { cordierite-spinel-sillimanite-quartz-feldspars }
$$

The boundary separating (b) and (d) is believed to have a steep positive slope on the basis of combined theoretical and experimental evidence. 
At higher pressure, above the breakdown of cordierite, the assemblages

$$
\begin{aligned}
& \text { garnet-sillimanite-quartz-feldspars } \\
& \text { and } \\
& \text { spinel-sillimanite-quartz-feldspars }
\end{aligned}
$$

are also separated by a boundary with a positive slope.

Two runs at $1100^{\circ} \mathrm{C}, 9$ and $9.9 \mathrm{~kb}$, with assemblages (e)

and (c) respectively are shown in Figs.4.10 and 4.11 .

Composition of experimentally produced phases

The results of microprobe analyses of garnet, cordierite and spinel are given in Table 4.5. Only one run provided the analyses of a garnet-cordierite pair and even in this case the garnet analyses show a spread of $\mathrm{Mg} / \mathrm{Mg}+\mathrm{Fe}^{2+}$ values. The garnet analyses of the high temperature runs, the $1100^{\circ} \mathrm{C}$ run (no. 1960) in particular, show the effect of partial melting on the $\mathrm{Mg} / \mathrm{Mg}+\mathrm{Fe}^{2+}$ ratio of the solids. These analyses clearly indicate that Fe distributes in favour of the melt with the result that the $\mathrm{Mg}_{\mathrm{g}} \mathrm{Mg}+\mathrm{Fe}^{2+} \mathrm{ratio}$ of the garnet, being the only ferromagnesian phase present, increases. The large range of composition found in each of these runs, suggests that melting occurs locally and that an overall equilibration of solids and liquid has not taken place. Localized occurrence of glass could be verified optically in some cases and is attributed to local access of water from the dehydrating talc pressure 


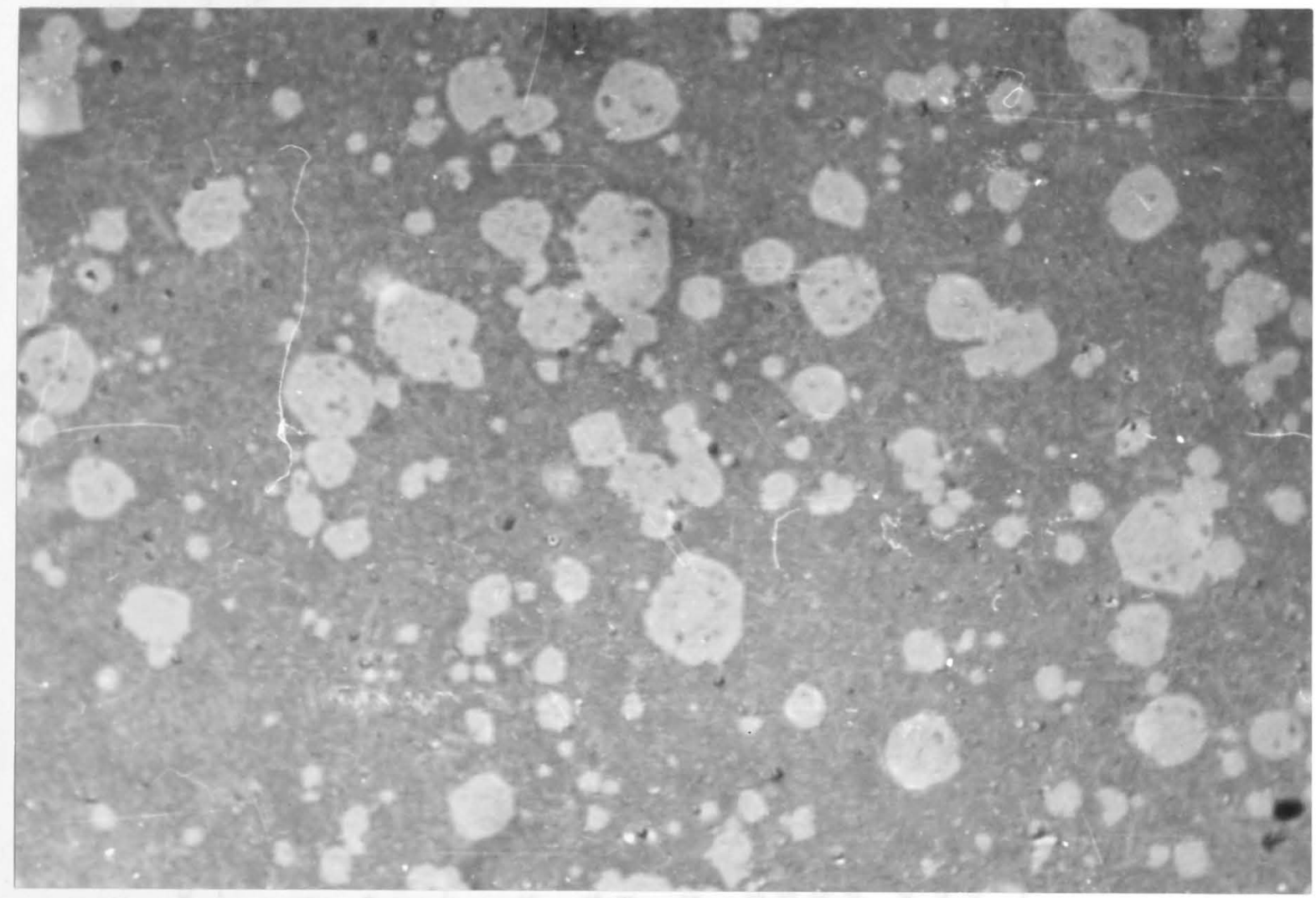

Fig. 4.11. Garnet (high relief) at $1100^{\circ} \mathrm{C}$, $9.9 \mathrm{~kb}$ (run 1960); polished mount, $650 X$.

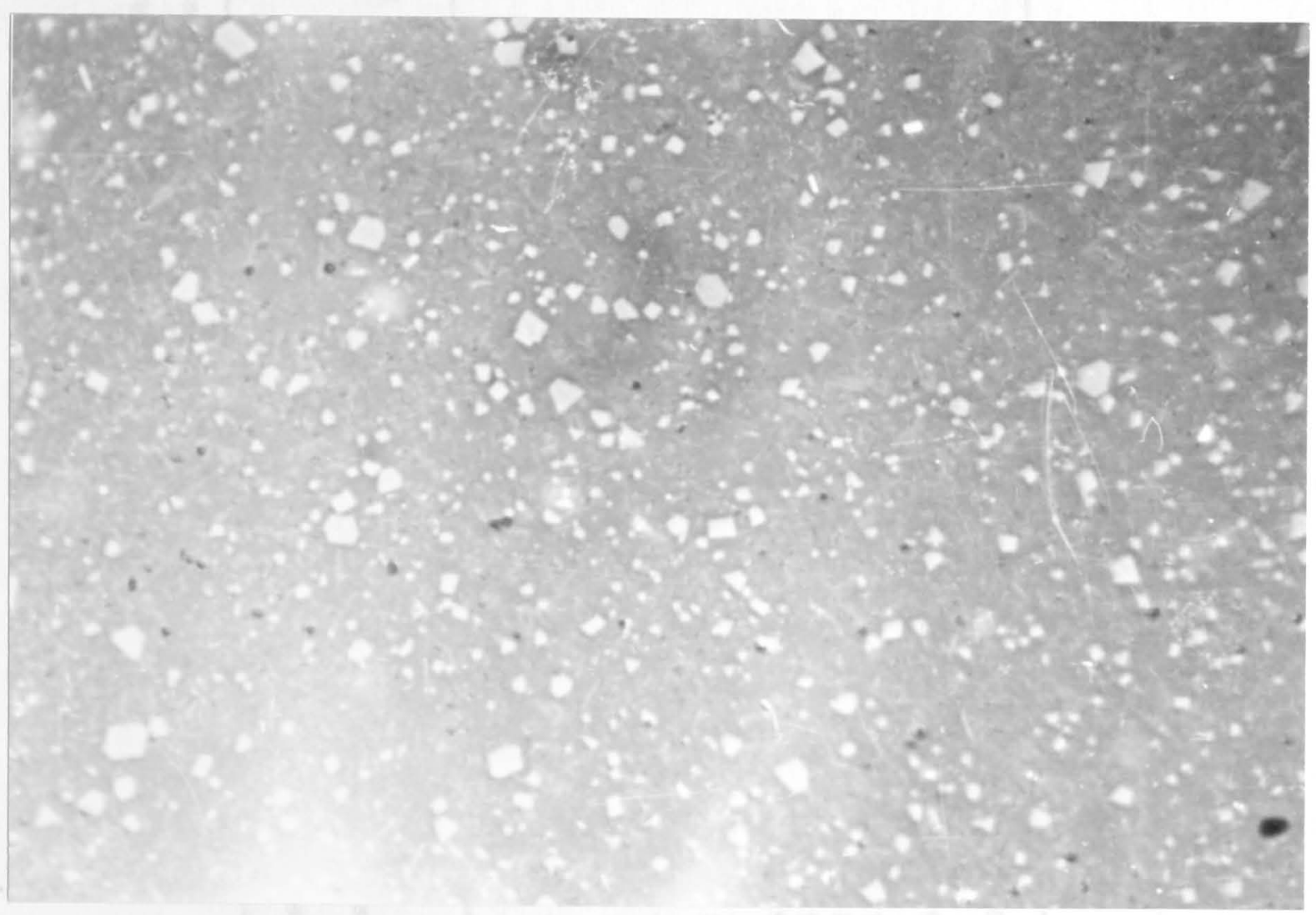

Fig. 4.10. Euhedral spinel (high relief) at $1100^{\circ} \mathrm{C}, 9 \mathrm{~kb}$ (run 1995); polished mount, $650 x$. 
TABLE 4.5

Microprobe analyses of experimentally produced phases $\left(\mathrm{C}_{30}\right)$

\begin{tabular}{|c|c|c|c|c|c|c|c|c|c|c|c|c|c|c|c|c|}
\hline $\begin{array}{l}\text { Garne } \\
\text { Run } \\
\text { No. }\end{array}$ & $\begin{array}{l}\text { et an } \\
\text { Temp } \\
{ }_{\mathrm{C}}\end{array}$ & $\begin{array}{l}\text { alyses } \\
\text { Press } \\
\mathrm{Kb}\end{array}$ & 100 & $\mathrm{Mg} / \mathrm{Mg}+\mathrm{Fe}^{2+}$ & $\begin{array}{l}\text { Mole } \% \\
\text { gross }\end{array}$ & $\begin{array}{c}\text { No. of } \\
\text { analyses }\end{array}$ & $\begin{array}{c}\text { Percentage of } \\
\text { total falling } \\
\text { within these } \\
\text { limits }\end{array}$ & 100 & $\begin{array}{l}\text { Maximum } \mathrm{lim} \\
\mathrm{Mg} / \mathrm{Mg}+\mathrm{Fe}^{2+}\end{array}$ & $\begin{array}{l}\text { its } \\
\text { Mole } \% \\
\text { gross }\end{array}$ & 100 & $\begin{array}{l}\text { ordierite an } \\
\mathrm{Mg} / \mathrm{Mg}+\mathrm{Fe}^{2+}\end{array}$ & $\begin{array}{l}\text { nalysis } \\
\text { No. of } \\
\text { analyses }\end{array}$ & 100 & $\begin{array}{l}\text { Spinel anal } \\
\mathrm{Mg} / \mathrm{Mg}+\mathrm{Fe}^{2+}\end{array}$ & $\begin{array}{l}\text { Nosis } \\
\text { No. of } \\
\text { analyses }\end{array}$ \\
\hline 1995 & 1100 & 9 & & & & & & & & & & & & & $34-37$ & 6 \\
\hline 1960 & $"$ & 9.9 & & $34 \pm 4$ & $5 \pm 1$ & 60 & 100 & & $30-38$ & 4-6 & & & & & & \\
\hline 1959 & 1050 & 7.2 & & $32+2$ & $5+1$ & 33 & 91 & & $27-34$ & $4-6$ & & & & & & \\
\hline 1953 & $"$ & 8.1 & & $34 \mp 2$ & $5 \nsubseteq 1$ & 9 & 100 & & $32-36$ & $4-6$ & & & & & & \\
\hline 2011 & 1000 & 7.2 & & $30+2$ & $5+1$ & 8 & 100 & & $28-32$ & $4-6$ & & & & & & \\
\hline 1977 & 950 & 3.6 & & & & 11 & & & $24-35$ & $4-6$ & & & & & & \\
\hline 1964 & $"$ & 5.4 & & & & 23 & & & $26-33$ & $4-6$ & & & & & & \\
\hline 1952 & $"$ & 7.2 & & $24+2$ & $5+1$ & 27 & 44 & & $22-34$ & $4-6$ & & $52-53$ & 2 & & & \\
\hline 1985 & $"$ & 8.1 & & $30 \mp 2$ & $5 \pm 1$ & 26 & 92 & & $28-32$ & $4-6$ & & & & & & \\
\hline 1987 & 800 & 3.6 & & $32+2$ & $5+1$ & 14 & 100 & & $30-34$ & $4-6$ & & & & & & \\
\hline 1970 & $"$ & 9 & & & & 7 & & & $24-32$ & $4-6$ & & & & & & \\
\hline 1982 & $"$ & 9.9 & & & & 20 & & & $26-34$ & $4-6$ & & & & & & \\
\hline
\end{tabular}


medium. The spread of garnet compositions is least at $1000^{\circ} \mathrm{C}$. At lower temperature $\left(800-900^{\circ} \mathrm{C}\right)$ zoning of crystals occurs because the seeds, which are probably more magnesian than the bulk composition, ${ }^{1)}$ fail to equilibrate.

The analysed grossular content of the garnets is lower than that found in the $C_{70}$ composition, i.e. $5 \pm 1$ mole $\%$ compared to $6 \pm 1$ mole $\%$ in $\mathrm{C}_{70}$. The possible significance of this will be discussed in chapter 9.

Spinel is usually fine grained, but in one run grains approximately $5 \mu$ in size could be analysed. The $\mathrm{Mg} / \mathrm{Mg}+\mathrm{Fe}^{2+}$ ratio for these spinels is 37 , which is comparable to the values obtained for garnet formed at the same temperature (i.e. $1100^{\circ} \mathrm{C}$ ). Partial melting is thought to be responsible for the change in composition of these phases relative to the bulk composition $\left(100 \mathrm{x}_{\mathrm{b}}=30\right)$.

Discussion of the results

The various reactions that have been postulated to explain the observed relationships are listed in Table 4.6. The most notable aspect of the experimental data is the restriction of the stability field of cordierite to lower pressure in this composition compared to $\mathrm{C}_{70^{\circ}}$ The quasi-divariant band for the assemblage

1) Local partial melting occurred in the high capacity run used as seeding material. 
TABLE 4.6

Divariant and univariant reactions of $\mathrm{C}_{30}$

a) Divariant reactions

\begin{tabular}{ccrc} 
Assemblage & Reaction & No & $\Delta V$ \\
\hline $\mathrm{b}$ & $\mathrm{Cd} \rightleftharpoons \mathrm{Ga}+\mathrm{Si}+\mathrm{Qz}$ & (1) ve \\
$\mathrm{C} / \mathrm{e}$ & $\mathrm{Sp}+\mathrm{Qz} \rightleftharpoons \mathrm{Ga}+\mathrm{Si}$ & (5) \\
$\mathrm{d}$ & $\mathrm{Cd} \rightleftharpoons \mathrm{Sp}+\mathrm{Qz}$ & $(2)$ & $-\mathrm{ve}$ \\
\hline
\end{tabular}

b) Univariant reaction

\begin{tabular}{llll}
\hline $\begin{array}{l}\text { From assemblage } \\
\text { to assemblage }\end{array}$ & Reaction & No & $\Delta V$ \\
\hline $\mathrm{d} \rightleftharpoons \mathrm{b}$ & $\mathrm{Sp}+\mathrm{Qz} \rightleftharpoons \mathrm{Cd}+\mathrm{Ga}+\mathrm{Si}$ & (I) ve \\
\hline
\end{tabular}


cordierite-garnet-sillimani te-quartz-feldspars

lies at the low pressure side of the band for the same assemblage in the $C_{70}$ composition, and there is no overlap between the two bands for the temperature range studied (i.e. $800-1050^{\circ} \mathrm{C}$; compare Figs. 4.9 and 4.1). Note that limiting boundaries of the divariant bands are interpreted to diverge slightly with decreasing temperature. As a result of this, at low temperature an overlap between the bands will occur. This is an expression of the fact that the distribution coefficient $\left(K_{D}\right)$ increases with decreasing temperature, thereby allowing the same garnet and cordierite to coexist in both bulk compositions (compare Fig. 3.8).

The garnet contains 5 mole \% grossular, and this amount is apparently independent of pressure and temperature (for the P-T range covered by the experiments). Therefore, as the proportion of garnet increases, the normative plagioclase composition changes from An 43.3 to $\mathrm{An}_{32.7}$ across the divariant band. The stability field of the divariant assemblage (b) is limited towards high temperature by the quasi-univariant reaction

$$
\mathrm{Cd}+\mathrm{Ga}+\mathrm{Si} \rightleftharpoons \mathrm{Sp}+\mathrm{Qz}
$$

This reaction appears to have a steep positive slope (Fig. 4.9). On the high temperature side of this boundary we find the assemblage cordierite-spinel-sillimanite-quartz-feldspars 
representing the divariant reaction

$$
\mathrm{Cd} \rightleftharpoons \mathrm{Sp}+\mathrm{Qz}
$$

On the high pressure side of the breakdown of cordierite, the fields of stability of assemblages (c) and (e) are believed to be separated by the quasi-divariant reaction

$$
\mathrm{Ga}+\mathrm{Si} \rightleftharpoons \mathrm{Sp}+\mathrm{Qz}
$$

Theoretically this reaction has to occur on the high temperature side of reaction (I) since it can only occur inside the stability field of $S p+Q z$. This restriction puts limits on the position and slope of reaction (I). Since $\mathrm{fO}_{2}$ is very low ${ }^{1}$ ) and the presence of a large amount of Mg-spinel ${ }_{\text {ss }}$ probably reduces the amount of $\mathrm{Fe}^{3+}$ which is taken up by spinel at constant for (compare speidel, 1970), it is assumed that spinel does not contain a significant amount of magnetite ss .

This is not to say that the stability field of spinel in this composition would not be sensitive to oxygen fugacity. With increasing $\mathrm{fO}_{2}$, the field of spinel should enlarge at the expense of that of garnet. The present results are probably close to the minimum stability limits for aluminous spinel in this composition.

Increasing the $\mathrm{Mg} / \mathrm{Mg}+\mathrm{Fe}^{2+}$ ratio would marginally increase the stability field of spinel with respect to

1) See Chapter 2 . 
garnet (compare B $_{50}$ composition), provided the assumption that Mg distributes in favour of spinel with respect to garnet is correct. No experimental evidence has been obtained for this, but in a natural metamorphic rock from the Antarctic, the distribution of $\mathrm{Mg}$ in coexisting (intergrown) low calcium garnet and hercynite-spinelss is definitely in favour of the latter mineral ${ }^{1}$ ) (unpublished microprobe analysis).

The results on the $\mathrm{C}_{30}$ composition can be combined with those on $\mathrm{C}_{70}$ to construct $\mathrm{P}-\mathrm{X}$ diagrams for the C-series of compositions. In this manner, additional restrictions on the data are introduced by the geometry of the diagram relating the two sets of experimental results. The P-X diagrams are presented in the following section.

\subsection{P-T-X RELATIONSHIPS IN THE C-SERIES OF COMPOSITIONS}

The experimental and analytical results on the $\mathrm{C}_{70}$ and $\mathrm{C}_{30}$ compositions have been combined and extrapolated to obtain the general P-T-X relationships for the entire compositional range of the C-series (from $100 \mathrm{Mg} / \mathrm{Mg}+\mathrm{Fe}^{2+}=$ O to 100). P-X diagrams have been used for the graphical representation of the phase relationships. These diagrams are isothermal sections through P-T-X space. The Mg/Mg $+\mathrm{Fe}^{2+}$

1) Further discussion in Chapter 9 . 
ratio is regarded as the only significant chemical variable influencing the relative stability of the ferromagnesian phases. The deduced phase relationships are relevant only to assemblages formed under conditions of $\mathrm{low}_{\mathrm{fO}}$, containing excess plagioclase, sillimanite and quartz. The presence of alkali feldspar is not required and, as discussed earlier, the composition of the plagioclase can be disregarded, at least for intermediate plagioclase compositions.

The P-X diagrams (Figs. 4.12 to 4.16 ) have been constructed using the following information:

1. The phase boundaries deduced from the experimental results on the $\mathrm{C}_{70}$ and $\mathrm{C}_{30}$ compositions. The phase boundaries limiting divariant fields in the P-T diagrams are represented by points on the P-X diagram, while univariant boundaries appear as isobaric lines on the P-X plane. Both the points and the lines have been taken directly from the P-T diagrams (Figs. 4.1 and 4.9). Experimental uncertainty has not been shown for these points in order to obtain a clearer representation of the phase relationships.

2. The $\mathrm{Mg} / \mathrm{Mg}+\mathrm{Fe}^{2+}$ ratios of coexisting phases in the experimental runs obtained by microprobe analyses (Tables 3.2 and 3.4 ). The range in $\mathrm{Mg} / \mathrm{Mg}+\mathrm{Fe}^{2+}$ ratio and the uncertainty in 
pressure measurement $(+0.4 \mathrm{~kb})$ has been shown on the diagrams.

3. The distribution coefficients derived from the above microprobe analyses. The $\mathrm{K}_{\mathrm{D}}(\mathrm{Cd}-\mathrm{Ca})$ is approximately independent of the cordierite and garnet composition for intermediate values of $\mathrm{X}_{\mathrm{Ga}}$ and $\mathrm{X}_{\mathrm{Cd}}$, but may increase significantly as $X_{\mathrm{Ga}}$ and $\mathrm{X}_{\mathrm{Cd}}$ approach 1. Given the position of one compositional curve (e.g. $\left.\mathrm{X}_{\mathrm{Ga}}\right)$, the position of the other one (e.g. $\mathrm{X}_{\mathrm{Cd}}$ ) is determined for a given $\mathrm{K}_{\mathrm{D}}$. Therefore the distribution coefficient puts restrictions on the relative positions of the $\mathrm{X}_{\mathrm{Cd}}$ and $\mathrm{X}_{\mathrm{Ga}}$ curves and thus on the shape of the divariant loops.

4. The reactions for the end members in the systems $\mathrm{FeO}-\mathrm{Al}_{2} \mathrm{O}_{3}-\mathrm{SiO}_{2}$ and $\mathrm{MgO}_{\mathrm{A}} \mathrm{Al}_{2} \mathrm{O}_{3}-\mathrm{SiO}_{2} \cdot$ The breakdown curve of Fe-cordierite (Richardson, 1968) has been extrapolated to higher temperature. In the presence of plagioclase, Fe-cordierite will probably break down at slightly lower pressure than in the simple ternary system. For the Mg-endmember reactions, the data obtained on the B 100 composition (Chapter 5.4) have been used.

5. The results of analyses of coexisting phases in the B-series. These introduce an additional 
constraint on the shape of the divariant loops. Unless the distribution coefficient $\left(K_{D}\right)$ is significantly affected by pressure (which seems unlikely), the distribution of Fe and Mg between a garnet and a cordierite of a certain composition should be the same in the assemblages $\mathrm{Cd}-\mathrm{Ga}-\mathrm{Si}-\mathrm{Qz}$ and $\mathrm{Cd}-\mathrm{Hy}-\mathrm{Ga}-\mathrm{Qz}$, although these occur at different pressures (see discussion in Chapter 3.3$)$.

The P-X diagrams in Figs. 4.12 to 4.16 illustrate the stability relationships of the various mineral assemblages as a function of pressure and composition for each chosen temperature. $^{1)}$ The curves marking the boundaries of the divariant fields also fix the compositions of the coexisting phases in divariant equilibrium. The univariant and divariant reactions that occur in the P-X diagrams have been listed in Table 4.7 .

$\underline{P-X}$ diagrams

$$
\underline{1100^{\circ} \mathrm{C}}(\mathrm{Fig} \cdot 4.12)
$$

Although at this temperature no analytical data are available, the phase relationships as shown on the diagram are believed to be at least qualitatively correct. The divariant field for the assemblage Sa-Sp-Qz has not been

1) For theoretical aspects see chapter 3. 
TABLE 4.7

a) Univariant reactions

\begin{tabular}{ccc}
\hline Reaction & $\Delta \mathrm{V}$ & No。 \\
\hline $\mathrm{Cd}+\mathrm{Ga} \rightleftharpoons \mathrm{Hy}+\mathrm{Si}+\mathrm{Qz}$ & $-\mathrm{ve}$ & $(\mathrm{I})$ \\
$\mathrm{Sp}+\mathrm{Qz} \rightleftharpoons \mathrm{Cd}+\mathrm{Ga}+\mathrm{Si}$ & $-\mathrm{ve}$ & $(\mathrm{II})$ \\
$\mathrm{Sp}+\mathrm{Cd} \rightleftharpoons \mathrm{Sa}+\mathrm{Qz}$ & $-\mathrm{ve}$ & $(\mathrm{III})$ \\
$\mathrm{Cd}+\mathrm{Ga} \rightleftharpoons \mathrm{Hy}+\mathrm{Ky}+\mathrm{Qz}$ & $-\mathrm{ve}$ & $\left.(\mathrm{x})^{1}\right)$ \\
\hline
\end{tabular}

b) Divariant reactions

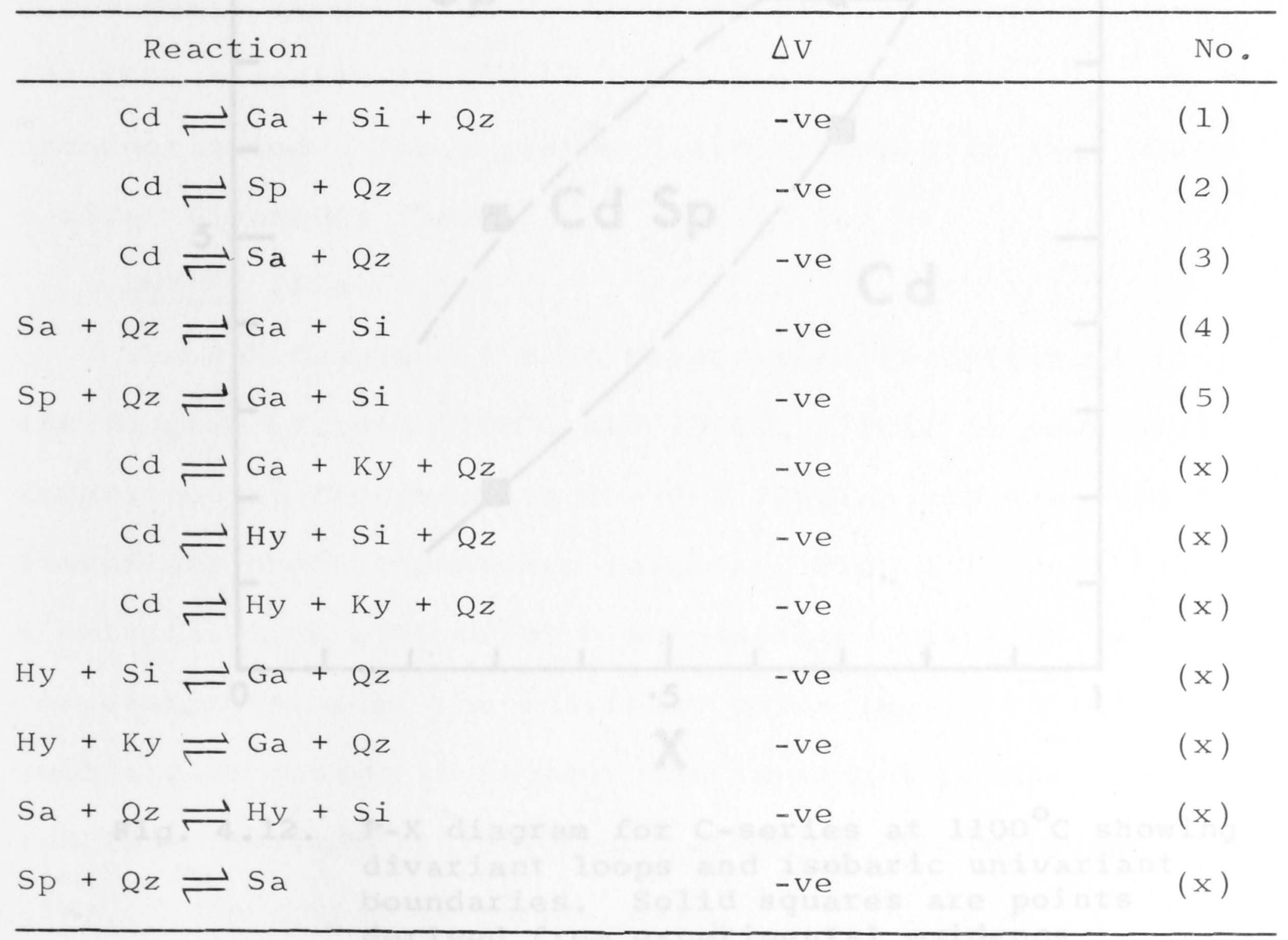

1) Reactions marked ( $x$ ) have not been observed experimentally but have been deduced from a combination of experimental and theoretical evidence. 


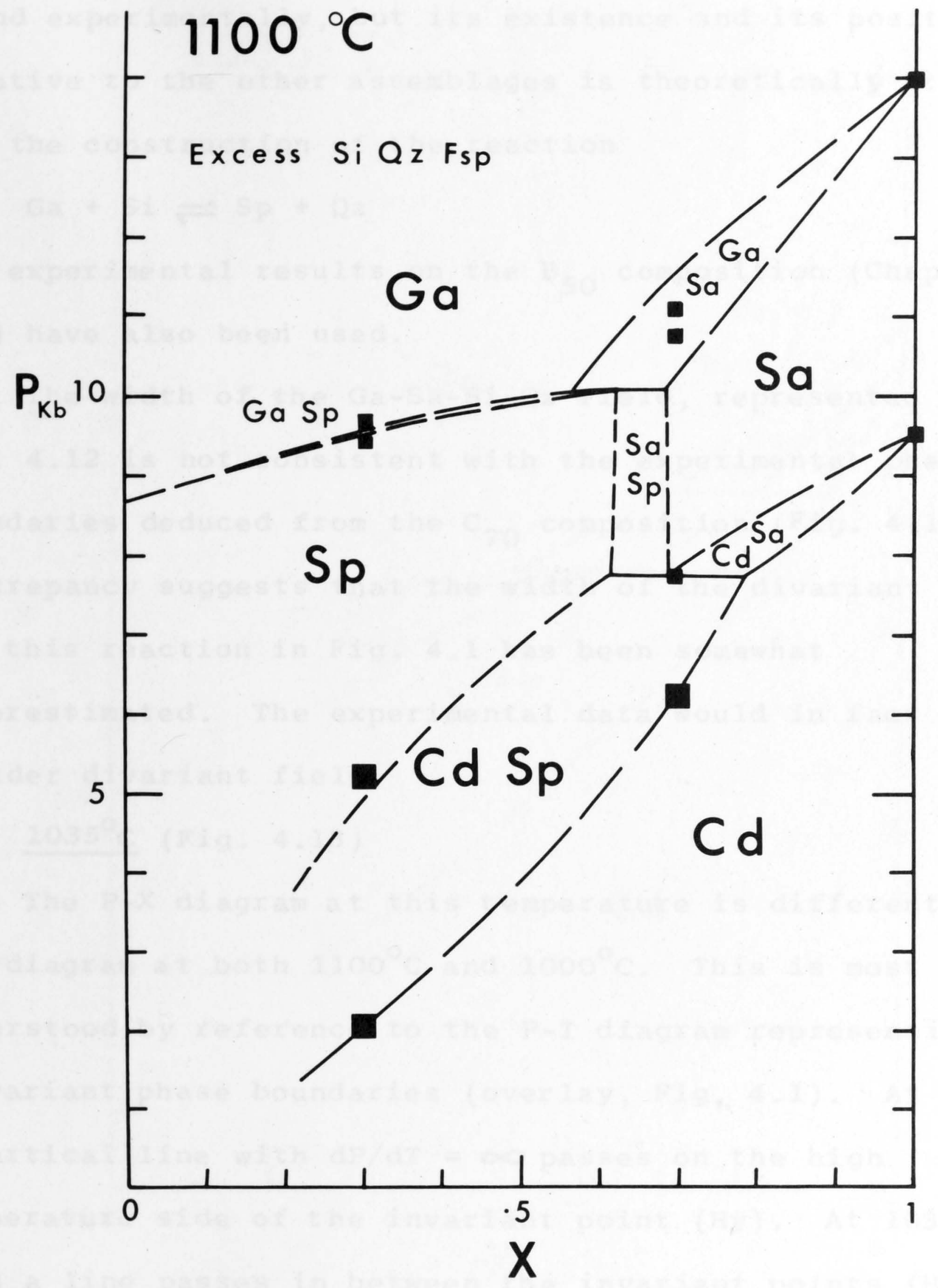

Fig. 4.12. P-X diagram for C-series at $1100^{\circ} \mathrm{C}$ showing divariant loops and isobaric univariant boundaries. Solid squares are points derived from experimental evidence (uncertainty not shown). The positions of the phase boundaries are approximate. 
found experimentally, but its existence and its position relative to the other assemblages is theoretically predicted. For the construction of the reaction

$$
\mathrm{Ga}+\mathrm{Si} \rightleftharpoons \mathrm{Sp}+\mathrm{Qz}
$$

the experimental results on the $B_{50}$ composition (Chapter 5.2) have also been used.

The width of the Ga-Sa-Si-Qz field, represented in Fig. 4.12 is not consistent with the experimental phase boundaries deduced from the $C_{70}$ composition (Fig. 4.1). The discrepancy suggests that the width of the divariant band for this reaction in Fig. 4.1 has been somewhat underestimated. The experimental data would in fact allow a wider divariant field.

$$
1035^{\circ} \mathrm{C}(\mathrm{Fig} \cdot 4.13)
$$

The P-X diagram at this temperature is different from the diagram at both $1100^{\circ} \mathrm{C}$ and $1000^{\circ} \mathrm{C}$. This is most easily understood by reference to the P-T diagram representing the univariant phase boundaries (overlay, Fig.4.1). At $1100^{\circ} \mathrm{C}$ a vertical line with $\mathrm{dP} / \mathrm{dT}=\infty$ passes on the high temperature side of the invariant point (Hy). At $1035^{\circ} \mathrm{C}$ such a line passes in between the invariant points (Hy) and $(\mathrm{Sp})$, whereas at $1000^{\circ} \mathrm{C}$ it passes on the low temperature side of the invariant point (Sp). 


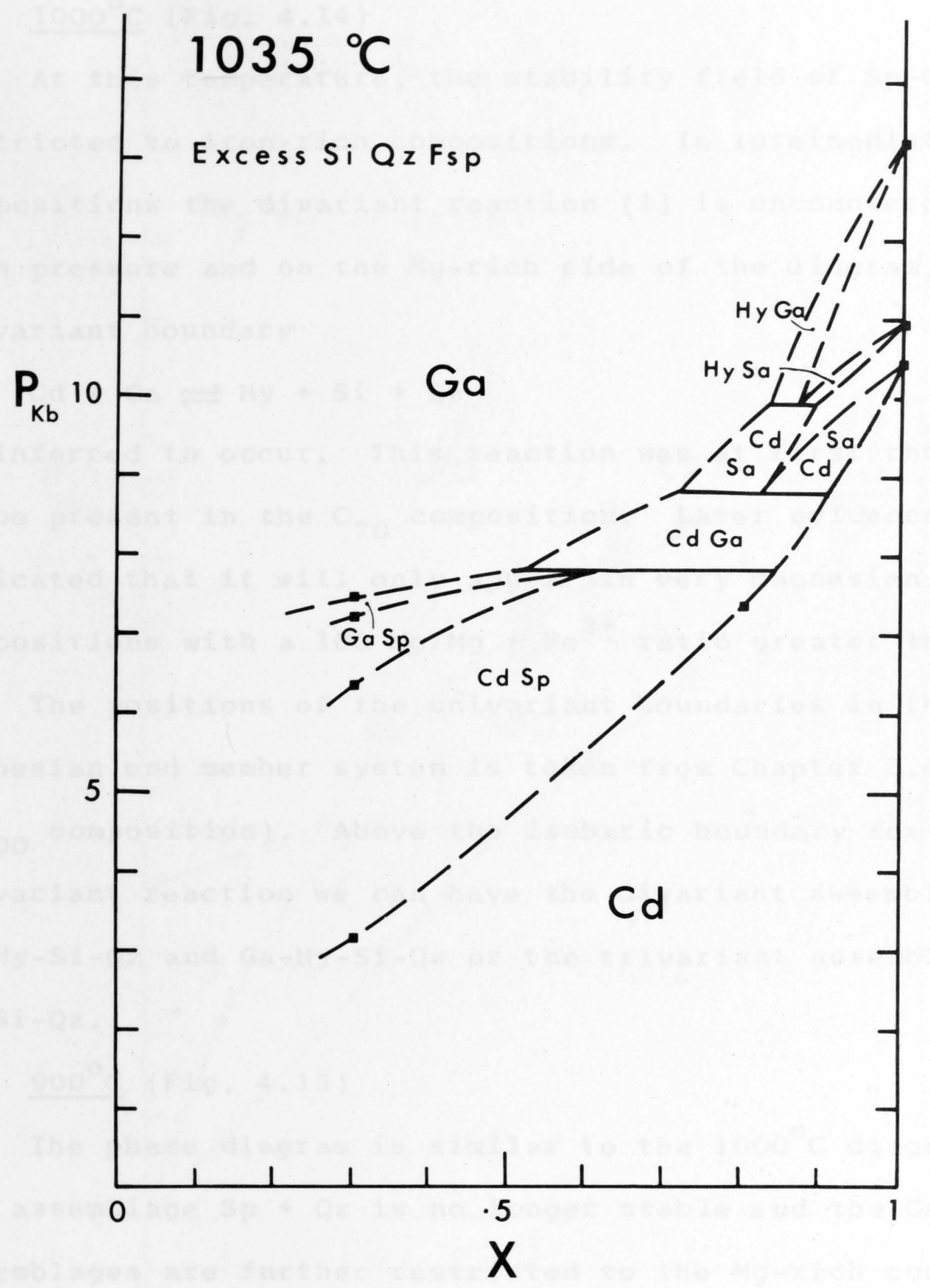

Fig. 4.13. P-X diagram for C-series at $1035^{\circ} \mathrm{C}$.

The positions of the phase boundaries are approximate. 


\section{$\underline{1000^{\circ} \mathrm{C}}(\mathrm{Fig} \cdot 4 \cdot 14)$}

At this temperature, the stability field of Sp-Qz is restricted to iron-rich compositions. In intermediate compositions the divariant reaction ( 1 ) is encountered. At high pressure and on the Mg-rich side of the diagram, the univariant boundary

$$
\mathrm{Cd}+\mathrm{Ga} \rightleftharpoons \mathrm{Hy}+\mathrm{Si}+\mathrm{Qz}
$$

is inferred to occur. This reaction was at first thought to be present in the $\mathrm{C}_{70}$ composition. Later evidence has indicated that it will only appear in very magnesian compositions with a $100 \mathrm{Mg} / \mathrm{Mg}+\mathrm{Fe}^{2+}$ ratio greater than 70. The positions of the univariant boundaries in the magnesian end member system is taken from Chapter 5.4 (B 100 composition). Above the isobaric boundary for the univariant reaction we can have the divariant assemblages $\mathrm{Cd}-\mathrm{Hy}-\mathrm{Si}-\mathrm{Qz}$ and $\mathrm{Ga}-\mathrm{Hy}-\mathrm{Si}-\mathrm{Qz}$ or the trivariant assemblage $\mathrm{Hy}-\mathrm{Si}-\mathrm{Qz}$.

$$
\underline{900^{\circ} \mathrm{C}}(\mathrm{Fig} \cdot 4 \cdot 15)
$$

The phase diagram is similar to the $1000^{\circ} \mathrm{C}$ diagram. The assemblage $\mathrm{SP}+\mathrm{Qz}$ is no longer stable and the Ga-Hy-Si assemblages are further restricted to the Mg-rich compositions. At high pressure the $\mathrm{Ky} \rightleftharpoons \mathrm{Si}$ phase boundary intersects with the reaction

$$
\mathrm{Ga}+\mathrm{Qz} \rightleftharpoons \mathrm{Hy}+\mathrm{Si}
$$

changing it to 


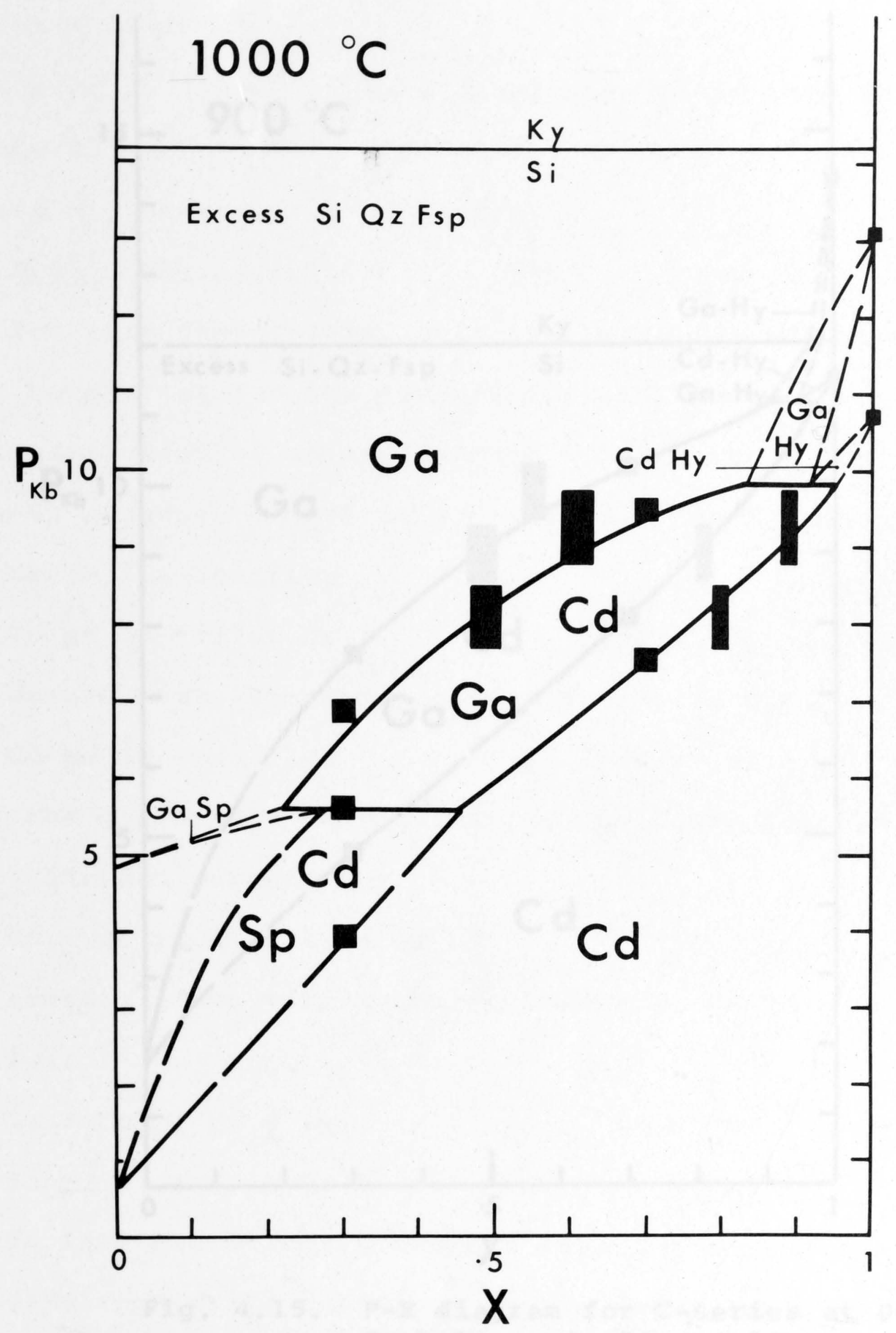

Fig. 4.14. P-X diagram for C-series at $1000^{\circ} \mathrm{C}$.

Solid squares: phase boundaries derived from experimental work (uncertainty not shown)

Solid rectangles: $\mathrm{X}_{\mathrm{Cd}}$ and $\mathrm{X}_{\mathrm{Ga}}$ (compositional range and pressure uncertaina shown). Dashed boundaries are approximate. 


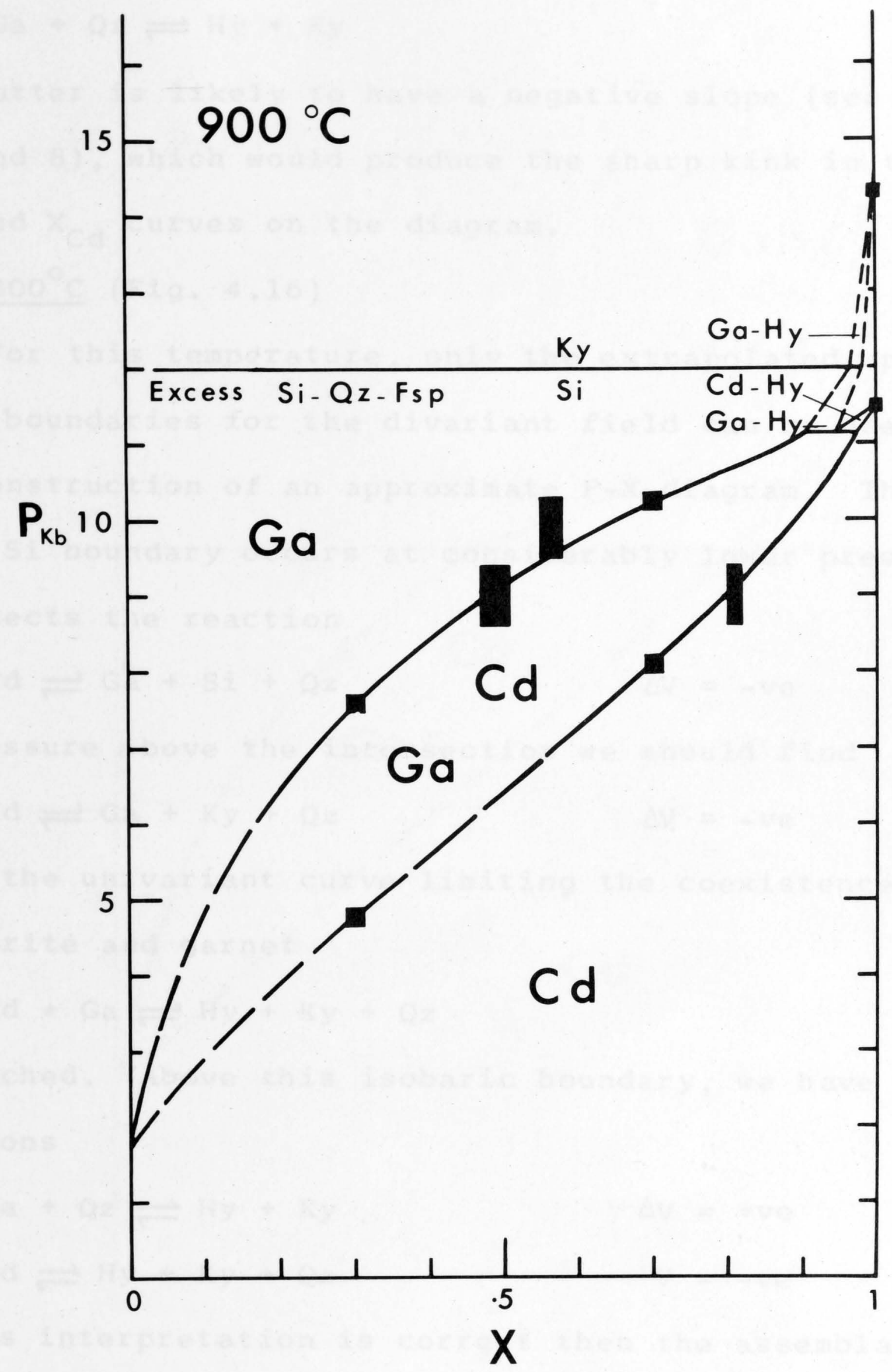

Fig. 4.15. P-X diagram for C-series at $900^{\circ} \mathrm{C}$. symbols as in Fig. 4.14. 


$$
\mathrm{Ga}+\mathrm{Qz} \rightleftharpoons \mathrm{Hy}+\mathrm{Ky}
$$

The latter is likely to have a negative slope (see Chapter 5.4 and 8), which would produce the sharp kink in the $\mathrm{X}_{\mathrm{Ga}}$ and $\mathrm{X}_{\mathrm{Cd}}$ curves on the diagram. $\underline{800^{\circ} \mathrm{C}}(\mathrm{Fig} \cdot 4.16)$

For this temperature, only the extrapolated upper and lower boundaries for the divariant field can be used for the construction of an approximate P-X diagram. The Ky $\rightleftharpoons$ Si boundary occurs at considerably lower pressure and intersects the reaction

$$
\mathrm{Cd} \rightleftharpoons \mathrm{Ga}+\mathrm{Si}+\mathrm{Qz} \quad \Delta \mathrm{V}=-\mathrm{ve}
$$

At pressure above the intersection we should find

$$
\mathrm{Cd} \rightleftharpoons \mathrm{Ga}+\mathrm{Ky}+\mathrm{Qz} \quad \Delta \mathrm{V}=-\mathrm{ve}
$$

until the univariant curve limiting the coexistence of cordierite and garnet

$$
\mathrm{Cd}+\mathrm{Ga} \rightleftharpoons \mathrm{Hy}+\mathrm{Ky}+\mathrm{Qz}
$$

is reached. Above this isobaric boundary, we have the reactions

$$
\begin{array}{lrl}
\mathrm{Ga}+\mathrm{Qz} \rightleftharpoons \mathrm{Hy}+\mathrm{Ky} & \Delta \mathrm{V}=+\mathrm{ve} \\
\mathrm{Cd} \rightleftharpoons \mathrm{Hy}+\mathrm{Ky}+\mathrm{Qz} & \mathrm{V}=-\mathrm{ve}
\end{array}
$$

If this interpretation is correct then the assemblage pyrope-Mg-cordierite cannot be stable under any conditions (see also discussion in Chapter 8). 


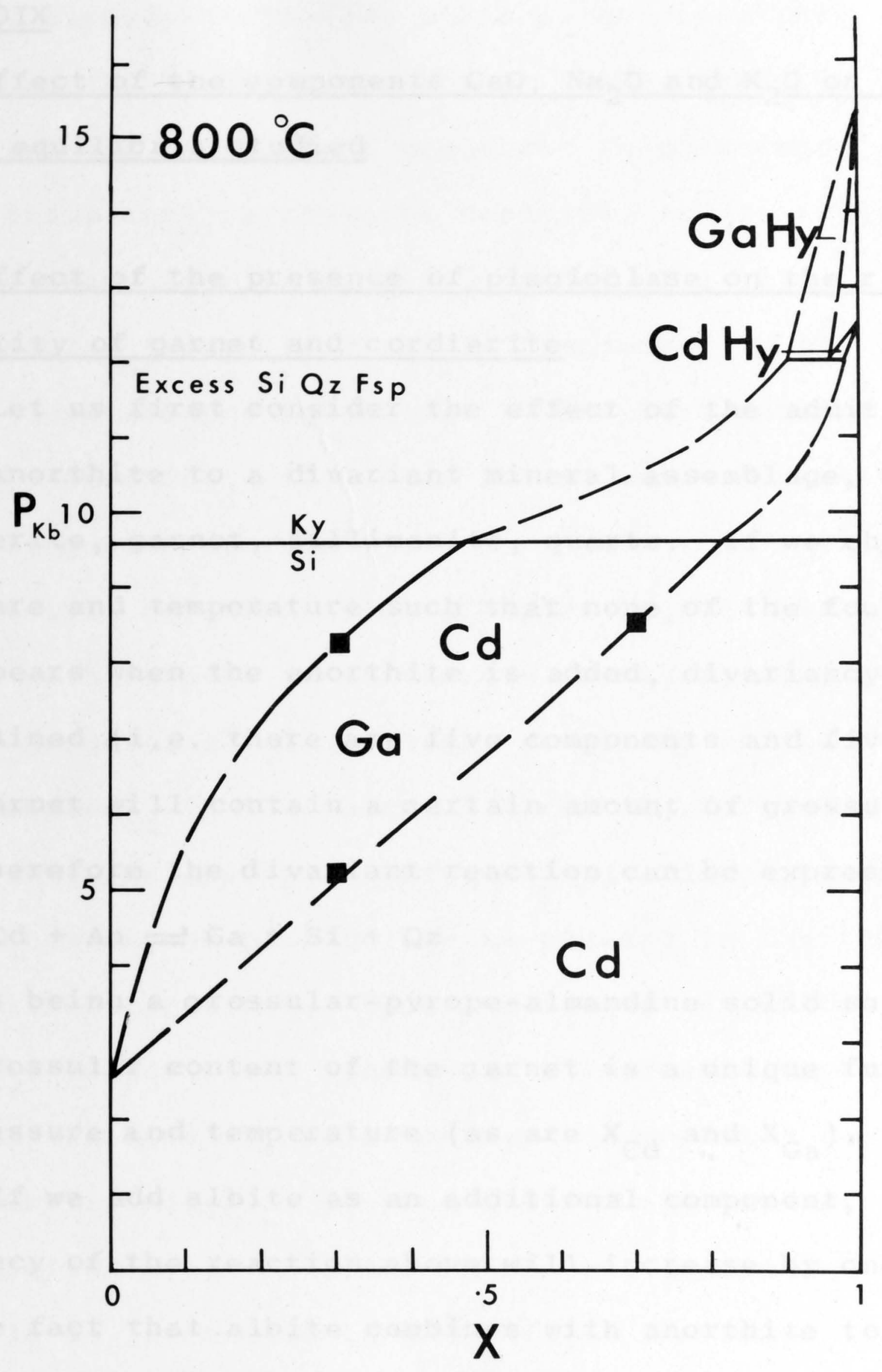

Fig. 4.16. P-X diagram for C-series at $800^{\circ} \mathrm{C}$. Phase boundaries are approximate. 
APPENDIX

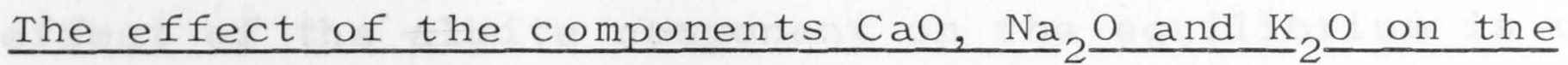

phase equilibria studied

The effect of the presence of plagioclase on the relative stability of garnet and cordierite

Let us first consider the effect of the addition of pure anorthite to a divariant mineral assemblage, e.g. cordierite, garnet, sillimanite, quartz. If we choose pressure and temperature such that none of the four phases disappears when the anorthite is added, divariancy is maintained (i.e. there are five components and five phases). The garnet will contain a certain amount of grossular ss, and therefore the divariant reaction can be expressed as

$$
\mathrm{Cd}+\mathrm{An} \rightleftharpoons \mathrm{Ga}+\mathrm{Si}+\mathrm{Qz}
$$

garnet being a grossular-pyrope-almandine solid solution. The grossular content of the garnet is a unique function of pressure and temperature (as are $\mathrm{X}_{\mathrm{Cd}}$ and $\mathrm{X}_{\mathrm{Ga}}$ ).

If we add albite as an additional component, the variancy of the reaction above will increase by one owing to the fact that albite combines with anorthite to form plagioclase. As a result we now have six components and five phases. This means that three independent variables have to be chosen (e.g. P, T, $\left.x_{C d}\right)$ to determine the remaining compositional variables ( $\mathrm{X}_{\mathrm{Ga}}$, mole \% $\mathrm{Gr}$ in garnet, mole \% An in plagioclase). 
As already indicated, there is evidence that the effect of the albite component on the equilibrium is very small and can probably be neglected in most cases. The equilibrium can therefore be described as quasi-divariant. If this assumption is correct, garnet will be near saturated in grossularss ( at any $P$ and $T$ ) independent of the composition of the coexisting plagioclase. ${ }^{1}$ ) Complete saturation can, strictly speaking, only occur in the case of garnet coexisting with anorthite.

As will be shown later (Chapter 7), the stability of garnet with respect to cordierite is significantly affected by the presence of plagioclase, resulting in the formation of grossulars in the garnet. From the foregoing it is clear that the assumption of quasi-divariancy can only apply when excess plagioclase is present in the bulk composition concerned. This requirement is fulfilled for all bulk compositions studied in the present investigation. By the addition of orthoclase component a new phase i.e. alkali feldspar, is produced and the variance of the equilibrium is not affected. Moreover, another chemical variable is introduced in the form of the composition of the alkali feldspar. The compositions of plagioclase and alkali feldspar are related by a distribution coefficient.

1) At least for intermediate plagioclase compositions, i.e. oligoclase-bytownite. 
Therefore, the amount of alkali feldspar relative to plagioclase in any bulk composition will affect the plagioclase composition to a certain extent (compare Cd-Hy, Chapter 3.3). As a result, the presence of alkali feldspar could theoretically have a "third order", indirect effect on the stability of garnet to the extent that the garnet stability is influenced by the composition of the coexisting plagioclase. Since, as pointed out above, the stability of the garnet does not appear to be significantly affected by the plagioclase composition, the effect of alkali feldspar can be neglected. 


\section{CHAPTER 5}

\section{EXPERIMENTAL STUDY OF THE B-SERIES OF COMPOSITIONS}

The B-series of compositions is modelled on a relatively alumina-poor metapelite. It differs from the $\mathrm{C}$-series in having a lower $\mathrm{Al}_{2} \mathrm{O}_{3} / \mathrm{FeO}+\mathrm{MgO}$ ratio $(\mathrm{A} / \mathrm{F}+\mathrm{M}$ (1). 1) Sillimanite is therefore not an excess phase in this series.

Three intermediate members of the series, $\mathrm{B}_{70}, \mathrm{~B}_{50}$ and $\mathrm{B}_{30}$ and the two end members $\mathrm{B}_{100}$ and $\mathrm{B}_{\mathrm{O}}$ have been investigated experimentally. The results have been combined to deduce the P-T-X relations for this series involving the phases cordierite, hypersthene, garnet, sapphirine, olivine, spinel and sillimanite, in the presence of excess plagioclase, alkali feldspar and quartz.

\subsection{PHASE RELATIONS IN THE B 7 COMPOSITION}

Composition and starting material

The chemical composition of $B_{70}$ is:

1) Figure 1.1 illustrates the chemographic relationships among the series and among the compositions within each series. 


$$
\begin{array}{llll}
\mathrm{SiO}_{2} & - & 53.82 \\
\mathrm{Al}_{2} \mathrm{O}_{3} & - & 25.43 \\
\mathrm{FeO} & - & 6.83 & \\
\mathrm{MgO} & - & 8.95 & 100 \mathrm{Mg} / \mathrm{Mg}+\mathrm{Fe}^{2+}=70 \\
\mathrm{CaO} & - & 2.42 & \text { Normative plagioclase: An } 53.2 \\
\mathrm{Na}_{2} \mathrm{O} & - & 1.18 & \\
\mathrm{~K}_{2} \mathrm{O} & - & 1.35
\end{array}
$$

The starting material used in the experiments consisted of :

10\% low pressure assemblage, crystallised from glass at $1000^{\circ} \mathrm{C}, 7.2 \mathrm{~kb}$, containing cordierite, hypersthene, minor spinel, quartz and feldspars. 10\% high pressure assemblage, crystallised at $1100^{\circ} \mathrm{C}, 18 \mathrm{~kb}$, consisting of garnet, quartz, minor feldspars, minor corundum and minor glass. $80 \%$ glass (for preparation methods see Chapter $2.2)$

Two reversals have been carried out with completely crystalline starting materials (to be described later). Results of seeded glass experiments

The experimental data are given in Figure 5.1 and Table 5.1. At temperatures from $800-1050^{\circ} \mathrm{C}$ the following assemblages have been observed with increasing pressure: cordierite-hypersthene-quartz cordierite-garnet-hypersthene-quartz 
TABLE 5.1

Experimental data for $B_{70}$ composition

\begin{tabular}{|c|c|c|c|c|c|c|c|c|c|c|c|c|c|}
\hline \multirow{2}{*}{$\begin{array}{l}\text { Run } \\
\text { No. }\end{array}$} & \multirow{2}{*}{ Temp } & \multirow{2}{*}{$\begin{array}{c}\text { Press } \\
\mathrm{Kb}\end{array}$} & \multirow{2}{*}{$\begin{array}{r}\text { Time } \\
\text { hrs }\end{array}$} & \multicolumn{10}{|c|}{ Phases present } \\
\hline & & & & $\mathrm{Cd}$ & $\mathrm{Ga}$ & Hy & $\mathrm{Si}$ & $Q z$ & $\mathrm{Sa}$ & sp & $\mathrm{Bi}$ & Fsp & Glass \\
\hline 1605 & 1200 & 7.2 & 2 & M & & $\operatorname{tr}$ & & $\operatorname{tr}$ & M & & & tr & $\mathrm{L} / \mathrm{M}$ \\
\hline 1606 & " & 9 & 2 & & & $\operatorname{tr} / \mathrm{L}$ & & $\mathrm{M}$ & $\mathrm{H}$ & & & $\operatorname{tr}$ & $\mathrm{L} / \mathrm{M}$ \\
\hline 1339 & $"$ & 14.4 & 2 & & $\mathrm{H}$ & tr & $\mathrm{L} / \mathrm{M}$ & $\mathrm{L}$ & $\operatorname{tr}$ & & & $\mathrm{L}$ & $\mathrm{L}$ \\
\hline 1675 & 1150 & 11.7 & 4 & & $\mathrm{H}$ & $t r$ & $\mathrm{~L}$ & M & $\mathrm{L}$ & & & $\mathrm{L}$ & $\mathrm{L}$ \\
\hline 1592 & 1100 & 5.4 & 19 & $\mathrm{H}$ & & $\mathrm{L} / \mathrm{M}$ & & & & & & $\mathrm{L}$ & $\mathrm{L}$ \\
\hline 1595 & $"$ & 6.3 & 18 & $\mathrm{H}$ & & $\mathrm{L} / \mathrm{M}$ & & & & & & $\mathrm{L}$ & $\mathrm{L}$ \\
\hline 1589 & $" 1$ & 7.2 & 18 & $\mathrm{H}$ & $\mathrm{L}$ & $\mathrm{L} / \mathrm{M}$ & & & & $\operatorname{tr}$ & & $\mathrm{L}$ & $\mathrm{L}$ \\
\hline 1694 & $"$ & 7.2 & 44 & $\mathrm{H}$ & $\mathrm{L} / \mathrm{M}$ & L & & tr & & & & $\mathrm{L}$ & $\mathrm{L}$ \\
\hline 1625 & $"$ & 8.1 & 18 & $M$ & M & L & & $\mathrm{L} / \mathrm{M}$ & $\mathrm{L} / \mathrm{M}$ & & & $\mathrm{L}$ & $\mathrm{L}$ \\
\hline 1594 & $"$ & 9 & 18 & & $\mathrm{H}$ & $\mathrm{L}$ & & M & M & tr & & $\mathrm{L}$ & $\mathrm{L}$ \\
\hline 1669 & $"$ & 9.9 & 13 & & $\mathrm{H}$ & $\mathrm{L}$ & & M & $M$ & & & $\mathrm{~L}$ & $\mathrm{~L}$ \\
\hline 1673 & $"$ & 10.8 & 20 & & $\mathrm{H}$ & tr & $L / M$ & M & $L / M$ & & & $\mathrm{~L}$ & $\mathrm{~L}$ \\
\hline 1627 & $"$ & 11.7 & 15 & & $H$ & $\operatorname{tr}$ & $L / M$ & $M$ & $\operatorname{tr}$ & & & $\mathrm{L}$ & $\mathrm{L}$ \\
\hline 1622 & " & 13.5 & 12 & & $\mathrm{H}$ & & $\mathrm{L} / \mathrm{M}$ & M & & & & $\mathrm{L}$ & $\mathrm{L}$ \\
\hline 1664 & 1050 & 9 & 43 & $\mathrm{~L}$ & tr & $\mathrm{H}$ & $t r$ & M & tr & & & $\mathrm{L}$ & $\mathrm{L}$ \\
\hline $\left.1604^{1}\right)$ & 1000 & 5.4 & 45 & $\mathrm{H}$ & tr & $M$ & & $\operatorname{tr} / \mathrm{L}$ & & & & $\mathrm{L}$ & $\mathrm{tr}$ \\
\hline $1593^{2)}$ & 1 & 6.3 & 44 & $\mathrm{H}$ & $\mathrm{L}$ & L & & $\mathrm{L}$ & & & & $\mathrm{L}$ & tr \\
\hline 1573 & $"$ & 7.2 & 43 & $\mathrm{M} / \mathrm{H}$ & $\mathrm{M} / \mathrm{H}$ & $\mathrm{L}$ & & $\mathrm{L}$ & & & & $\mathrm{L}$ & $t r$ \\
\hline 15973 ) & $"$ & 9 & 46 & & $\begin{array}{l}\mathrm{H} \\
\mathrm{M}\end{array}$ & $\operatorname{tr} / \mathrm{L}$ & & M & & & & $\mathrm{L}$ & $\operatorname{tr}$ \\
\hline $1.560^{\circ}$ & $"$ & 9 & 70 & & M & tr & & & & & & tr $\mathrm{r} / \mathrm{L}$ & $\mathrm{L} / \mathrm{M}$ \\
\hline $\begin{array}{l}1616 \\
1608\end{array}$ & " & $\begin{array}{r}9.9 \\
10.8\end{array}$ & $\begin{array}{l}45 \\
45\end{array}$ & & $\underset{\mathrm{H}}{\mathrm{H}}$ & $\underset{t r / L}{\operatorname{tr} / L}$ & $\stackrel{\mathrm{L}}{\mathrm{L} / \mathrm{M}}$ & $\mathrm{M}$ & & & & $\stackrel{L}{L}$ & $\begin{array}{l}\operatorname{tr} \\
\operatorname{tr}\end{array}$ \\
\hline 2785 & 950 & 9 & 96 & M & M & $\mathrm{tr} / \mathrm{L}$ & & M & & & & L & L. \\
\hline 1676 & $"$ & 9.9 & 72 & $\mathrm{~L} / \mathrm{M}$ & $\mathrm{H}$ & $\mathrm{t} r$ & tr & M & & & & $\mathrm{L}$ & $\operatorname{tr}$ \\
\hline $1518_{3}^{3)}$ & 900 & 4.5 & 18 & $\mathrm{H}$ & & M & & $t r$ & & & & L & trr \\
\hline $1536_{3}^{3)}$ & " & 5.4 & 70 & $\mathrm{H}$ & & M & & $\operatorname{tr}$ & & & & $\mathrm{L}$ & $\mathrm{L}$ \\
\hline $\left.1586_{3}^{3}\right)$ & $"$ & 6.3 & 72 & $\mathrm{M} / \mathrm{H}$ & M & $\mathrm{L} / \mathrm{M}$ & & $\mathrm{L}$ & & & & L & $\operatorname{tr} / \mathrm{L}$ \\
\hline $\left.1570_{4}^{3}\right)$ & $"$ & 7.2 & 72 & $\mathrm{M}$ & $\mathrm{M} / \mathrm{H}$ & $\operatorname{tr} / \mathrm{L}$ & & M & & & & L & $\operatorname{tr} / \mathrm{L}$ \\
\hline $\left.1620^{4}\right)$ & 11 & 10.8 & 70 & $\mathrm{tr} / \mathrm{L}$ & $\mathrm{H}$ & tr & $\mathrm{L}$ & M & & & tr & $\mathrm{L}$ & L \\
\hline 1628 & " & 11.7 & 72 & tr & $\mathrm{H}$ & tr & L & M & & & & $\mathrm{L}$ & trr \\
\hline $2032^{1)}$ & 800 & 4.5 & 98 & $\mathrm{H}$ & $\mathrm{tr} / \mathrm{L}$ & $\mathrm{L}$ & & $\mathrm{L}$ & & & & $\mathrm{L}$ & $\mathrm{L}$ \\
\hline$\left.H 8^{5}\right)$ & 750 & 3.8 & 288 & $\mathrm{H}$ & & & & $\mathrm{tr}$ & & & M & $\operatorname{tr} / \mathrm{L}$ & $\mathrm{L}$ \\
\hline \multicolumn{14}{|c|}{ Reversals } \\
\hline \multicolumn{4}{|c|}{ Starting material } & & $\mathrm{H}$ & $\operatorname{tr} / \mathrm{L}$ & $\mathrm{L} / \mathrm{M}$ & M & $\operatorname{tr}$ & & & $\mathrm{L}$ & $\mathrm{L}$ \\
\hline 1664 & 1100 & 9 & 16 & & $\mathrm{H}$ & $\operatorname{tr}$ & $\operatorname{tr} / \mathrm{L}$ & M & L & & & $\mathrm{L}$ & $\mathrm{L}$ \\
\hline \multicolumn{4}{|c|}{ Starting material } & $\mathrm{tr} / \mathrm{L}$ & $\mathrm{H}$ & $\mathrm{tr}$ & M & $M$ & & & & $\mathrm{~L}$ & t.r. \\
\hline 2293 & 900 & 9.9 & 95 & $\mathrm{~L} / \mathrm{M}$ & $\mathrm{H}$ & tr & $\operatorname{tr} / \mathrm{L}$ & $\mathrm{L} / \mathrm{M}$ & & & & $\operatorname{tr}$ & $\mathrm{L}$ \\
\hline
\end{tabular}

1) Rare irregular shaped garnet relics

2 ) More abundant rounded garnets

3) Runs in Pt-capsules

4) Runs in $\mathrm{Ag} / \mathrm{Pd}$ capsules

5) Hydrothermal run. Ag/Pd capsule. $\mathrm{fO}_{2}$ between that of the iron-wustite and quartz-fayalite-magnetite buffers
Relative proportions of phases are indicated by: $\mathrm{H}=$ high

$M=\operatorname{medium}$

$\mathrm{L}=10 \mathrm{w}$

$\operatorname{tr}=\mathrm{trace}$ 


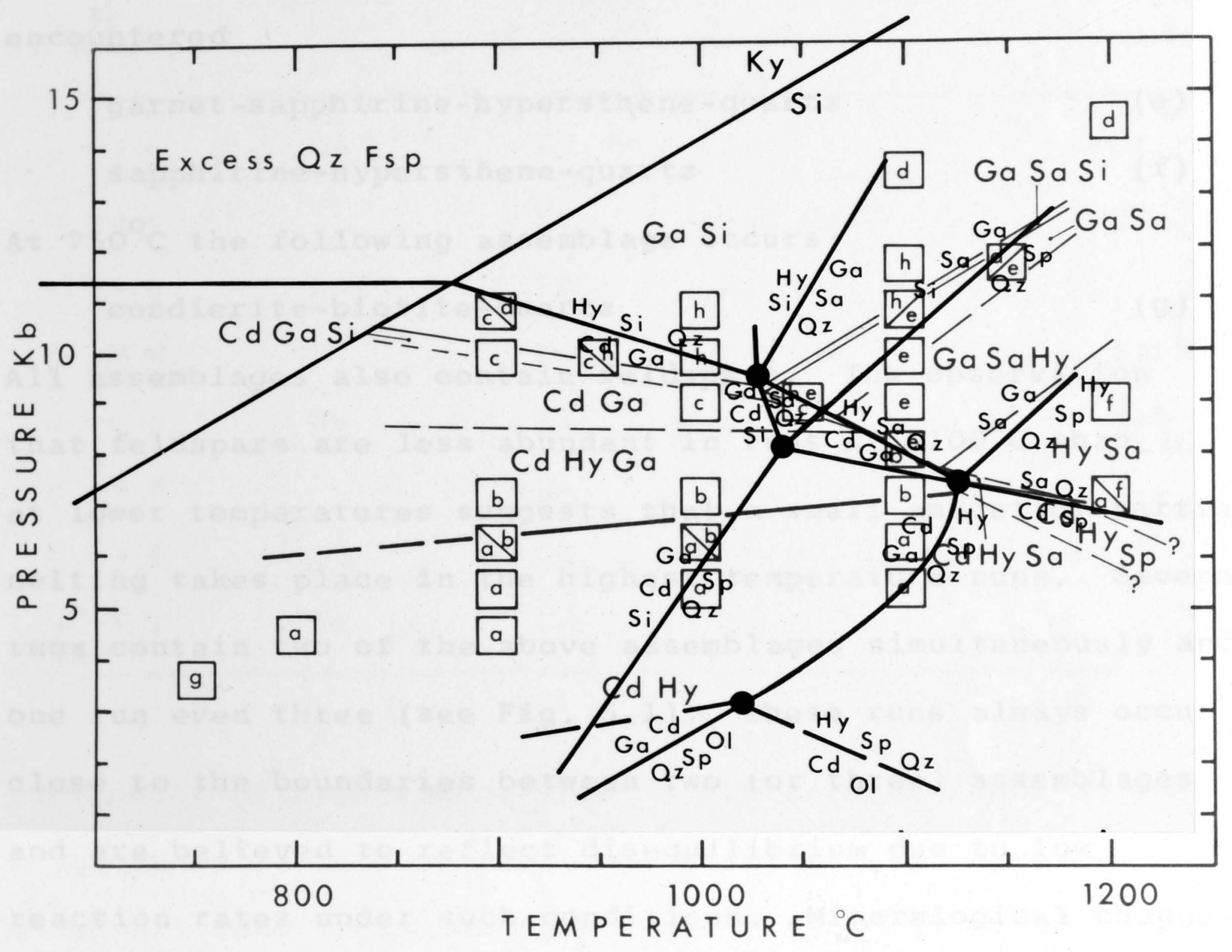

Fig. 5.1. P-T diagram for B 70 composition. The observed mineral assemblages are indicated by letters also used in the text. The relative position of the derived phase relations to the quasiunivariant boundaries in the general P-T diagram are shown by the overlay. 


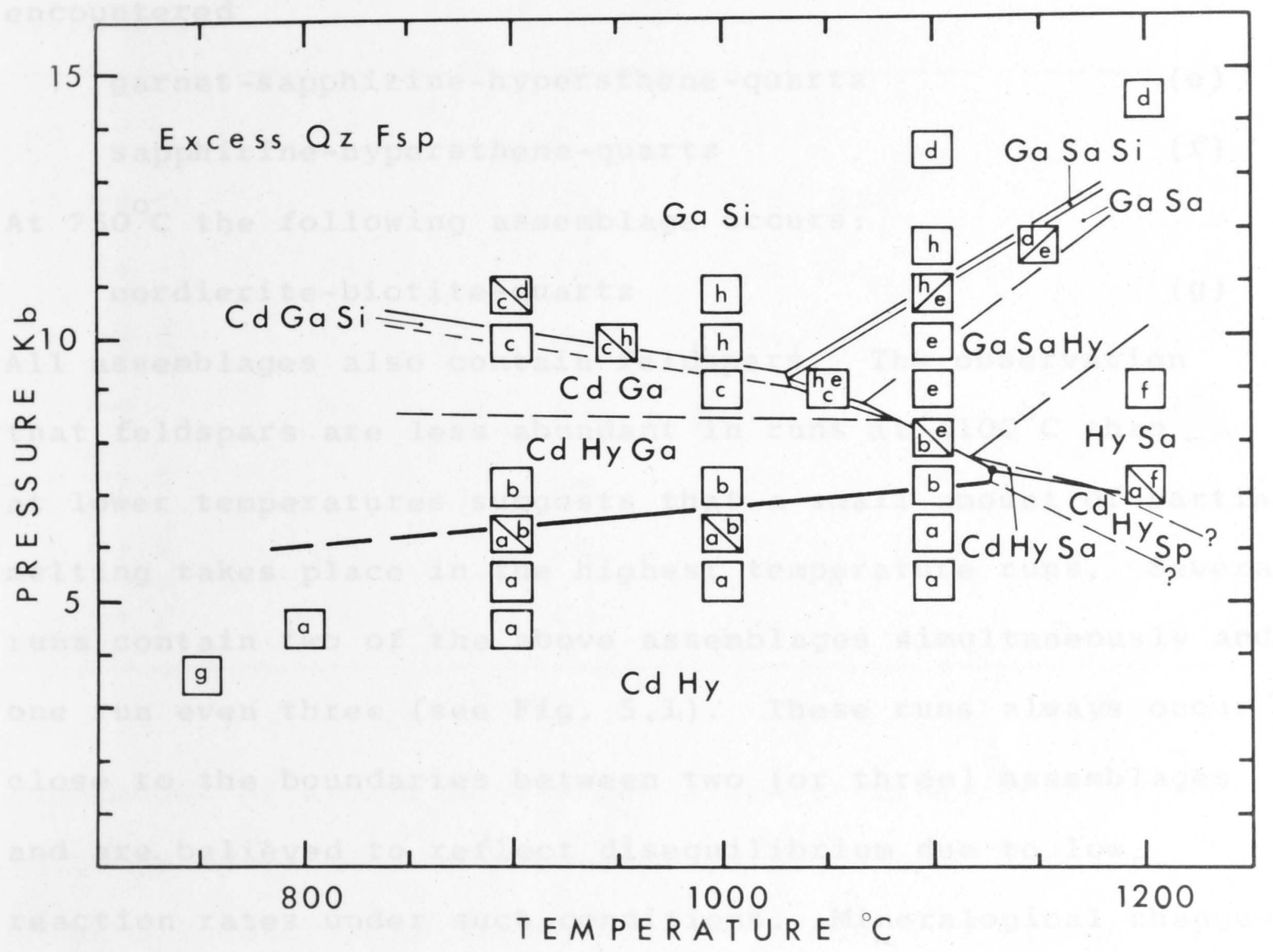

Fig. 5.1. P-T diagram for B 70 composition. The observed mineral assemblages are indicated by letters also used in the text. The relative position of the derived phase relations to the quasiunivariant boundaries in the general P-T diagram are shown by the overlay. 


$$
\begin{aligned}
& \text { cordierite-garnet-quartz } \\
& \text { garnet-hypersthene-sillimanite-quart } z \\
& \text { garnet-sillimanite-quartz }
\end{aligned}
$$

At temperatures above $1050^{\circ} \mathrm{C}$ two more assemblages were encountered

$$
\begin{aligned}
& \text { garnet-sapphirine-hypersthene-quartz } \\
& \text { sapphirine-hypersthene-quartz }
\end{aligned}
$$

At $750^{\circ} \mathrm{C}$ the following assemblage occurs:

$$
\text { cordierite-biotite-quartz }
$$

All assemblages also contain feldspars. The observation that feldspars are less abundant in runs at $1100^{\circ} \mathrm{C}$ than at lower temperatures suggests that a small amount of partial melting takes place in the highest temperature runs. Several runs contain two of the above assemblages simultaneously and one run even three (see Fig. 5.1). These runs always occur close to the boundaries between two (or three) assemblages. and are believed to reflect disequilibrium due to low reaction rates under such conditions. Mineralogical changes from one assemblage to the next are shown in Table 5.2.

In the interval in which garnet and cordierite coexist the amount of garnet increases while that of cordierite decreases with increasing pressure. 
TABLE 5.2

Observed changes in mineral as semblages

\begin{tabular}{|c|c|c|c|c|}
\hline $\begin{array}{c}\text { From } \\
\text { assemblage } \\
\text { to } \\
\text { assemblage }\end{array}$ & Appear & Dis appear & Increase & Decrease \\
\hline$a \rightarrow b$ & $\mathrm{Ga}$ & - & $\mathrm{Q} z$ & $\mathrm{Cd}, \mathrm{Hy}$ \\
\hline $\mathrm{b} \rightarrow \mathrm{c}$ & & Hy & $\mathrm{Ga}, \mathrm{Qz}$ & $\mathrm{Cd}$ \\
\hline $\mathrm{c} \longrightarrow \mathrm{h}$ & $\mathrm{Si}$ & $\mathrm{Cd}$ & $\mathrm{Ga}, \mathrm{Qz}, \mathrm{Hy}(?)$ & \\
\hline$c \rightarrow d$ & - & Hy & $\mathrm{Ga}, \mathrm{Qz}$ & Si (?) \\
\hline $\mathrm{d} \rightarrow \mathrm{e}$ & Sa & $\mathrm{Si}$ & $\mathrm{Qz}$ & $\mathrm{Ga}$ \\
\hline $\mathrm{e} \rightarrow \mathrm{f}$ & & $\mathrm{Ga}$ & $\mathrm{Hy}, \mathrm{Sa}, \mathrm{Qz}$ & \\
\hline $\mathrm{b} \rightarrow \mathrm{e}$ & $\mathrm{Sa}$ & $\mathrm{Cd}$ & $\mathrm{Hy}(?), \mathrm{Ga}, \mathrm{Qz}$ & \\
\hline$a \rightarrow f$ & $\mathrm{Sa}$ & $\mathrm{Cd}$ & $\mathrm{Q} z$ & \\
\hline
\end{tabular}

The amount of hypersthene shows a distinct decrease at the incoming of garnet and decreases while garnet increases. ${ }^{1}$ ) Under all conditions the $\mathrm{Mg} / \mathrm{Mg}+\mathrm{Fe}^{2+}$ ratio is highest in cordierite and lowest in garnet. All three ferromagnesian phases become more Mg-rich with increasing pressure.

Quantitative analyses of the crystalline phases using the electron microprobe are reported below.

1) The amount of hypersthene present is difficult to estimate both by $x-r a y$ and optical methods. An indirect method to determine the disappearance of hypersthene is given in the discussion. 


\section{Reversals}

The boundary $(\mathrm{a} \rightarrow \mathrm{b})$ marking the incoming of garnet has been reversed. Garnet seeds break down on the low pressureside of this curve and grow at higher pressure at the expense of the low pressure assemblage (which crystallised from the glass initially). ${ }^{1}$ ) This is shown in a series of three photographs for the incoming of garnet at $1000^{\circ} \mathrm{C}$ (Fig. 5.2). At the lowest pressure $(5.4 \mathrm{~kb})$, only a few skeletal garnet relics remain after the run. At $6.3 \mathrm{~kb}$ there is no detectable change in the amount of garnet, but the garnets have irregular outlines. At $7.2 \mathrm{~kb}$ garnet has clearly increased and has taken on a round subhedral shape. The possibility existed that the breakdown of cordierite $(\mathrm{c} \rightarrow \mathrm{d})$ in seeded glass experiments occurred according to a temperature dependent rate process rather than an equilibrium reaction. Therefore, a run was carried out using crystalline garnet, sillimanite and quartz from previous high pressure runs, seeded with a very small amount of cordierite-bearing intermediate pressure assemblage. At $900^{\circ} \mathrm{C}, 9.9 \mathrm{~kb}$ just below the anticipated equilibrium curve, a distinct increase in the amount of cordierite was observed. Since cordierite is absent in the seeded runs at $1000^{\circ} \mathrm{C}, 10.8 \mathrm{~kb}$ and $9.9 \mathrm{~kb}$, but is present in moderately

1) See Chapter 2.3. 


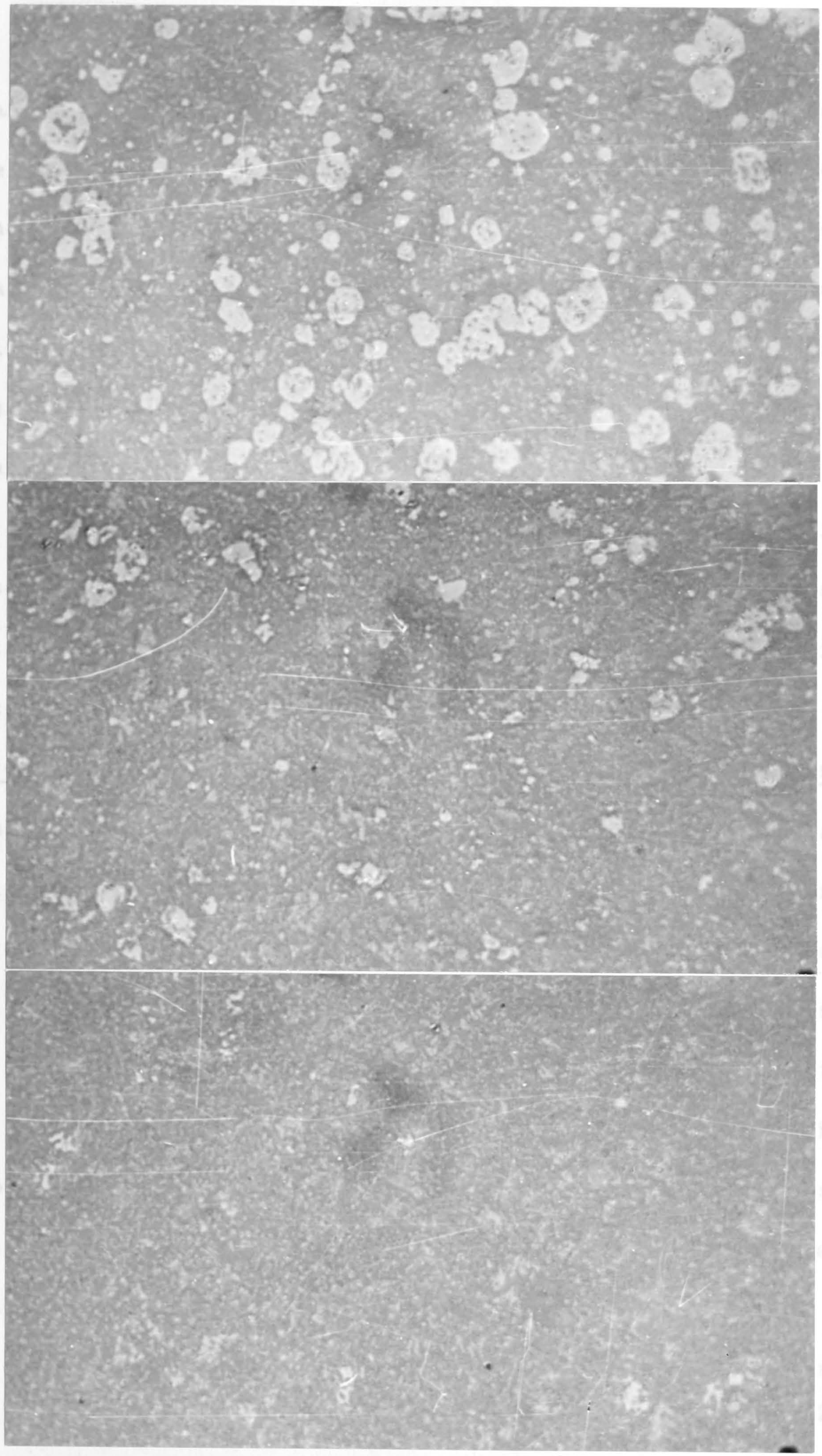

Fig. 5.2. Incoming of garnet (high relief) at $1000^{\circ} \mathrm{C}$. Bottom: corroded garnet relics at $5.4 \mathrm{~kb}$ (run 1604). Middle: irregular partly corroded seeds at $6.3 \mathrm{~kb}$ (run 1593). Top: garnet grown at $7.2 \mathrm{~kb}$ (run 1573) (Polished mounts, 650X) 
large amounts in the $1000^{\circ} \mathrm{C}, 8.1 \mathrm{~kb}$ run, the negative slope for the breakdown of cordierite seems adequately demonstrated. The sapphirine encountered above $1050^{\circ} \mathrm{C}$ could be a metastable breakdown product of cordierite. A cordieritefree mixture, prepared from high pressure runs, and made up of garnet $\left(100 \mathrm{x}_{\mathrm{Ga}}=70\right)$, sillimanite, quartz and very small amounts of hypersthene and sapphirine, was run at $1100^{\circ} \mathrm{C}, 9 \mathrm{~kb}$ (run no. 1644). An increase of sapphirine was observed, while the amount of sillimanite decreased. There can be little doubt that sapphirine is stable in the presence of quartz under these conditions.

Microprobe analysis of experimentally produced phases

Analyses of garnet, cordierite and hypersthene are given in Table 5.3. The procedure followed in obtaining these results has been described in Chapter 2.7. The garnet analyses show the same general characteristics as those reported in the previous chapter. The composition of the garnets is uniform in most runs, indicating that equilibrium was closely approached in the experiments.

An important aspect of the analyses is the large variation in the $\mathrm{Mg} / \mathrm{Mg}+\mathrm{Fe}^{2+}$ ratio in the different runs. The data clearly show that garnets formed at different pressures and temperatures have different $\mathrm{Mg} / \mathrm{Mg}+\mathrm{Fe}^{2+}$ ratios. The seed garnets have either re-equilibrated (at temperatures of $1000^{\circ} \mathrm{C}$ or more) or else remained as 
TABLE 5.3

Microprobe analyses of experimentally produced phases $\left(\mathrm{B}_{70}\right)$

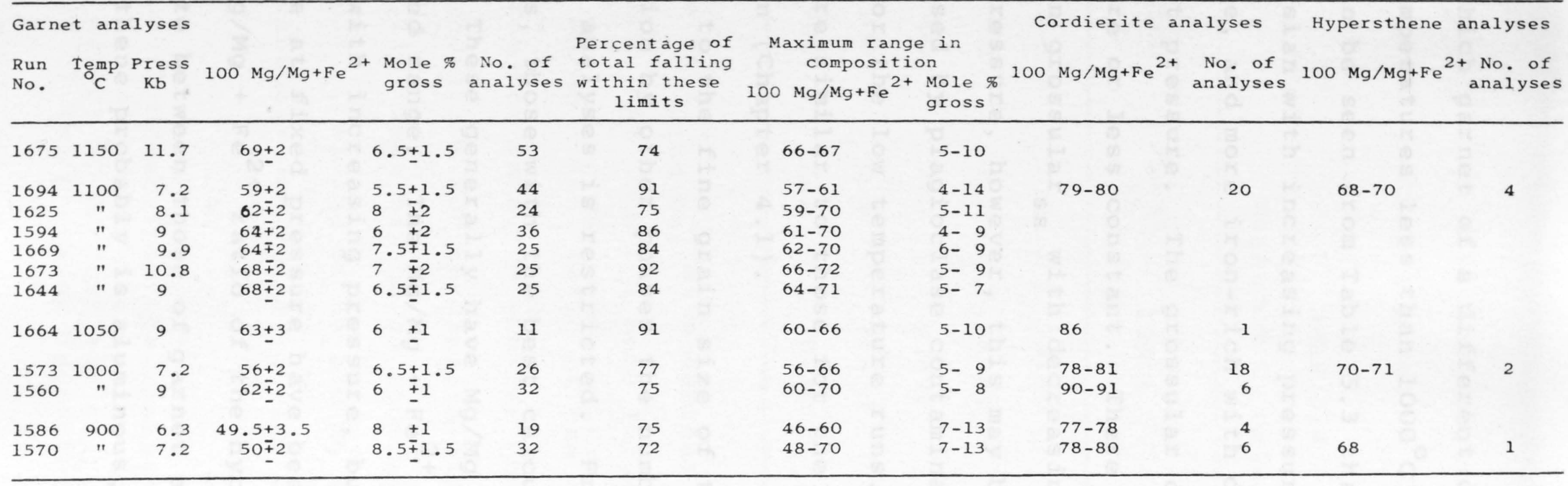


cores on which garnet of a different composition has grown (at low temperatures less than $1000^{\circ} \mathrm{C}$ ).

It can be seen from Table 5.3 that garnet becomes more magnesian with increasing pressure, at constant temperature, and more iron-rich with decreasing temperature, at constant pressure. The grossular content of the garnet remains more or less constant. There is possibly a slight increase in grossular ss with decreasing temperature at constant pressure, however, this may be only an apparent effect caused by plagioclase contamination in the garnet analyses for the low temperature runs. The grossular contents are similar to those for the garnets in the $\mathrm{C}_{70}$ composition (Chapter 4.1).

Owing to the fine grain size of the cordierite and contamination by other phases the number of reliable cordierite analyses is restricted. From a large number of analyses, those with the best calculated totals were selected. These generally have $\mathrm{Mg} / \mathrm{Mg}+\mathrm{Fe}^{2+}$ ratios within a restricted range. The $\mathrm{Mg} / \mathrm{Mg}+\mathrm{Fe}^{2+}$ ratio of cordierite increases with increasing pressure, but no changes with temperature at fixed pressure have been detected.

The $\mathrm{Mg} / \mathrm{Mg}+\mathrm{Fe}^{2+}$ ratio of the hypersthene is intermediate between those of garnet and cordierite. The hypersthene probably is aluminous, containing ca. 
10-12\% $\mathrm{Al}_{2} \mathrm{O}_{3} \cdot{ }^{1)}$ The distribution coefficients for the analysed mineral pairs are given in Table 5.4.

\section{TABLE 5.4}

Measured $\mathrm{K}_{\mathrm{D}}$ values

\begin{tabular}{|c|c|c|c|c|c|c|c|c|}
\hline $\begin{array}{l}\text { Run } \\
\text { No. }\end{array}$ & $\begin{array}{l}\text { Temp } \\
{ }_{\mathrm{O}}\end{array}$ & $\begin{array}{c}\text { Press } \\
\mathrm{Kb}\end{array}$ & $100 \mathrm{x}_{\mathrm{Cd}}$ & \multicolumn{2}{|c|}{$\mathrm{K}_{\mathrm{D}}(\mathrm{Cd}-\mathrm{Ga})$} & \multicolumn{3}{|c|}{${ }^{\mathrm{K}} \mathrm{D}(\mathrm{Cd}-\mathrm{Hy})$} \\
\hline 1694 & 1100 & 7.2 & $79-80$ & 2.7 & \pm 0.3 & 1.8 & \pm & .1 \\
\hline 1573 & 1000 & 7.2 & $78-81$ & 3 & \pm 0.6 & 1.7 & \pm & .1 \\
\hline 1560 & 1000 & 9.0 & $90-91$ & 5.5 & \pm 0.5 & & & \\
\hline 1586 & 900 & 6.3 & $77-78$ & 3.6 & \pm 0.6 & & & \\
\hline 1570 & 900 & 7.2 & $78-80$ & 3.8 & +0.5 & 1.9 & & \\
\hline
\end{tabular}

An increase in $\mathrm{K}_{\mathrm{D}(\mathrm{Cd}-\mathrm{Ga})}$ with decreasing temperature is shown by these data. At $1000^{\circ} \mathrm{C}$ a much larger increase with increasing $\mathrm{Mg} / \mathrm{Mg}+\mathrm{Fe}^{2+}$ ratio of the coexisting phases is apparent from the data. A similar observation was made for the $\mathrm{C}_{70}$ composition for cordierite with $100 \mathrm{x}_{\mathrm{Cd}} \approx 90$

(Chapter 4.1). This may be an indication that at high values for $\mathrm{X}_{\mathrm{Cd}}$ and $\mathrm{X}_{\mathrm{Ga}}$, mixing of $\mathrm{Fe}$ and $\mathrm{Mg}$ in one or both of the phases is strongly non ideal, giving rise to the sudden

1) This value is taken from the analytical data on aluminous

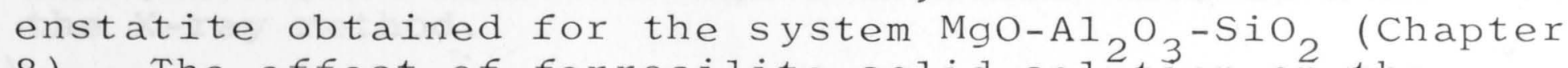
$8)$. The effect of ferrosilite solid solution on the Al-content of the pyroxene is unknown. 
increase in the distribution coefficient. ${ }^{1}$ )

Interpretation of results

The experimentally determined boundaries have been interpreted in terms of reactions which are given in Table 5.5. For simplicity, the phases plagioclase and alkali feldspar, which are probably both present in all runs, $\left.{ }^{2}\right)$ have not been included in the reactions in Table 5.5 .

As discussed in Chapter 4.1 , the stability of the garnet is not believed to be significantly influenced by the composition of the plagioclase, and, as a result, the reactions can be treated as quasi-univariant and quasidivariant. In $\mathrm{B}_{70}$, the normative composition of the plagioclase changes from $A_{53.2}$ at low pressure (no garnet present) to $\mathrm{An}_{35.8}$ at high pressure (garnet being the only ferromagnesian phase present), assuming a garnet with 6.5 mole \% grossularss ${ }^{3}$ ) (the value obtained from the analytical data, Table 5.3).

The quasi-divariant reactions are represented by bands on a P-T diagram (Fig. 5.1). Within these bands, reactants

1) Unless $K_{D}$ is strongly pressure dependent, which is unlikely (see Appendix to Chapter 3).

$2)$ Because of the low abundance of feldspars in the experimental runs, the presence of two phases cannot be ascertained by the $\mathrm{X}$-ray method.

$3)$ For method of calculation see Chapter 4.1 . 


\section{TABLE 5.5}

Divariant and univariant reactions

a) Divariant reactions

As semblage

Reaction

No .

b

$c / d$

$\mathrm{d} / \mathrm{e}$

e

$\mathrm{a} / \mathrm{f}$ and $\mathrm{c} / \mathrm{e}$

$\mathrm{Hy}+\mathrm{Sa}+\mathrm{Qz} \rightleftharpoons \mathrm{Ga}$

$\mathrm{Cd} \rightleftharpoons \mathrm{Ga}+\mathrm{Si}+\mathrm{Qz}$

$\mathrm{Sa}+\mathrm{Qz} \rightleftharpoons \mathrm{Ga}+\mathrm{Si}$

$(\mathrm{Cd}, \mathrm{Hy}, \mathrm{sp})^{*}$

$\mathrm{Cd} \rightleftharpoons \mathrm{Sa}+\mathrm{Qz}$

$\mathrm{Cd} \rightleftharpoons \mathrm{Sp}+\mathrm{Qz}$
- ve

-ve

-ve

-ve

-ve

-ve

b) Univariant reactions

\section{From assemblage}

to assemblage
Reaction

$\mathrm{Cd}+\mathrm{Ga}+\mathrm{Si} \rightleftharpoons \mathrm{Sa}+\mathrm{Qz}$

$c / d \rightleftharpoons d / e$

$\mathrm{b} \rightleftharpoons \mathrm{a} / \mathrm{f}$

$\mathrm{b} \rightleftharpoons \mathrm{e}$

$\mathrm{b} \rightleftharpoons(\mathrm{Cd}, \mathrm{Hy}, \mathrm{Sp})^{*} \mathrm{Cd}+\mathrm{Ga} \rightleftharpoons \mathrm{Hy}+\mathrm{Sp}+\mathrm{Qz}$

$(\mathrm{Cd}, \mathrm{Hy}, \mathrm{Sp}) \rightleftharpoons \mathrm{a} / \mathrm{f} \mathrm{Cd}+\mathrm{Sp} \rightleftharpoons \mathrm{Sa}+\mathrm{Qz}$

\section{$c / d \rightleftharpoons c / e$}

$$
c / d \rightleftharpoons d / e
$$$$
\mathrm{Cd}+\mathrm{Ga} \rightleftharpoons \mathrm{Hy}+\mathrm{Sa}+\mathrm{Qz}
$$

No . 
and products of the reactions coexist. With increasing pressure the phases on the high volume side of each of the above reactions decrease in amount while the others increase. At the same time the $\mathrm{M}_{\mathrm{g} / \mathrm{Mg}}+\mathrm{Fe}^{2+}$ ratio of the ferromagnesian phases increases. The necessity for all phases to become more magnesian is clear if one considers that the relative composition of the coexisting phases is determined by a distribution coefficient $\left(K_{D}\right)$, which is primarily a function of temperature. ${ }^{1}$ )

The quasi-divariant band for the assemblage cordierite-hypersthene-garnet-quartz-feldspars represents the reaction

$$
\mathrm{Cd}+\mathrm{Hy} \rightleftharpoons \mathrm{Ga}+\mathrm{Qz}
$$

At the high pressure side of this reaction we have the assemblage

$$
\text { garnet-cordierite-quartz-feldspars }
$$

which is trivariant. At still higher pressure cordierite should break down according to reaction

$$
\mathrm{Cd} \rightleftharpoons \mathrm{Ga}+\mathrm{Si}+\mathrm{Qz}
$$

However, the assemblage Ga-Cd-Si-Qz has not been encountered experimentally in the present composition. Its occurrence can be predicted, because cordierite and hypersthene do

1) Simple mathematical equations relating the amount of reaction, the bulk composition, the composition of the ferromagnesian phases and the distribution coefficient are discussed in Chapter 3.4 . 
not occur in the appropriate molar proportions to form garnet according to reaction (6).

Previously (Hensen and Green, 1970), before analytical data were available, the divariant band for the assemblage Cd-Ga-Hy-Qz was deduced to be considerably wider, hypersthene being present up to and beyond the boundary marking the breakdown of cordierite. This interpretation of the results required the existence of the reaction

$$
\mathrm{Cd}+\mathrm{Ga} \rightleftharpoons \mathrm{Hy}+\mathrm{Si}+\mathrm{Qz}
$$

thereby explaining the occurrence of the assemblage $\mathrm{Ga}-\mathrm{Hy}-\mathrm{Si}-\mathrm{Qz}$ at $1000^{\mathrm{O}} \mathrm{C}-9.9$ and $10.8 \mathrm{~kb}$. However, the analytical data indicate that the hypersthene which was tentatively determined by $x-r a y$ in the runs just below the breakdown of cordierite, is probably very small in amount and likely to be metastable. This can be deduced by comparing the cordierite and garnet compositions $\left(\mathrm{X}_{\mathrm{Cd}}\right.$ and $\left.\mathrm{X}_{\mathrm{Ga}}\right)$, with the $\mathrm{Mg} / \mathrm{Mg}+\mathrm{Fe}^{2+}$ ratio of the bulk composition $\left(\mathrm{X}_{\mathrm{b}}\right)$. The procedure is most easily demonstrated by an AFM diagram (Fig. 5.3). As cordierite and garnet become more magnesian, a point is reached at which the Cd-Ga join passes through the point representing the bulk composition. At the pressure corresponding to this situation, hypersthene will disappear from the mineral assemblage. Using this graphical check, it has been found that in all runs where previously a trace of hypersthene was thought to be present, the Cd-Ga 


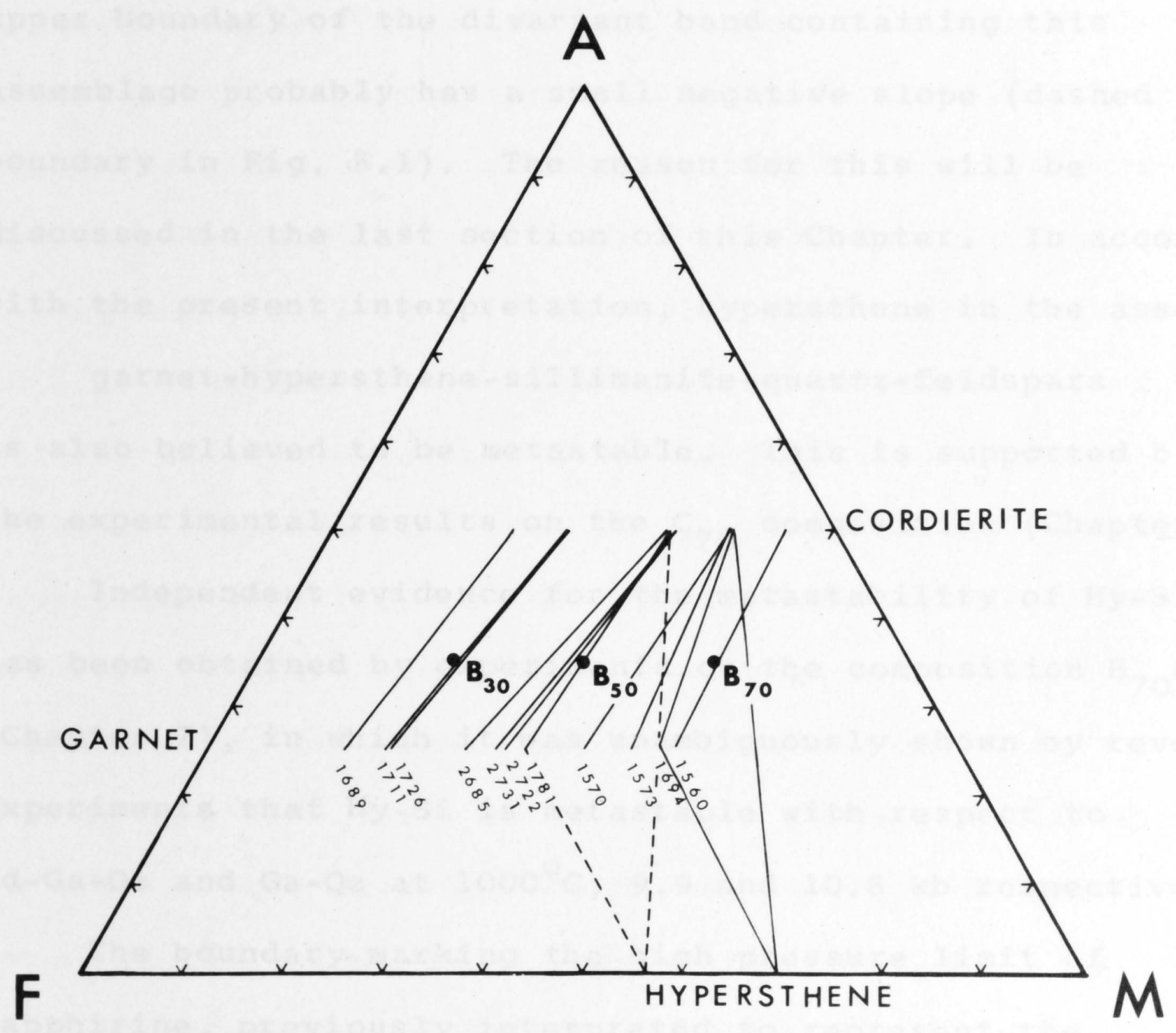

Fig. 5.3. AFM diagram showing the $\mathrm{Mg} / \mathrm{Mg}+\mathrm{Fe}^{2+}$ ratios of coexisting cordierite, garnet and hypersthene in runs on the $B_{70}, B_{50}$ and $B_{30}$ compositions. Run numbers and analyses can be found in Tables 5.3, 5.7 and 5.11. Note that in runs where hypersthene is interpreted to be present as a trace, the Cd-Ga join passes through the point representing the bulk composition. The hypersthene is probably aluminous but this has not been shown in the diagram. 
join passes through the bulk compositional point (Fig. 5.3). It is therefore concluded that the stability field of Cd-Hy-Ga-Qz is smaller than was previously believed. The upper boundary of the divariant band containing this assemblage probably has a small negative slope (dashed boundary in Fig. 5.1). The reason for this will be discussed in the last section of this Chapter. In accordance with the present interpretation, hypersthene in the assemblage garnet-hypersthene-sillimanite-quartz-feldspars

is also believed to be metastable. This is supported by the experimental results on the $\mathrm{C}_{70}$ composition (Chapter 4.1). Independent evidence for the metastability of Hy-Si has been obtained by experiments on the composition $\mathrm{B}_{70} \mathrm{~S}$ (Chapter 7), in which it was unambiguously shown by reversal experiments that $\mathrm{Hy}-\mathrm{Si}$ is metastable with respect to $\mathrm{Cd}-\mathrm{Ga}-\mathrm{Qz}$ and $\mathrm{Ga}-\mathrm{Qz}$ at $1000^{\circ} \mathrm{C}, 9.9$ and $10.8 \mathrm{~kb}$ respectively.

The boundary marking the high pressure limit of sapphirine, previously interpreted to represent the univariant boundary

$$
\mathrm{Hy}+\mathrm{Si} \rightleftharpoons \mathrm{Ga}+\mathrm{Sa}+\mathrm{Qz}
$$

is now believed to be a divariant band representing the reaction

$$
\mathrm{Sa}+\mathrm{Qz} \rightleftharpoons \mathrm{Ga}+\mathrm{Si}
$$

This interpretation is in better agreement with the experimental data. The divariant band (d/e) has a moderate 
positive slope and is identical, within experimental error, to that deduced from the $\mathrm{C}_{70}$ results. One would theoretically expect the divariant interval in B 70 to be somewhat narrower since in this composition garnet also occurs at the high temperature, low pressure side of the band. As a result the coexisting sapphirine cannot have the same $\mathrm{Mg} / \mathrm{Mg}+\mathrm{Fe}^{2+}$ ratio as the bulk composition, and consequently will be more magnesian than the sapphirine in $\mathrm{C}_{70^{\circ}}$. Therefore, the high temperature boundary in $\mathrm{B}_{70}$ will be displaced towards lower temperature and higher pressure compared with that of $\mathrm{C}_{70}$, thus enlarging the sapphirine stability field. The low temperature, high pressure boundary should be the same in both bulk compositions, the garnet on this boundary having a $100 \mathrm{Mg} / \mathrm{Mg}+\mathrm{Fe}^{2+}$ ratio of 70 in both cases. A difference in width of the divariant bands has not been detected experimentally and may be very small (see Fig. 5.15).

The breakdown of garnet is interpreted to take place over a quasi-divariant interval according to the reaction

$$
\mathrm{Ga} \rightleftharpoons \mathrm{Hy}+\mathrm{Sa}+\mathrm{Qz}
$$

The divariant field ((e) in Fig. 5.1) for this reaction is separated from the divariant assemblages Cd-Hy-Ga-Qz (b) and Cd-Ga-Sa-Qz (not observed) by the univariant reaction

$$
\mathrm{Cd}+\mathrm{Ga} \rightleftharpoons \mathrm{Hy}+\mathrm{Sa}+\mathrm{Qz}
$$


At high temperature, we find the trivariant assemblage $\mathrm{Hy}-\mathrm{Sa}-\mathrm{Qz}$ (f). This assemblage is probably bounded on the low pressure side by the divariant reaction

$$
\mathrm{Cd} \rightleftharpoons \mathrm{Sa}+\mathrm{Qz}
$$

which is indicated by assemblage a/f in Figure 5.1, and perhaps bounded also by the univariant reaction

$$
\mathrm{Sa}+\mathrm{Qz} \rightleftharpoons \mathrm{Cd}+\mathrm{Sp}
$$

The existence of a stability field for the assemblage Cd-Hy-sp in this composition has not been verified experimentally. However, the relationships as shown in Figure 5.1 are dictated by the geometry because the lower boundary of the divariant field Cd-Hy-Ga-Qz intersects the univariant curve

$$
\mathrm{Cd}+\mathrm{Ga} \rightleftharpoons \mathrm{Hy}+\mathrm{Sp}+\mathrm{Qz}
$$

rather than the curve

$$
\mathrm{Cd}+\mathrm{Ga} \rightleftharpoons \mathrm{Hy}+\mathrm{Sa}+\mathrm{Qz}
$$

\subsection{PHASE RELATIONS IN THE B 50 COMPOSITION}

The chemical composition of $\mathrm{B}_{50}$ is

$$
\begin{array}{llll}
\mathrm{SiO}_{2} & - & 52.84 \\
\mathrm{Al}_{2} \mathrm{O}_{3} & - & 24.90 \\
\mathrm{FeO} & - & 11.11 & \\
\mathrm{MgO} & - & 6.24 & 100 \mathrm{Mg} / \mathrm{Mg}+\mathrm{Fe}^{2+}=50 \\
\mathrm{CaO} & - & 2.35 & \text { Normative plagioclase: An } 52.4 \\
\mathrm{Na}_{2} \mathrm{O} & - & 1.18 & \\
\mathrm{~K}_{2} \mathrm{O} & - & 1.35
\end{array}
$$


The position of $B_{50}$ in compositional diagrams is given in Chapter 1.2, Fig. 1.1.

The starting material used in the experiments was:

10\% low pressure assemblage, crystallised from the glass at $1000^{\circ} \mathrm{C}-5.4 \mathrm{~kb}$, consisting of cordierite hypersthene, spinel, feldspars and quartz.

10\% high pressure assemblage, crystallised from glass at $1100^{\circ} \mathrm{C}-18 \mathrm{~kb}$, consisting of garnet, quartz, minor kyanite, minor feldspars and a trace of corundum. 80\% glass (for preparation of glasses see Chapter.2).

\section{Experimental results}

The experimental data are given in Table 5.6 and Figure 5.4. The phase assemblages found at $1000^{\circ} \mathrm{C}$ with increasing pressure are:

cordierite-hypersthene-quartz-feldspars garnet-cordierite-hypersthene-quartz-feldspars garnet-cordierite-quartz-feldspars garnet-sillimanite-quartz-feldspars

and at $1100^{\circ} \mathrm{C}$

cordierite-hypersthene-feldspars-quart $z^{1}$ )

1) Below x-ray detection limit. 
TABLE 5.6

Experimental data for B50 composition

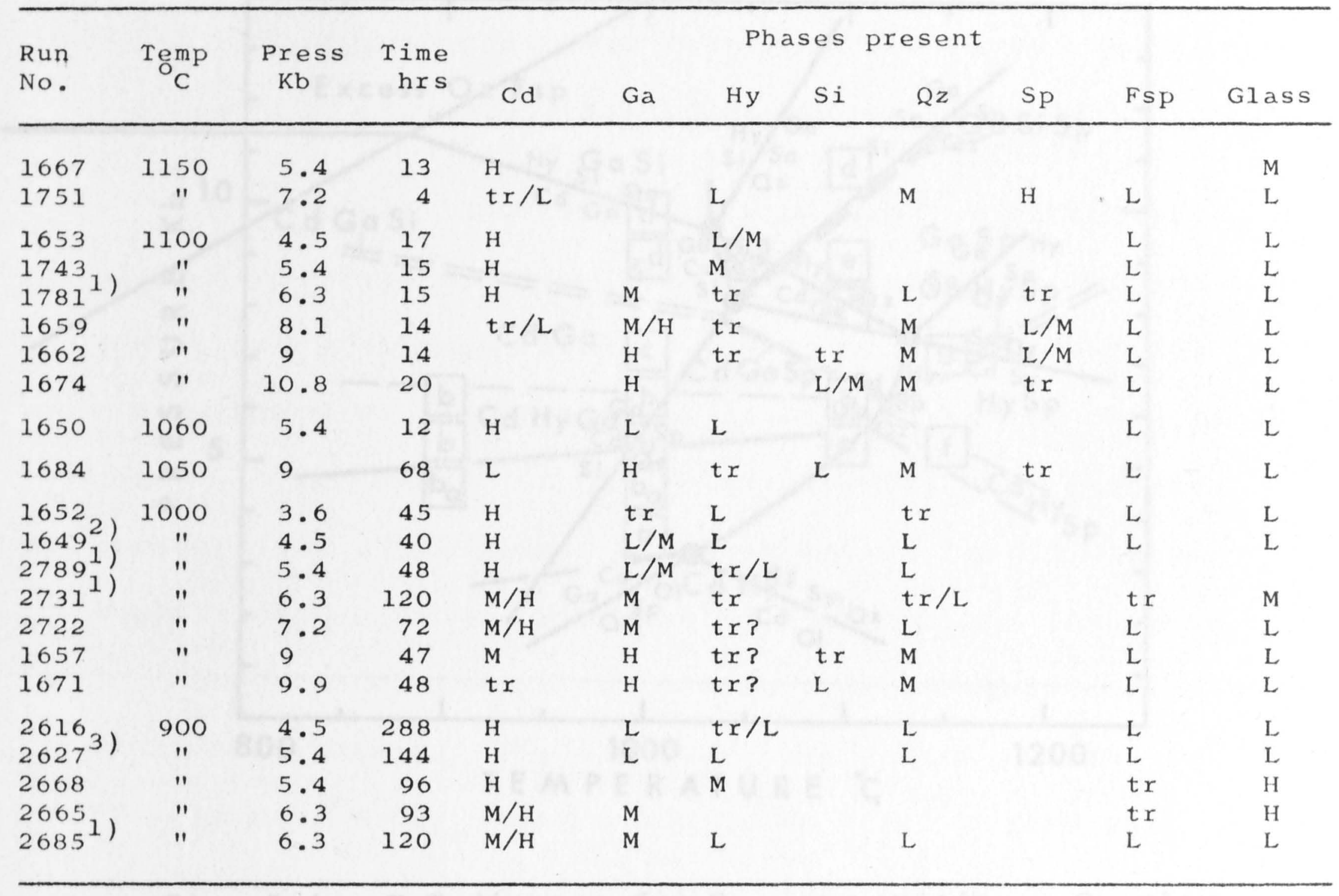

1) Garnet increased

2) Garnet unchanged

3) Very slight increase in garnet

Relative proportions of the phases are indicated by: $H=$ high

$M=$ medium

$L=10 w$

$t x=t$ race 


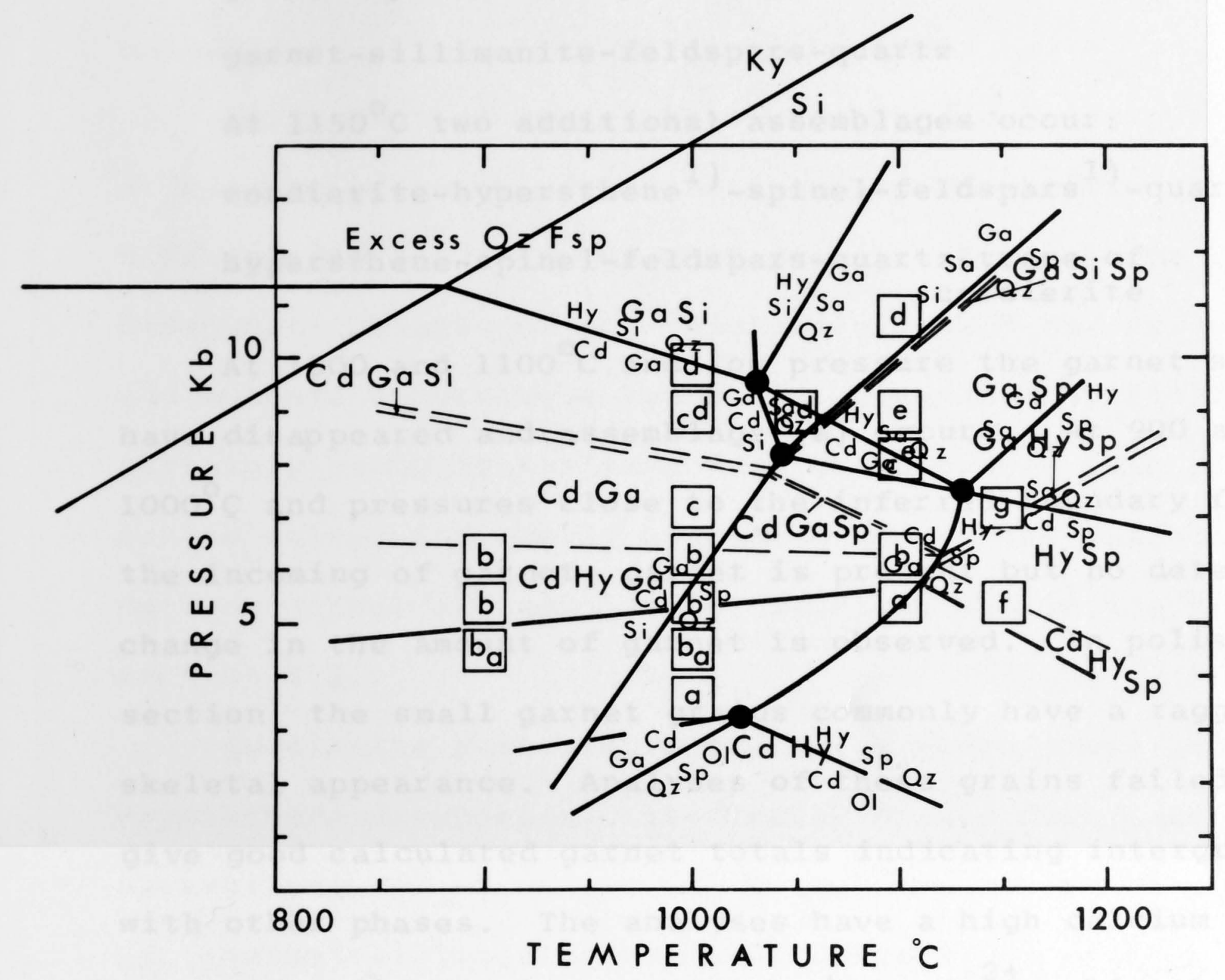

Fig. 5.4. P-T diagram for B 50 composition. Overlay shows the relation between divariant and univariant boundaries. Observed mineral assemblages are indicated by letters also used in the text. 


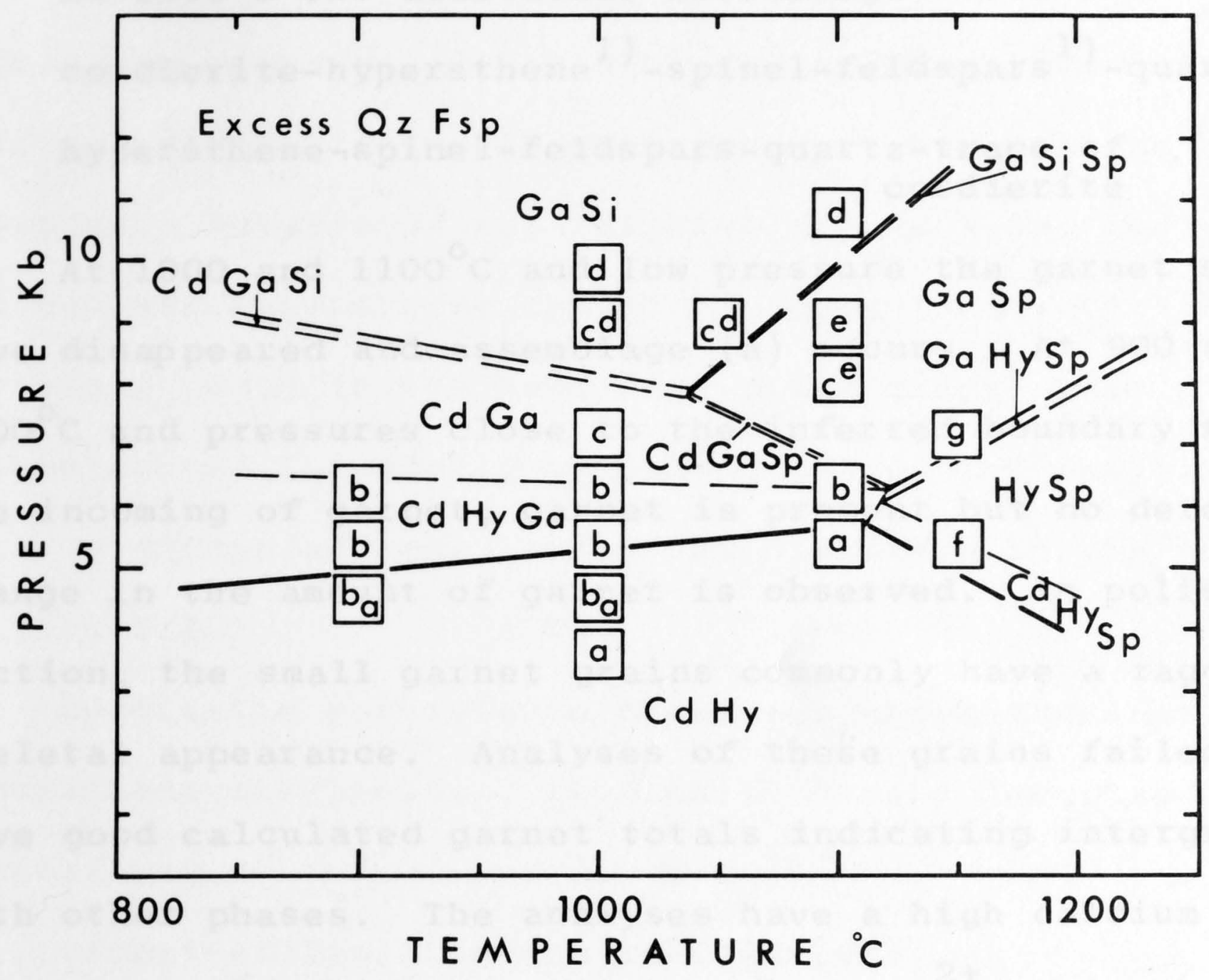

Fig. 5.4. P-T diagram for B 50 composition. Overlay shows the relation between divariant and univariant boundaries. Observed mineral assemblages are indicated by letters also used in the text. 
garnet-cordierite-hypersthene-feldspars-quartz

garnet-spinel-feldspars-quartz

garnet-sillimanite-feldspars-quartz

At $1150^{\circ} \mathrm{C}$ two additional assemblages occur:

cordierite-hypersthene ${ }^{1}$ ) -spinel-feldspars ${ }^{1}$ ) -quartz

hypersthene-spinel-feldspars-quartz-trace of

cordierite

At 1000 and $1100^{\circ} \mathrm{C}$ and low pressure the garnet seeds have disappeared and assemblage (a) occurs. At 900 and $1000^{\circ} \mathrm{C}$ and pressures close to the inferred boundary for the incoming of garnet, garnet is present but no detectable change in the amount of garnet is observed. In polished section, the small garnet grains commonly have a ragged, skeletal appearance. Analyses of these grains failed to give good calculated garnet totals indicating intergrowth with other phases. The analyses have a high calcium content $\left(7-14\right.$ mole $\left.\% \mathrm{Gr}_{\mathrm{ss}}\right)$ and a $100 \mathrm{Mg} / \mathrm{Mg}+\mathrm{Fe}^{2+}$ ratio that is very close to 50 (i.e. the composition of the seed garnets). Above the boundary between assemblages ( a ) and (b) (Fig. 5.4) an increase in the proportion of garnet can be detected on the X-ray photographs. The garnets have a different habit from those below the boundary; they have fewer inclusions and sharp, in some cases euhedral,

1) Below X-ray detection limit. 
outlines. Chemical analyses show these garnets to have a much lower $\mathrm{Mg} / \mathrm{Mg}+\mathrm{Fe}^{2+}$ ratio than that of the seed material.

The amount of hypersthene sharply decreases with increasing pressure after the incoming of garnet. It is difficult to determine at what pressure hypersthene disappears because of its relatively weak X-ray reflections and because hypersthene cannot be recognized optically with certainty owing to its very fine grain size. This problem can be solved indirectly by making use of the analytical data on garnet and cordierite, as discussed in the previous section 5.1 .

Cordierite persists to pressures above those at which hypersthene disappears. It finally breaks down, and the as semblage

garnet-sillimanite-quartz-feldspars

is found at $1000^{\circ} \mathrm{C}, 9.9 \mathrm{~kb}$ and $1050^{\circ} \mathrm{C}, 9 \mathrm{~kb} .{ }^{1}$ )

$$
\begin{aligned}
& \text { At } \left.1100^{\circ} \mathrm{C}, 8.1 \text { and } 9 \mathrm{~kb} \text {, the assemblage }{ }^{2}\right) \\
& \text { garnet-spinel-quartz-feldspars-trace of hypersthene (e) }
\end{aligned}
$$

occurs. The spinel is fine grained and is present

throughout the run. At $10.8 \mathrm{~kb}$ spinel has completely

1) Both runs contain only traces of cordierite.
2) The run at $8.1 \mathrm{~kb}$ contains a trace of cordierite. 
disappeared and the high pressure assemblage (d) is found. The stability of the spinel at this temperature has not been demonstrated by reversal experiments. However, as will be shown in the discussion, its occurrence is consistent with results in the $\mathrm{C}_{30}$ composition (Chapter 4.2 ) and $\mathrm{B}_{30}$ composition (next section).

The feldspar reflections on the powder photographs do not show any detectable changes with pressure. At low pressure and high temperature both quartz and feldspars decrease in amount due to partial melting. Patches of glass occur localized in the charge, commonly near the wall of the capsule. Melting is probably caused by the introduction of water through the graphite capsule walls. The amount of melting increases in runs at higher temperature and of longer duration.

Composition of experimentally produced phases

Analyses for garnet, hypersthene and cordierite are given in Table 5.7. The garnet analyses provide the same general picture as encountered in the $B_{70}$ composition. The $\mathrm{Mg} / \mathrm{Mg}+\mathrm{Fe}^{2+}$ ratio decreases with decreasing temperature at constant pressure and increases with increasing pressure. At low pressure, the garnets are considerably more Fe-rich than the garnet seeds, which have the $\mathrm{Mg} / \mathrm{Mg}+\mathrm{Fe}^{2+}$ ratio of the bulk composition. Remnants of garnet seeds have occasionally been found 
TABLE 5.7

Microprobe analyses of experimentally produced phases ( ${ }_{50}$ )

\begin{tabular}{|c|c|c|c|c|c|c|c|c|c|c|c|c|c|c|c|c|}
\hline \multirow{2}{*}{$\begin{array}{l}\text { Garne } \\
\text { Run } \\
\text { No. }\end{array}$} & \multirow{2}{*}{$\begin{array}{l}\text { et an } \\
{ }_{\mathrm{C}}^{\mathrm{T}} \mathrm{mp}\end{array}$} & \multirow[b]{2}{*}{$\begin{array}{l}\text { Press } \\
\mathrm{Kb}\end{array}$} & \multirow[b]{2}{*}{100} & \multirow[b]{2}{*}{$\mathrm{Mg} / \mathrm{Mg}+\mathrm{Fe}^{2+}$} & \multirow[b]{2}{*}{$\begin{array}{l}\text { Mole \% } \\
\text { gross }\end{array}$} & \multirow[b]{2}{*}{$\begin{array}{l}\text { No. of } \\
\text { analyses }\end{array}$} & \multirow{2}{*}{$\begin{array}{c}\text { Percentage of } \\
\text { total falling } \\
\text { within these } \\
\text { limits }\end{array}$} & \multirow{2}{*}{100} & \multirow{2}{*}{\multicolumn{2}{|c|}{$\begin{array}{l}\text { Maximum range in } \\
\text { composition }\end{array}$}} & \multicolumn{3}{|c|}{ Cordierite analyses } & \multicolumn{3}{|c|}{ Hypersthene analyses } \\
\hline & & & & & & & & & & $\begin{array}{l}\text { ion } \\
\text { Mole } \% \\
\text { gross }\end{array}$ & 100 & $\mathrm{Mg} / \mathrm{Mg}+\mathrm{Fe}^{2+}$ & $\begin{array}{c}\text { No. of } \\
\text { analyses }\end{array}$ & 100 & $\mathrm{Mg} / \mathrm{Mg}+\mathrm{Fe}^{2+}$ & $\begin{array}{c}+ \text { No. of } \\
\text { analyses }\end{array}$ \\
\hline 1781 & 1100 & 6.3 & 42 & \pm 2 & $6 \pm 2$ & 25 & 72 & & $40-50$ & $4-10$ & & $66-69$ & 7 & & 56 & 1 \\
\hline 2731 & 1000 & 6.3 & 37. & $.5 \pm 2.5$ & $6.5 \pm 1.5$ & 23 & 83 & & $35-44$ & $4-8$ & & $68-70$ & 4 & & & \\
\hline 2722 & " & 7.2 & 39 & $\mp 2$ & $6 \mp 2$ & 24 & 75 & & $37-51$ & $4-13$ & & 70 & 1 & & & \\
\hline 2668 & 900 & 5.4 & & & & & & & 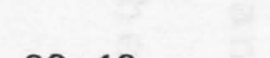 & & & $75-76$ & 6 & & $57-58$ & 9 \\
\hline 2685 & " & 6.3 & 34 & \pm 2 & $7 \pm 1$ & 16 & 63 & & $32-48$ & $6-13$ & & $66-67$ & 5 & & & \\
\hline 2665 & $"$ & 6.3 & 43 & $\mp 2$ & $8.5 \mp 1.5$ & 16 & 88 & & $41-50$ & $7-13$ & & $74-76$ & 5 & & & \\
\hline
\end{tabular}


preserved as cores of garnet grains. This zoning has the effect of enlarging the maximum range of garnet composition (Table 5.7)

The grossular content of the garnets is the same, within analytical error, as that found in the more magnesian garnets in the $\mathrm{B}_{70}$ composition. A slight increase in the amount of grossularss with decreasing temperature is apparent.

Cordierite is considerably more magnesian than the bulk composition. No change with temperature can be ascertained because of the relatively poor quality of the data.

Hypersthene has been analysed in two runs. Its composition is intermediate between that of cordierite and garnet.

The distribution coefficients derived from the analyses of coexisting minerals are given below.

$$
\text { TABLE } 5.8
$$

Measured distribution coefficients

\begin{tabular}{|c|c|c|c|c|c|}
\hline $\begin{array}{l}\text { Run } \\
\text { No. }\end{array}$ & $\begin{array}{c}\text { Temp } \\
{ }_{\mathrm{C}}\end{array}$ & $\begin{array}{c}\text { Press } \\
\mathrm{Kb}\end{array}$ & $100 \mathrm{x}_{\mathrm{Cd}}$ & $\mathrm{K}_{\mathrm{D}}(\mathrm{Cd}-\mathrm{Ga})$ & ${ }^{K} \mathrm{D}(\mathrm{Cd}-\mathrm{Hy})$ \\
\hline 1781 & 1100 & 6.3 & $66-69$ & $2.9 \pm .4$ & 1.8 \\
\hline 2731 & 1000 & 6.3 & $68-70$ & $3.7+.5$ & \\
\hline 2722 & " & 7.2 & $\sim 70$ & $\sim 3.7$ & \\
\hline 2685 & 900 & 6.3 & $66-67$ & $3.9+.4$ & \\
\hline 2665 & $"$ & 6.3 & $74-76$ & $4 \mp \mp .5$ & \\
\hline 2668 & $"$ & 5.4 & $75-76$ & & $2.3+.1$ \\
\hline
\end{tabular}


The $K_{D}$ values are not significantly different from those obtained from more magnesian pairs in the ${ }^{B} 70$ composition (previous section). Because of the relatively large uncertainty in the data, a small change of $\mathrm{K}_{\mathrm{D}}$ with composition cannot be ruled, out. The results demonstrate, however, that the distribution coefficient is not strongly dependent on composition. Discussion of the results

The quasi-divariant and quasi-univariant reactions that have been deduced from the experimental data are listed in Table 5.9.

The most noteworthy feature of the phase relations in this composition is the appearance of garnet at lower pressure than in the more magnesian $B_{70}$ composition (compare Figs. 5.1 and 5.4). Garnet is produced by the same quasi-divariant reaction as in $\mathrm{B}_{70}$ i.e.

$$
\mathrm{Cd}+\mathrm{Hy} \rightleftharpoons \mathrm{Ga}+\mathrm{Qz}
$$

The garnet is considerably more iron-rich in this case, demonstrating that the stability field of garnet increases with decreasing $\mathrm{Mg} / \mathrm{Mg}+\mathrm{Fe}^{2+} \mathrm{ratio}$.

The width of the divariant band for reaction (6) has been deduced indirectly, using the analytical data on $\mathrm{X}_{\mathrm{Ga}}$ and $\mathrm{X}_{\mathrm{Cd}}($ see Fig. 5.3). The change in normative plagioclase composition ${ }^{1}$ ) across the divariant band is 1) For method of calculation see Chapter 4.1 (discussion). 


$$
\text { TABLE } 5.9
$$

Divariant and univariant reactions in $B_{50}$

a) Divariant reactions

Assemblage

Reaction

No .

$\triangle \mathrm{V}$

$\begin{array}{lrrr}\mathrm{b} & \mathrm{Cd}+\mathrm{Hy} \rightleftharpoons \mathrm{Ga}+\mathrm{Qz} & (6) & -\mathrm{ve} \\ \mathrm{C} / \mathrm{d} & \rightleftharpoons \mathrm{Ga}+\mathrm{Si}+\mathrm{Qz} & (1) & -\mathrm{ve} \\ \mathrm{C} / \mathrm{e} & \mathrm{Cd} \rightleftharpoons \mathrm{Sp}+\mathrm{Qz}+\mathrm{Qz} & \text {-ve } \\ \mathrm{f} & \mathrm{Hy}+\mathrm{Sp}+\mathrm{Qz} \rightleftharpoons \mathrm{Ga} \\ \mathrm{e} / \mathrm{g} & \mathrm{Sp}+\mathrm{Qz} \rightleftharpoons \mathrm{Ga}+\mathrm{Si} & \text {-ve } \\ \mathrm{d} / \mathrm{e} & \end{array}$

b) Univariant reactions

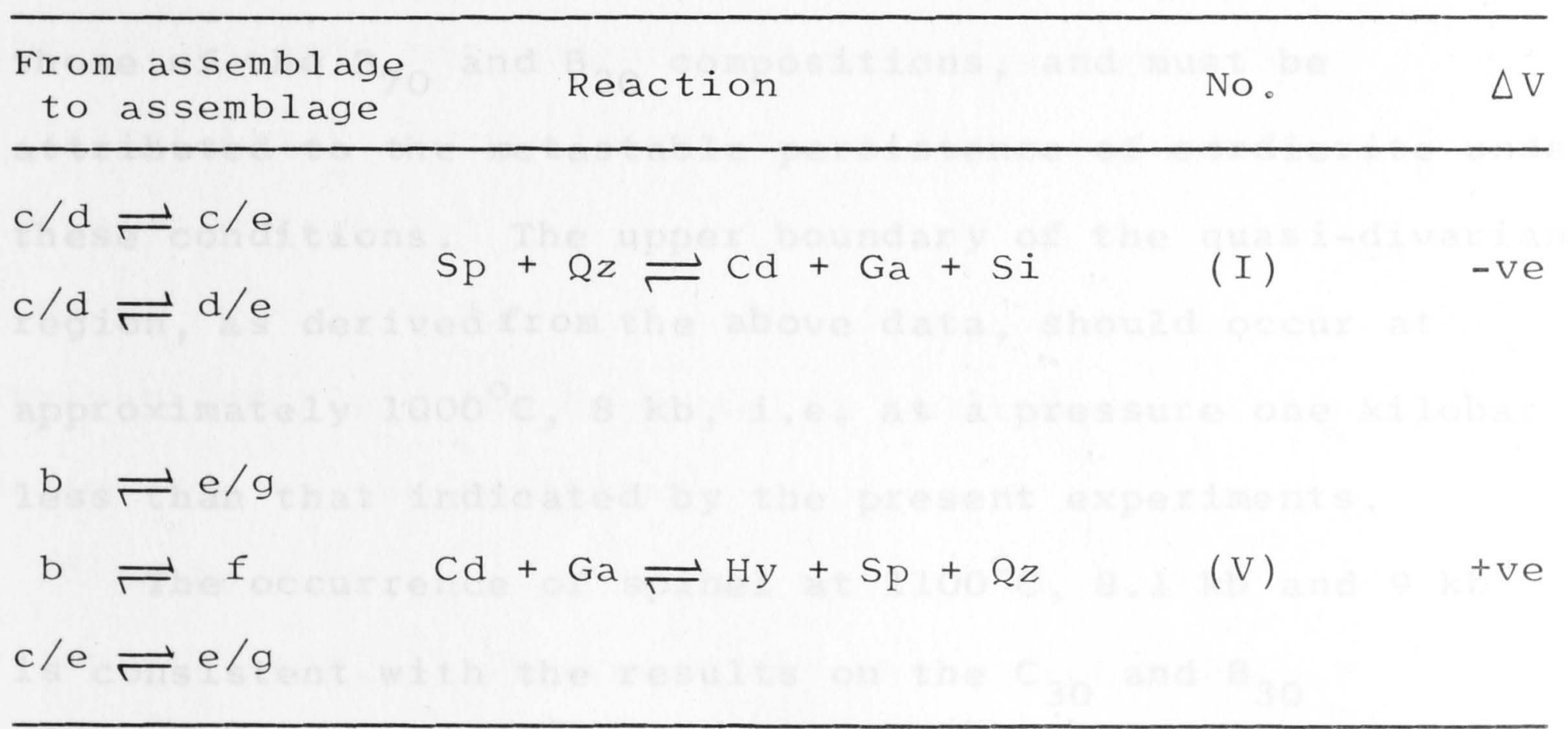


from An 52.4 to An 34.9 assuming a garnet with 6.5 mole \% grossular ss (see Table 5.7).

When hypersthene disappears, we should find the trivariant assemblage

$$
\text { cordierite-garnet-quartz-feldspars }
$$

The composition of cordierite and garnet will not change with increasing pressure until the quasi-divariant band for the breakdown of the particular cordierite is reached (compare Chapter 3.3; Fig. 3.7). At that point, sillimanite should appear. This expected sequence has not been found in the experiments. No difference has been observed in the pressure at which cordierite disappears compared with $\mathrm{B}_{7 \mathrm{O}}$. The occurrence of cordierite at $1000^{\circ} \mathrm{C}, 9 \mathrm{~kb}$ is inconsistent with both the results of the C-series (Chapter 4.3) and those of the $B_{70}$ and $B_{30}$ compositions, and must be attributed to the metastable persistence of cordierite under these conditions. The upper boundary of the quasi-divariant region, as derivedfrom the above data, should occur at approximately $1000^{\circ} \mathrm{C}, 8 \mathrm{~kb}$, i.e. at à pressure one kilobar less than that indicated by the present experiments.

The occurrence of spinel at $1100^{\circ} \mathrm{C}, 8.1 \mathrm{~kb}$ and $9 \mathrm{~kb}$ is consistent with the results on the $\mathrm{C}_{30}$ and $\mathrm{B}_{30}$ compositions.

The quasi-trivariant fields of assemblages

$$
\mathrm{Ga}-\mathrm{Si}-\mathrm{Q} z-\mathrm{FsP}
$$


and

$$
\mathrm{Ga}-\mathrm{Sp}-\mathrm{Q} z-\mathrm{Fsp}
$$

are separated by the quasi-divariant reaction

$$
\mathrm{Sp}+\mathrm{Qz} \rightleftharpoons \mathrm{Ga}+\mathrm{Si} \quad \Delta \mathrm{V}=-\mathrm{ve}
$$

At low pressure this reaction intersects, and is terminated by, the univariant reaction

$$
\mathrm{Sp}+\mathrm{Qz} \rightleftharpoons \mathrm{Cd}+\mathrm{Ga}+\mathrm{Si} \quad \Delta \mathrm{V}=-\mathrm{ve}
$$

On this univariant boundary, the theoretically required divariant bands for the reactions

$$
\mathrm{Cd} \rightleftharpoons \mathrm{Ga}+\mathrm{Si}+\mathrm{Qz} \quad \Delta \mathrm{V}=-\mathrm{ve}
$$

and

$$
\mathrm{Cd} \rightleftharpoons \mathrm{Sp}+\mathrm{Qz}
$$

intersect also, as shown in Figure 5.4. A schematic representation of the P-T relations, showing the various intersecting bands more clearly is given in Fig. 5.5.

Garnet breaks down at high temperature according to the divariant reaction

$$
\mathrm{Ga} \rightleftharpoons \mathrm{Hy}+\mathrm{Sp}+\mathrm{Qz} \quad \Delta \mathrm{V}=-\mathrm{ve}
$$

The trivariant field for Hy-Sp-Qz is limited on the low pressure side by the reaction

$$
\mathrm{Cd} \rightleftharpoons \mathrm{Sp}+\mathrm{Qz} \quad \Delta \mathrm{V}=-\mathrm{ve}
$$

Reactions (8) and (2) intersect the univariant curve limiting the coexistence of garnet and cordierite:

$$
\mathrm{Cd}+\mathrm{Ga} \rightleftharpoons \mathrm{Hy}+\mathrm{Sp}+\mathrm{Qz} \quad \Delta \mathrm{V}=+\mathrm{ve}
$$

This reaction has a positive slope. 


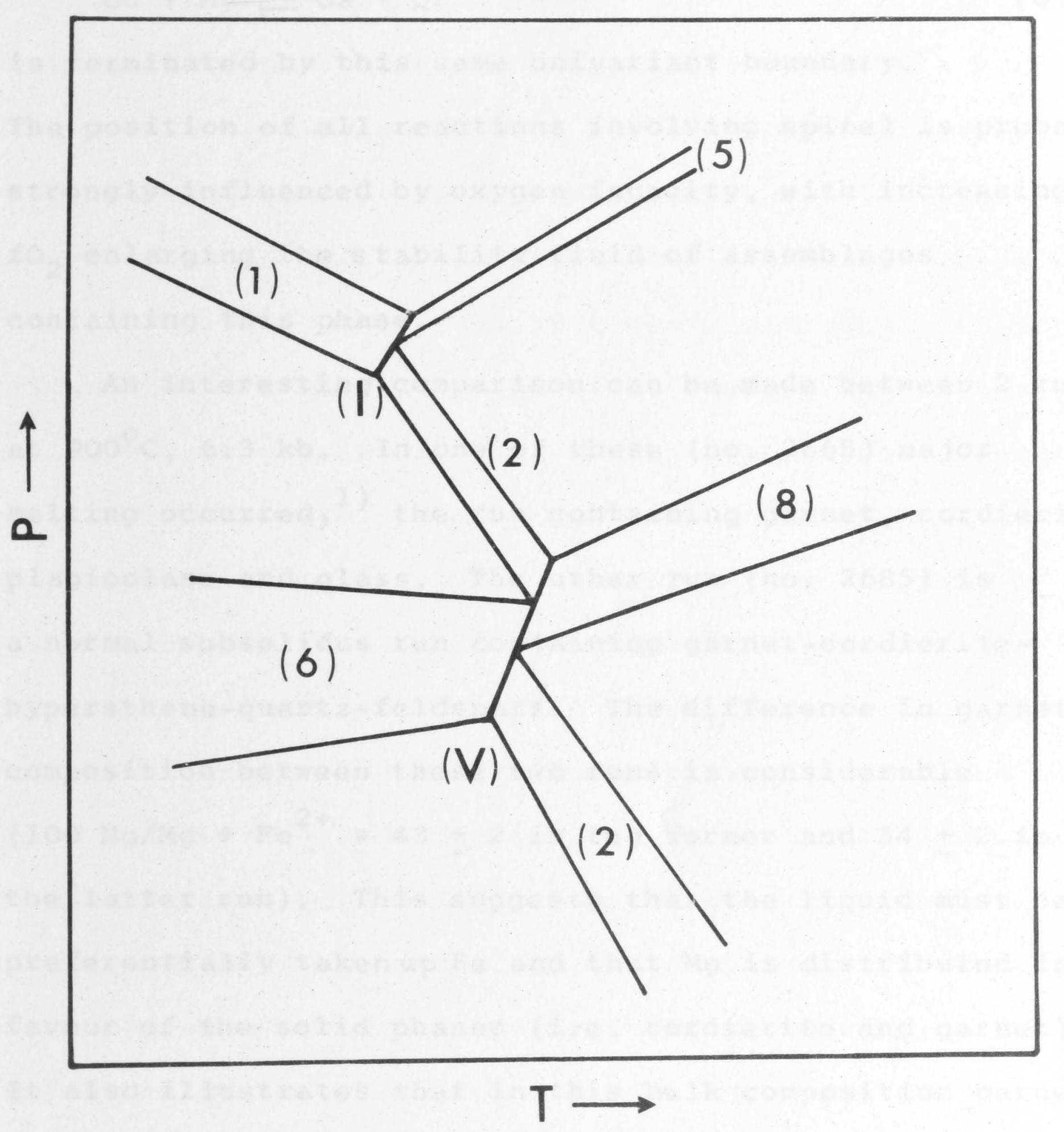

Fig. 5.5. Schematic phase relations at high temperature in $B_{50}$ and $B_{30}$ compositions, showing the relative position of divariant bands and univariant boundaries (compare Figs. 5.4 and 5.6). Numbers refer to those used in Tables 5.9 and 5.13 . 
The reaction

$$
\mathrm{Cd}+\mathrm{Hy} \rightleftharpoons \mathrm{Ga}+\mathrm{Qz}
$$

is terminated by this same univariant boundary.

The position of all reactions involving spinel is probably strongly influenced by oxygen fugacity, with increasing $\mathrm{fO}_{2}$ enlarging the stability field of assemblages containing this phase.

An interesting comparison can be made between 2 runs at $900^{\circ} \mathrm{C}, 6.3 \mathrm{~kb}$. In one of these (no. 2665) major melting occurred, $\left.{ }^{1}\right)$ the run containing garnet, cordierite, plagioclase and glass. The other run (no. 2685) is a normal subsolidus run containing garnet-cordieritehypersthene-quartz-feldspars. The difference in garnet composition between these two runs is considerable $\left(100 \mathrm{Mg} / \mathrm{Mg}+\mathrm{Fe}^{2+}=43 \pm 2\right.$ in the former and $34 \pm 2$ in the latter run). This suggests that the liquid must have preferentially taken up Fe and that $\mathrm{Mg}$ is distributed in favour of the solid phases (i.e. cordierite and garnet). It also illustrates that in this bulk composition garnet in equilibrium with a melt is more magnesian than garnet in a subsolidus assemblage (containing quartz) at the same pressure and temperature. The supersolidus garnet contains slightly more Ca than the subsolidus garnet.

1) A small amount of water had been added to this run in an attempt to increase reaction rates. 
At a pressure of one kilobar less (i.e. $5.4 \mathrm{~kb}$ ), another run with major melting ${ }^{1)}$ contains crystals of cordierite hypersthene and plagioclase, while a subsolidus run under the same conditions has a garnet-cordierite hypersthene - quartz - feldspars assemblage. The two experiments in which there is a similar, large degree of partial melting, show that at a certain pressure, Ca-poor, almandine-rich garnet may exist in equilibrium with a melt, but at a pressure of $1 \mathrm{~kb}$ less, garnet would react with the liquid to yield hypersthene and cordierite. The experiments therefore offer an explanation for the existence of garnet-bearing restites in anatectic silica-rich magmas, showing this very type of reaction relationship (Zeck, 1968). The experiments also indicate that grossular-poor almandine may be a near-liquidus or residual phase in the melting of pelitic compositions under deep crustal conditions and emphasize the sensitive role of load pressure in determining the stability of garnet in equilibrium with a melt (T.H. Green and A.E. Ringwood, 1969 )

1) Also with added water. 
5.3 PHASE RELATIONSHIPS IN THE B 30 COMPOSITION

The chemical composition of $\mathrm{B}_{30}$ is:

$$
\begin{array}{llll}
\mathrm{SiO}_{2} & - & 51.91 & \\
\mathrm{Al}_{2} \mathrm{O}_{3} & - & 24.39 & \\
\mathrm{FeO} & - & 15.19 & \\
\mathrm{MgO} & - & 3.65 & 100 \mathrm{Mg} / \mathrm{Mg}+\mathrm{Fe}^{2+}=30 \\
\mathrm{CaO} & - & 2.30 & \text { Normative plagioclase: } \mathrm{An}_{52} \\
\mathrm{Na}_{2} \mathrm{O} & - & 1.18 & \\
\mathrm{~K}_{2} \mathrm{O} & - & 1.35 &
\end{array}
$$

The starting material used in the experiments consisted of :

20 weight $\%$ of intermediate pressure assemblage crystallized from glass at $1000^{\circ} \mathrm{C}, 5.4 \mathrm{~kb}$, containing cordierite, garnet, hypersthene, spinel, quartz and feldspars .

80 weight \% glass.

Experimental data

The experimental results are given in Table 5.10 and 5.6 .

At $1000^{\circ} \mathrm{C}$ and $1050^{\circ} \mathrm{C}$ the following sequence of assemblages is found with increasing pressure:

cordierite-olivine (Fe-rich)-feldspars-quart ${ }^{1}$ )

cordierite-hypersthene-feldspars-quart $z^{1}$ )

1) Below $\mathrm{x}$-ray detection limit. 
TABLE 5.10

Experimental data for $\mathrm{B}_{30}$ composition

\begin{tabular}{|c|c|c|c|c|c|c|c|c|c|c|c|c|c|}
\hline \multirow{2}{*}{$\begin{array}{l}\text { Run } \\
\text { Na. }\end{array}$} & \multirow{2}{*}{${ }_{\mathrm{C}}^{\text {Temp }}$} & \multirow{2}{*}{$\begin{array}{c}\text { Press } \\
\mathrm{Kb}\end{array}$} & \multirow{2}{*}{$\begin{array}{r}\text { Time } \\
\text { hrs }\end{array}$} & \multicolumn{10}{|c|}{ Phases present } \\
\hline & & & & $\mathrm{Cd}$ & $\mathrm{Ga}$ & Hy & $\mathrm{Si}$ & $\mathrm{Qz}$ & $\mathrm{Sp}$ & 01 & Co & Fsp & Glass \\
\hline $1692_{11}$ & 1100 & 4.5 & 13 & $\mathrm{H}$ & & $\mathrm{tr}$ & & & L & & & L & $\mathrm{L}$ \\
\hline $2039^{11}$ & 1 & 5.4 & 12 & $\mathrm{H}$ & $\mathrm{L}$ & $\operatorname{tr}$ & & $\mathrm{L}$ & $\mathrm{H}$ & & & $\mathrm{L}$ & $\mathrm{L}$ \\
\hline 1720 & $"$ & 6.3 & 12 & & M & $\operatorname{tr}$ & & M & $\mathrm{H}$ & & & L & $\mathrm{L}$ \\
\hline 1714 & $"$ & 7.2 & 12 & & $\mathrm{H}$ & $\mathrm{tr}$ & & M & $\mathrm{H}$ & & & L & $\mathrm{L}$ \\
\hline 1708 & $"$ & 8.1 & 14 & & $\mathrm{H}$ & $\operatorname{tr}$ & & M & $\mathrm{H}$ & & & L & $L$ \\
\hline $1690_{21}$ & $"$ & 9 & 13 & & $\mathrm{H}$ & $\operatorname{tr}$ & & M & M & & & $\mathrm{L}$ & $\mathrm{L}$ \\
\hline $1696^{21}$ & $"$ & 10.8 & 13 & & $\mathrm{H}$ & tr & tr & M & $\mathrm{L}$ & & & $\mathrm{L}$ & L. \\
\hline $1.727^{4)}$ & 1050 & 1.8 & 14 & $\mathrm{H}$ & & & & & & L & & $L$ & L \\
\hline 1715 & " & 2.7 & 40 & $\mathrm{H}$ & & & & & & & & $\mathrm{L}$ & $\mathrm{L}$ \\
\hline 1710 & " & 3.6 & 45 & $\mathrm{H}$ & & L & & & $\operatorname{tr}$ & & & $\mathrm{L}$ & I. \\
\hline $1711^{1)}$ & $"$ & 4.5 & 40 & M & $\mathrm{H}$ & $\operatorname{tr}$ & & tr & tr & & & L & L \\
\hline 1721 & $"$ & 5.4 & 23 & & $\mathrm{H}$ & & & $\mathrm{L}$ & $\mathrm{L}$ & & & $\mathrm{L}$ & $L$ \\
\hline 1949 & $"$ & 6.3 & 31 & $\mathrm{tr} / \mathrm{L}$ & $\mathrm{H}$ & $\operatorname{tr} ?$ & & $\bar{M}$ & $\overrightarrow{\mathrm{M}}$ & & & $\mathrm{L}$ & $\mathrm{L}$ \\
\hline $1700_{31}$ & 1.000 & 1.8 & 4.5 & $\mathrm{H}$ & & & & & & $\mathrm{L}$ & & $L$ & $\mathrm{~L}$ \\
\hline 17043$)$ & 11 & 2.7 & 45 & $\mathrm{H}$ & $\operatorname{tr}$ & L & & & & & & L & $\mathrm{L}$ \\
\hline $1689^{11}$ & $"$ & 3.6 & 46 & $\mathrm{H}$ & M & $\mathrm{L}$ & & tr & & & & $\mathrm{L}$ & $\mathrm{L}$ \\
\hline 1726 & $"$ & 5.4 & 49 & M & M & $t r$ & & L & tr & & & L & $\mathrm{L}$ \\
\hline 1713 & " & 6.3 & 25 & $M$ & $M$ & $t x ?$ & & $\mathrm{~L} / \mathrm{M}$ & L & & & L. & $\mathrm{L}$ \\
\hline 1719 & $"$ & 7.2 & 48 & $\mathrm{tr}$ & $\mathrm{H}$ & tr? & & M & $\mathrm{L}$ & & & L. & $\mathrm{L}$ \\
\hline 1709 & $"$ & 8.1 & 47 & & $\mathrm{H}$ & tr? & & M & M & & & L & L \\
\hline 1703 & $"$ & 9 & 43 & & $\mathrm{H}$ & $\operatorname{tr} ?$ & & M & L & & & L & $\mathrm{L}$ \\
\hline 17.12 & $"$ & 10.8 & 47 & & $\mathrm{H}$ & tr? & & M & & & $\mathrm{L} / \mathrm{M}$ & $L$ & $\mathrm{~L}$ \\
\hline 1705 & 950 & 2.7 & 76 & $\mathrm{H}$ & $\mathrm{L}$ & $\mathrm{L}$ & & & & & & L & $\mathrm{L}$ \\
\hline
\end{tabular}

1) Ga increased

2) Rare si-needles

3) Ga unchanged

4) Glass starting material

Relative proportions of the phases are indicated by: $H=h i g h$

$M=$ medium

$\mathrm{L}=1 \mathrm{ow}$

$\mathrm{tr}=\mathrm{trace}$ 


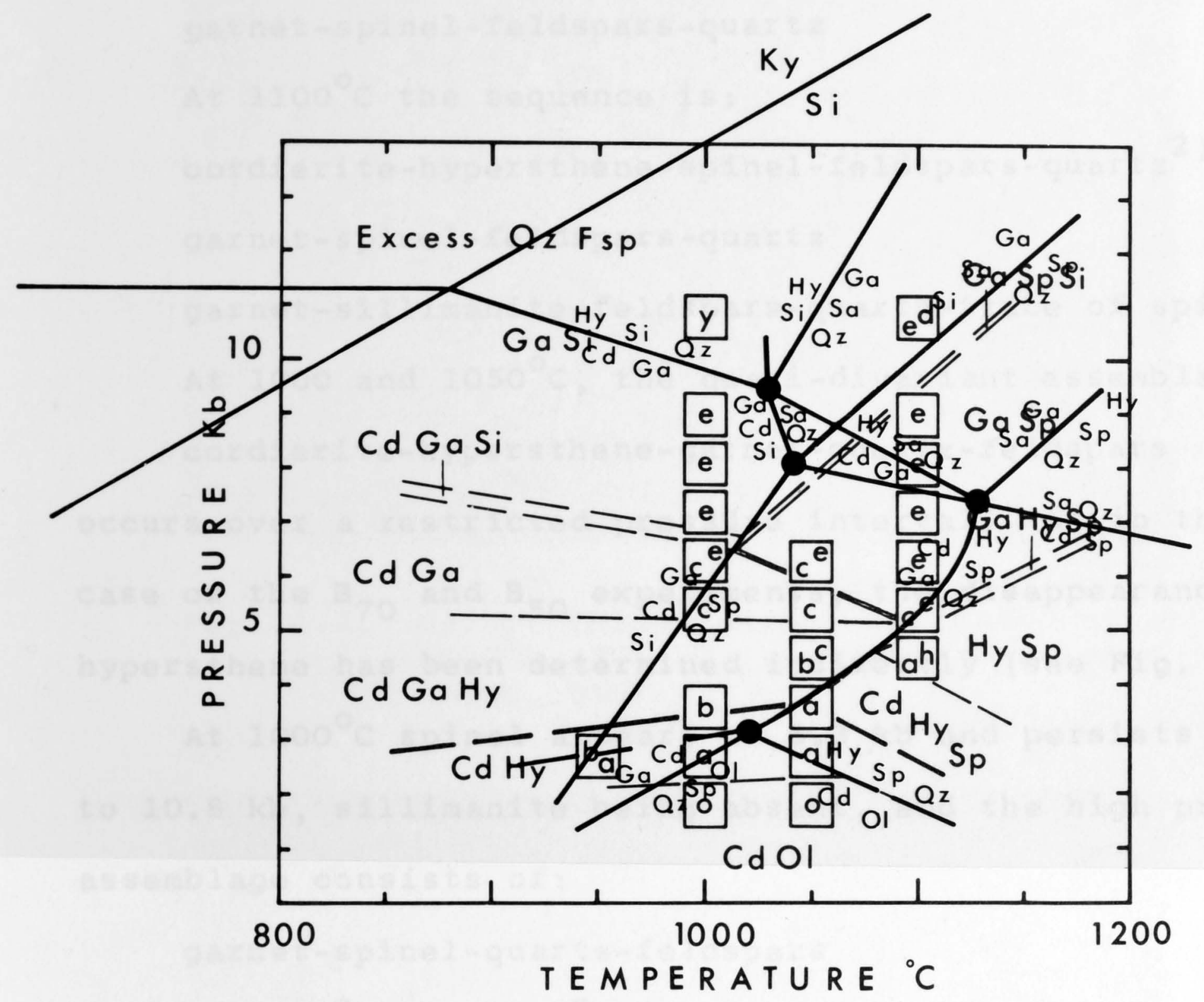

Fig. 5.6. P-T diagram for $\mathrm{B}_{30}$ composition. Overlay shows the relation between divariant and univariant boundaries. Observed phase assemblages are indicated by letters also used in the text. 


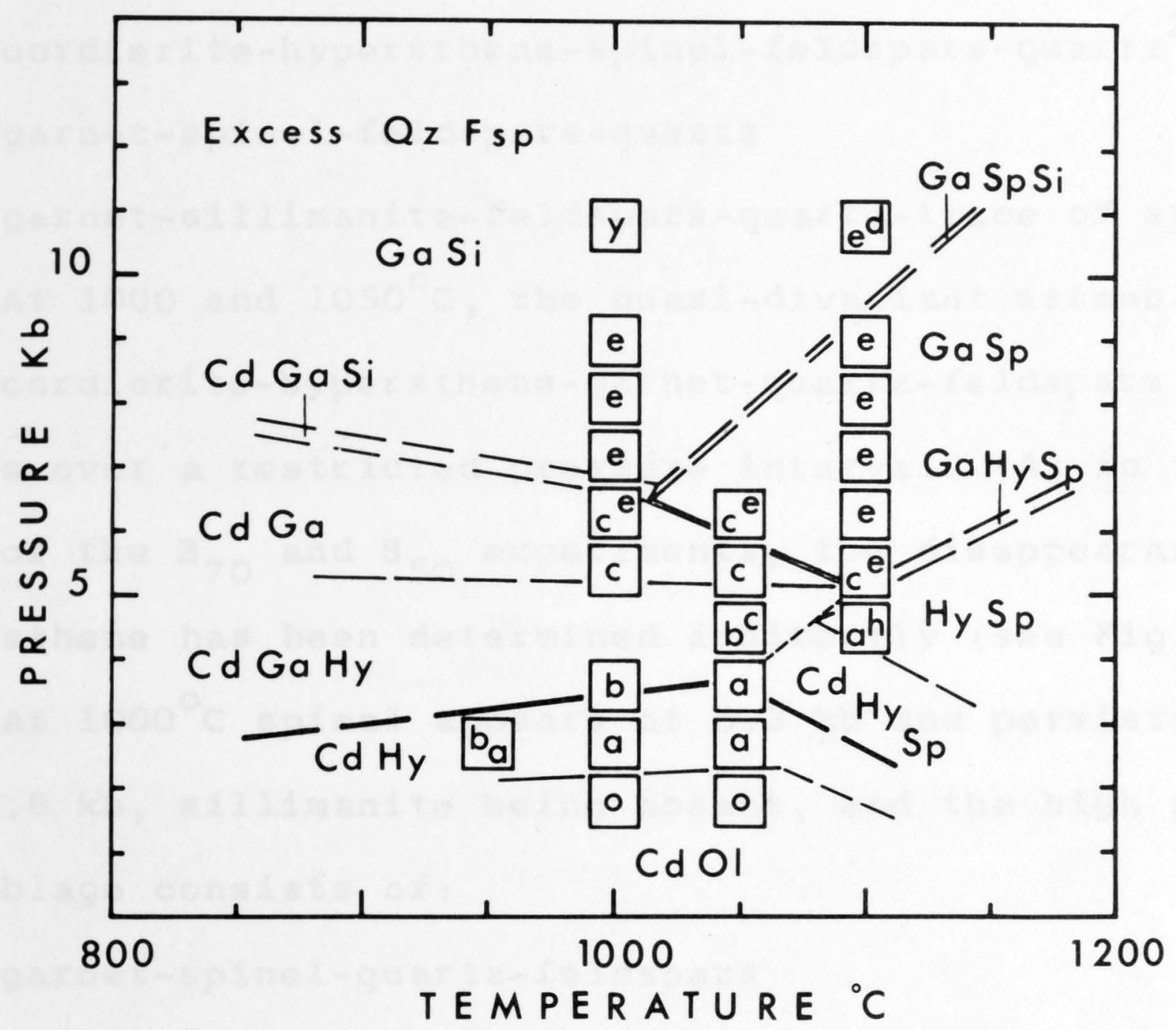

Fig. 5.6. $\mathrm{P}-\mathrm{T}$ diagram for $\mathrm{B}_{30}$ composition. Overlay shows the relation between divariant and univariant boundaries. Observed phase assemblages are indicated by letters also used in the text. 
garnet-cordierite-hypersthene-feldspars-quartz

garnet-cordierite-feldspars-quartz

garnet-spinel-feldspars-quartz

At $1100^{\circ} \mathrm{C}$ the sequence is:

cordierite-hypersthene-spinel-feldspars-quart $z^{2}$ )

garnet-spinel-feldspars-quartz

garnet-sillimanite-feldspars-quartz-trace of spinel

At 1000 and $1050^{\circ} \mathrm{C}$, the quasi-divariant assemblage cordierite-hypers thene-garnet-quartz-feldspars

occurs over a restricted pressure interval. As in the case of the $B_{70}$ and $B_{50}$ experiments, the disappearance of hypersthene has been determined indirectly (see Fig. 5.3).

At $1000^{\circ} \mathrm{C}$ spinel appears at $6.3 \mathrm{~kb}$ and persists up to $10.8 \mathrm{~kb}$, sillimanite being absent, and the high pressure as semblage consists of:

garnet-spinel-quartz-feldspars

At $1050^{\circ} \mathrm{C}$ and $1100^{\circ} \mathrm{C}$, partial melting presents

a major problem in this iron-rich composition. The analytical data provide evidence of the effect of partial melting on the $\mathrm{Mg} / \mathrm{Mg}+\mathrm{Fe}^{2+}$ ratio of the residual solids. It is estimated from the analytical data, that at most a 15-20\% increase in the $\mathrm{Mg} / \mathrm{Mg}+\mathrm{Fe}^{2+}$ ratio of the

1) The incoming of garnet at $1000^{\circ} \mathrm{C}$ is shown in Figs. 5.7 and 5.8 .

2) Below X-ray detection limit. 


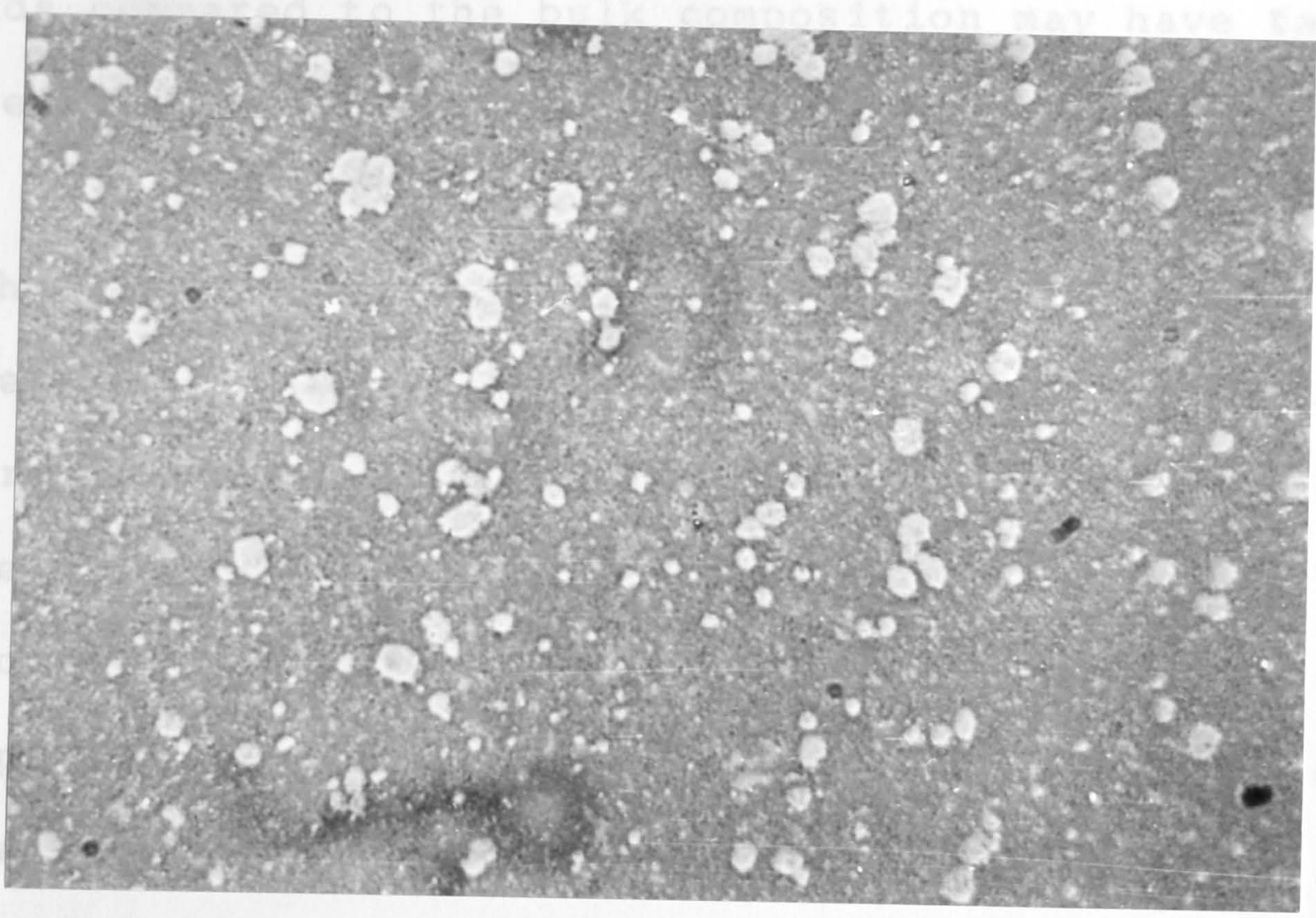

Fig. 5.8. Garnet (high relief) increased at $1000^{\circ} \mathrm{C}, 3.6 \mathrm{~kb}$ (run 1689); polished mount, $650 x$.

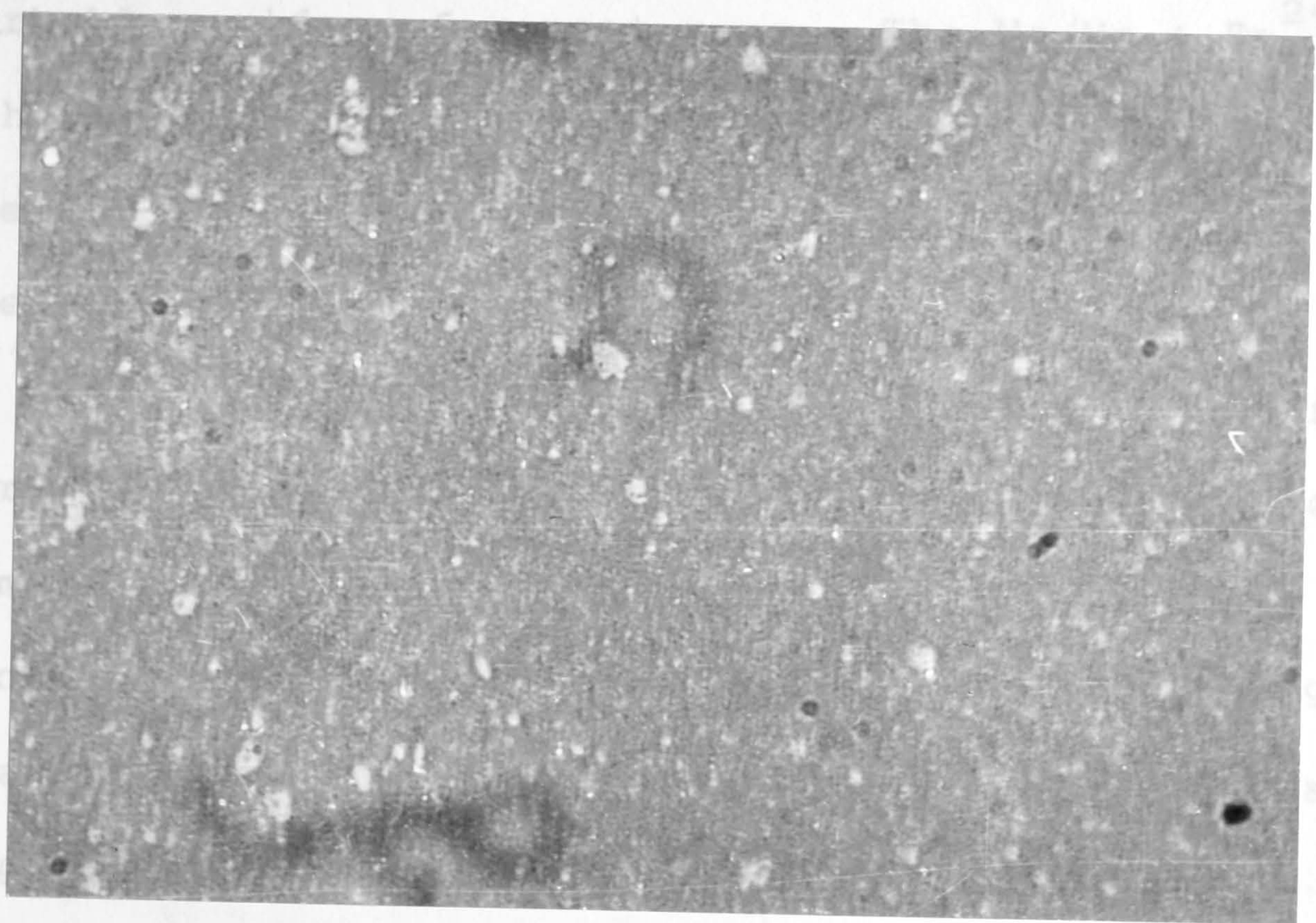

Fig. 5.7. Garnet relics at $1000^{\circ} \mathrm{C}, 2.7 \mathrm{~kb}$ (run 1704); polished mount, 650X. 
solids compared to the bulk composition may have taken place.

At $1100^{\circ} \mathrm{C}$ spinel appears on the low pressure side of the boundary marking the appearance of garnet. It is quite abundant at $5.3 \mathrm{~kb}$ where garnet has increased, and remains a major phase up to $9 \mathrm{~kb}$. At $10.8 \mathrm{~kb}$ the presence of sillimanite, although below the X-ray

detection limit, could be verified optically. The amount of spinel in this run is small. Cordierite breaks down between 5.4 and $6.3 \mathrm{~kb}$ at this temperature. Composition of experimentally produced phases

The analyses of garnet and cordierite obtained are given in Table 5.11. Garnet compositions are once again remarkably uniform for most runs. The $\mathrm{Mg} / \mathrm{Mg}+\mathrm{Fe}^{2+} \mathrm{ratio}$ of the garnets increases with increasing pressure, and there is some indication that it may decrease with decreasing temperature.

The grossular content of the garnets is significantly lower than for the $B_{70}$ and $B_{50}$ compositions (i.e. 4 mole \% compared to 6 mole $\%$ grossular $\left.{ }_{\text {ss }}\right)$. The possible reasons for this are discussed elsewhere (Chapter 9). The amount of grossular ss does not show any measurable change with $\mathrm{P}$ or $\mathrm{T}$.

The cordierite analyses at $1000^{\circ} \mathrm{C}$ show an increase of the $\mathrm{Mg} / \mathrm{Mg}+\mathrm{Fe}^{2+}$ ratio with increasing pressure. 
TABLE 5.11

Microprobe analyses of experimentally produced phases ( $\left.B_{30}\right)$

\begin{tabular}{|c|c|c|c|c|c|c|c|c|c|c|c|c|c|}
\hline \multirow{2}{*}{$\begin{array}{l}\text { Garnet } \\
\text { Run } \\
\text { No. }\end{array}$} & \multicolumn{2}{|c|}{ analyses } & \multirow[b]{2}{*}{100} & \multirow[b]{2}{*}{$\mathrm{Mg} / \mathrm{Mg}+\mathrm{Fe}^{2+}$} & \multirow[b]{2}{*}{$\begin{array}{l}\text { Mole \% } \\
\text { gross }\end{array}$} & \multirow[b]{2}{*}{$\begin{array}{c}\text { No. of } \\
\text { analyses }\end{array}$} & \multirow{2}{*}{$\begin{array}{c}\text { Perçentage of } \\
\text { total falling } \\
\text { within these } \\
\text { limits }\end{array}$} & \multicolumn{3}{|c|}{$\begin{array}{c}\text { Maximum range in } \\
\text { composition }\end{array}$} & \multirow[b]{2}{*}{100} & \multirow{2}{*}{$\begin{array}{l}\text { Cordierite } \\
\mathrm{Mg} / \mathrm{Mg}+\mathrm{Fe}^{2+}\end{array}$} & \multirow{2}{*}{$\begin{array}{c}\text { analyses } \\
\text { No. of } \\
\text { anaiyses }\end{array}$} \\
\hline & ${ }_{\mathrm{C}}^{\mathrm{Temp}}$ & $\begin{array}{l}\text { Press } \\
\mathrm{Kb}\end{array}$ & & & & & & 100 & $\mathrm{Mg} / \mathrm{Mg}+\mathrm{Fe}^{2+}$ & $\begin{array}{l}\text { Mole \% } \\
\text { gross }\end{array}$ & & & \\
\hline 2039 & 1100 & 5.4 & & $28+2$ & $4.5+1$ & 13 & 100 & & $26-30$ & $4-6$ & & $51-54$ & 3 \\
\hline 1696 & $"$ & 10.8 & & & & 8 & & & $30-35$ & $3.5-4.5$ & & & \\
\hline 1711 & 1050 & 4.5 & & $24 \pm 1$ & 4 & 16 & 100 & & $23-25$ & $3.5-4.5$ & & $45-49$ & 12 \\
\hline 1949 & $"$ & 6.3 & & & & 9 & & & $26-29$ & $4-5$ & & & \\
\hline 1689 & 1000 & 3.6 & & 18 & 4 & 18 & 94 & & $18-20$ & $3.5-4.5$ & & $34-38$ & 10 \\
\hline 1726 & $"$ & 5.4 & & $23.5 \pm .5$ & 4 & 9 & 89 & & $23-27$ & $3.5-4.5$ & & $44-50$ & 4 \\
\hline 1719 & $"$ & 7.2 & & $28 \mp 1$ & 4 & 9 & 78 & & $27-31$ & $3 \cdot 5-4 \cdot 5$ & & & \\
\hline 1709 & $"$ & 8.1 & & & & 4 & & & $26-30$ & $3.5-4.5$ & & & \\
\hline 1703 & $"$ & 9 & & & & 6 & & & $28-32$ & $3.5-4.5$ & & & \\
\hline 1700 & $"$ & 10.8 & & & & 9 & & & $29-31$ & $4-5$ & & & \\
\hline
\end{tabular}


The measured distribution coefficients of $\mathrm{Mg}$ and $\mathrm{Fe}$ between cordierite and garnet are given below.

$$
\text { TABLE } 5.12
$$

\begin{tabular}{lcccc}
\hline $\begin{array}{l}\text { Run } \\
\text { No. }\end{array}$ & $\begin{array}{c}\text { Temp } \\
\mathrm{C}_{\mathrm{C}}\end{array}$ & $\begin{array}{c}\text { Press } \\
\mathrm{Kb}\end{array}$ & $100 \mathrm{x}_{\mathrm{Cd}}$ & $\mathrm{K}_{\mathrm{D}(\mathrm{Cd}-\mathrm{Ga})}$ \\
\hline 2039 & 1100 & 5.4 & $51-54$ & $2.9 \pm .2$ \\
1711 & 1050 & 4.5 & $45-49$ & $2.8 \pm .2$ \\
1689 & 1000 & 3.6 & $34-38$ & $2.6 \pm .2$ \\
1726 & 1000 & 4.5 & $44-50$ & $3.0 \pm .4$ \\
\hline
\end{tabular}

The $K_{D}$ values have a tendency to be slightly lower than those in the more magnesian compositions. However, the rather poor quality of the cordierite analyses prevents unequivocal demonstration of this relationship.

Discussion of the results

The quasi-divariant and quasi-univariant reactions that have been deduced from the experimental data are listed in Table 5.13.

$$
\text { Compared to the } \mathrm{B}_{70} \text { and } \mathrm{B}_{50} \text { compositions the }
$$
appearance of garnet occurs at lower pressure, by the same divariant reaction

$$
\mathrm{Cd}+\mathrm{Hy} \rightleftharpoons \mathrm{Ga}+\mathrm{Qz}
$$

On the high pressure side of this band, the assemblage cordierite-garnet-quartz 
TABLE 5.13

Divariant and univariant reactions

a) Divariant reactions

Assemblage

Reaction

No 。

$\triangle \mathrm{V}$

b

$\mathrm{o} / \mathrm{a}$

$(\mathrm{Cd}, \mathrm{Ga}, \mathrm{Si})^{*}$

$\mathrm{e} / \mathrm{d}$

$\mathrm{a} / \mathrm{h}$ and $\mathrm{c} / \mathrm{e}$

$(\mathrm{Ga}, \mathrm{Hy}, \mathrm{Sp})^{*}$

$\mathrm{Hy}+\mathrm{Sp}+\mathrm{Qz} \rightleftharpoons \mathrm{Ga}$ -ve

-ve

-ve

-ve

-ve

- ve

b) Univariant reactions

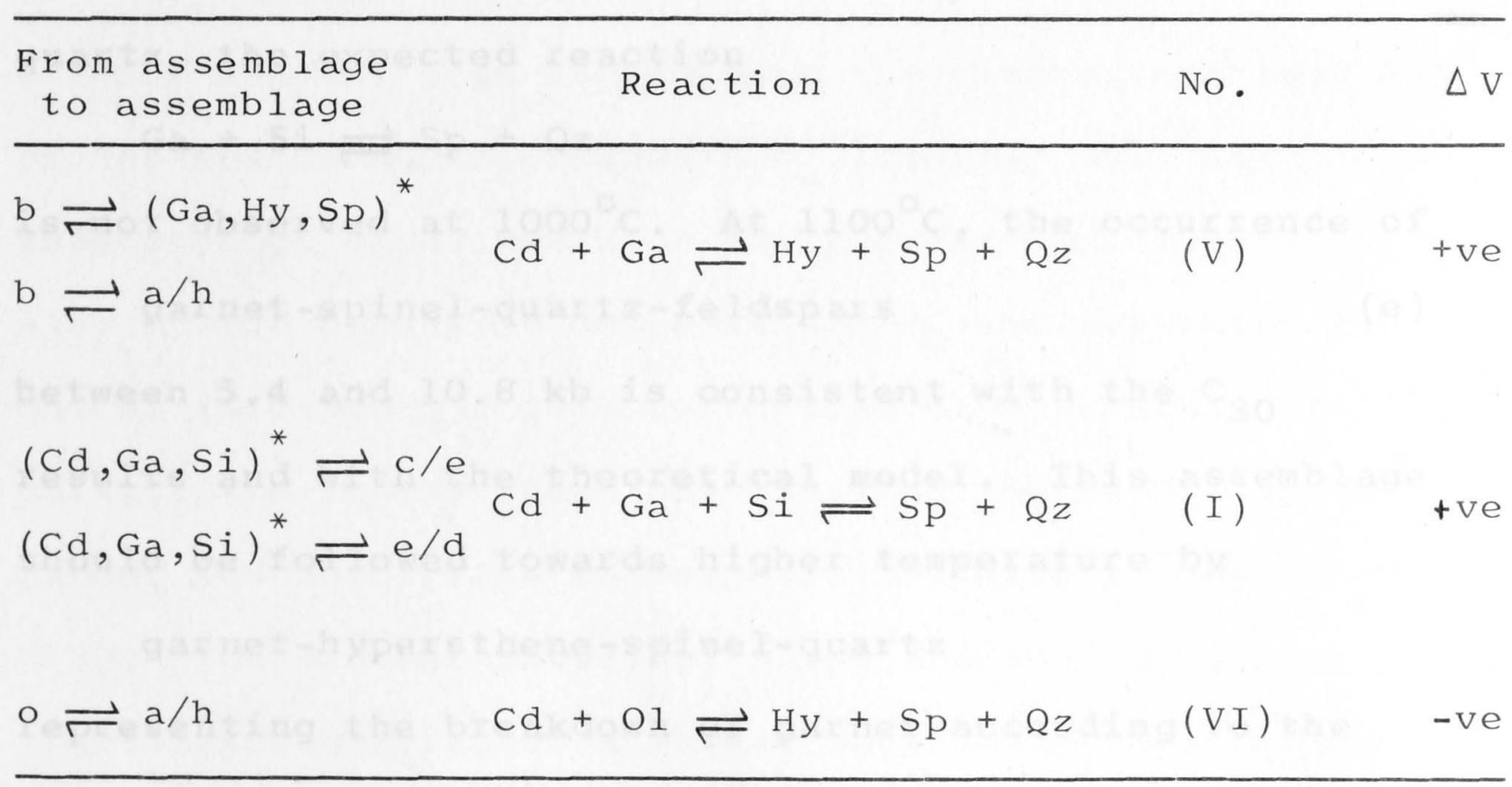


would be expected to occur (compare sections 5.1 and 5.2), followed at still higher pressure by the disappearance of cordierite by the reaction

$$
\mathrm{Cd} \rightleftharpoons \mathrm{Ga}+\mathrm{Si}+\mathrm{Qz}
$$

Reaction (1) has not been encountered experimentally in the present composition. The dashed phase boundaries in Figure 5.6 show the phase relations as required by the theoretical restrictions (see $B_{70}$ and $B_{50}$ composition). The results on the $\mathrm{C}_{30}$ composition (Chapter 4.2 ), showing the relative stabilities of garnet and spinel, indicate that the occurrence of spinel + quart $z$ instead of garnet + sillimanite in the $1000^{\circ} \mathrm{C}$ runs must be metastable. Because of the metastable persistence of spinel and quartz, the expected reaction

$$
\mathrm{Ga}+\mathrm{Si} \rightleftharpoons \mathrm{Sp}+\mathrm{Qz}
$$

is not observed at $1000^{\circ} \mathrm{C}$. At $1100^{\circ} \mathrm{C}$, the occurrence of

$$
\text { garnet-spinel-quartz-feldspars }
$$

between 5.4 and $10.8 \mathrm{~kb}$ is consistent with the $\mathrm{C}_{30}$ results and with the theoretical model. This assemblage should be followed towards higher temperature by garnet-hypers thene-spinel-quartz representing the breakdown of garnet according to the quasi-divariant reaction

$$
\mathrm{Ga} \rightleftharpoons \mathrm{Hy}+\mathrm{Sp}+\mathrm{Qz} \quad \Delta \mathrm{V}=+\mathrm{ve}
$$

Between the assemblage Ga-Hy-Sp-Qz and the assemblage 
Cd-Ga-Hy-Qz, the univariation reaction

$$
\mathrm{Cd}+\mathrm{Ga} \rightleftharpoons \mathrm{Hy}+\mathrm{Sp}+\mathrm{Qz} \quad \Delta \mathrm{V}=+\mathrm{ve}
$$

should occur. Evidence for the existence of this reaction has been obtained in the $B_{50}$ experiments (previous section). The geometry of the phase relationships in the high temperature part of the diagram is identical to that in the $\mathrm{B}_{50}$ composition (see Fig. 5.5).

At low pressure, olivine rather than hypersthene is found coexisting with cordierite. This suggests we have crossed the divariant reaction (represented by a single line in Fig. 5.6).

$$
\left.\mathrm{Hy}+\mathrm{Qz} \rightleftharpoons \mathrm{Ol}^{1}\right)
$$

Olivine has not been included in the theoretical analysis of the system $\mathrm{MgO}-\mathrm{FeO}-\mathrm{Al}_{2} \mathrm{O}_{3}-\mathrm{SiO}_{2}$ (Chapter 3). As indicated by experiments on the present composition and also on the pure iron compositions $\mathrm{B}_{\mathrm{O}}$ and almandine + quartz (section 5), olivine instead of hypersthene will participate in the reactions limiting the stability of garnet and cordierite in compositions with $100 \mathrm{Mg} / \mathrm{Mg}+\mathrm{Fe}^{2+}$ <30. The deduced invariant point and the univariant reactions radiating from it,are shown diagrammatically in Figure 5.9. One of the univariant curves is the reaction

$$
\mathrm{Cd}+\mathrm{Ga} \rightleftharpoons \mathrm{Hy}+\mathrm{Sp}+\mathrm{Qz} \quad \Delta \mathrm{V}=+\mathrm{ve}(?)
$$

1) This reaction has been studied experimentally by Smith (1970) 


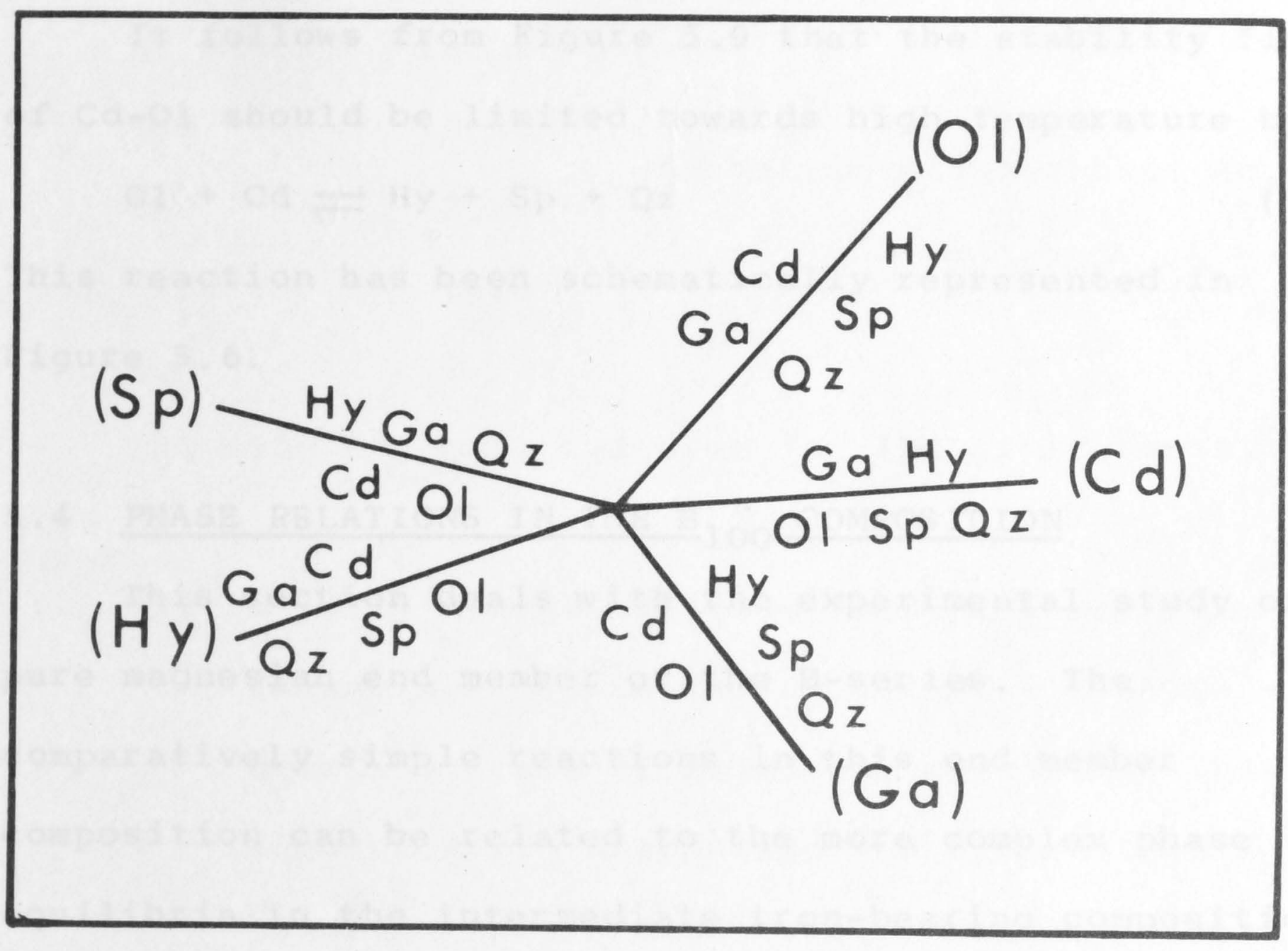

Fig. 5.9. Schematic P-T diagram of the invariant point involving the phases $\mathrm{Cd}, \mathrm{Ga}, \mathrm{Hy}$, $\mathrm{Ol}, \mathrm{Sp}$ and $\mathrm{Qz}$ assuming $\mathrm{X}_{\mathrm{Cd}}>\mathrm{x}_{\mathrm{H}}>\mathrm{X}_{\mathrm{Sp}}>\mathrm{x}_{\mathrm{Ga}}$. 
This reaction is replaced at low pressure and low values of $\mathrm{Mg} / \mathrm{Mg}+\mathrm{Fe}^{2+}$ ratio by

$$
\mathrm{Cd}+\mathrm{Ga} \rightleftharpoons \mathrm{Ol}+\mathrm{Sp}+\mathrm{Qz} \quad \Delta \mathrm{V}=+\mathrm{ve}(?)
$$

It follows from Figure 5.9 that the stability field of Cd-Ol should be limited towards high temperature by

$$
\mathrm{Ol}+\mathrm{Cd} \rightleftharpoons \mathrm{Hy}+\mathrm{Sp}+\mathrm{Qz}
$$

This reaction has been schematically represented in Figure 5,6.

\subsection{PHASE RELATIONS IN THE B 100 COMPOS IT ION}

This section deals with the experimental study of the pure magnesian end member of the B-series. The comparatively simple reactions in this end member composition can be related to the more complex phase equilibria in the intermediate iron-bearing compositions $\left(\mathrm{B}_{30}, \mathrm{~B}_{50}\right.$ and $\left.\mathrm{B}_{70}\right)$. The study of $\mathrm{B}_{100}$ also provides a link between the B-series and the simple system $\mathrm{MgO}-\mathrm{Al}_{2} \mathrm{O}_{3}-\mathrm{SiO}_{2}$ which is described in Chapter 8.

\section{Procedure}

The experiments run for more than 12 hours at 900 $1100^{\circ} \mathrm{C}$ were carried out in graphite capsules since it was found empirically that this avoided the low reaction rates in the anhydrous, sealed, platinum runs, and also the problem of a high degree of melting in unsealed platinum runs. 


\section{Composition studied}

$$
\text { The chemical composition of } \mathrm{B}_{100^{1}} \text { is: }
$$

$\begin{array}{lr}\mathrm{SiO}_{2} & 55.35 \\ \mathrm{Al}_{2} \mathrm{O}_{3} & 26.29 \\ \mathrm{MgO} & 13.28 \\ \mathrm{CaO} & 2.51 \\ \mathrm{Na}_{2} \mathrm{O} & 1.18 \\ \mathrm{~K}_{2} \mathrm{O} & 1.35\end{array}$

The starting material used for the experiments was either:

(I) a (4:1) mixture of glass and high pressure assemblage consisting of garnet + kyanite + quartz + trace of aluminous enstatite. This high pressure assemblage was synthesized from glass at $1200^{\circ} \mathrm{C}$ and $27 \mathrm{~kb}$. The grossular content of the garnet is $10 \pm 1$ mole \%.

(II) a (4:1) mixture of a fired oxide-mix, consisting of cordierite, pyroxene, feldspars and quartz (?), with the same high pressure as semblage.

Experimental data

The results of the experiments are given in Table 5.14 and their interpretation in Figure 5.10. At low

1) For chemographic representation see Fig. 1.1. 
TABLE 5.14

Experimental data for $B_{100}$ composition

\begin{tabular}{|c|c|c|c|c|c|c|c|c|c|c|c|c|c|c|c|}
\hline \multirow{2}{*}{$\begin{array}{l}\text { Run } \\
\text { No. }\end{array}$} & \multirow{2}{*}{ Temp } & \multirow{2}{*}{$\begin{array}{l}\text { Press } \\
\mathrm{Kb}\end{array}$} & \multirow{2}{*}{$\begin{array}{r}\text { Time } \\
\text { hrs }\end{array}$} & \multirow{2}{*}{$\begin{array}{l}\text { Starting } \\
\text { material }\end{array}$} & \multirow{2}{*}{$\mathrm{cd}$} & \multirow[b]{2}{*}{ Ga } & \multirow[b]{2}{*}{ En } & \multicolumn{5}{|c|}{ Phases present } & \multirow[b]{2}{*}{ Fsp } & \multirow[b]{2}{*}{ Glass } & \multirow{2}{*}{ Comments } \\
\hline & & & & & & & & $\mathrm{Sa}$ & Si & Ky & $Q z$ & Co & & & \\
\hline 1836 & 1200 & 13.5 & 8 & II & & & M & $\mathrm{H}$ & & & M & & $\operatorname{tr}$ & L & \\
\hline 1827 & $"$ & 14.4 & 3 & I & & $\mathrm{L}$ & & $\mathrm{H}$ & & & $\mathbf{M}$ & & $\operatorname{tr}$ & $\mathrm{L}$ & Garnet persisted. \\
\hline 1835 & $"$ & 15.3 & 21 & I I & & L & tr & $\mathrm{H}$ & & & M & & tr & L & Garnet unchanged. \\
\hline 1819 & $"$ & 16.2 & 4 & I & & $\mathrm{H}$ & & tr & M & & M & & $\mathrm{L}$ & L & Almost complete reaction to garnet, sillimanite, quartz. \\
\hline 1820 & 1150 & 16.2 & 21 & I & & $\mathrm{H}$ & & & M & & $\operatorname{tr}$ & & & M & Melting. Only a trace of quartz. \\
\hline 1805 & 1100 & 7.2 & 12 & I & $\mathrm{H}$ & & M & & & & $\mathbf{L}$ & & L & L & \\
\hline 1810 & $"$ & 11.7 & 48 & $"$ & & & M & $\mathrm{H}$ & & & $\mathrm{L} / \mathrm{M}$ & & L & L & \\
\hline 1800 & $"$ & 13.5 & 12 & $"$ & & M & M & $\mathrm{L} / \mathrm{M}$ & M & & M & & $\mathbf{L}$ & $\mathrm{L}$ & Garnet probably slightly increased. \\
\hline 1826 & $"$ & 14.4 & 22 & $"$ & & $\mathrm{H}$ & & & $\mathrm{L}$ & & L & & tr & M & Enstatite broken down. \\
\hline 1816 & 1000 & 9 & 40 & I & $\mathrm{H}$ & & $\mathrm{L} / \mathrm{M}$ & & & & & & $\mathrm{L}$ & $\mathbf{M}$ & \\
\hline 1814 & $"$ & 10.8 & 69 & $"$ & L & & $\mathrm{H}$ & & L & & & $L / M$ & $\mathrm{~L}$ & $\mathbf{M}$ & \\
\hline 1817 & $"$ & 12.6 & 49 & $"$ & & $\mathrm{~L}$ & $\mathrm{H}$ & & $\mathrm{L}$ & & $\mathrm{L}$ & L & $\mathrm{L}$ & M & Garnet seeds persisting. \\
\hline 1846 & $"$ & 13.5 & 68 & $"$ & & $\mathrm{H}$ & L & & tr & & $\operatorname{tr}$ & M & $\operatorname{tr}$ & $\mathbf{M}$ & Garnet strongly increased, but a lot of corundum and glass. \\
\hline 1821 & $"$ & 14.4 & 65 & $"$ & & $\mathrm{H}$ & M & & & $\mathrm{L} / \mathrm{M}$ & M & tr & L & L & Enstatite persisting; garnet grown. \\
\hline 1831 & 900 & 12.6 & 86 & II & & $\mathbf{L}$ & $\mathrm{H}$ & & $\operatorname{tr}$ & $\mathrm{L} / \mathrm{M}$ & tr & tr & L & M & $\begin{array}{l}\text { Garnet seeds persisting (slight decrease compared to } \\
\text { starting mix. }\end{array}$ \\
\hline
\end{tabular}

The relative proportions of the phases are indicated by: $H=$ high

$M=$ medium

$L=10 w$

tr $=$ trace 


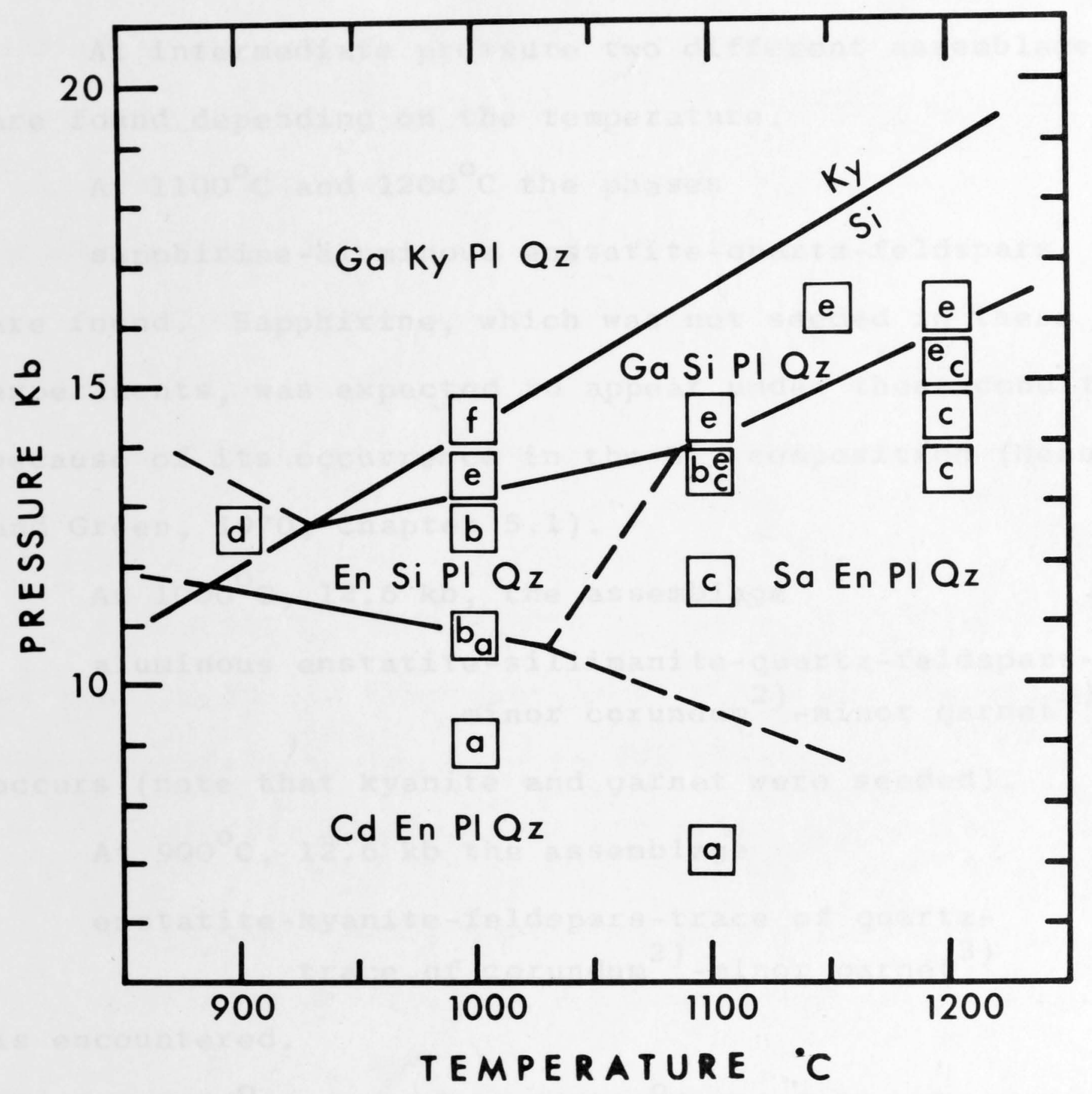

Fig. 5.10. P-T diagram for B 100 composition. Observed mineral assemblages are indicated by letters also used in the text. 
pressures the charge consists of

cordierite-aluminous enstatite-quart $z^{1}$-feldspars (a)

At intermediate pressure two different assemblages are found depending on the temperature.

At $1100^{\circ} \mathrm{C}$ and $1200^{\circ} \mathrm{C}$ the phases

sapphirine-aluminous enstatite-quartz-feldspars

are found. Sapphirine, which was not seeded in these experiments, was expected to appear under these conditions, because of its occurrence in the $B_{70}$ composition (Hensen and Green, 1970, Chapter 5.1).

At $1000^{\circ} \mathrm{C}, 12.6 \mathrm{~kb}$, the assemblage

aluminous enstatite-sillimanite-quartz-feldsparsminor corundum ${ }^{2}$ ) -minor garnet $\left.{ }^{3}\right)$

occurs (note that kyanite and garnet were seeded).

At $900^{\circ} \mathrm{C}, 12.6 \mathrm{~kb}$ the assemblage

enstatite-kyanite-feldspars-trace of quartz-

trace of corundum ${ }^{2}$ )-minor garnet ${ }^{3}$ )

is encountered.

At $1100^{\circ} \mathrm{C}, 14.4 \mathrm{~kb}$ and $1200^{\circ} \mathrm{C}, 16.2 \mathrm{~kb}$, the assemblage garnet-sillimanite-feldspars

1) Below X-ray detection limit.

2 ) Corundum is associated with partial melting which occurs locally in the charge due to access of water through the capsule walls.

3) Garnet seeds have failed to disappear. 
occurs. The grossular content of garnet is $5+2$ mole $\%$ at $1100^{\circ} \mathrm{C}$ and $7 \pm 2$ mole $\%$ at $1200^{\circ} \mathrm{C}$ (note that the garnet seeds have $10 \pm 2$ mole $\%$ grossular).

Discussion of the results

The disappearance of cordierite with increasing pressure (Fig. 5.10) is due to the following reactions ${ }^{1}$ )

cordierite $\rightleftharpoons$ sapphirine + quartz

at $1100^{\circ} \mathrm{C}$ and $1200^{\circ} \mathrm{C}$, and

cordierite $\rightleftarrows$ aluminous enstatite + sillimanite + quartz

at $1000^{\circ} \mathrm{C}$.

Below $900^{\circ} \mathrm{C}$, sillimanite in reaction (2) is replaced by kyanite due to intersection with the kyanite-sillimanite phase boundary giving rise to the reaction:

cordierite $\rightleftharpoons$ aluminous enstatite + kyanite + quartz

At intermediate pressure we have the reaction: aluminous enstatite + sillimanite $\rightleftharpoons$ sapphirine + quartz

The position of the phase boundaries for the reactions

(1), (2) and (3) and of the invariant point at their intersection, has been taken from the proposed phase diagram for the system $\mathrm{MgO}-\mathrm{Al}_{2} \mathrm{O}_{3}-\mathrm{SiO}_{2}$ (Chapter 8 , Figure 8.3). This is justified because the relative stabilities

1) The numbering of reactions in this section is not related to that used in the intermediate compositions. 
of the phases cordierite, aluminous enstatite and sapphirine are probably not significantly affected by the presence of $\mathrm{Ca}{ }^{1}$ )

The reactions for the incoming of garnet can be expressed as follows:

At $\mathrm{T}>1100^{\circ} \mathrm{C}$,

sapphirine + aluminous enstatite + calcic plagioclase

+ quartz grossular-pyrope + less calcic plagioc 1 ase

At $\mathrm{T} \approx 950-1100^{\circ} \mathrm{C}$

aluminous enstatite + calcic plagioclase + sillimanite $\rightleftharpoons$ grossular-pyrope + less calcic plagioclase + quartz

Reactions (4) and (5) are strictly divariant. 2)

Therefore reactants and products of these reactions may coexist over a restricted P-T interval. It is believed however, that the persistence of garnet below the boundary in Figure $5_{\wedge}^{.10}$ marking the breakdown of the phases enstatite and sapphirine, is more likely to be a metastable phenomenon. The amount of garnet in these runs shows no change compared to the starting material. Moreover a change in the composition of the garnet with increasing

1) The presence of a small amount of Ca Tschermak's component in enstatite could possibly extend the stability field of enstatite at the expense of cordierite and sapphirine.

2) The univariant equivalents of these reactions involving anorthite have to occur at lower pressure. 
pressure, which would be required in the case of a divariant equilibrium, has not been detected. However, the existence of a small compositional difference cannot be excluded as the cell sizes could not be accurately determined by $x$-ray diffraction, owing to the scarcity of garnet in these runs.

At a temperature of approximately $950^{\circ} \mathrm{C}$, reaction (5) intersects the kyanite-sillimanite phase boundary ${ }^{1}$ ) (Figure 5.10). The run at $900^{\circ} \mathrm{C}, 12.6 \mathrm{~kb}$ in which garnet shows no sign of growth, suggests that the reaction aluminous enstatite + calcic plagioclase + kyanite $\rightleftharpoons$ grossular-pyrope + less calcic plagioclase +

quartz

may have a negative slope. A negative slope is also deduced for the similar reaction without plagioclase and

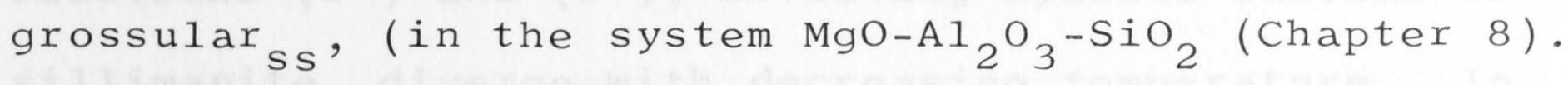

The present data show that a relatively small amount of grossular ss $(4-8$ mole $\%)$ has a considerable effect on the stability of pyrope-rich garnet (compare Figs. 8.1 and 8.3 in Chapter 8 ). At temperatures above $1050^{\circ} \mathrm{C}$, the stability limit of garnet (+ quartz) is lowered by ca. $2 \mathrm{~kb}$ compared to pure pyrope + quartz. This clearly indicates that calcium is an important component in 1) The slope and location of this boundary are discussed
in Chapter 8 . 
controlling the stability of garnet even though the amount of grossular substitution is small. It is worth noting that in the experiments the $100 \mathrm{Ca} / \mathrm{Ca}+\mathrm{Mg} \mathrm{ratio}$ of the garnet (4-8) is lower than that of the bulk composition $(100 \mathrm{Ca} / \mathrm{Ca}+\mathrm{Mg}=12)$. The garnet produced in the high pressure run at $1200^{\circ} \mathrm{C}, 27 \mathrm{~kb}$, which has been used as seed in the starting material, has $100 \mathrm{Ca} / \mathrm{Ca}+\mathrm{Mg}=10-12$, i.e. almost all of the anorthite component in the plagioclase has broken down to grossular ss + kyanite + quartz.

Comparison with intermediate members of the B-series

As shown in Figure 5.10 the stable coexistence of cordierite and garnet is precluded in this composition. This is a necessary result of the interpretation that reactions ( $2^{\prime}$ ) and (5'), involving kyanite instead of sillimanite, diverge with decreasing temperature. In the intermediate Fe-bearing compositions (e.g. $\mathrm{B}_{70}$ ), reactions (2) and (5) occur at considerably lower pressure. They constitute broad quasi-divariant bands that intersect well within the stability field of sillimanite. Their intersection gives rise to two other quasi-divariant equilibria involving

a) cordierite-garnet-plagioclase-sillimanite-quartz and

b) cordierite-garnet-hypersthene-plagioc 1 ase-quartz. 
The stability field for sapphirine-quartz found in the present composition extends to lower temperature than the field encountered in $B_{70}$, whereas the stability field of cordierite extends to somewhat higher pressure. The relationships between the univariant boundaries and invariant points in this end member composition and the quasi-univariant and divariant reactions in the intermediate compositions is dealt with in section 5.6 and Chapter 9 .

\subsection{PHASE RELATIONS IN THE B O AND ALMANDINE + QUARTZ}

\section{COMPOSITIONS}

Although there is much experimental information on the system $\mathrm{FeO}-\mathrm{Al}_{2} \mathrm{O}_{3}-\mathrm{SiO}_{2}$ (Hsu, 1968; Richardson, 1968 ; Rutherford, 1968), no data are available for temperatures above $900^{\circ} \mathrm{C}$. The present experiments were intended to provide the low pressure limits of the P,T region in which almandine-rich garnet, cordierite, fayalite-rich olivine and quartz coexist. The existence of such a phase assemblage at low pressure is indicated by the experimental data on the complex $\mathrm{B}_{30}$ composition (Chapter 5.3). In the $\mathrm{B}_{30}$ composition, the hypersthene of the assemblage cordierite-hypersthene-quartz, is replaced by iron-rich olivine at low pressure (below that for the incoming of garnet). It is therefore 
likely that in more iron-rich compositions, where garnet appears at even lower pressure, hypersthene will be absent. The assemblage garnet-cordierite-olivine-quartz would then have a restricted, quasi-divariant, ${ }^{1}$ ) stability field.

The existence of the univariant reaction between Fe-cordierite and fayalite to produce almandine and quartz can be predicted theoretically on the basis of other known reactions in the simple system (Rutherford, 1968). Using the available experimental evidence it is possible to construct a model phase diagram for the silica-saturated part of the system $\mathrm{FeO}-\mathrm{Al}_{2} \mathrm{O}_{3}-\mathrm{SiO}_{2}$. The effect of oxygen fugacity in this system is of major importance. It has not been investigated experimentally but it is considered in the discussion of the theoretical model.

Experimental procedure

Most of the experiments were carried out using the techniques set out in Chapter 2.1. Two low pressure runs have been carried out using standard hydrothermal equipment and techniques. The samples with added water were sealed

\footnotetext{
1) The assemblages are not strictly divariant because in the experiments the garnet has a small amount of grossular substitution.
} 
in silver-palladium tubes which in turn were sealed in gold tubing containing an oxygen-buffer assemblage and water. The original buffer assemblage was ironwüstite. However, in both runs oxidation of this assemblage took place. In one run (no. 10) the assemblage changed to another buffer, magnetite + wüstite. In the other run (no. 9) only wüstite was found after the run indicating slightly more reducing conditions (intermediate between iron-wüstite and wüstite-magnetite buffers). In the piston cylinder experiments the oxygen fugacity is low but not controlled in a strictly buffered state. For a discussion of this, the reader is referred to Chapter 2.5 .

Compositions studied

In addition to the $\mathrm{B}_{\mathrm{O}}$ composition, constituting the Fe-end member of the complex B-series of compositions (Chapter 1.2), the composition almandine + quartz has been studied to evaluate the influence of grossular ss on almandine-rich garnet in $\mathrm{B}_{\mathrm{O}}$. Two hydrothermal experiments have been carried out on the almandine + quartz mix and, simultaneously, on a starting material consisting of almandine + quartz + sillimanite, to compare the stability of almandine relative to cordierite in these two different assemblages. Compositions and starting materials are given below. 
1. B $_{\mathrm{O}}$ composition

The composition of $\mathrm{B}_{\mathrm{O}}$ is:

$$
\begin{array}{ll}
\mathrm{SiO}_{2} & -50.61 \\
\mathrm{Al}_{2} \mathrm{O}_{3} & -23.66 \\
\mathrm{FeO} & -20.95 \\
\mathrm{CaO} & -2.22 \\
\mathrm{Na}_{2} \mathrm{O}-1.18 \\
\mathrm{~K}_{2} \mathrm{O}-1.35
\end{array}
$$$$
\text { Normative plagioclase: } A_{51}
$$

The position of this composition in the various compositional diagrams is shown in Figure 1.1. The starting material used in the experiments consists of high pressure assemblage and glass in a 1:4 ratio. The high pressure assemblage was crystallised from the glass at $950^{\circ} \mathrm{C}-4.5 \mathrm{~kb}$ (run no. 1783) and contains the minerals garnet, hercynitess, quartz and feldspars.

2. The composition almandine + quart $z^{1}$ )

The starting material was:

25\% low pressure as semblage (oxide mix fired at $950^{\circ} \mathrm{C}$ under vacuum for 12 hours, containing hercynite ${ }_{\text {ss }}+$ fayalite + quartz).

25\% high pressure assemblage, prepared from glass at $1000^{\circ} \mathrm{C}-18 \mathrm{~kb}$ (run no. 1919) consisting of almandine + quartz. $50 \%$ glass.

1)For chemical analysis see Table 1.1. 
3. The almandine + quartz mix with added $32 \%$ natural sillimanite.

\section{Experimental data}

\section{1. $\underline{B}_{\mathrm{O}}$ composition}

The results of the experiments are given in Table 5.15 and Figure 5.11. At $1000^{\circ} \mathrm{C}, 1.8 \mathrm{~kb}$, the assemblage consists of:

fayalite-hercynite $s_{s}-q u a r t z-f e l d s p a r s$ At $1050^{\circ} \mathrm{C}$ and $3.6 \mathrm{~kb}$ only hercynites and minor quartz occur accompanied by major glass. The disappearance of fayalite is probably caused by melting rather than by oxidation (compare with results on almandine + quartz under the same conditions). At both $1000^{\circ} \mathrm{C}$ and $1050^{\circ} \mathrm{C}$ the assemblage garnet-hercynite-quartz-feldspars is found at 2.7 and $4.5 \mathrm{~kb}$ respectively. At $900^{\circ} \mathrm{C}$ this assemblage forms at $1.8 \mathrm{~kb}$. The amount of grossulars in the garnet is low (ca. $4 \pm 2$ mole \%, determined by X-ray diffraction).

The composition of the spinel does not measurably change with temperature. Spinel and garnet compositions, as determined by cell edge measurements, are given below: 
TABLE 5.15

Experimental data for $\mathrm{B}_{\mathrm{O}}$ and $\mathrm{Al}+\mathrm{Qz}$ compositions

\begin{tabular}{|c|c|c|c|c|c|c|c|c|c|c|c|c|}
\hline \multirow{2}{*}{$\begin{array}{l}\text { Run } \\
\text { No. }\end{array}$} & \multirow{2}{*}{$\underset{\mathrm{C}}{\mathrm{Temp}}$} & \multirow{2}{*}{$\begin{array}{c}\text { Press } \\
\mathrm{Kb}\end{array}$} & \multirow{2}{*}{\multicolumn{2}{|c|}{$\begin{array}{l}\text { Time } \\
\text { hrs }\end{array}$}} & \multirow[b]{2}{*}{$\mathrm{Cd}$} & \multirow[b]{2}{*}{$\mathrm{Ga}(\mathrm{Al})$} & \multicolumn{3}{|c|}{ Phases present } & \multirow[b]{2}{*}{$\mathrm{Si}$} & \multirow[b]{2}{*}{ Fsp } & \multirow[b]{2}{*}{ Glass } \\
\hline & & & & & & & $\mathrm{Fa}$ & $\mathrm{Hc}$ & $Q z$ & & & \\
\hline 1786 & 1100 & 9.9 & & 15 & & $\mathrm{H}$ & & M & M & & $\mathrm{L}$ & $\mathrm{L}$ \\
\hline $\begin{array}{l}\left.1792^{1)}\right) \\
\left.1796^{2}\right)\end{array}$ & $\begin{array}{c}1050 \\
"\end{array}$ & $\begin{array}{l}3.6 \\
4.5\end{array}$ & & $\begin{array}{l}16 \\
15\end{array}$ & & $\mathrm{~L} / \mathrm{M}$ & & $\begin{array}{l}\mathrm{H} \\
\mathrm{H}\end{array}$ & $\begin{array}{l}\mathrm{L} \\
\mathrm{M}\end{array}$ & & $\begin{array}{l}\mathrm{L} \\
\mathrm{L}\end{array}$ & $\begin{array}{l}\text { M } \\
\text { L }\end{array}$ \\
\hline $\begin{array}{l}1795 \\
1788\end{array}$ & $\begin{array}{c}1000 \\
" 1\end{array}$ & $\begin{array}{l}1.8 \\
2.7\end{array}$ & & $\begin{array}{l}42 \\
37\end{array}$ & & $\mathrm{~L} / \mathrm{M}$ & M & $\begin{array}{l}\mathrm{H} \\
\mathrm{H}\end{array}$ & $\begin{array}{l}M \\
M\end{array}$ & & $\begin{array}{l}\mathrm{L} \\
\mathrm{L}\end{array}$ & $\begin{array}{l}\mathrm{L} \\
\mathrm{L}\end{array}$ \\
\hline 1801 & 900 & 1.8 & & 89 & & $\mathrm{H}$ & & M & M & & $\mathrm{L}$ & $\mathrm{L}$ \\
\hline \multicolumn{11}{|c|}{ Almandine + quartz mix } & & \multirow{7}{*}{ M } \\
\hline $2135^{3)}$ & 1100 & 4.5 & & 23 & & & & $\mathrm{H}$ & M & & & \\
\hline $\begin{array}{l}2138 \\
1965\end{array}$ & $\begin{array}{c}1050 \\
" 1\end{array}$ & $\begin{array}{l}3.6 \\
5.4\end{array}$ & & $\begin{array}{l}18 \\
21\end{array}$ & & $\mathrm{H}$ & $\begin{array}{l}\mathrm{H} \\
\mathrm{tr}\end{array}$ & $\begin{array}{l}M / H \\
L\end{array}$ & $\begin{array}{l}M / H \\
M / H\end{array}$ & & & \\
\hline $\begin{array}{l}9 \mathrm{C} \\
10 \mathrm{C}\end{array}$ & $\begin{array}{l}750 \\
" 1\end{array}$ & $\begin{array}{l}1.1 \\
2.2\end{array}$ & $\begin{array}{l}35 \\
30\end{array}$ & $\begin{array}{l}\text { days } \\
\text { days }\end{array}$ & $\mathrm{M} / \mathrm{H}$ & $\begin{array}{l}\mathrm{M} \\
\mathrm{H}\end{array}$ & $\begin{array}{l}\mathrm{L} / \mathrm{M} \\
\mathrm{L}\end{array}$ & $\begin{array}{l}\text { tr } \\
L\end{array}$ & $\begin{array}{l}\mathrm{L} / \mathrm{M} \\
\mathrm{tr} / \mathrm{M}\end{array}$ & & & \\
\hline \multicolumn{4}{|c|}{ Almandine + } & \multicolumn{3}{|c|}{+ quartz mix } & & & & & & \\
\hline $9 \mathrm{~A}$ & 750 & 1.1 & 35 & days & $\mathrm{H}$ & $M$ & & $\operatorname{tr} / 1$ & $M$ & $\mathrm{~L} / \mathrm{M}$ & & \\
\hline $10 \mathrm{~A}$ & $"$ & 2.2 & 30 & days & $\mathrm{H}$ & M & & $\operatorname{tr} / 1$ & M & $L / M$ & & \\
\hline
\end{tabular}

1) Moderately common glass. No garnet.

2) Garnet increased.

3) Major glass.

The relative proportions of the phases are indicated by:

$$
\begin{aligned}
H & =\text { high } \\
M & =\text { medium } \\
L & =\text { low } \\
t r & =\text { trace }
\end{aligned}
$$




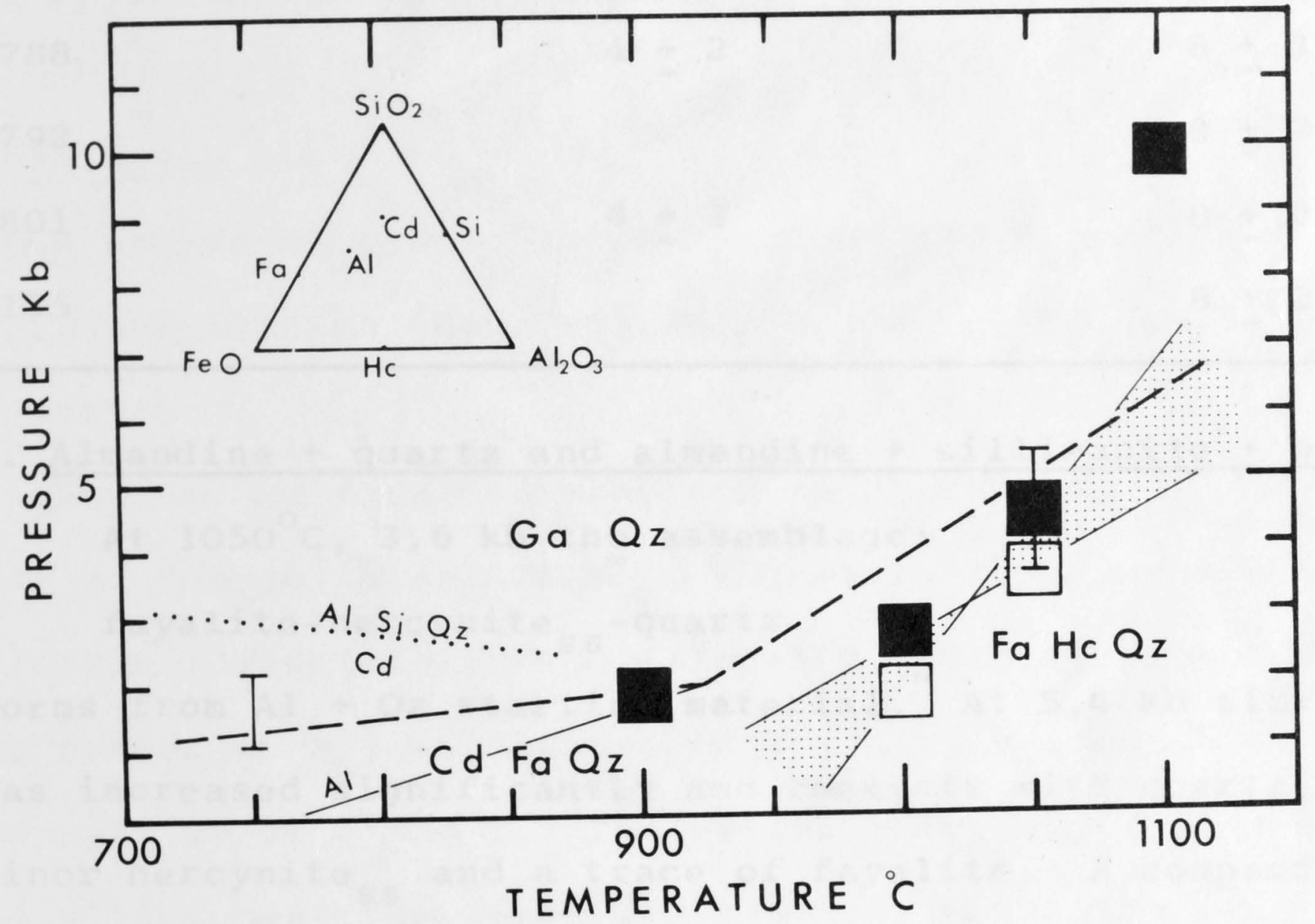

Fig. 5.11. P-T diagram for $\mathrm{B}_{\mathrm{O}}$ and almandine + quartz compositions. Dashed lines: "univariant" boundaries for almandine + quartz composition. The experiments on this composition are indicated by I bars. Shaded area: possible location of lower stability limit of garnet in $\mathrm{B}$ Dotted line: approximate upper stability limit of Fe-cordierite (after Richardson, 1968). Light line marked Al: lower stability limit of almandine (with respect to cordierite, fayalite, hercynitess) from the data of Hsu (1968). 


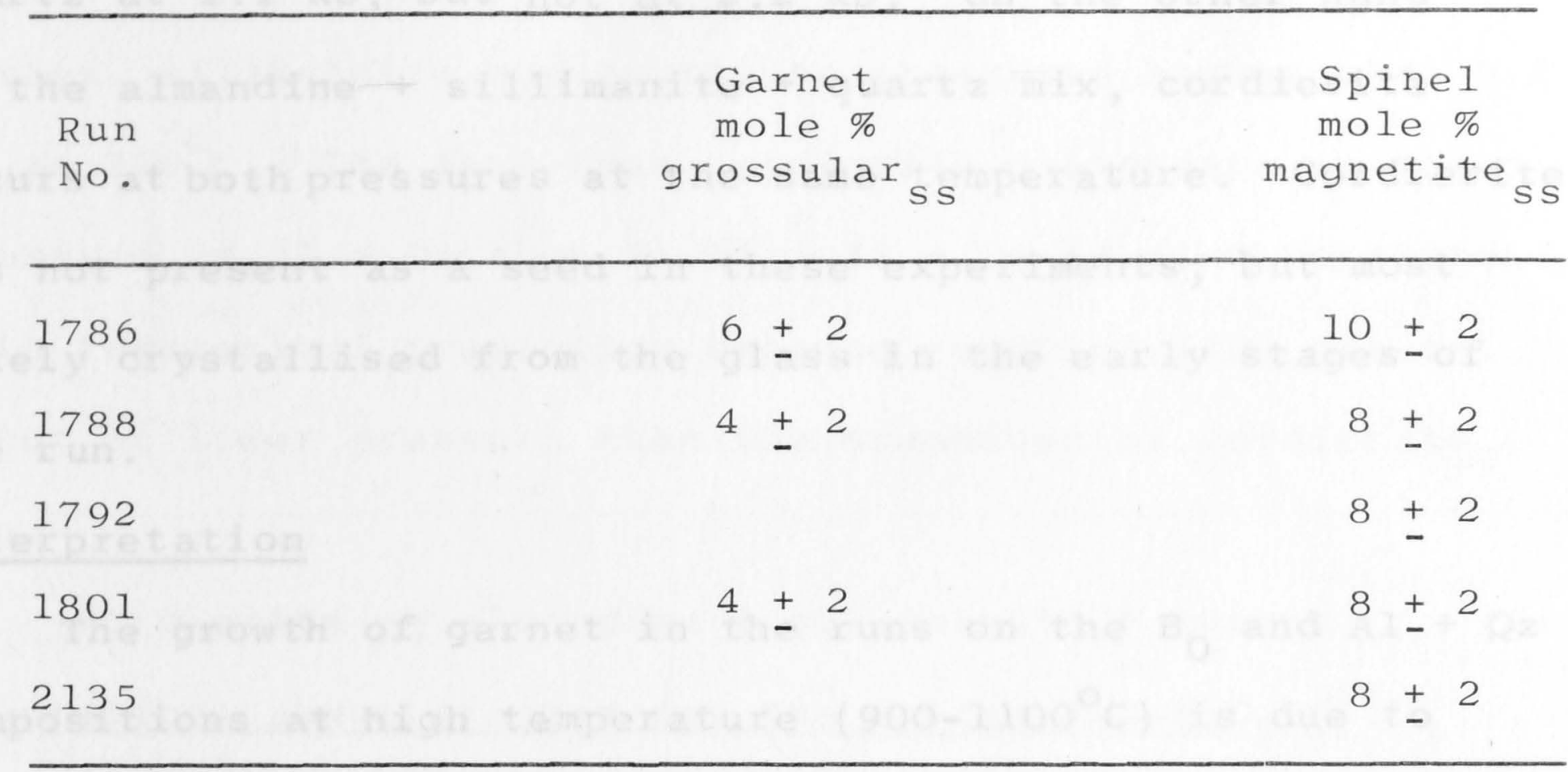

2. Almandine + quartz and almandine + sillimanite + quartz At $1050^{\circ} \mathrm{C}, 3.6 \mathrm{~kb}$ the as semblage:

fayalite-hercynite ss $^{-q u a r t z}$

forms from Al + Qz starting material. At $5.4 \mathrm{~kb}$ almandine has increased significantly and coexists with quartz, minor hercynite ${ }_{\text {s }}$ and a trace of fayalite. A comparison with the ${ }^{B}$ o results shows that the boundary marking the incoming of garnet in the $\mathrm{B}_{\mathrm{O}}$ composition is probably at lower pressure than the stability limit for pure almandine + quartz (Fig. 5.11). At $1100^{\circ} \mathrm{C}$ in the almandine + quartz composition, melting has eliminated all solid phases other than hercynite ${ }_{\text {s }}$ and quartz.

The results of the hydrothermal experiments on almandine + quart $z$ at $750^{\circ} \mathrm{C}$ suggest that the assemblage fayalite + cordierite is stable relative to almandine + 
quartz at $1.1 \mathrm{~kb}$, but not at $2.2 \mathrm{~kb}$. On the other hand in the almandine + sillimanite + quartz mix, cordierite occurs at both pressures at the same temperature. Cordierite was not present as a seed in these experiments, but most likely crystallised from the glass in the early stages of the run.

\section{Interpretation}

The growth of garnet in the runs on the $\mathrm{B}_{\mathrm{O}}$ and $\mathrm{Al}+\mathrm{Qz}$ compositions at high temperature $\left(900-1100^{\circ} \mathrm{C}\right)$ is due to the reaction

$$
\text { almandine } \rightleftharpoons \text { fayalite + hercynite } \text { fs }_{\text {f }}+\text { quartz }
$$

Because of the solid solution of magnetite in hercynite this equilibrium (disregarding the effect of grossular component in the garnet in $\mathrm{B}_{\mathrm{O}}$ ) is divariant, i.e. it is a function of $\mathrm{fO}_{2}$ as well as of $\mathrm{P}$ and $\mathrm{T}$. The estimated curve (Figure 5.11) probably lies near the upper limit of the stability of almandine. Under more oxidising conditions, the boundary will be displaced towards lower temperature (Hsu, 1968). The results on the almandine + quartz mix at $750^{\circ} \mathrm{C}$ suggest the reaction

$$
\text { cordierite + fayalite } \rightleftharpoons \text { almandine + quartz }
$$

takes place between 1.1 and $2.2 \mathrm{~kb}$.

The results on the almandine + sillimanite + quartz mix are in agreement with the data of Richardson (1968). 
They indicate that cordierite is stable with respect to garnet, sillimanite and quartz to pressures higher than 2.2 $\mathrm{kb}$ at $750^{\circ} \mathrm{C}$. The fact that cordierite disappears at lower pressure in $A I+Q z$ than in $A I+S i+Q z$ is a 1 so consistent with theoretical prediction because reaction (10) has to occur at lower pressure than the breakdown of cordierite, i.e.

cordierite $\rightleftharpoons$ almandine + sillimanite + quartz

Theoretical phase diagram for the system FeO-SiO $2-_{2} \underline{-A}_{3}$

(reducing conditions)

Two hypothetical phase diagrams for the simple ternary

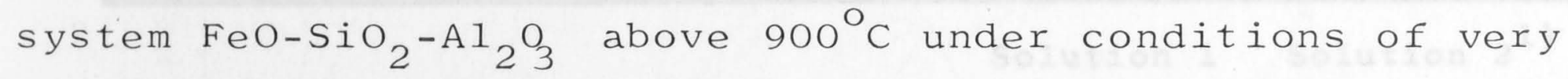
low oxygen fugacity (where pure hercynite is stable) are represented in Figures 5.12 and 5.13. Only the phases cordierite, almandine, fayalite, hercynite, sillimanite and quartz have been taken into account. Corundum and mullite have been disregarded.

The univariant reactions between the six phases considered have been listed.in Table 5.16. On theoretical grounds the geometry represented in Figure 5.12 is a possible solution. This geometry is very similar to that proposed for the system $\mathrm{MgO}-\mathrm{Al}_{2} \mathrm{O}_{3}-\mathrm{SiO}_{2}$ (Chapter 8). However, there is no experimental evidence for the existence of a stability field for the join fayalite-sillimanite (or fayalitemullite). 
TABLE 5.16

Phases and univariant reactions in part of the system $\mathrm{FeO}-\mathrm{Al}_{2} \mathrm{O}_{3}-\mathrm{SiO}_{2}$

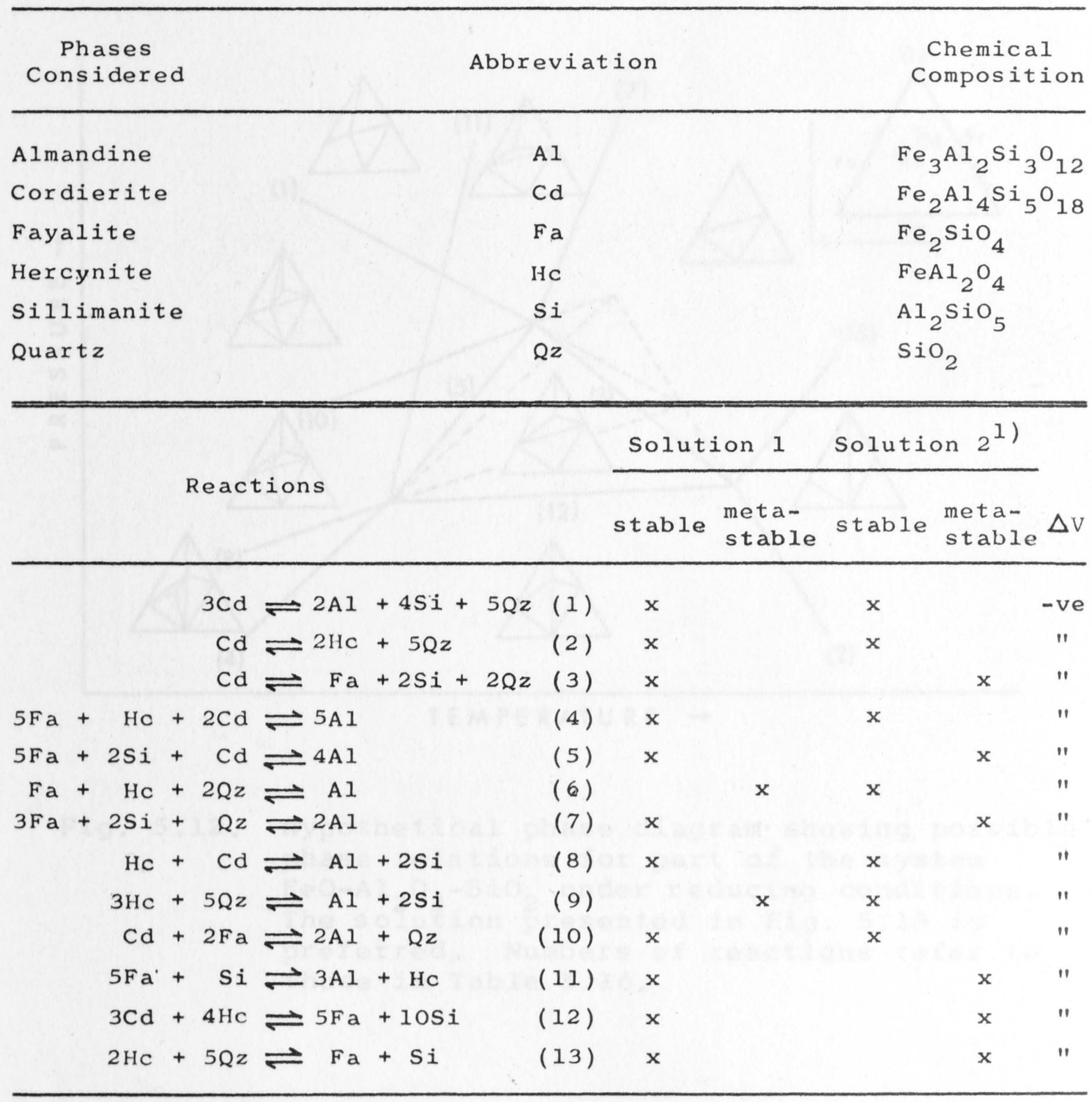

1) Solution 2 is most likely the more stable of the two (see text and fig.5.12 and 5.13). 


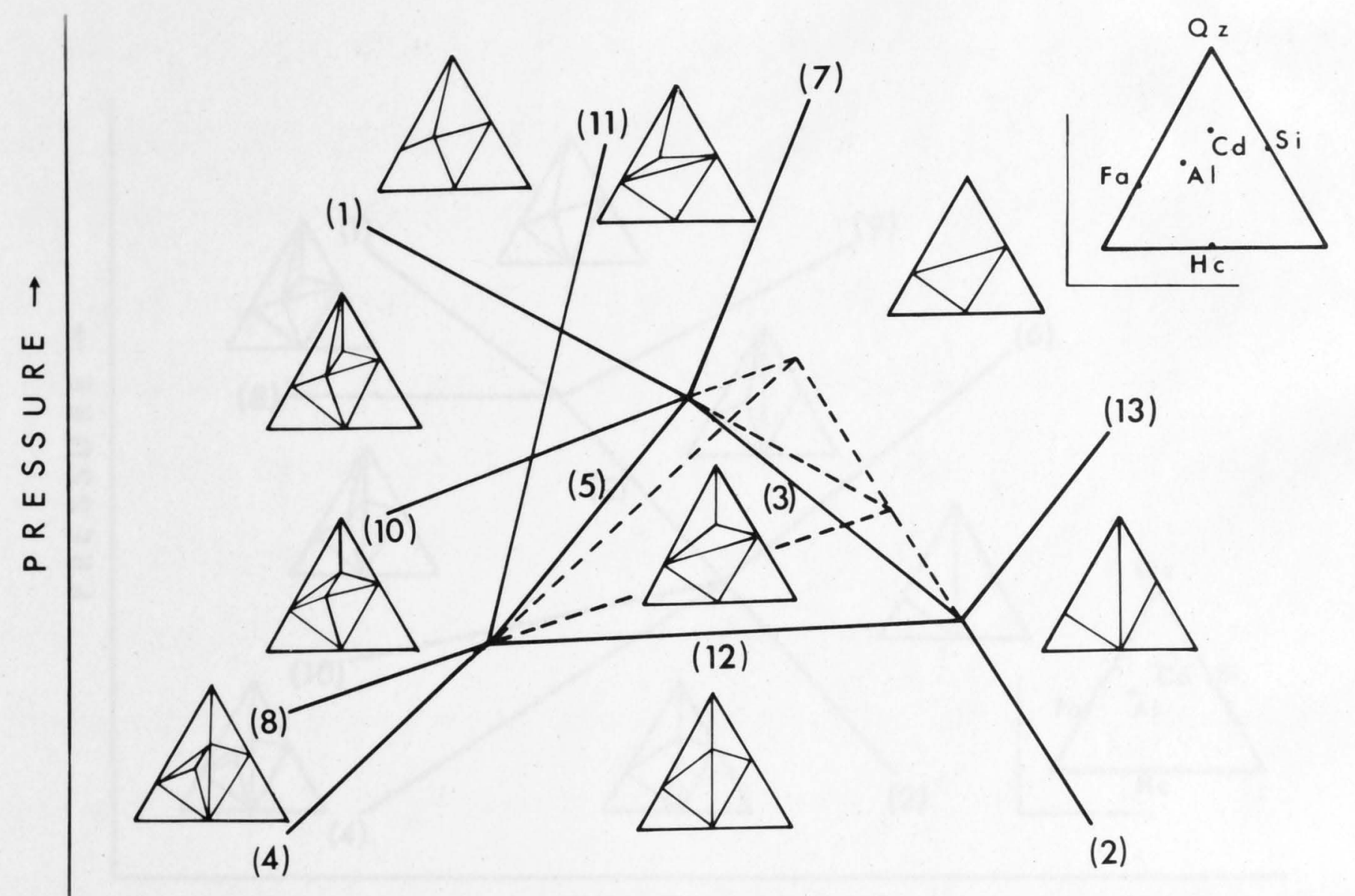

TEMPERATURE $\rightarrow$

Fig. 5.12. Hypothetical phase diagram showing possible phase relations for part of the system $\mathrm{FeO}-\mathrm{Al}_{2} \mathrm{O}_{3}-\mathrm{SiO}_{2}$ under reducing conditions. The solution presented in Fig. 5.13 is preferred. Numbers of reactions refer to those in Table 5.16. 


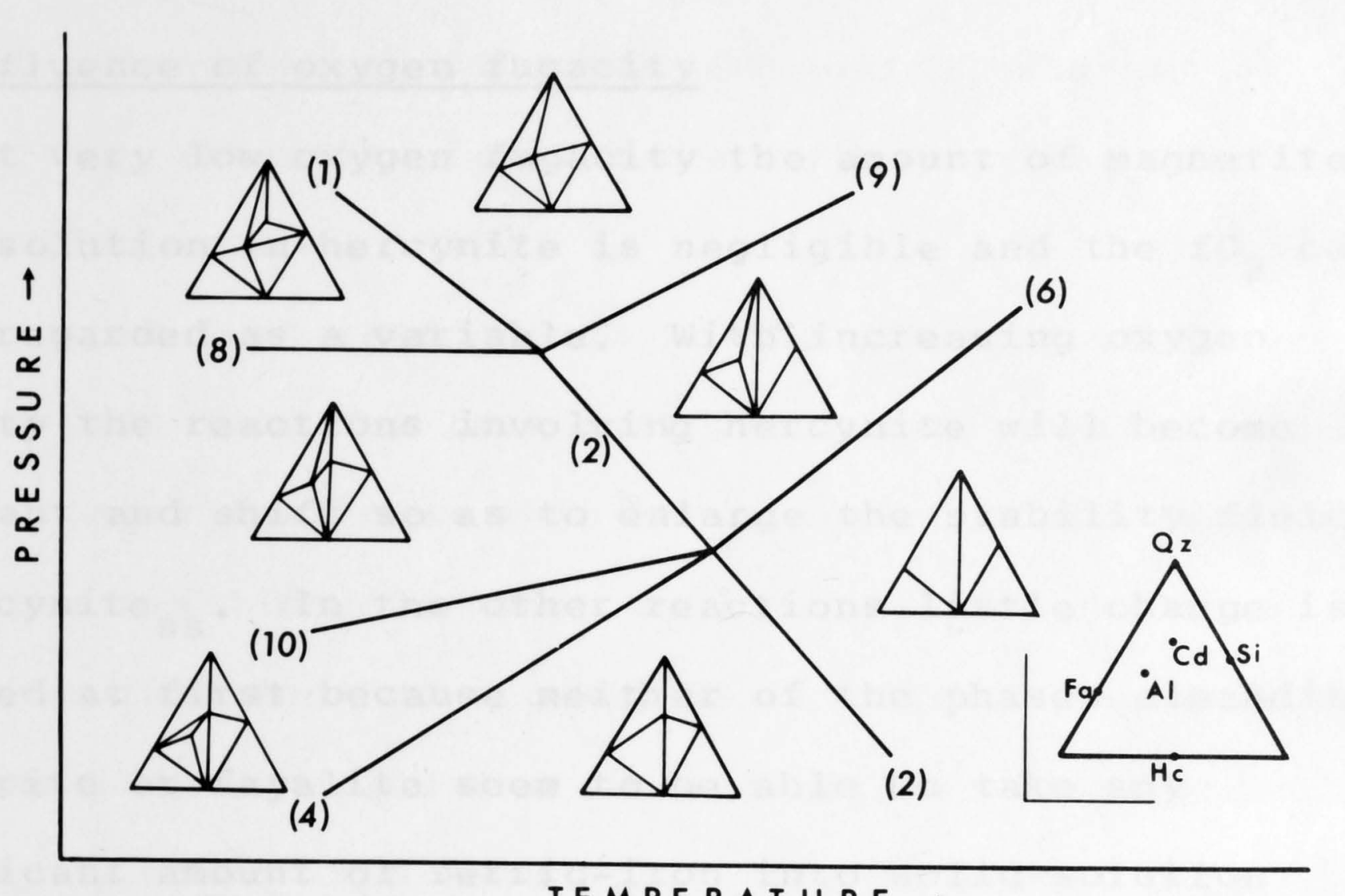


An invariant point involving the phases almandine, hercynite $s$, cordierite, fayalite and quartz has been found experimentally by Hsu (1968). Therefore the solution of Figure $5.13^{1}$ ) which incorporates a stable invariant point at which these phases coexist, is preferred as the more likely phase diagram for this system.

\section{The influence of oxygen fugacity}

At very low oxygen fugacity the amount of magnetite solid solution in hercynite is negligible and the $\mathrm{fO}_{2}$ can be disregarded as a variable. With increasing oxygen fugacity the reactions involving hercynite will become divariant and shift so as to enlarge the stability field of hercynitess. In the other reactions little change is expected at first because neither of the phases almandine, cordierite or fayalite seem to be able to take any significant amount of ferric-iron into solid-solution (compare Hsu, 1968). However, when the $\mathrm{fO}_{2}$ is increased beyond a certain fixed value at any temperature (or total pressure), hercynite-magnetite ss will appear as an additional phase. This univariant situation ${ }^{2}$ ) is represented by a line

1) The reactions that are stable in either solution have been indicated in Table 5.16.

2) On a $\mathrm{P}_{\text {total }}$-T diagram where $\mathrm{fO}_{2}$ is fixed by a buffer this willalconstitute an invariant point. 
in $\mathrm{P}, \mathrm{T}, \mathrm{fO}_{2}$ space. The composition of the hercynites continually changes along this line.

When we further increase the $\mathrm{fO}_{2}$ (at constant $\mathrm{P}$ and T) one of the ferrous phases has to disappear from the reaction. This is illustrated by the breakdown reaction for cordierite. At low oxygen fugacity cordierite breaks down to almandine, sillimanite and quartz, whereas at higher $\mathrm{fO}_{2}$, almandine is replaced by hercynite ss $_{\text {and }}$ quartz (Richardson, 1968).

Another important change to the geometry of Figure 5.13 results from the fact that cordierite, spinel and quartz are no longer co-linear when the spinel contains magnetite s. $^{*}$ Therefore reaction (2) which is a degenerate reaction, splits up into two non-degenerate reactions, one of which involves almandine and the other fayalite. The resulting topologyis shown in Figure 5.14. The invariant point ${ }^{1}$ ) (Fa') has been proposed by Richardson (1968). The point (Si') has been theoretically treated by Rutherford (1968) and Hsu (1968).

Each of the divariant reactions involving hercynitess constitute a "sliding" buffer assemblage (represented by a curved surface in $\mathrm{P}, \mathrm{T}, \mathrm{fO}_{2}$ space). The oxygen fugacities

1) Invariant for a fixed $\mathrm{fO}_{2}$. 


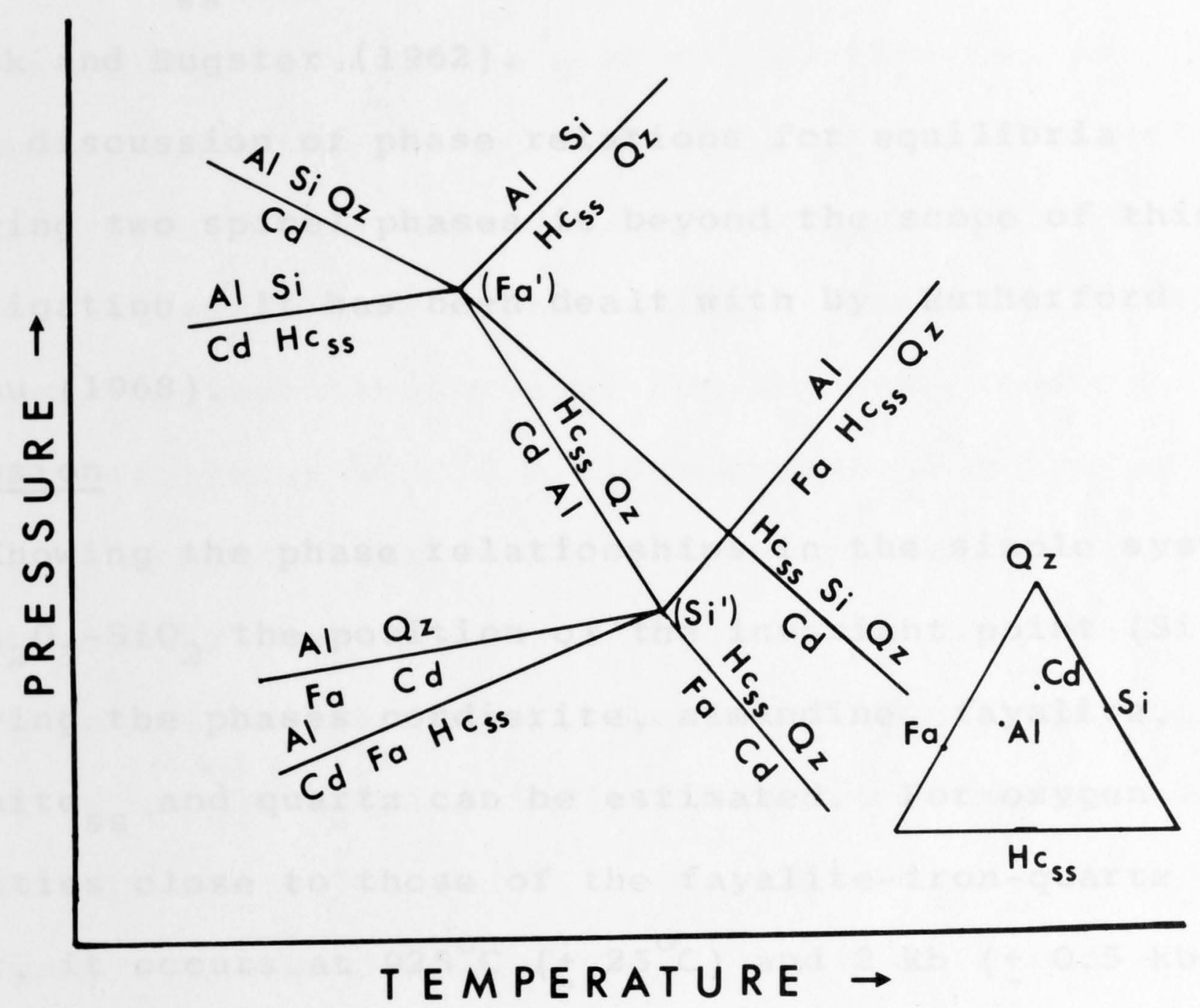

Fig. 5.14. Hypothetical phase diagram for part of the system FeO-AI ${ }_{2} \mathrm{O}_{3}-\mathrm{SiO}_{2}$ in a buffered state. Conditions are more oxidising than for Fig. 5.13. All reactions involving $\mathrm{HC}_{\text {ss }}$ also involve oxygen. 
determined by any of these equilibria (involving either of the phases almandine, cordierite, sillimanite, fayalite and quartz) will be intermediate between those fixed by the assemblages hercynite ${ }_{\text {ss }}+$ corundum, and hercynite $_{s}+$ iron (or hercynitess + iron + wüstite etc.) as determined by Turnock and Eugster (1962).

A discussion of phase relations for equilibria involving two spinel phases is beyond the scope of this investigation. It has been dealt with by Rutherford (1968) and Hsu (1968).

$\underline{\text { Discussion }}$

Knowing the phase relationships in the simple system FeO-Al ${ }_{2} \mathrm{O}_{3}-\mathrm{SiO}_{2}$ the position of the invariant point (Si') involving the phases cordierite, almandine, fayalite, hercynitess and quartz can be estimated. For oxygen fugacities close to those of the fayalite-iron-quartz buffer, it occurs at $925^{\circ} \mathrm{C}\left( \pm 25^{\circ} \mathrm{C}\right)$ and $2 \mathrm{~kb}( \pm 0.5 \mathrm{~kb})$ (Figure 5.11).

The location of this invariant point has been arrived at by combining the data of Hsu (1968) and the present experimental reversal at $1050^{\circ} \mathrm{C}$. To obtain a solution which is consistent with both sets of experimental data, it is necessary to take the least slope (dP/dT) for the breakdown of almandine (reaction 4) allowed by Hsu's data (Hsu, 1968; Table 4). The $\mathrm{fO}_{2}$ in Hsu's experiments was 
buffered by the iron-fayalite-quartz buffer. The spinel, formed at $886^{\circ} \mathrm{C}$ and $1.5 \mathrm{~kb}$, has ca. 8 mole $\%$ magnetite $\mathrm{ss}$ which is comparable to the values obtained in the present work. The flat slope is necessary because a steeper slope such as that proposed by Hsu, would require the slope of reaction (6) to be less than that of reaction (4) for consistency with the point at $1050^{\circ} \mathrm{C}, 5.4 \mathrm{~kb}$ (this work). This is theoretically impossible (see Figures 5.11 and 5.13). It also follows from the above discussion that the discrepancy between the data of Hsu and the present piston cylinder results at $1050^{\circ} \mathrm{C}$ would increase if a pressure correction greater than $-10 \%$ would be applied to the piston cylinder results. This suggests that at low pressure, in long duration experiments, the proportional pressure not correction $\operatorname{may}_{\wedge}$ be significantly different from that required at higher pressure.

The present estimate of the isobaric invariant point (Si') at $2 \mathrm{~kb}$ lies at higher temperature (ca. $925^{\circ} \mathrm{C}$ ) and lower $\mathrm{fO}_{2}$ (ca. $10^{-17}$ bars) than that estimated by Hsu (his point O, Figure 9), which lies at approximately $870^{\circ} \mathrm{C}$ $10^{-16}$ bars.

Reaction (10) which passes through the same univariant point (Figures 5.11 and 5.13) is probably not affected very much by a change in $\mathrm{fO}_{2}$ until one of the participating phases breaks down due to oxidation. The occurrence of almandine 
and quartz at $900^{\circ} \mathrm{C}, 1.8 \mathrm{~kb}$ is consistent with the present choice of the invariant point (the assemblage should have been cordierite + fayalite according to the phase diagram of $\mathrm{Hsu})$.

Under pyroxene hornfels facies conditions (600 - $\left.700^{\circ} \mathrm{C}\right)$ pure almandine, sillimanite and quartz can only occur at pressures greater than 2 to $4 \mathrm{~kb}$ (Richardson, 1968), but the formation of the assemblage almandine + quartz probably does not require more than 0.5 to $1 \mathrm{~kb}$ under these conditions. The presence of $\mathrm{Ca}$ or Mn lowers the minimum pressure limit for the appear ance of almandine, while the presence of Mg will move it to higher pressure. If the assumption that both almandine and cordierite have negligible $\mathrm{Fe}^{3+}$ substitution is correct, the above relationships will not be greatly influenced by oxygen fugacity. Strong oxidation will lead to the formation of spinel phases and eventually to the breakdown of cordierite and garnet.

\subsection{P-T-X RELATIONS FOR B-SERIES OF COMPOSITIONS}

The experimental and analytical evidence obtained for the B-series of compositions ${ }^{1}$ ) have been combined for the construction of a number of isothermal P-X diagrams. Extrapolation between the different members of the B-series

1) Chapters 5.1 to 5.5 . 
allows the prediction of $\mathrm{P}-\mathrm{T}-\mathrm{X}$ relations for the entire compositional range of this series. The type of information used for the construction of the diagrams is the same as that discussed in Chapter 4.3. In the B-series, however, two divariant reactions, involving three ferromagnesian minerals are encountered, and this introduces some additional complications. A detailed discussion of divariant reactions with three solid solutions is given in Chapter 3.3. It should suffice here to emphasize that in the P-X diagrams for this type of divariant equilibria, the curves representing the change in composition of the coexisting phase do not, as a rule, also define the boundaries of the divariant stability field, as they do in divariant equilibria with only two ferromagnesian solid solutions. ${ }^{1}$ )

In the B-series cordierite and hypersthene are not in the correct proportions to yield garnet and quartz, cordierite being in excess. As a result the reactions already dealt with in Chapter 4.3 occur in addition to the reactions involving hypersthene, which are characteristic for this series. In the following P-X diagrams the phase relations unique to this series have been indicated in heavy lines, whereas the remaining boundaries, discussed previously, are shown as thin dashed lines.

1) Chapter 4.3 . 


\section{$1100^{\circ} \mathrm{C}(\mathrm{Fig} \cdot 5.15)$}

The P-X diagram is somewhat complicated because cordierite and hypersthene are not in the correct proportions to yield garnet and quartz by the reaction

$$
\mathrm{Cd}+4 \mathrm{Hy} \rightleftharpoons 2 \mathrm{Ga}+3 \mathrm{Qz}
$$

As a result, cordierite persists on the high pressure side of the divariant field containing the assemblage Cd-Hy-Ga-Qz The cordierite breaks down eventually to either spinel plus quartz by the divariant reaction

$$
\mathrm{Cd} \rightleftharpoons \mathrm{SP}+\mathrm{Qz}
$$

or, for a small range of very magnesian bulk compositions, to sapphirine plus quartz by the reaction

$$
\mathrm{Cd} \rightleftharpoons \mathrm{Sa}+\mathrm{Qz}
$$

Similarly, for the divariant field Ga-Hy-Sa-Qz, Ga-Sa-Qz will persist at the high pressure side of this field and sapphirine will eventually break down by reaction

$$
\mathrm{Sa}+\mathrm{Qz} \rightleftharpoons \mathrm{Ga}+\mathrm{Si}
$$

For clarity of representation, the curved boundaries limiting the stability fields of the divariant assemblages with three solid solutions (reactions (6) and (7)) have been omitted from the diagram. Both the incoming of garnet and the disappearance of hypersthene for any composition in the B-series will fall inside the $\mathrm{X}_{\mathrm{Cd}}$ and $\mathrm{X}_{\mathrm{Ga}}$ curves (heavy lines in Figure 5.15). The deduced boundaries for the divariant fields in the $\mathrm{B}_{70}$ and $\mathrm{B}_{50}$ composition are 


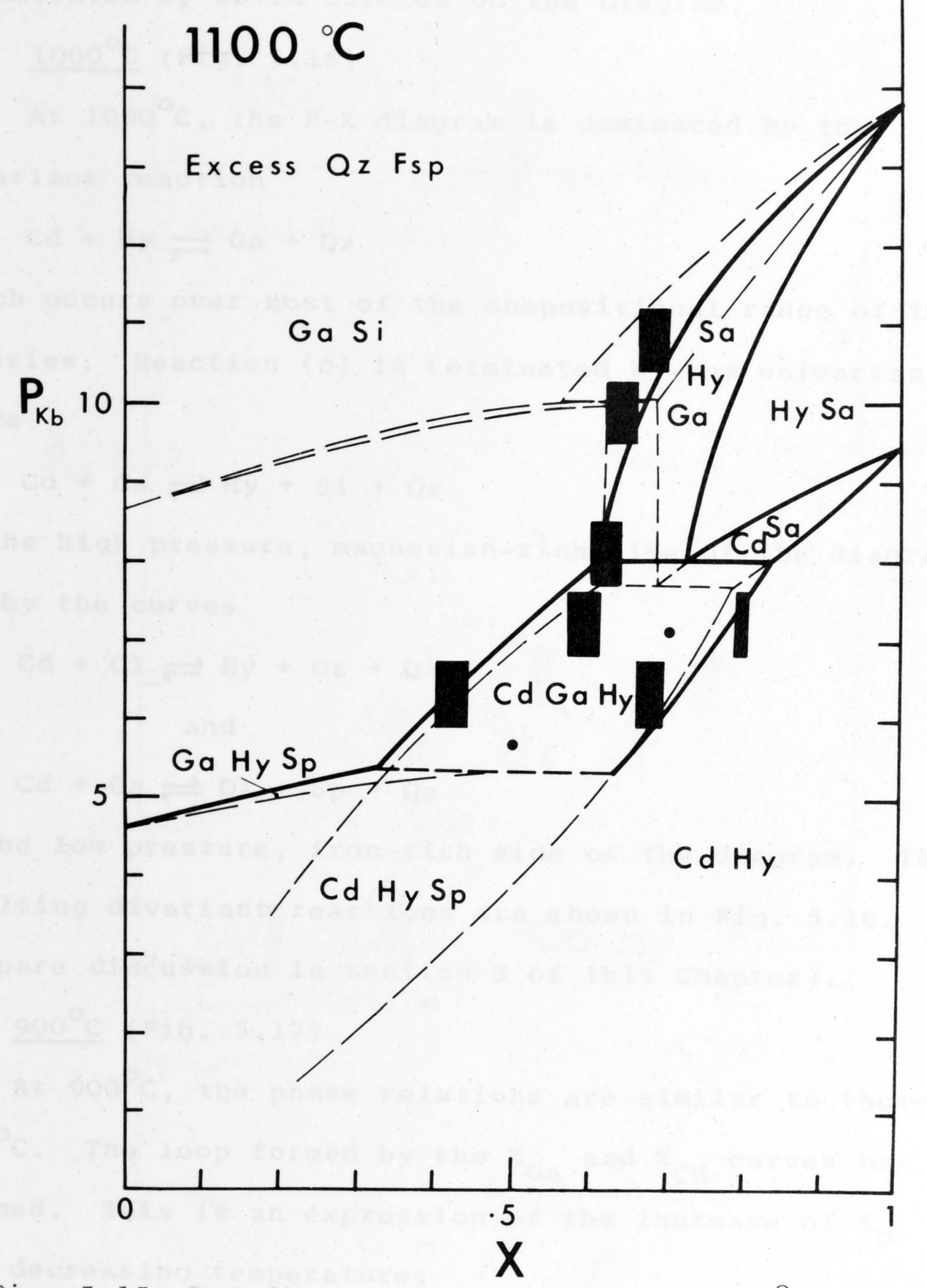

Fig. 5.15. P-X diagram for B-series at $1100^{\circ} \mathrm{C}$. Heavy lines: equilibria applicable only to the B-series. Light dashed lines: phase boundaries taken from the C-series (Fig, 4.14). These are applicable to the B-series above the disappearance of hypersthene, where sillimanite is formed from the breakdown of cordierite. Solid circles: appearance of garnet. Solid rectangles: $\mathrm{X}_{\mathrm{Cd}}$ and $\mathrm{X}_{\mathrm{Ga}}$ (compositional range and pressure uncertainty shown). 
represented by solid circles on the diagram.

$$
1000^{\circ} \mathrm{C}(\mathrm{Fig} \cdot 5.16)
$$

At $1000^{\circ} \mathrm{C}$, the $\mathrm{P}-\mathrm{X}$ diagram is dominated by the

divariant reaction

$$
\mathrm{Cd}+\mathrm{Hy} \rightleftharpoons \mathrm{Ga}+\mathrm{Qz}
$$

which occurs over most of the compositional range of the B-series. Reaction (6) is terminated by the univariant curve

$$
\mathrm{Cd}+\mathrm{Ga} \rightleftharpoons \mathrm{Hy}+\mathrm{Si}+\mathrm{Qz}
$$

on the high pressure, magnesian-rich side of the diagram, ${ }^{1}$ ) and by the curves

$$
\begin{aligned}
\mathrm{Cd}+\mathrm{Ol} \rightleftharpoons \mathrm{Hy}+\mathrm{Ga}+\mathrm{Qz} \\
\text { and } \\
\mathrm{Cd}+\mathrm{Ga} \rightleftharpoons \mathrm{Ol}+\mathrm{Sp}+\mathrm{Qz}
\end{aligned}
$$

on the low pressure, iron-rich side of the diagram. The resulting divariant reactions are shown in Fig. 5.16. (Compare discussion in section 3 of this Chapter).

$$
\underline{900^{\circ} \mathrm{C}}(\mathrm{Fig} \cdot 5.17)
$$

At $900^{\circ} \mathrm{C}$, the phase relations are similar to those at $1000^{\circ} \mathrm{C}$. The loop formed by the $\mathrm{X}_{\mathrm{Ga}}$ and $\mathrm{X}_{\mathrm{Cd}}$ curves has widened. This is an expression of the increase of $K_{D}$ with decreasing temperature.

1) Note that the compositions of garnet and cordierite from the reactions $\mathrm{Cd}+\mathrm{Hy} \rightleftharpoons \mathrm{Ga}+\mathrm{Qz}$ (6) and $\mathrm{Cd} \rightleftharpoons \mathrm{Ga}+\mathrm{Si}+\mathrm{Qz}$ (1) coincide at the pressure of the univariant boundary. 


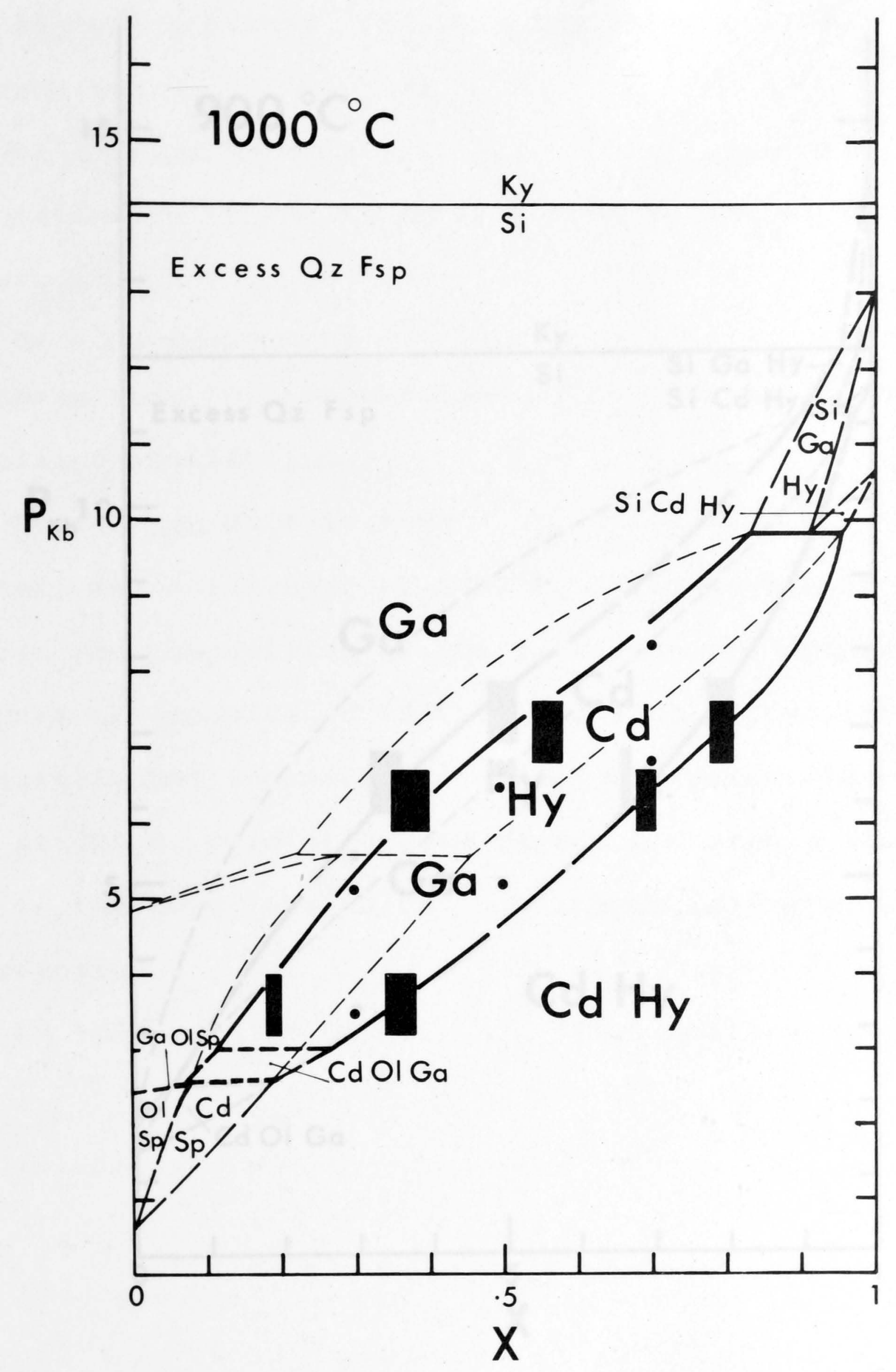

Fig. 5.16. P-X diagram for B-series at $1000^{\circ} \mathrm{C}$. Solid circles indicate the incoming of garnet and the disappearance of hypersthene. Compare Figs. 5.15 and 5.17. 


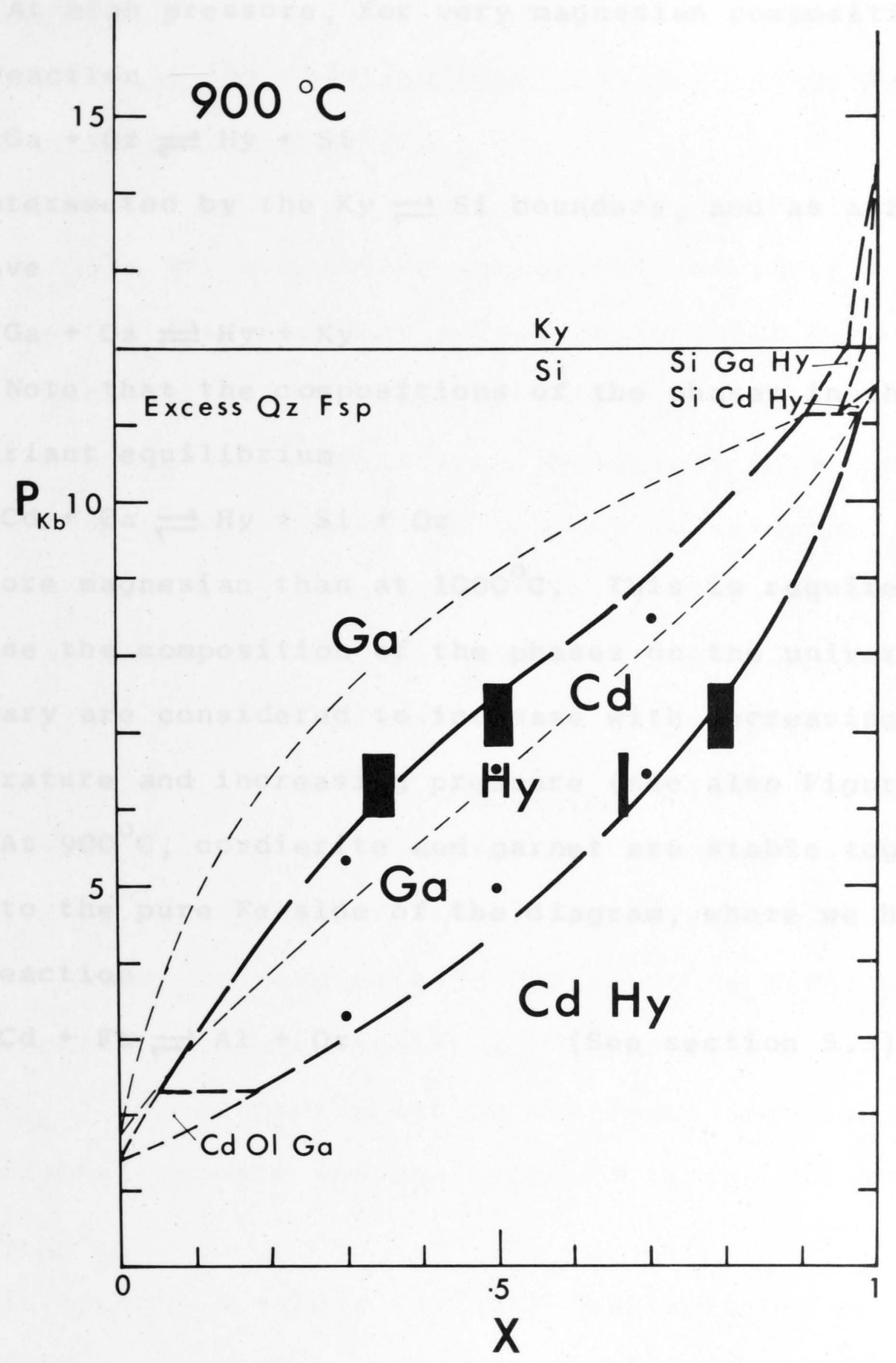

Fig. 5.17. P-X diagram for B-series at $900^{\circ} \mathrm{C}$. Solid circles indicate incoming of garnet and disappearance of hypersthene. Compare Figs. 5.15 and 5.16. 
At high pressure, for very magnesian compositions, the reaction

$$
\mathrm{Ga}+\mathrm{Qz} \rightleftharpoons \mathrm{Hy}+\mathrm{Si}
$$

is intersected by the $\mathrm{Ky} \rightleftharpoons \mathrm{Si}$ boundary, and as a result we have

$$
\mathrm{Ga}+\mathrm{Qz} \rightleftharpoons \mathrm{Hy}+\mathrm{Ky}
$$

Note that the compositions of the phases in the univariant equilibrium

$$
\mathrm{Cd}+\mathrm{Ga} \rightleftharpoons \mathrm{Hy}+\mathrm{Si}+\mathrm{Qz}
$$

are more magnesian than at $1000^{\circ} \mathrm{C}$. This is required because the composition of the phases on the univariant boundary are considered to increase with decreasing temperature and increasing pressure (see also Figure 9.1). At $900^{\circ} \mathrm{C}$, cordierite and garnet are stable together down to the pure Fe-side of the diagram, where we have the reaction

$$
\mathrm{Cd}+\mathrm{Fa} \rightleftharpoons \mathrm{Al}+\mathrm{Qz} \quad \text { (See section 5.5) }
$$




\section{APPENDIX}

The problem of the relative composition of coexisting

garnet and hercynite-spine 1 ss

Hsu and Burnham (1969) concluded from their experimental evidence that spinel has a lower $\mathrm{Mg} / \mathrm{Mg}+\mathrm{Fe}^{2+}$

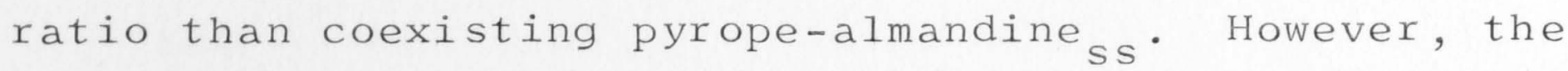
author has analysed coexisting, intimately intergrown garnet ( $94 \%$ pyrope-almandine) and hercynite-spinelss from a natural rock from Antarctica by electron microprobe and established that in this natural rock example the $\mathrm{Mg} / \mathrm{Mg}+\mathrm{Fe}^{2+}$ ratio is higher in the spinel phase $\left(\mathrm{X}_{\mathrm{Ga}}=36\right.$ and $\left.\mathrm{X}_{\mathrm{Sp}}=41 \mathrm{i} \cdot \mathrm{e} \cdot \mathrm{K}_{\mathrm{D}(\mathrm{Sp}-\mathrm{Ga})}=1.2\right)$. Another example in which $\mathrm{X}_{\mathrm{Ga}}<\mathrm{X}_{\mathrm{Sp}}$ is provided by coexisting minerals in the Cortlandt (N.Y.) hornfelses, Barker (1964).

It cannot be deduced with certainty from the present experimental evidence whether $\mathrm{X}_{\mathrm{Sp}}$ is greater or smaller than $\mathrm{X}_{\mathrm{Ga}}$. As has been shown in the foregoing, the experimental results are consistent with the assumption that $\mathrm{x}_{\mathrm{Sp}}>\mathrm{x}_{\mathrm{Ga}}$.

It appears possible that the distribution of $\mathrm{Fe}^{2+}$ and $\mathrm{Mg}$ in very Fe-rich bulk compositions is significantly influenced by oxygen fugacity. Since the experiments by Hsu and Burnham (1969) were carried out under more oxidizing conditions (QFM buffer) than the present 
experiments, their conclusions are not necessarily

inconsistent with the assumption of $\mathrm{x}_{\mathrm{Sp}}>\mathrm{X}_{\mathrm{Ga}}$ made in this thesis. 


\section{CHAPTER 6 \\ PHASE RELATIONS IN A 70 COMPOSITION}

Starting material

$\begin{array}{lll}\mathrm{SiO}_{2} & - & 54.84 \\ \mathrm{Al}_{2} \mathrm{O}_{3} & - & 17.90 \\ \mathrm{FeO} & - & 9.55 \\ \mathrm{MgO} & - & 12.50 \\ \mathrm{CaO} & - & 2.65 \\ \mathrm{Na}_{2} \mathrm{O} & - & 1.18 \\ \mathrm{~K}_{2} \mathrm{O} & - & 1.35 \\ & & 99.97\end{array}$

The starting material used was composed of:

10\% low pressure assemblage crystallized at ca. $1000^{\circ} \mathrm{C}, 4.5 \mathrm{~kb}$, consisting of aluminous hypersthene and a trace of cordierite and feldspars.

10\% high pressure assemblage crystallized at $1125^{\circ}$, $18 \mathrm{~kb}$, consisting of major garnet, hypersthene and quartz, and a trace of feldspar. $80 \%$ glass.

One run was carried out with 50\% low pressure assemblage and $50 \%$ high pressure assemblage as starting $\operatorname{mix}$

For comparison, the results of a number of experimental runs using glass only as starting material are also reported 
in this chapter. These results are very different from those obtained by the seeded glass method.

Experimental data

Results of the experiments are listed in Table 6.1 and the phase relations are illustrated in Figure 6.1. The low pressure runs yielded mineral assemblages which differ from those in the ${ }^{B_{70}}$ composition in an unexpected way. The minerals hypersthene, cordierite, osumilite ${ }^{1}$ ) and feldspars ocur together. The reason for the appearance of osumilite together with cordierite in this composition is not understood. Unfortunately, the composition of the osumilite, which forms thin prismatic crystals, could not be determined with the microprobe because of its small grain size.

The amount of osumilite is small at low pressure, and increases at higher pressure. It disappears at a pressure close to that for the incoming of garnet (Fig.6.1). At $1100^{\circ} \mathrm{C}, 7.2 \mathrm{~kb}$ cordierite is below the $\mathrm{x}-\mathrm{ray}$ detection limit and osumilite is quite abundant, while a small amount of garnet is also present. At $1100^{\circ} \mathrm{C}, 8.1 \mathrm{~kb}$, garnet has distinctly increased and neither cordierite nor osumilite was observed. A run at $1000^{\circ} \mathrm{C}, 6.3 \mathrm{~kb}$ gave an

1) General formula for osumilite is: ( $\mathrm{K}, \mathrm{Na}, \mathrm{Ca})\left(\mathrm{Mg}, \mathrm{Fe}^{2+}\right)_{2}$ $\left(\mathrm{Al}, \mathrm{Fe}^{3+}\right)_{3}(\mathrm{Si}, \mathrm{Al})_{12} \mathrm{O}_{30^{\circ}}$ 
TABLE 6.1

Experimental data for $A_{70}$ composition

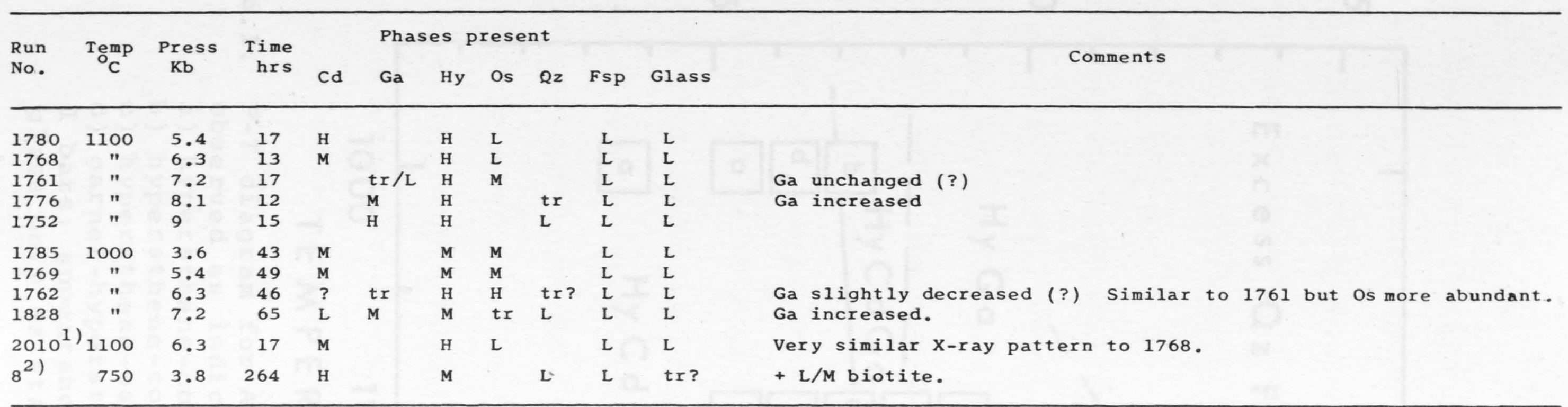

1) Run using starting material of 50/50 mix of low and high pressure assemblage

2) $\mathrm{fO}_{2}$ in magnetite field, probably close to quartz-fayalite-magnetite buffer

Relative proportions of the phases are indicated by: $\mathrm{H}=\mathrm{high}$

$M=$ medium

$\mathrm{L}=$ low

tr $=$ trace 


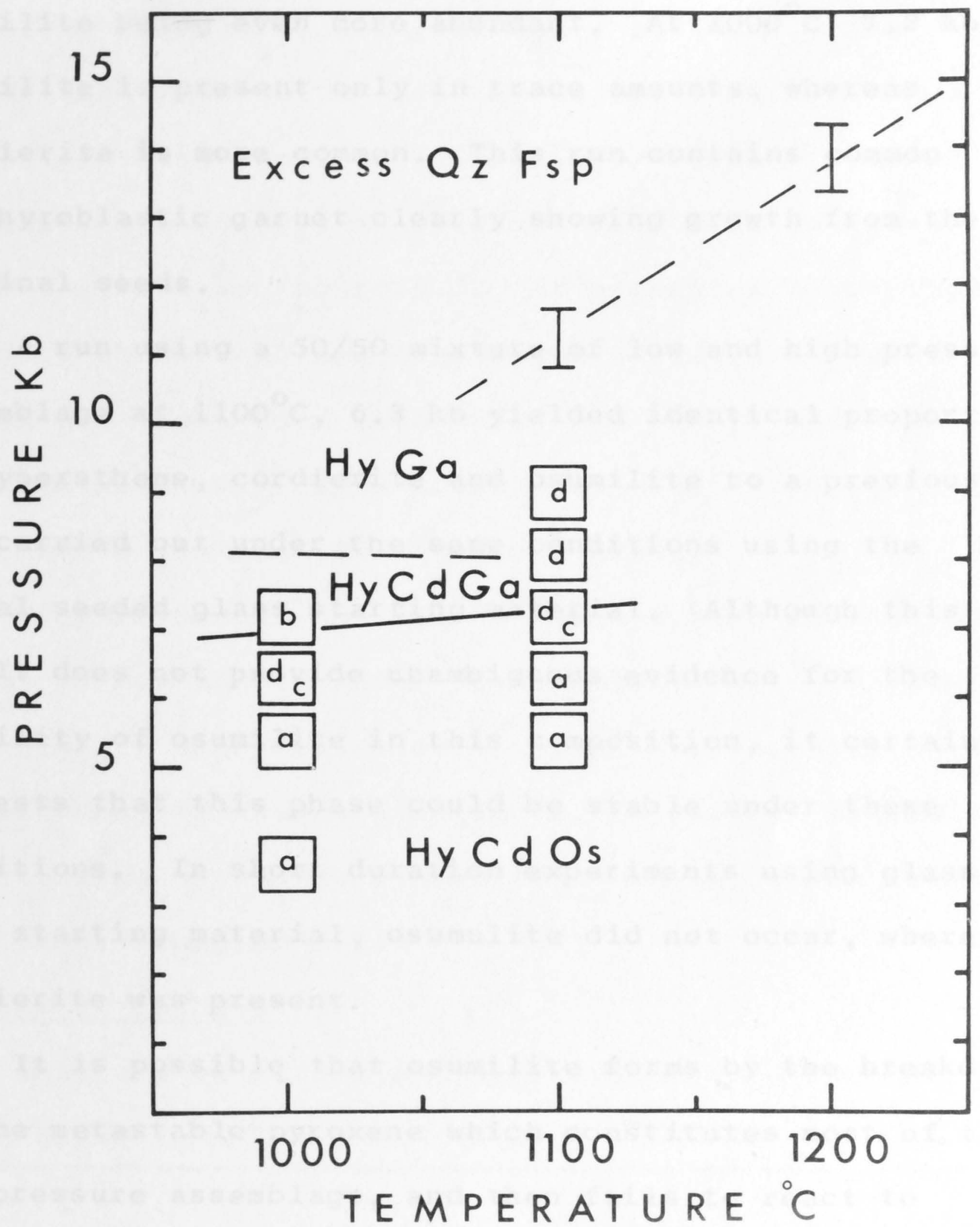

Fig. 6.1. P-T diagram for $A_{70}$ composition. Assemblages observed as indicated by letters

a) hypersthene-cordierite-osumilite-quartz

b) hypersthene-cordierite-garnet-quartz

c) hypersthene-osumilite-quartz

d) garnet-hypersthene-quartz.

I bars: appearance of garnet in runs using glass only as starting material. 
almost identical result to the $1100^{\circ} \mathrm{C}, 7.2 \mathrm{~kb}$ run, osumilite being even more abundant. At $1000^{\circ} \mathrm{C}, 7.2 \mathrm{~kb}$ osumilite is present only in trace amounts, whereas cordierite is more common. This run contains common porphyroblastic garnet clearly showing growth from the original seeds.

A run using a $50 / 50$ mixture of low and high pressure assemblage at $1100^{\circ} \mathrm{C}, 6.3 \mathrm{~kb}$ yielded identical proportions of hypersthene, cordierite and osumilite to a previous run carried out under the same conditions using the normal seeded glass starting material. Although this result does not provide unambiguous evidence for the stability of osumilite in this composition, it certainly suggests that this phase could be stable under these conditions. In short duration experiments using glass only as a starting material, os umulite did not occur, whereas cordierite was present.

It is possible that osumilite forms by the breakdown of the metastable pyroxene which constitutes most of the low pressure assemblage, and then fails to react to cordierite + feldspars. Note that os umilite coexists with cordierite and that its abundance seems to be a function of pressure. If it were metastable, this behaviour would not be expected. 
At $1100^{\circ} \mathrm{C}, 8.1$ and $9 \mathrm{~kb}$, the assemblage garnet-hypersthene-quartz-feldspars is found. The proportion of garnet is greater in the $9 \mathrm{~kb} r u n$. For comparison, the incoming of the first trace of garnet (detected optically), as obtained from runs on glass, has been shown in Figure 6,1. At pressures below this boundary the assemblage hypersthene-feldspars + quartz is found. Since no sillimanite is present, the metastable hypersthene must be highly aluminous. The calculated hypersthene contains 17.66 mole $\% \mathrm{Al}_{2} \mathrm{O}_{3}$.

A hydrothermal run at $750^{\circ} \mathrm{C}$ and $3.8 \mathrm{~kb}$ showed that garnet is not stable under these conditions. In this run, biotite appeared, coexisting with cordierite, hypersthene, feldspars and quartz. A similar assemblage (but lacking hypersthene) was found in $B_{70}$ under these conditions (Chapter 5.1).

Analytical results

Analyses of garnet and hypersthene from one run are given below

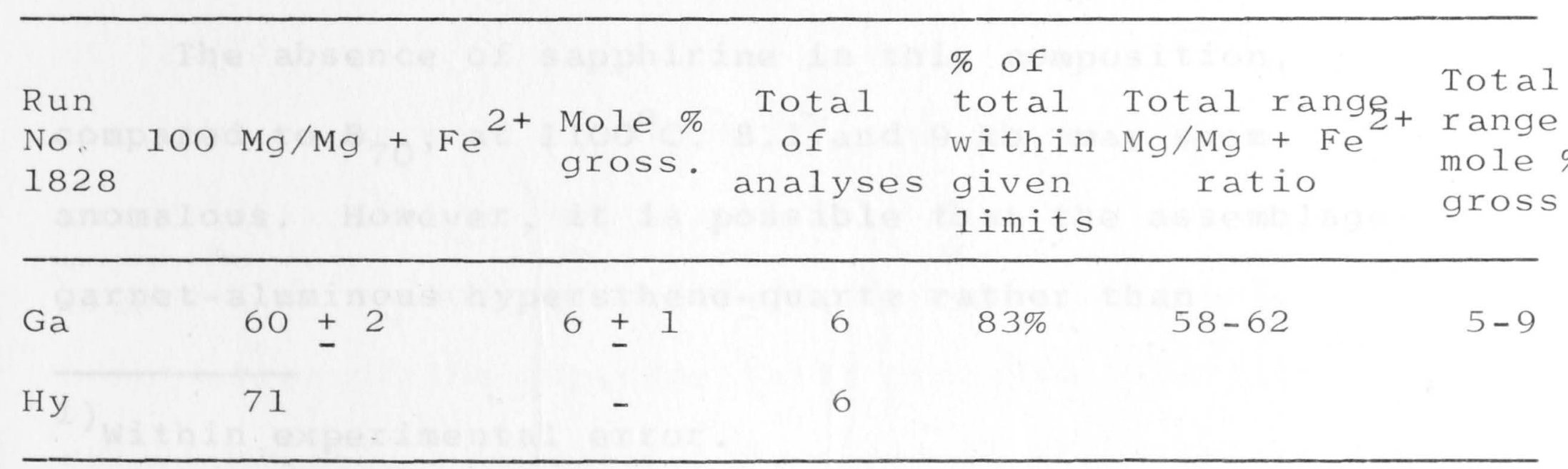


Discussion of the results

Notwithstanding the unexpected appear ance of another phase, i.e. osumilite, in this composition, the incoming of garnet occurs at approximately the same pressure and temperature ${ }^{1}$ ) as in $B_{70}$. This indicates that the theoretically predicted effect of the $\mathrm{Al}_{2} \mathrm{O}_{3} / \mathrm{FeO}+\mathrm{MgO}$ ratio of the bulk composition $((A / F+M) b$, Chapter 3.2), cannot be very large. Since $(\mathrm{A} / \mathrm{F}+\mathrm{M})_{\mathrm{A}_{70}}<(\mathrm{A} / \mathrm{F}+\mathrm{M})_{\mathrm{B}_{70}}$, the garnet in $A_{70}$ should appear at higher pressure than in $\mathrm{B}_{70}$, and also should be more magnesian than the first garnet to appear in the latter composition. Apparently the predicted differences are too small to be detected by the present methods.

The composition of the garnet at $1000^{\circ} \mathrm{C}$ and $7.2 \mathrm{~kb}$ is close to that observed in $B_{70}$ under the same conditions $\left(100 \mathrm{x}_{\mathrm{Ga}}=60 \pm 2\right.$, compared to $56 \pm 2$ in $\left.\mathrm{B}_{70}\right)$. The amount of grossularss is the same in both garnets. Considering the experimental uncertainties, the results are in reasonably good agreement.

The absence of sapphirine in this composition, compared to $\mathrm{B}_{70}$, at $1100^{\circ} \mathrm{C}, 8.1$ and $9 \mathrm{~kb}$, may seem anomalous. However, it is possible that the assemblage garnet-aluminous hypersthene-quartz rather than

1) Within experimental error. 
garnet-hypersthene-sapphirine-quartz is stable under

these conditions, since aluminous hypersthene is compositionally equivalent to a less aluminous hypersthene + sapphirine + quartz. The A70 bulk composition is less aluminous than $B_{70}$, and therefore no sapphirine is required to occur if a sufficiently aluminous hypersthene is stable under the above conditions. Garnet in the present composition could break down to aluminous hypersthene only if a hypersthene with 17.7 mole $\% \mathrm{Al}_{2} \mathrm{O}_{3}$ were stable (compare AFM diagram in Figure 1.1). Since no sapphirine seeds were present in the starting material used for the experiments, the present data neither prove nor disprove the stability of a highly aluminous hypersthene under these conditions. The data on aluminous enstatite in metastable equilibrium with sillimanite (Chapter 8) show that a temperature of $1300^{\circ} \mathrm{C}$ is required to produce an enstatite with 18 mole $\% \mathrm{Al}_{2} \mathrm{O}_{3}$. Since garnet is expected to disappear in $\mathrm{A}_{70}$ between 1100 and $1200^{\circ} \mathrm{C}$, it seems likely that sapphirine will be stable in this composition at $1200^{\circ} \mathrm{C}$.

The occurrence of osumilite remains an enigma. The possibility that it has a stability field in this composition cannot be excluded. Because the chemical composition of the experimentally produced osumilite is not known, it is impossible to evaluate the significance 
of its occurrence (if stable) in terms of the phase relations in the system studied. Natural osumilite has been reported from only three localities, where it occurs in cavities in volcanic rocks. Olson and Bunch (1970) have analysed samples from all three occurrences by electron microprobe. On the basis of their analyses they conclude that structural water is probably not present, as was thought previously (Miyashiro, 1965). Its association with tridymite and fayalitic olivine suggests the osumilite forms at high temperature under highly reducing conditions with $\mathrm{fO}_{2}$ below that of the quartz-fayalite-magnetite buffer. Schreyer and Seifert (1967) have suggested on the basis of an experimental investigation under hydrothermal conditions, that osumilite may be a metastable phase formed by rapid and non-equilibrium crystallisation in the sanidinite facies. They showed that synthetic osumilite of the composition $\mathrm{KMg}_{2} \mathrm{Al}_{3}\left(\mathrm{Si}_{10} \mathrm{Al}_{2} \mathrm{O}_{30}\right) \cdot \mathrm{XH}_{2} \mathrm{O}$ was not stable at $\mathrm{P}_{2} \mathrm{O}=1 \mathrm{~kb}$ and $\mathrm{T}=650-700^{\circ} \mathrm{C}$. Their results, however, do not preclude the possibility of a stability field for this phase at high temperature and low to intermediate pressure. 


\section{CHAPTER 7}

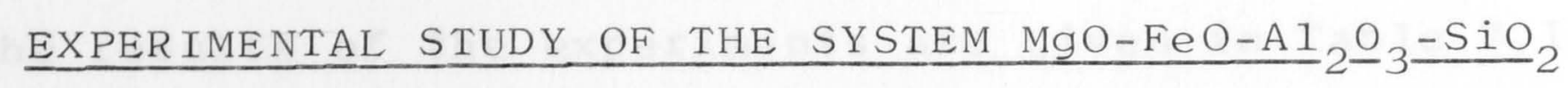

\section{$\left(\underline{B}_{70}\right.$ S COMPOSITION)}

The $\mathrm{B}_{70} \mathrm{~S}$ composition does not contain $\mathrm{CaO}, \mathrm{Na}_{2} \mathrm{O}$ and $\mathrm{K}_{2} \mathrm{O}$, but is otherwise equivalent to the $\mathrm{B}_{70}$ composition, described in Chapter 5.1. The study of this composition was undertaken to evaluate the stability of grossular free garnet. The chemical composition of $\mathrm{B}_{7 \mathrm{O}^{\mathrm{S}}}$ is given below

$$
\begin{array}{lll}
\mathrm{SiO}_{2} & -63.11 \\
\mathrm{Al}_{2} \mathrm{O}_{3} & -19.47 & 100 \mathrm{Mg} / \mathrm{Mg}+\mathrm{Fe}^{2+}=70 \\
\mathrm{FeO} & -7.54 \\
\mathrm{MgO} & -\frac{9.88}{100.00}
\end{array}
$$

The two starting materials used in this investigation are made up of crystalline materials only.

I. 10 weight \% high pressure assemblage, crystallised from glass at $1100^{\circ} \mathrm{C}-18 \mathrm{~kb}$, consisting of garnet, sillimanite and quartz.

go weight \% low pressure assemblage, crystallised from glass at $850^{\circ} \mathrm{C}-6.3 \mathrm{~kb}$, consisting of cordierite, hypersthene and quartz.

II. 40 weight \% high pressure assemblage (as above). 60 weight \% low pressure assemblage (as above). 
Experimental data

The results of the experiments are given in Table 7.1 and in Figure 7.1. At $1000^{\circ} \mathrm{C}$, the following assemblages have been encountered with increasing pressure.

$$
\begin{aligned}
& \mathrm{Cd}-\mathrm{Hy}-\mathrm{Qz} \\
& \mathrm{Ga}-\mathrm{Cd}-\mathrm{H} y-\mathrm{Q} z \\
& \mathrm{Ga}-\mathrm{Cd}-\mathrm{Qz} \text { and } \mathrm{Cd}-\mathrm{Ga}-\mathrm{Si}-\mathrm{Qz} \\
& \mathrm{Ga}-\mathrm{Si}-\mathrm{Qz}
\end{aligned}
$$

Using starting material $\mathrm{I}$, a run at $1000^{\circ} \mathrm{C}, 9.9 \mathrm{~kb}$ yielded Ga-Hy-Si-Cd-Qz. For this 5-phase assemblage to be in stable equilibrium, the run conditions must lie on a univariant phase boundary. It is more probable that one of the phases is metastable. To test this, a different starting material (II) was run under the same conditions. This run, initially with less Cd-Hy-Qz, yielded Cd-Ga-Si-Qztrace of Hy. Cordierite and garnet increased relative to the starting material, whereas sillimanite decreased and hypersthene disappeared. The run demonstrates that hypersthene is not stable relative to garnet and cordierite in the presence of sillimanite and quartz, and the assemblage Ga-Cd-Si-Qz is considered to be stable at $1000^{\circ} \mathrm{C}, 9.9 \mathrm{~kb}$. Similarly, a run at $1000^{\circ} \mathrm{C}, 10.8 \mathrm{~kb}$ using starting material (II), yielded the assemblage Ga-Si-Qz-trace of Cd. This demonstrates that $\mathrm{Ga}-\mathrm{Qz}-(\mathrm{Si})$ is stable relative to $\mathrm{Hy}-\mathrm{Si}-(\mathrm{Qz})$ under these conditions. 



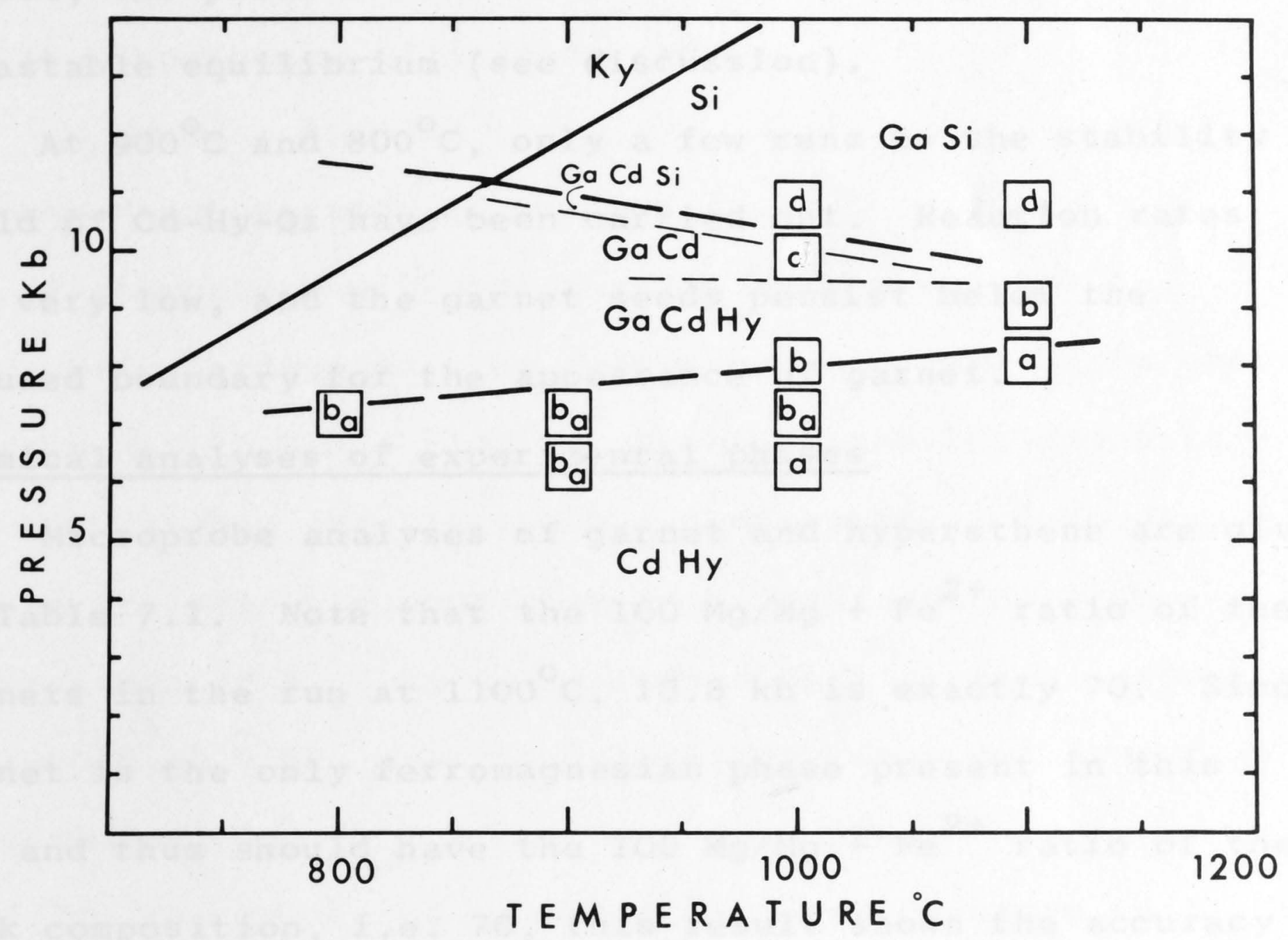

Fig. 7.1. P-T diagram for $\mathrm{B}_{70} \mathrm{~S}$ composition. Assemblages observed are indicated by letters also used in the text. 
At $1100^{\circ} \mathrm{C}$, garnet is present at $9 \mathrm{~kb}$, and cordierite disappears between 9 and $10.8 \mathrm{~kb}$. Sapphirine has not been observed in this composition. Since sapphirine was not seeded, the phase relations at $1100^{\circ} \mathrm{C}$ may represent metastable equilibrium (see discussion).

At $900^{\circ} \mathrm{C}$ and $800^{\circ} \mathrm{C}$, only a few runs in the stability field of Cd-Hy-Qz have been carried out. Reaction rates are very low, and the garnet seeds persist below the deduced boundary for the appearance of garnet. Chemical analyses of experimental phases

Microprobe analyses of garnet and hypersthene are given in Table 7.1. Note that the $100 \mathrm{Mg} / \mathrm{Mg}+\mathrm{Fe}^{2+} \mathrm{ratio}$ of the garnets in the run at $1100^{\circ} \mathrm{C}, 10.8 \mathrm{~kb}$ is exactly 70 . Since garnet is the only ferromagnesian phase present in this run and thus should have the $100 \mathrm{Mg} / \mathrm{Mg}+\mathrm{Fe}^{2+}$ ratio of the bulk composition, i.e. 70 , this result shows the accuracy of the analytical method. The garnet close to the interpreted low pressure boundary of the divariant band for the phases Ga-Cd-Hy-Qz is considerably enriched in Fe compared to the bulk composition. The distribution coefficient between hypersthene and garnet at $1100^{\circ} \mathrm{C}$ $\left(\mathrm{K}_{\mathrm{D}(\mathrm{Hy}-\mathrm{Ga})}=2 \pm 0.3\right)$ is not significantly different from that obtained in the $B_{70}$ composition.

No cordierite analyses have been obtained so that the distribution coefficients for Cd-Ga and Cd-Hy have not been determined. 
Discussion of the results

The observed changes in mineral assemblages can be explained by the divariant reactions

$$
\mathrm{Cd}+\mathrm{Hy} \rightleftharpoons \mathrm{Ga}+\mathrm{Qz}
$$

for the appearance of garnet, and

$$
\mathrm{Cd} \rightleftharpoons \mathrm{Ga}+\mathrm{Si}+\mathrm{Qz}
$$

for the disappearance of cordierite.

A comparison with the results on the complex ${ }^{B_{70}}$ composition brings out the following important differences. Firstly, at 1000 and $1100^{\circ} \mathrm{C}$, garnet appears at a pressure ca. $1 \mathrm{~kb}$ higher than in the $\mathrm{B}_{70}$ composition. Secondly, cordierite persists stably up to a pressure ca. $1 \mathrm{~kb}$ higher than in $\mathrm{B}_{70}$, as demonstrated by a reversal experiment at $1000^{\circ} \mathrm{C}, 9.9 \mathrm{~kb}$. Lastly, sapphirine does not appear in this composition.

The occurrence of garnet at a lower pressure in $\mathrm{B}_{70}$ must

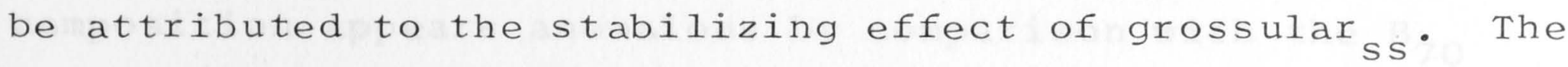
analytical data indicate that, at constant pressure and temperature, pure almandine-pyrope garnet in divariant equilibrium with cordierite, hypersthene and quartz, has a lower $\mathrm{Mg} / \mathrm{Mg}+\mathrm{Fe}^{2+}$ ratio than a garnet with $6 \pm 1$ mole $\%$ grossular ss in quasi-divariant equilibrium with the same phases and plagioclase.

The above observations clearly demonstrate that the incorporation of a relatively small amount of grossular ss 
has an important effect on the stability of garnet. This is also shown by the comparison of the $\mathrm{B}_{100}$ and $\mathrm{Py}+\mathrm{Qz}$ compositions (Chapters 5.4 and 8 ).

The observation that at $1000^{\circ} \mathrm{C}$ cordierite persists to higher pressure indicates that, in the presence of Si and Qz, a higher pressure is required to stabilize a pure almandine-pyrope garnet with $100 \mathrm{Mg} / \mathrm{Mg}+\mathrm{Fe}^{2+}=70$ than for a Ca-bearing garnet with the same $100 \mathrm{Mg} / \mathrm{Mg}+\mathrm{Fe}^{2+} \mathrm{ratio}$. At $9.9 \mathrm{~kb}$, hypersthene-sillimanite-quartz forms as a metastable breakdown product of cordierite when starting material I is used, but with starting material II (containing less cordierite and more garnet, sillimanite and quartz), hypersthene completely disappears. This is good evidence that at $1000^{\circ} \mathrm{C}$ the join Hy-si is not stable in this composition.

The total absence of sapphirine at $1100^{\circ} \mathrm{C}$ in the present composition appears anomalous by comparison with the ${ }^{B} 70$ composition. There seems to be no reason for the stability field of sapphirine-quartz to be reduced in the absence of calcium. On the contrary, one would predict a reduction of this field in the Ca-bearing composition owing to the stabilizing effect of grossular ss on garnet. The absence of sapphirine may be due to the fact that no sapphirine seeds were available in the starting material. This hypothesis is supported by a similar finding in the Py $+Q z$ 
composition (Chapter 8). Whereas in $B_{100}$ sapphirine forms readily at 1100 and $1200^{\circ} \mathrm{C}$ without seeds being present, in the Py $+Q z$ composition sapphirine could not be synthesized without seeding at temperatures up to $1350^{\circ} \mathrm{C}$. Apparently, nucleation of this phase is facilitated by the presence of either $\mathrm{CaO}$ and/or $\mathrm{Na}_{2} \mathrm{O}$ and/or $\mathrm{K}_{2} \mathrm{O}$ in the starting material. In conclusion, it should be emphasized that the present results show the important effect of the presence of plagioclase on the stability of garnet relative to cordierite, and underline the difficulty of predicting phase relationships in complex systems from simple system data. 
CHAPTER 8

STABILITY OF PYROPE-QUARTZ IN THE SYSTEM

$\underline{\mathrm{MgO}-\mathrm{Al}}_{2} \underline{\mathrm{O}}_{3} \frac{-\mathrm{SiO}_{2}}{2}$

\section{Introduction}

A composition on the join pyrope-quartz in the system $\mathrm{MgO}-\mathrm{Al}_{2} \mathrm{O}_{3}-\mathrm{SiO}_{2}$ has been studied experimentally as part of a larger project investigating phase relations in the complex system $\mathrm{MgO}-\mathrm{FeO}-\mathrm{Al}_{2} \mathrm{O}_{3}-\mathrm{SiO}_{2}-\mathrm{CaO}-\mathrm{K}_{2} \mathrm{O}-\mathrm{Na}_{2} \mathrm{O}$ (Hensen and Green, 1970). Schreyer and Seifert (1969 a,b) have recently presented a comprehensive study of the system $\mathrm{MgO}-\mathrm{Al}_{2} \mathrm{O}_{3}-\mathrm{SiO}_{2}-\mathrm{H}_{2} \mathrm{O}$. This chapter provides some additional experimental data and discusses their implications for the phase diagram of the high pressure - high temperature anhydrous part of the system.

The stability of pyrope under its own composition has been determined by Boyd and England (1959). They found that pyrope breaks down to aluminous enstatite, sapphirine and sillimanite over a temperature interval of $1100-1600^{\circ} \mathrm{C}$. Recent experimental evidence (Schreyer and Seifert, 1969a,b; Hensen and Green, 1969, 1970) suggests that most of this phase boundary where determined experimentally is metastable due to its intersection with the reaction:

aluminous enstatite + sillimanite $\rightleftharpoons$ sapphirine + quartz At temperatures above this intersection, pyrope will break 
down to aluminous enstatite, sapphirine and quartz. The reaction

pyrope + quartz $\rightleftharpoons$ aluminous enstatite + sillimanite which has been determined experimentally in this study, in part in its metastable extension, also passes through the same invariant point.

Chemical composition and starting material

The synthetic composition studied lies on the intersection of the joins enstatite-cordierite and pyrope-

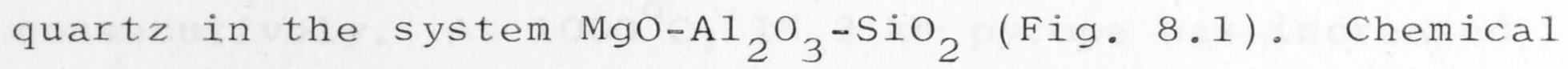
composition is as follows:

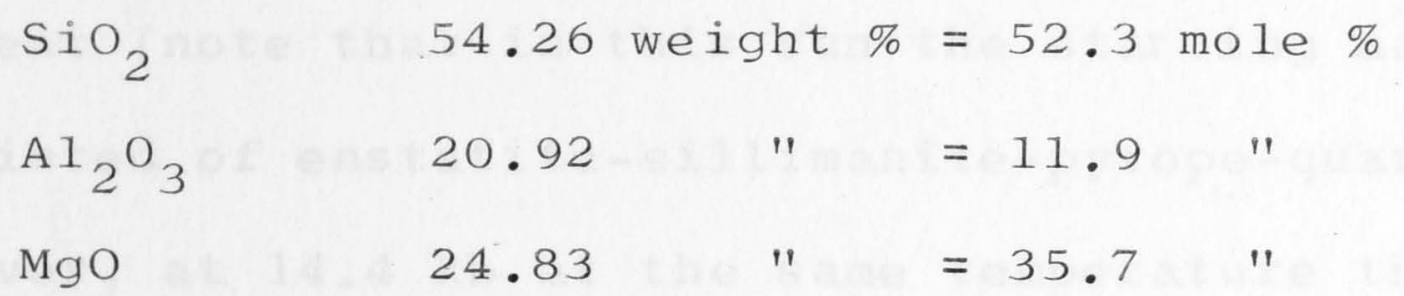

The starting material used in the experiments consists of: I. $50 \%$ finely ground oxide mix (fired at $1100^{\circ} \mathrm{C}$ for 12 hours )

$25 \%$ pyrope and quartz synthesized at $1200^{\circ} \mathrm{C}, 27 \mathrm{~kb}$ 25\% clino-enstatite + sillimanite (clino-enstatite from Tem Press INC).

Two runs at $1000^{\circ} \mathrm{C}$ were made with a starting material consisting of:

II. $80 \%$ clino-enstatite + sillimanite

10\% high pressure assemblage and two other runs with 
III. $72 \%$ clino-enstatite + sillimanite

8\% high pressure assemblage

$10 \%$ quartz

10\% kyanite

Results

Experimental data and their interpretation are given in Table 8.1 and Fig. 8.1. With increasing pressure and as semblages cordierite-aluminous enstatite-quartz, aluminous enstatite sillimanite-quartz and pyrope-quartz are found consecutively. At $1000^{\circ} \mathrm{C}, 15.3 \mathrm{~kb}$ pyrope has increased at the expense of enstatite and silimanite, which are still present (note that in this run the starting material consisted of enstatite-sillimanite-pyrope-quartz only). However, at $14.4 \mathrm{~kb}$ at the same temperature the assemblage aluminous enstatite-kyanite-minor corundum was obtained from the same starting material in a longer run. This result indicates conditions in the stability field of kyanite. The kyanite-sillimanite phase boundary at $1000^{\circ} \mathrm{C}$ is $10 \mathrm{cated}$ at $14.67 \mathrm{~kb}$ according to the preferred curve of Richardson et al. (1969). Taking experimental uncertainties into account there is no disagreement between these data. This result suggested that the growth of pyrope at $1000^{\circ} \mathrm{C}, 15.3$ $\mathrm{kb}$ at the expense of enstatite and sillimanite is a metastable process and that the assemblage aluminous enstatite and kyanite is stable under these conditions. 
TABLE 8.1

Experimental Data

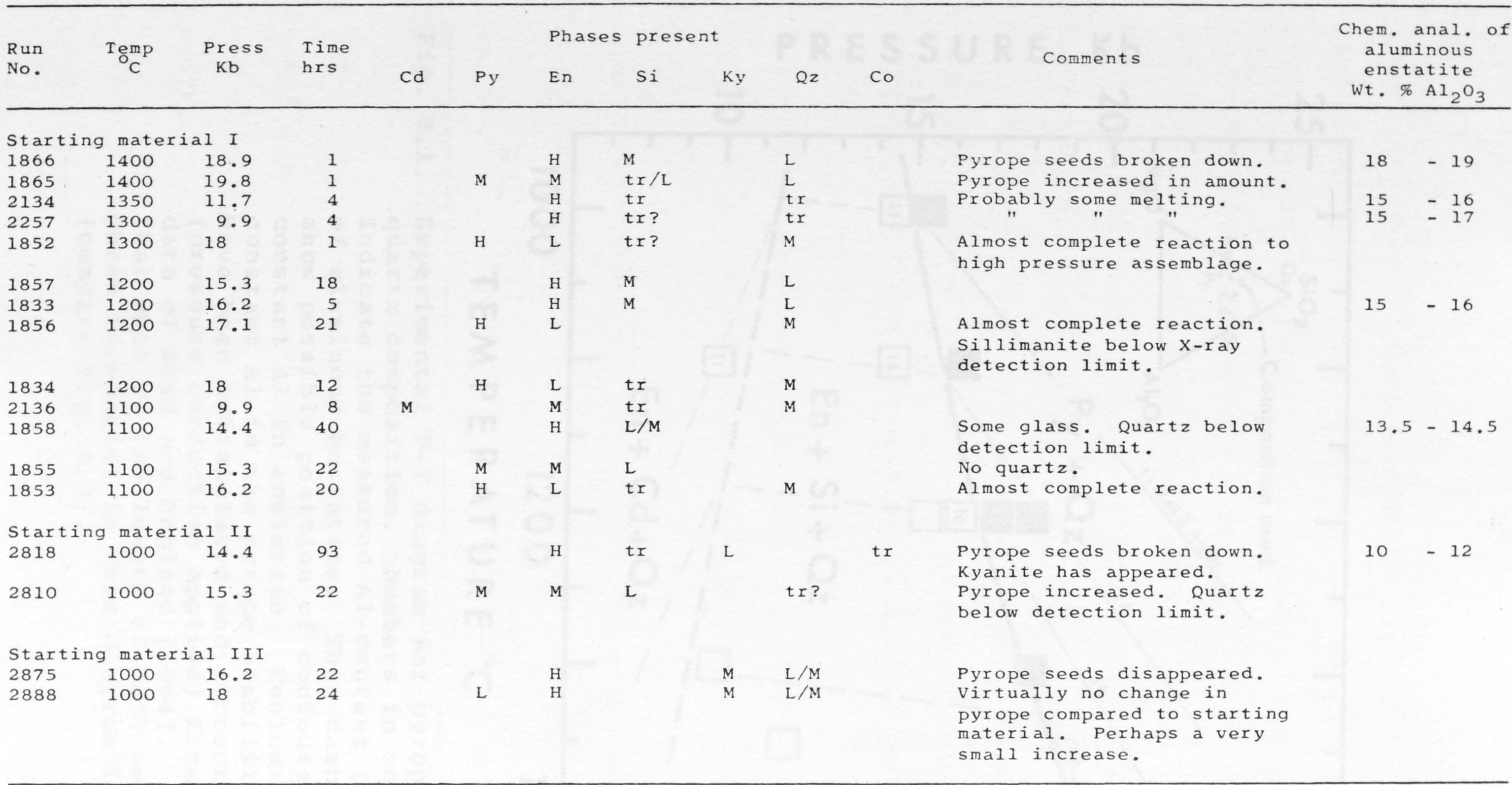

Relative proportions of the phases are indicated by: $H=$ high 


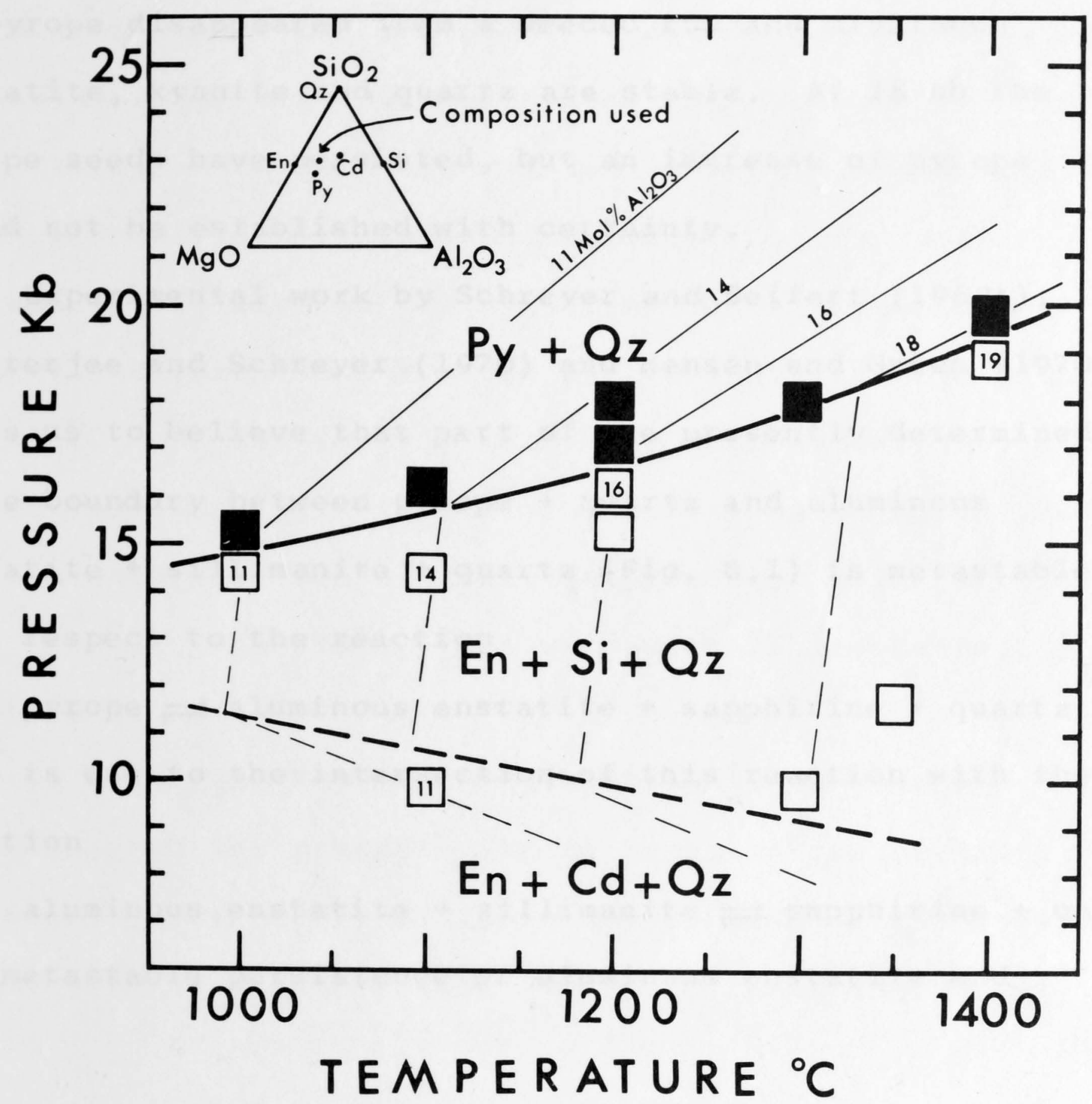

Fig. 8.1. Experimental P-T diagram for pyrope + quartz composition. Numbers in squares indicate the measured Al-content (mole \%) of aluminous enstatite. Thin dashed lines show possible position of contours for constant Al in enstatite. Contours for constant Al in the pyrope stability field have been extrapolated and corrected (pressure correction applied) from the data of Boyd and England (1964). Note that much of the length of both experimental phase boundaries in this diagram is metastable (compare Fig. 8.3). 
This has been verified experimentally. At $1000^{\circ} \mathrm{C}, 16.2$ kb pyrope disappeared from a seeded run and aluminous enstatite, kyanite and quartz are stable. At $18 \mathrm{~kb}$ the pyrope seeds have persisted, but an increase of pyrope could not be established with certainty.

Experimental work by Schreyer and Seifert (1969a), Chatter jee and Schreyer (1970) and Hensen and Green (1970) leads us to believe that part of the presently determined phase boundary between pyrope + quartz and aluminous enstatite + sillimanite + quartz (Fig. 8.1) is metastable with respect to the reaction

pyrope $\rightleftharpoons$ aluminous enstatite + sapphirine + quartz This is due to the intersection of this reaction with the reaction

aluminous enstatite + sillimanite $\rightleftharpoons$ sapphirine + quartz The metastable persistence of aluminous enstatite and sillimanite is apparently due to the failure of sapphirine to nucleate spontaneously in short duration runs in this part of the system.

The experimental data marking the breakdown of pyrope + quartz fit a slightly curved boundary. This is consistent with the observation that the alumina content of enstatite is strongly temperature dependent (Boyd and Engl and, 1964). The stability field of pyrope is probably progressively reduced with temperature due to this effect. The amount of 
curvature in the slope however is not well constrained by the present data, nor can it be predicted on the basis of presently available thermo-chemical information.

The reversed boundary for the breakdown of pyrope under its own composition as determined by Boyd and England (1959) lies at the high pressure side of the presently determined curve for pyrope + quartz from 1100 to $1400^{\circ} \mathrm{C}$. It now seems likely that both curves have been determined largely in their metastable extensions on the high temperature side of their intersection point at $1125 \pm 25^{\circ} \mathrm{C}$. Therefore, this situation is theoretically expected.

In comparing Boyd and England's data on pyrope breakdown, and the present data on pyrope + quartz, it is necessary to carefully evaluate any difference in experimental technique. Boyd and England used talc (American variety) whereas the present experiments use talc (Australian variety) and boron-nitride as pressure media.

A detailed study of pressure media by Essene, in preparation) suggests that a relative correction to the data of Boyd and England should be made to compare them with our data which have a-10\% pressure correction. Because at $1400^{\circ} \mathrm{C}$ talc by itself has a lower strength than talc + boron-nitride, only a $-6 \%$ correction has to be applied to their data at this temperature. At 
$1100^{\circ} \mathrm{C}$ a $-13 \%$ correction (which is $3 \%$ larger than our correction) needs to be made to Boyd and England's data. We can use these corrected values and compare them with the present data. In this manner, an invariant point at the intersection of the two phase boundaries can be estimated that is consistent with the available experimental data (Fig. 8.3)

The presence of a quenched liquid in experiments by Schreyer and seifert (1969b) at $975^{\circ} \mathrm{C}$ and lower temperatures makes it difficult to compare them with the other subsolidus data.

The occurrence of a large stability field for the assemblage pyrope-quartz as evidenced by the present data is in disagreement with the conclusion of Schreyer and Seifert (1969b) that pyrope is incompatible with free silica over the pressure-temperature range in which quartz is the stable polymorph.

The stippled boundary between the two and intermediate pressure assemblages in Fig. 8.1 represents the reaction cordierite $\rightleftarrows$ aluminous enstatite + sillimanite + quartz This transition is probably also largely metastable at high temperatures with respect to

cordierite $\rightleftharpoons$ sapphirine + quartz

which has to lie on its low pressure side. Both these breakdown reactions have been found experimentally at 1100 
and $1200^{\circ} \mathrm{C}$, respectively by Schreyer and Yoder (1960). Chemical analysis of aluminous pyroxenes

An electron probe X-ray microanalyser (A.R.L. Model EMX) was used for the analysis of aluminous pyroxenes. Setting: Accelerating voltage $12 \mathrm{kV}$, emission current $90 \mathrm{~mA}$. sample current 0.05 microamps, counting time 20 seconds. Mg, Si, and Al were analysed simultaneously. Synthetic pyrope was used as a standard. No corrections were made to the data (other than for drift, background and dead time). A large number of analyses was made on each sample. Only those analyses which recalculated to nearly stoichiometric pyroxenes were selected. In each run, a range of alumina content was found, indicating that the charge did not completely equilibrate. A strong concentration of values within a range of one or two weight percent was found in all samples. These are the values listed in Table 8.1. The higher values in the range measured for each temperature are consistent with experimental error with the extrapolated and corrected data of Boyd and England (1964) on aluminous enstatite in equilibrium with pyrope as shown in Fig. 8.1. The $\mathrm{Al}_{2} \mathrm{O}_{3}$-content of pyroxene in runs 2134 and 2257 is abnormal1y low. In these two runs, sillimanite is absent so that a different phase assemblage is present and the Al-content of enstatite is no longer fixed by the same partition relationships. Because the 
composition studied lies on the pyrope-quartz join (Fig.

8.1) aluminous enstatite does not occur in the high pressure assemblage. It coexists with sillimanite and quartz and with cordierite and quartz at intermediate and low pressures. The relevant exchange reactions are given below. They have been written such as to produce one mole of aluminous enstatite in each case:

$$
\begin{gathered}
\left.\mathrm{n}=14.8^{1}\right) \\
\left(\mathrm{cm}^{3}\right)
\end{gathered}
$$

$(1-\mathrm{n}) \mathrm{MgSiO}_{3}+\mathrm{ng}_{3} \mathrm{Al}_{3} \mathrm{Si}_{3} \mathrm{O}_{12} \underset{\text { enstatite }}{\rightleftharpoons}$
pyrope

(1) +1.27

$(1-\mathrm{n}) \mathrm{MgSiO}_{3} \cdot \mathrm{n} \mathrm{Al}_{2} \mathrm{O}_{3}$

aluminous enstatite

$\pm \quad .08$

$(1-n) \mathrm{MgSiO}_{3}+\mathrm{n} \mathrm{Al}_{2} \mathrm{SiO}_{5}$
enstatite $+\mathrm{Sillimanite}^{\rightleftharpoons}$

$(1-n) \mathrm{MgSiO}_{3} \cdot \mathrm{n} \mathrm{Al}_{2} \mathrm{O}_{3}+\mathrm{n} \mathrm{SiO}_{2}$
aluminous enstatite

$(1-2 n) \mathrm{MgSiO}_{3}+\frac{1}{2} \mathrm{n} \mathrm{Mg}_{2} \mathrm{Al}_{4} \mathrm{Si}_{5} \mathrm{O}_{18} \rightleftharpoons$
enstatite

$-3.27$

$(1-n) \mathrm{MgSiO}_{3} \cdot \mathrm{n} \mathrm{Al} \mathrm{O}_{3}+\frac{3}{2} \mathrm{n} \mathrm{SiO}_{2}$

aluminous enstatite ${ }^{3}$ quart $z^{2}$

$\mathrm{n}=$ mole fraction of $\mathrm{Al}_{2} \mathrm{O}_{3}$ in enstatite. ${ }^{2}$ ) The aluminous enstatite can also be written as $\left(\mathrm{Mg}_{1-n} \mathrm{Al}_{n}\right)\left(\mathrm{Si}_{1-n} \mathrm{Al}_{n}\right) \mathrm{O}_{3}$.

1)Volume data for aluminous enstatite from Skinner and Boyd (1964): Volume for $\mathrm{n}=14.8 \frac{1}{3}$ ( $=15$ weight $\% \mathrm{Al}_{2} \mathrm{O}_{3}=30.87$ $\mathrm{cm}^{3}$. The error of $\pm .05 \mathrm{~cm}^{3}$ has been estimated.

2) The expression of the reactions proposed here is different from that employed by Ringwood et al. (1964) and McGregor and Ringwood (1964). Their use of molecular percent instead of mole per cent or mole fraction is confusing. 
For the undersaturated part of the system two more reactions of the same type involving corundum and spinelforsterite can be written.

Al1 these equilibria are divariant ${ }^{1}$ ) and have in common that they involve only one phase of variable composition (i.e. aluminous enstatite). The composition of the enstatite fixes pressure and temperature on a "univariant" compositional contour (Fig. 8.1). In the case of divariant reactions involving both aluminous enstatite and aluminous sapphirine, we have two phases of variable composition, and thus both pressure and temperature are uniquely determined by the compositions of the coexisting sapphirine and enstatite. On a P-T diagram, this is represented by the intersection of two compositional contours. Examples of such equilibria include: aluminous enstatite-aluminous sapphirine-quartz, aluminous enstatitealuminous sapphirine-sillimanite, aluminous enstatitealuminous sapphirine-cordierite. These will occur within the stability fields of sapphirine-quartz, enstatite-

1) Reaction (1) is a degenerate case of a divariant equilibrium since enstatite, aluminous enstatite and pyrope are co-linear. 
sillimanite and cordierite respectively (see Fig. 8.3).

With increasing temperature both enstatite and

sapphirine should become more aluminous in these equilibria.

Natural rock data (e.g. Barker 1964; Chapter 10) indicate

that the amount $\mathrm{Al}-\mathrm{Al} \rightleftharpoons \mathrm{Mg}-\mathrm{Si}$ substitution in (coexisting)

hypersthene and sapphirine may be very similar. Therefore

it seems unlikely that the above equilibria will be

useful as geothermometers or geobarometers for natural

environments.

Topological analysis

In order to evaluate the implications of the experimental

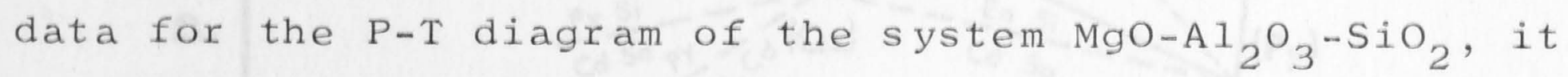
is useful to consider theoretically the possible geometry of phase relationships in this system.

The topology of the six phase system cordieriteenstatite-pyrope-sapphirine ${ }^{1)}$-sillimanite-quartz is represented in Figure 8.2. The P-I diagram has been constructed by Schreinemaker's method with the additional restrictions imposed by the knowledge of the following information:

1) For simplicity, the variable alumina content of enstatite and sappirine has been neglected. The role of kyanite and other phases such as corundum, spinel and olivine, which become important in undersaturated compositions, has been disregarded. 


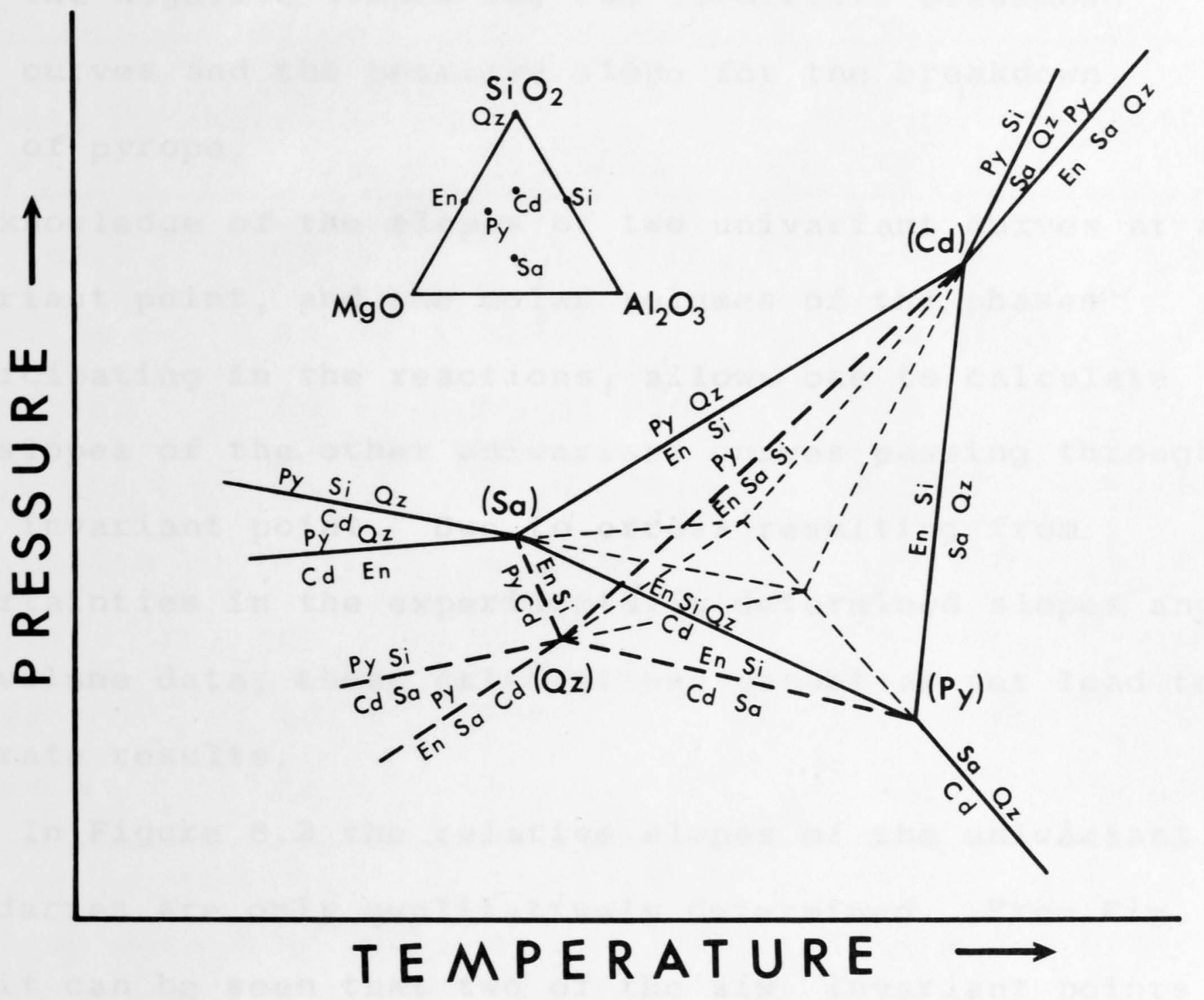

Fig. 8.2. Theoretical phase analysis of the system $\mathrm{MgO}-\mathrm{Al}_{2} \mathrm{O}_{3}-\mathrm{SiO}_{2}$ at high pressure and temperature. 
1. the volume changes of the univariant reactions ( Table 8.2)

2. the negative slopes for the cordierite breakdown curves and the positive slope for the breakdown of pyrope.

The knowledge of the slopes of two univariant curves at an invariant point, and the molar volumes of the phases participating in the reactions, allows one to calculate the slopes of the other univariant curves passing through this invariant point. Due to errors resulting from uncertainties in the experimentally determined slopes and the volume data, these calculations cannot as yet lead to accurate results.

In Figure 8.2 the relative slopes of the univariant boundaries are only qualitatively determined. From Fig. 8.2 it can be seen that two of the six invariant points in the system have to be metastable. The other points (Py), (Cd), (Sa) and ( $\mathrm{Q} z$ ) theoretically could be stable. The stable status of the latter two points is brought into question by considering the introduction of two new phases, e.g. kyanite and corundum.

As indicated previously, the kyanite-sillimanite phase boundary intersects the curves $\left.(\mathrm{Cd}, \mathrm{Sa})^{1}\right)$ and (Cd, Qz). 1) $(X, Z)$ indicates reaction from which phases $X$ and $Z$ are both absent. This reaction connects invariant points (X) and (Z) (See Table 8.2) 
TABLE 8.2

Chemical and thermodynamic information for

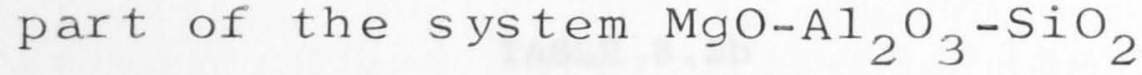

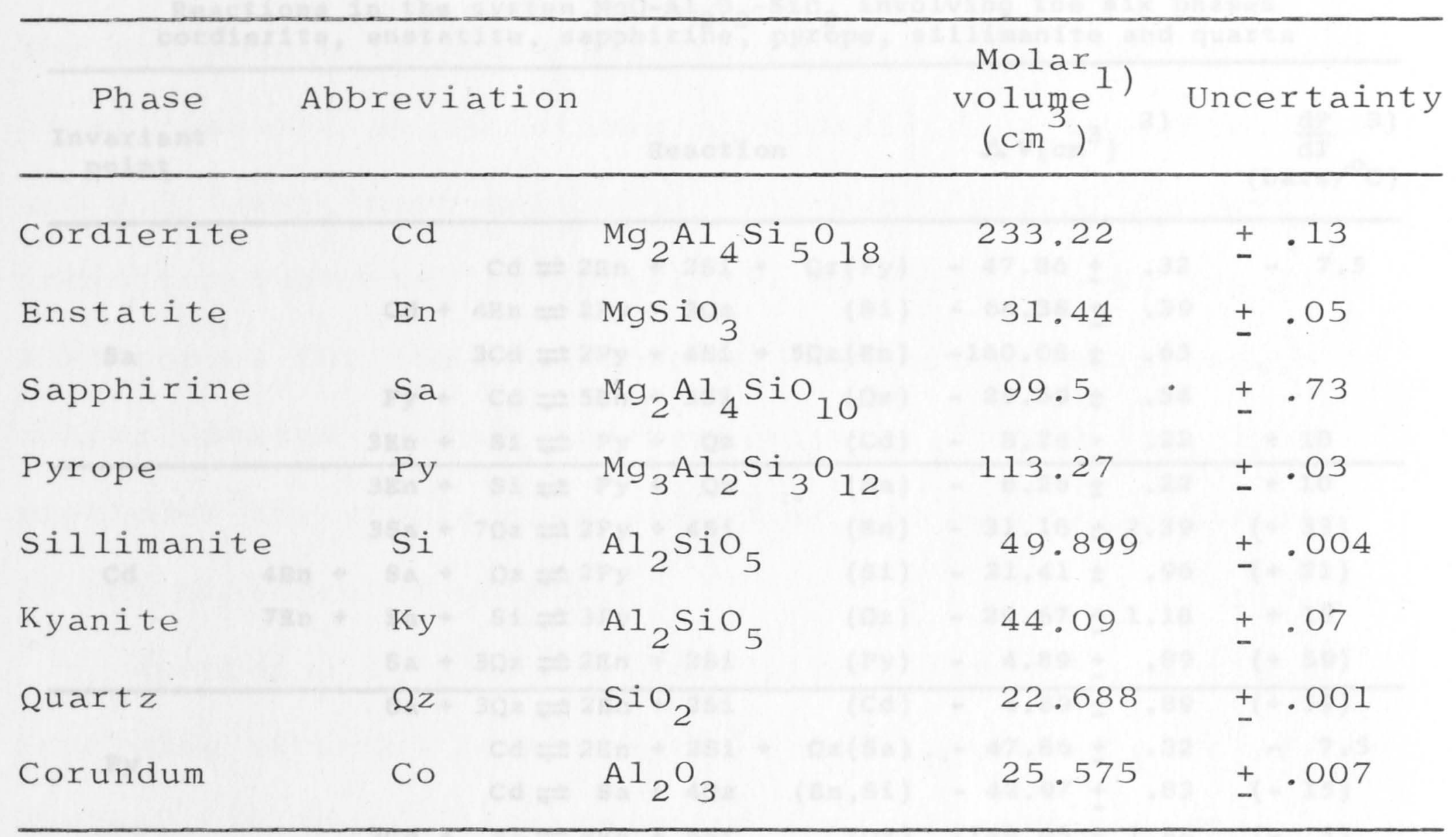

1) Volume data from Robie et al. (1967) at room temperature. 
TABLE $8.2 \mathrm{~b}$

Reactions in the system $\mathrm{MgO}-\mathrm{Al}_{2} \mathrm{O}_{3}-\mathrm{SiO}_{2}$ involving the six phases cordierite, enstatite, sapphirine, pyrope, sillimanite and quartz

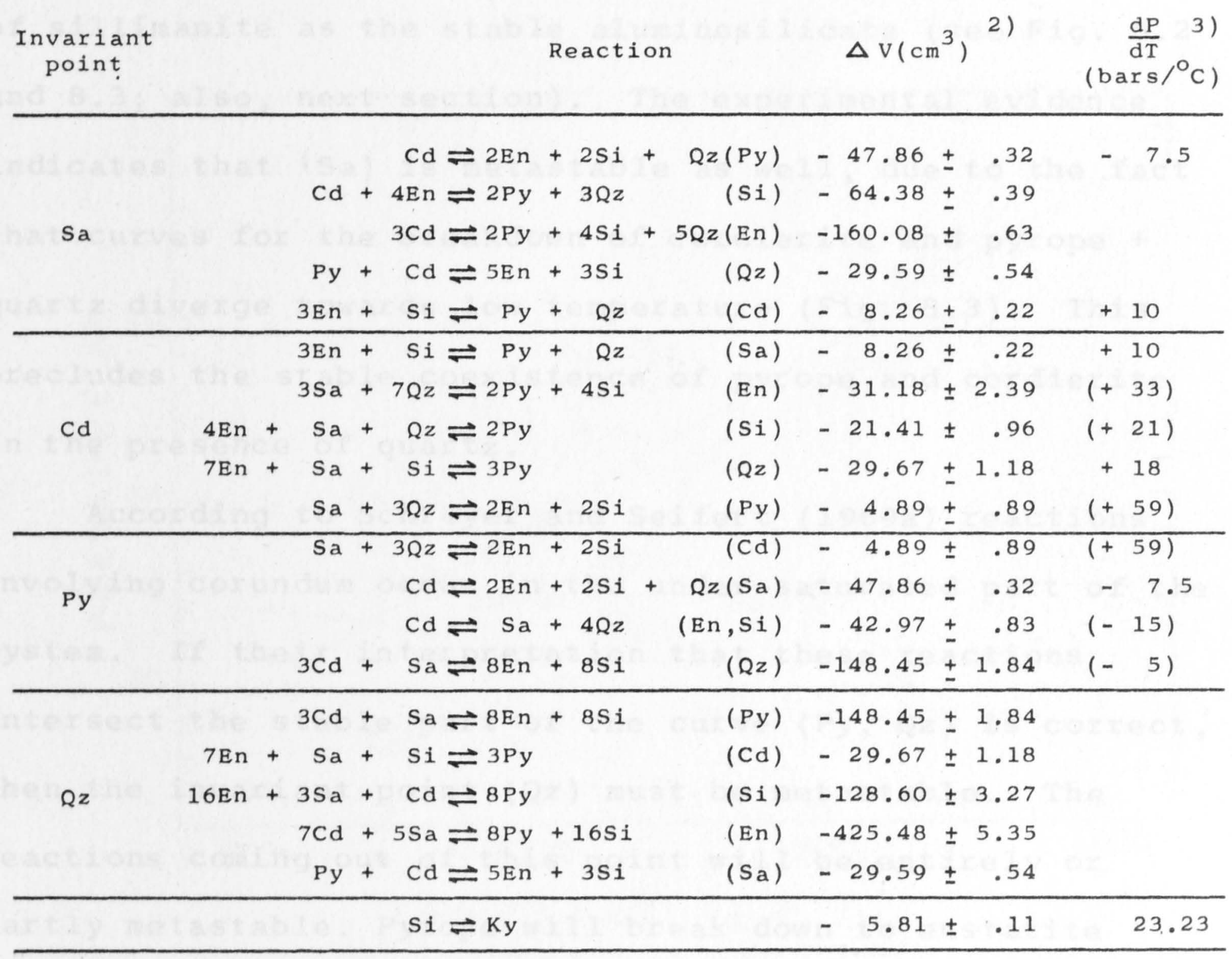

1) The sillimanite in the reactions can be replaced by kyanite. For a reaction involving $n$ moles of sillimanite the volume change of that reaction has to be adjusted by: $n(5.81 \pm .11)$.

2) The reactions have been written such that the right hand side always has the lower volume.

$3)$ Slopes estimated from experimental evidence. Figures in brackets are calculated from these using the volume data at room temperature given in the table, thus ignoring compressibilities and thermal expansions. 
This will have the effect of moving the invariant points ( $\mathrm{Sa}$ ) and $(\mathrm{Q} z)$ to lower temperatures because of the necessary inflections of all curves intersected by the Ky-Si inversion. The new points ( $\mathrm{Sa}$ ) and $(\mathrm{Qz})$ would then have kyanite instead of sillimanite as the stable aluminosilicate (see Fig. 8.2 and 8.3; also, next section). The experimental evidence indicates that ( $\mathrm{Sa}$ ) is metastable as well, due to the fact that curves for the breakdown of cordierite and pyrope + quartz diverge towards low temperature (Fig.8.3). This precludes the stable coexistence of pyrope and cordierite in the presence of quartz.

According to Schreyer and Seifert (1969a) reactions involving corundum occur in the under-saturated part of the system. If their interpretation that these reactions intersect the stable part of the curve (Py; Qz) is correct, then the invariant point $(Q z)$ must be metastable. The reactions coming out of this point will be entirely or partly metastable. Pyrope will break down to enstatite and corundum below the intersection of the curve (Cd, Qz) and $\mathrm{Sa}+\mathrm{Si} \rightleftharpoons \mathrm{En}+\mathrm{Co}$ (Schreyer, 1968).

\section{$\underline{\text { Summary }}$}

All available experimental evidence has been combined for the construction of a phase diagram for the silica-

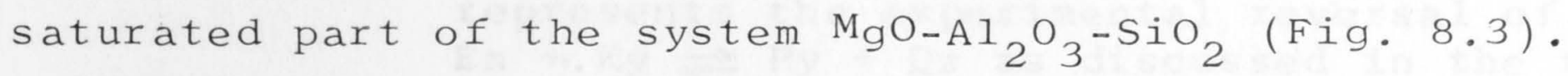
The invariant point ( $\mathrm{Cd}$ ) has been obtained by a combination 


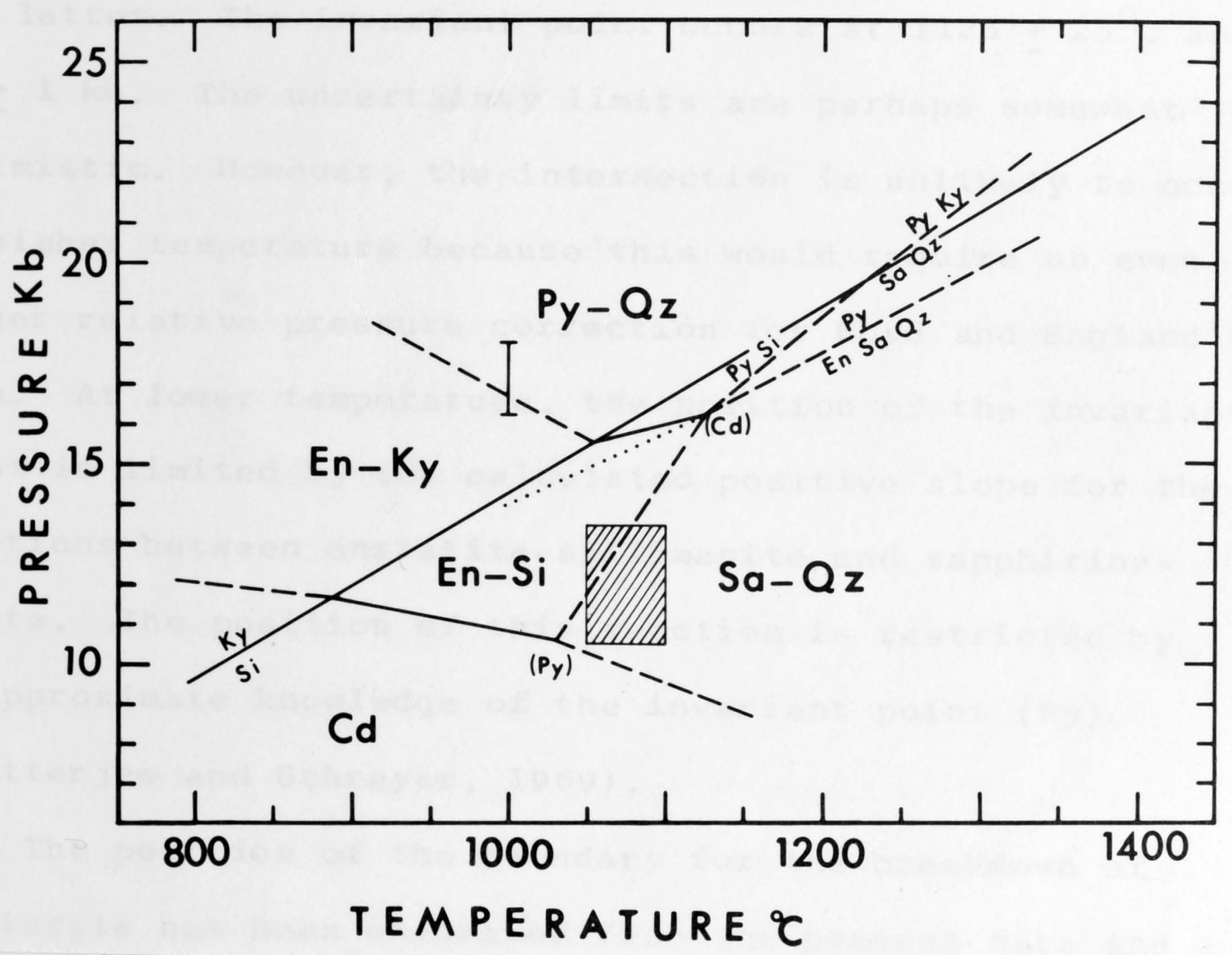

Fig. 8.3. Model phase diagram for the system $\mathrm{MgO}-\mathrm{Al}_{2} \mathrm{O}_{3}-\mathrm{SiO}_{2}$. Solid lines: Ky-Si phase boundary after Richardson et al. (1968) (pressure correction applied). The other two lines are segments of the phase boundaries from Fig. 8.1. Dotted line: corrected and extrapolated phase boundary for the breakdown of pyrope to enstatite, sapphirine and sillimanite (Boyd and England, 1959). Dashed lines: calculated phase boundaries. The I bar represents the experimental reversal of $\mathrm{En}+\mathrm{Ky} \rightleftharpoons \mathrm{Py}+\mathrm{Qz}$ as discussed in the text. Shaded rectangle: estimated position of the invariant point (Py) by Chatterjee and Schreyer (1969). 
of the breakdown curves for pyrope + quartz (this work) and for pyrope (Boyd and England, 1964). The slope of the former reaction has been estimated at +10 bars $/{ }^{\circ} \mathrm{C}$. The maximum slope allowed by the experimental data (after pressure correction) of +18 bars $/{ }^{\circ} \mathrm{C}$ has been chosen for the latter. The invariant point occurs at $1125 \pm 25^{\circ} \mathrm{C}$ and $16 \pm 1 \mathrm{~kb}$. The uncertainty limits are perhaps somewhat optimistic. However, the intersection is unlikely to occur at higher temperature because this would require an even larger relative pressure correction for Boyd and England's data. At lower temperature, the position of the invariant point is limited by the calculated positive slope for the reactions between enstatite-sillimanite and sapphirinequartz. The position of this reaction is restricted by an approximate knowledge of the invariant point (Py) (Chatterjee and Schreyer, 1969).

The position of the boundary for the breakdown of cordierite has been estimated from the present data and data on the $B_{100}$ composition (Chapter 5.4). The slope of -7.5 bars $/{ }^{\circ} \mathrm{C}$ is consistent with available evidence. The negative slopes for the breakdown curves of cordierite require this phase to have a lower entropy than its less voluminous breakdown products. The high temperature entropies for the phases cordierite, enstatite, sillimanite and quartz are known (Robie and Waldbaum, 1968). On the 
basis of this information, the entropy change for the reaction involving these phases should be negative for the temperature range of interest. It is possible that ordering in the cordierite and mixing of $\mathrm{Al}_{2} \mathrm{O}_{3}$ in the enstatite and sapphirine cause the change of sign required by the experimental evidence.

The kyanite-sillimanite boundary has been constructed such as to pass below $14.4 \mathrm{~kb}$ at $1000^{\circ} \mathrm{C}$. If the triple point of Richardson et al. (1969) at $622^{\circ} \mathrm{C}, 5.5 \mathrm{~kb}$ is taken as being correct, a slope of 23.2 bars $/{ }^{\circ} \mathrm{C}$ is consistent with the present data. This slope happens to require a $-6 \%$ correction for the "piston in" data at $1500^{\circ} \mathrm{C}$ cf Richardson et al. (1968). This is the same correction which has been applied to Boyd and England's pyrope data at $1400^{\circ} \mathrm{C}$. The calculated (negative) slope for the reaction enstatite + kyanite $\rightleftharpoons$ pyrope + quartz is -21 bars $/{ }^{\circ} \mathrm{C}$. The other slopes for reactions of interest have been calculated and are given in Table 8.2 and shown in Figure 8.3. It has to be emphasized that although the phase diagram is consistent with experimental evidence to date, there still remains considerable uncertainty as to the exact location of the invariant points and the slopes of the phase boundaries. 
Application

Direct applications of simple system data to natural rocks are necessarily restricted because rocks sufficiently close in composition to the system $\mathrm{MgO}_{-} \mathrm{Al}_{2} \mathrm{O}_{3}-\mathrm{SiO}_{2}$ are very rare. Chinner and Sweatman (1968) have described a rock the composition of which is very close to that of pure magnesian cordierite. They concluded that this rock, now mainly consisting of enstatite and sillimanite (with additional cordierite, quartz and corundum) previously contained the assemblage enstatite-kyanite-quartz. Their estimate for the formation of this assemblage above $10 \mathrm{~kb}$ is consistent with Figure 8.3 .

As indicated above, the presence of FeO (in most natural rocks) considerably changes the phase relationships in this system. An example is the incompatibility of pyrope and cordierite in the presence of quartz. Both from experimental evidence (Hensen and Green, 1969, 1970 and Hirschberg and Winkler, 1968) and from natural rocks it is well established that cordierite, almandine-pyrope garnet and quartz can coexist over a wide range of pressures, temperatures and chemical compositions. This also shows that the univariant equilibria which are generally metastable in the end member system, can become stable (divariant) by the addition of another component (in this case FeO). (See Chapters 4 and 5). 
CHAPTER 9

SYNTHESIS OF EXPERIMENTAL PHASE EQUILIBRIA IN

MODEL PELITIC COMPOSITIONS

9.1 GENERAL P-T DIAGRAM FOR SILICA-SATURATED PELITIC

COMPOSITIONS

In order to relate the phase relations observed in the individual bulk compositions and to test the results for internal consistency, a general P-T diagram has been constructed using the experimental data on the B- and C-series of compositions (Chapters 4 and 5) and the theoretical

constraints discussed in Chapter 3. This diagram (Figure 9.1) gives the quasi-univariant phase boundaries that are relevant to all model pelitic compositions studied in this investigation. $^{1)}$ The quasi-univariant phase boundaries limit the stability fields of specific mineral pairs or specific three phase assemblages. The general topology of the P-T diagram is similar to that of the theoretical phase diagram for the system $\mathrm{MgO}-\mathrm{FeO}-\mathrm{Al}_{2} \mathrm{O}_{3}-\mathrm{SiO}_{2}$ (Fig. 3.1) and the discussion of the latter diagram (Chapter 3.1) is applicable also to Figure 9.1.

Additional constraints on the position and slope of some of the univariant boundaries are introduced by the positions

1) The diagram has been used as an overlay on the P-T diagrams for the $\mathrm{B}$ - and $\mathrm{C}$-series of compositions (Chapters 4 and 5 ). 


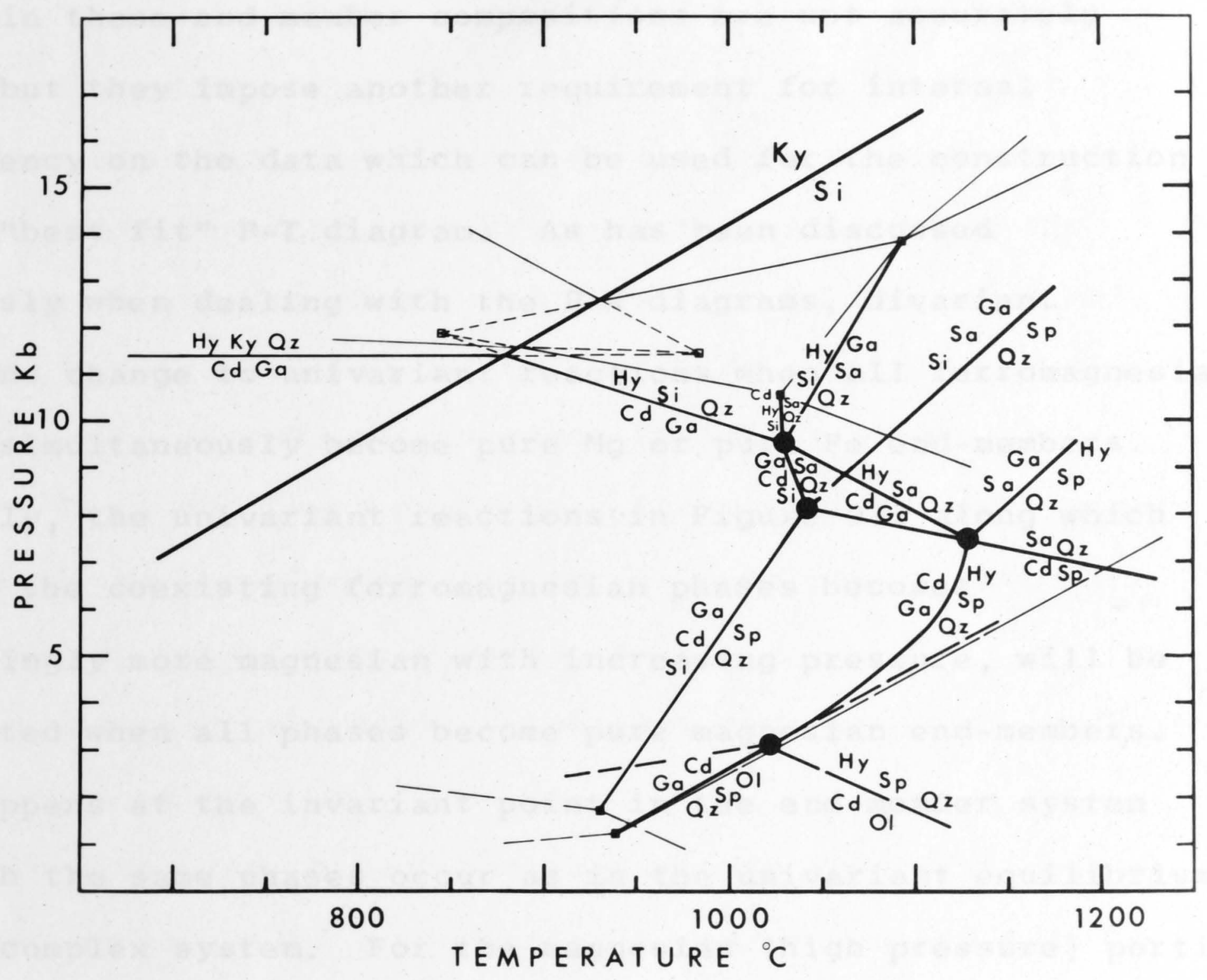

Fig. 9.1. General P-T diagram for B and C-series of compositions. Heavy lines: quasiunivariant boundaries. Light lines: quasi-univariant boundaries in $\mathrm{B}_{\mathrm{O}}$ and B100 compositions. These boundaries emanate from invariant points indicated by solid squares $\left(B_{O}\right)$ and open squares $\left(B_{100}\right)$. The diagram is a "best fit" consistent with all experimental data. 
of the invariant points in the end member compositions $\mathrm{B}_{\mathrm{O}}$ and $\mathrm{B}_{100}$. These constraints are imperfect, since the invariant points in these end member compositions are not accurately known, but they impose another requirement for internal consistency on the data which can be used for the construction of the "best fit" P-T diagram. As has been discussed previously when dealing with the P-X diagrams, divariant reactions change to univariant reactions when all ferromagnesian phases simultaneously become pure Mg or pure Fe end-members. Similarly, the univariant reactions in Figure 9.1 along which each of the coexisting ferromagnesian phases becomes increasingly more magnesian with increasing pressure, will be terminated when all phases become pure magnesian end-members. This happens at the invariant point in the end-member system at which the same phases occur as in the univariant equilibrium ${ }^{1}$ ) in the complex system. For the magnesian (high pressure) portion of the diagram, three such invariant points exist, as shown in Figure 9.1. The relationships for two of these, the invariant points (Py) and (Cd) in the endmember system are self explanatory (compare Chapters 5.4 and 8 ).

1) Not all univariant reactions have corresponding invariant points in the end member system (see Figure 9.1). 
However, the third case involving the univariant curves $\mathrm{Cd}+\mathrm{Ga} \rightleftharpoons \mathrm{Hy}+\mathrm{Si}+\mathrm{Qz}$ and $\mathrm{Cd}+\mathrm{Ga} \rightleftharpoons \mathrm{Hy}+\mathrm{Ky}+\mathrm{Qz}$

needs some explanation. Because of the interference of the $\mathrm{Ky} \rightleftharpoons \mathrm{Si}$ phase boundary, the univariant boundaries in the simple system are deflected, and give rise to two metastable invariant points situated one on each side of the Ky $\rightleftharpoons S i$ boundary. The assemblages at these invariant points are Cd-En-Py-Si-Qz and Cd-En-Py-Ky-Qz. The metastable extensions of each of the above univariant curves must pass through the corresponding metastable invariant points.

The entirely metastable univariant reaction

$$
\mathrm{Cd}+\mathrm{En} \rightleftharpoons \mathrm{Py}+\mathrm{Qz}
$$

is required to pass through both metastable invariant points mentioned above. A line connecting these two points has a slightly negative slope which is very close to the slope attributed to the $\mathrm{X}_{\mathrm{Ga}}$ constant contours for the divariant reaction

$$
\mathrm{Cd}+\mathrm{Hy} \rightleftharpoons \mathrm{Ga}+\mathrm{Qz}
$$

Since it is believed that the $x_{G a}$ contours should be approximately parallel to the end-member reaction boundary, the observed similarity in slope may be significant.

The position of the two invariant points in the low pressure, iron-rich portion of the diagram is only very approximately 
known. The limiting reaction for the breakdown of almandine (in the presence of plagioclase) i.e.

$$
\mathrm{Al} \rightleftharpoons \mathrm{Fa}+\mathrm{HC}+\mathrm{Qz}
$$

has been taken from the results on the $\mathrm{B}_{\mathrm{O}}$ composition (Figure 5.11). The invariant point involving the phases Fe-Cd, Al, Fa, Hc, Qz has been placed at slightly lower pressure and higher temperature than that proposed for the pure almandine + quartz system (Figure 5.11), thus taking the stabilising effect of the grossulars on garnet into account. The position of the invariant point involving the phases Fe-Cd, Al, Hc, Si, Qz has been estimated. It has to occur on the low temperature, high pressure side of the invariant point mentioned above (compare Figure 5.11).

The strong curvature in the univariant phase boundary for the reaction

$$
\mathrm{Cd}+\mathrm{Ga} \rightleftharpoons \mathrm{Hy}+\mathrm{Sp}+\mathrm{Qz}
$$

is required because theoretically it must intersect $\wedge_{\text {one }}$ point with the reactions

$$
\begin{gathered}
\mathrm{Cd}+\mathrm{Ga} \rightleftharpoons \mathrm{Hy}+\mathrm{Si}+\mathrm{Qz} \\
\text { and } \\
\mathrm{Cd}+\mathrm{Ga}+\mathrm{Si} \rightleftharpoons \mathrm{Sp}+\mathrm{Qz}
\end{gathered}
$$

The point of intersection corresponds to the metastable invariant point ( $\mathrm{Sa}$ ) in the system $\mathrm{MgO}-\mathrm{FeO}-\mathrm{Al}_{2} \mathrm{O}_{3}-\mathrm{SiO}_{2}$ (Chapter 3, Table 3.1). In order for the curve for reaction (V) to backbend, the volume change of the reaction must change 
from positive to negative. As indicated previously (Chapter

5), the volume change of this reaction is probably very small (in the order of 2 or $3 \%$ ). Calculations using linearly extrapolated volume data suggest that, for fixed $K_{D}$ values, ${ }^{1}$ ) the volume change of the reaction could be negative for high values of $\mathrm{Mg} / \mathrm{Mg}+\mathrm{Fe}^{2+}$ of the coexisting phases and positive for low values of the same ratio, thus permitting the curvature of reaction (V) (shown in Figure 9.1).

9.2 P-T -X GRID FOR THE DIVARIANT EQUILIBRIA Cd $\rightleftarrows \mathrm{Ga}+\mathrm{Si}+\mathrm{Qz}(1)$ $\underline{\mathrm{AND}} \mathrm{Cd}+\mathrm{Hy} \rightleftharpoons \mathrm{Ga}+\mathrm{Qz}(6)$

The divariant reactions (1) and (6), described in Chapters 4 and 5 respectively, extend to temperatures at which natural metamorphic rocks are believed to have formed. These reactions are of particular interest, since the P-T-X relations determined experimentally should provide information about the temperature and pressure of formation of natural high grade meta-pelites. Ideally the $\mathrm{Mg} / \mathrm{Mg}+\mathrm{Fe}^{2+}$ ratios of a single cordieritegarnet pair from a quasi-divariant assemblage allows the determination of the temperature and total pressure at which the particular divariant assemblage was formed. Although data obtained in the present investigation are far from complete

1) The $K_{D}$ values determine the coffficients of the univariant reaction, given the $\mathrm{Mg} / \mathrm{Mg}+\mathrm{Fe}^{2+} \mathrm{ratio}$ of one of the phases. 
and therefore application to natural rocks must remain

tentative, the following treatment demonstrates the potential

of this type of approach for obtaining information on the pressure-temperature conditions of metamorphic rocks. For the purpose of direct application to natural assemblages, the P-T-X relations are shown in P-T diagrams contoured for constant garnet and cordierite composition (Figures 9.2 and 9.3). Given the $\mathrm{Mg} / \mathrm{Mg}+\mathrm{Fe}^{2+}$ ratios of coexisting garnet and cordierite, pressure and temperature are determined by the point of intersection of the appropriate $\mathrm{x}_{\mathrm{Cd}}$ and $\mathrm{X}_{\mathrm{Ga}}$ contours. The $\mathrm{X}_{\mathrm{Ga}}$ and $\mathrm{X}_{\mathrm{Cd}}$ values have been taken from the $\mathrm{P}-\mathrm{X}$ diagrams discussed in Chapters 4.3 and 5.6 (Figures 4.12 to 4.16 and 5.15 to 5.17$)$

The slope (dP/dT) and the position of the contours are not accurately known because of uncertainties in pressure and temperature calibration (Chapter 2.1) and problems inherent in extrapolation high temperature results to lower temperatures. However, the following evidence supports the $\mathrm{P}-\mathrm{T}-\mathrm{X}$ relations as represented in Figures 9.2 to 9.4 :

1. A negative slope for the breakdown of cordierite in reaction (1) has been well established and is in agreement with experimental evidence from both the Fe and Mg end-member systems. (Richardson, 1968; Schreyer and Yoder, 1964; Chapters 5.4, 5.5 and 8). Therefore, negative slopes for the $\mathrm{x}_{\mathrm{Cd}}$ and $\mathrm{x}_{\mathrm{Ga}}$ contours 
are most probably correct.

2. Hirschberg and Winkler (1968) found that a cordierite with $100 \mathrm{Mg} / \mathrm{Mg}+\mathrm{Fe}^{2+}$ of $\mathrm{ca} \cdot 68$ coexisting with

sillimanite, quartz and biotite, does not show any sign of breakdown to garnet at $700^{\circ} \mathrm{C}, 7 \mathrm{~kb}$, in the presence of garnet seeds. Compared with the present results, this indicates that $\mathrm{X}_{\mathrm{Cd}}$ contours must at least be horizontal ( $\mathrm{dP} / \mathrm{dT}=\mathrm{O})$ and that a negative slope for the contours is consistent with the data. ${ }^{1}$ ) The above authors also found a negative slope for the appearance of garnet in a more Fe-rich composition.

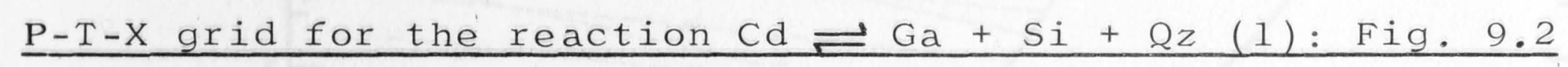

The contours for $\mathrm{X}_{\mathrm{Cd}}$ and $\mathrm{X}_{\mathrm{Ga}}$ for this divariant assemblage Cd-Ga-Si-Qz terminate on the univariant reactions

$$
\begin{gathered}
\mathrm{Cd}+\mathrm{Ga} \rightleftharpoons \mathrm{Hy}+\mathrm{Si}+\mathrm{Qz} \\
\mathrm{Cd}+\mathrm{Ga}+\mathrm{Si} \rightleftharpoons \mathrm{Sp}+\mathrm{Qz} \\
\text { and }
\end{gathered}
$$

\section{$\mathrm{Ky} \rightleftharpoons \mathrm{Si}$}

The compositions of the coexisting garnet and cordierite in divariant equilibrium are uniquely fixed by pressure and temperature. Conversely, if $x_{C d}$ and $x_{G a}$ are known, then $P$

1) Note that Hirschberg and Winkler's experiments were carried out in hydrothermal apparatus. If a larger pressure correction were required for the present data from solid media apparatus, the negative slope would be accentuated. 


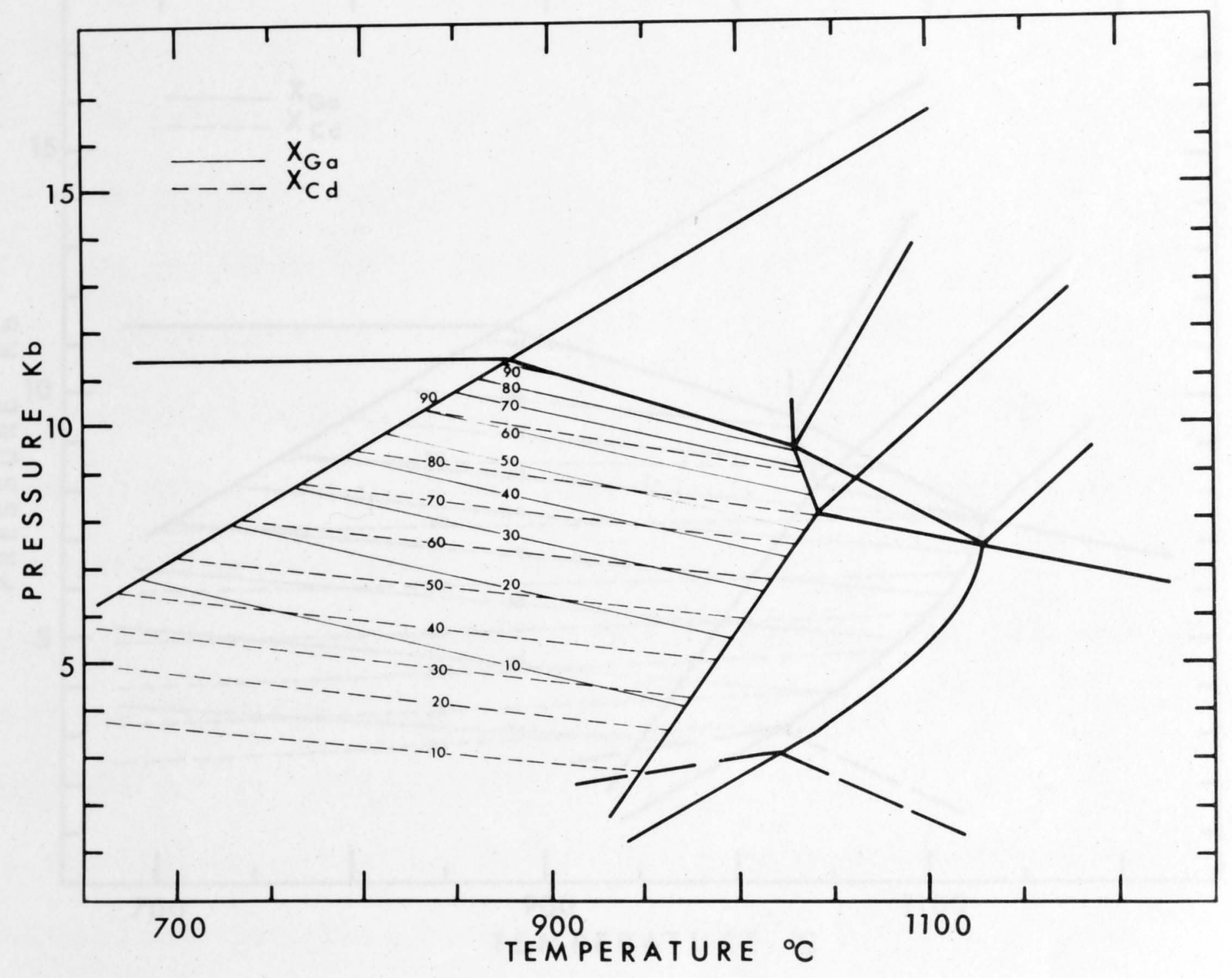

Fig. 9.2. P-T diagram with $\mathrm{X}_{\mathrm{Cd}}$ and $\mathrm{X}_{\mathrm{Ga}}$ contours for the quasi-divariant reaction cordierite $\rightleftharpoons$ garnet + sillimanite + quartz ( 1 ). 


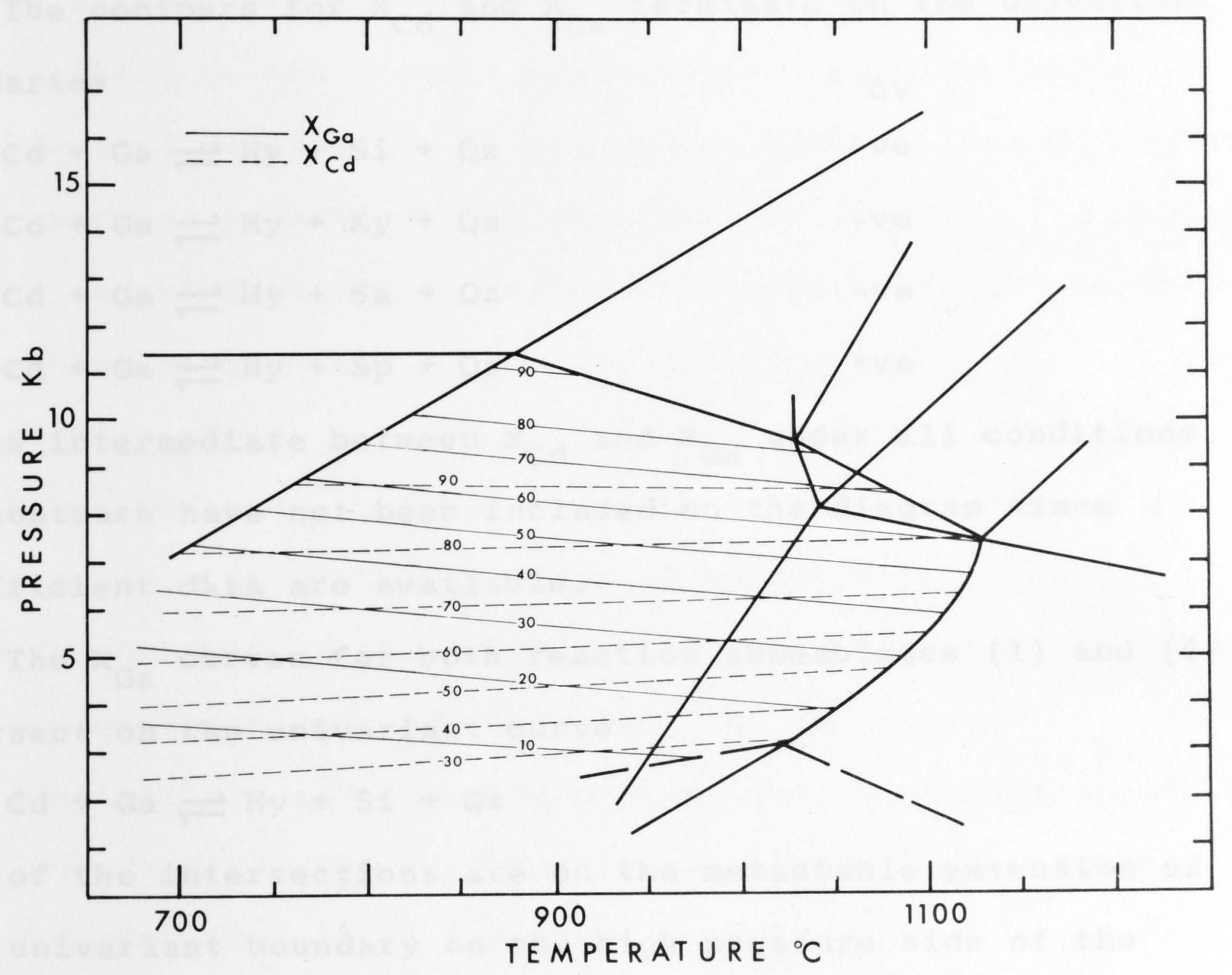

Fig. 9.3. P-T diagram with $\mathrm{X}_{\mathrm{Cd}}$ and $\mathrm{X}_{\mathrm{Ga}}$ contours for the quasi-divariant reaction cordierite + hypersthene $\rightleftharpoons$ garnet + quartz (6). 
and $\mathrm{T}$ are determined.

$\underline{P-T}-\mathrm{X}$ grid for the reaction $\mathrm{Cd}+\mathrm{Hy} \rightleftharpoons \mathrm{Ga}+\mathrm{Qz}(6)$ : Figure 9.3

The contours for $\mathrm{X}_{\mathrm{Cd}}$ and $\mathrm{X}_{\mathrm{Ga}}$ terminate on the univariant

boundaries

$$
\begin{array}{rr}
\mathrm{Cd}+\mathrm{Ga} \rightleftharpoons \mathrm{Hy}+\mathrm{Si}+\mathrm{Qz} & \Delta \mathrm{V} \\
\mathrm{Cd}+\mathrm{Ga} \rightleftharpoons \mathrm{Hy}+\mathrm{Ky}+\mathrm{Qz} & -\mathrm{ve} \\
\mathrm{Cd}+\mathrm{Ga} \rightleftharpoons \mathrm{Hy}+\mathrm{Sa}+\mathrm{Qz} & -\mathrm{ve} \\
\mathrm{Cd}+\mathrm{Ga} \rightleftharpoons \mathrm{Hy}+\mathrm{Sp}+\mathrm{Qz} & +\mathrm{ve}
\end{array}
$$$$
\mathrm{Cd}+\mathrm{Ga} \rightleftharpoons \mathrm{Hy}+\mathrm{Si}+\mathrm{Qz}
$$$$
\mathrm{Cd}+\mathrm{Ga} \rightleftharpoons \mathrm{Hy}+\mathrm{Sa}+\mathrm{Qz} \quad-\mathrm{ve}
$$

$\mathrm{X}_{\mathrm{Hy}}$ is intermediate between $\mathrm{x}_{\mathrm{Cd}}$ and $\mathrm{X}_{\mathrm{Ga}}$ under all conditions. $\mathrm{X}_{\mathrm{Hy}}$ contours have not been included on the diagram since insufficient data are available.

The $\mathrm{X}_{\mathrm{Ga}}$ curves for both reaction assemblages (1) and (6) intersect on the univariant curve

$$
\mathrm{Cd}+\mathrm{Ga} \rightleftharpoons \mathrm{Hy}+\mathrm{Si}+\mathrm{Qz}
$$

Most of the intersections are on the metastable extension of this univariant boundary on the high pressure side of the invariant point (Sp) (compare Figure 9.1).

\subsection{INFLUENCE OF FACTORS OTHER THAN THE $\mathrm{Mg} / \mathrm{Mg}+\mathrm{Fe}^{2+} \mathrm{RATIO}$ ON THE P-T-X RELATIONS}

\section{$\underline{\text { Ca-content }}$}

The grossular content of the experimentally produced garnets ranges from $4 \pm 1$ mole $\%$ in the $B_{30}$ composition to $6 \pm 1$ mole $\%$ in the $B_{70}$ composition. Since most experiments on iron-rich composition $\mathrm{B}_{30}$ were carried out at low pressure 
and most runs on the magnesian-rich composition $B_{70}$ at relatively higher pressure, it is not possible to separate the effects of pressure and composition on the amount grossular ss in the garnet in the present experiments. As discussed earlier, the effect of grossular ss in extending the stability of garnet in the various assemblages is considerable (Chapter 7). The present experiments are therefore only applicable to assemblages with excess plagioclase.

$\underline{M n-\text { and } T i-\text { content }}$

Since Mn tends to concentrate in garnet, its presence will increase the stability field of garnet with respect to the other ferromagnesian phases. However, most garnets from cordierite-garnet bearing rocks have low Mn-contents

$($ Mn $<1$ weight \%), and thus the present data should be applicable.

The Ti-content is also very low in these garnets and therefore can be disregarded as an important factor.

Oxygen fugacity

In the present experiments, carried out in graphite capsules, oxygen fugacity is low (Chapter 2.5). Variations in oxygen fugacity could affect the solid-solid equilibria studied in two ways.

1. If ferric iron substitutes in one or several of the ferromagnesian phases, this would alter the relative stability of these phases. It is believed, however, that this effect will be small in most cases since 
neither cordierite nor pyrope-almandine garnet appear to be able to accommodate a significant amount of ferric iron. Hsu (1968) found no detectable change in the $x-r a y$ properties of almandine, crystallised under various conditions of oxygen fugacity, thus indicating negligible $\mathrm{Fe}^{3+}$ substitution. The garnets produced in the present experiments (and those in natural rocks also) ${ }^{1}$ ) contain a small amount of calcium which allows the incorporation of $\mathrm{Fe}^{3+}$ in the form of andradite substitution. However, analyses of experimental garnets suggest that $\mathrm{Ca}$ in the garnet is accommodated in the form of grossular rather than as andradite ${ }_{S s}$. Therefore the assumption made here that oxygen fugacity will not significantly influence the equilibrium between garnet and cordierite, is probably correct.

Aluminous hypersthene could incorporate some ferric iron, and the stabilityof hypersthene with regard to garnet and cordierite may be extended under more oxidizing conditions than those prevailing in the present experiments (see Chapter 10).

The stability of hercynite-spinel-magnetite solid solutions will also be extended by increasing $\mathrm{fO}_{2}$.

1) In most garnets from natural cordierite-garnet rocks, andradite substitution is low ( $<2$ mole \%). 
Below ca. $900^{\circ} \mathrm{C}$, two spinel phases, i.e. hercynitess and magnetitess, should occur rather than one ( Turnock and Eugster, 1962).

2. If an additional magnetite-rich spinel phase forms in the divariant assemblage as a result of high oxygen fugacity, then the equilibrium between the other ferromagnesian phases is not affected, provided the assumption that these phases do not incorporate $\mathrm{Fe}^{3+}$ is correct. However, since the $\mathrm{Mg} / \mathrm{Mg}+\mathrm{Fe}^{2+} \mathrm{ratio}$ of the spinel will not be the same as that of the bulk composition, the relative proportions of the original ferromagnesian phases must change, but the composition of each phase will remain constant. ${ }^{1}$ ) If a large amount of magnetite ${ }_{s s}$ is produced, the most Fe-rich phase in the divariant assemblage will eventually disappear. The addition of magnetite to a trivariant assemblage e.g. Cd-Ga-Qz, will result in both cordierite and garnet becoming more magnesian, with garnet eventually disappearing. From the foregoing it is evident that the presence or absence of garnet or cordierite in a particular bulk composition can be governed by oxygen fugacity. However, provided that garnet and cordierite continue to coexist,

1) The situation is analogous to the addition of a hydrous phase e.g. biotite (next section). 
changes in $\mathrm{fO}_{2}$ will not significantly affect the experimentally derived P-T-X relationships for reactions (1) and (6). Structural state and water content of cordierite

The cordierite produced in the experiments is possibly a "high" cordierite as defined by Schreyer and Schairer (1961). The effect of the structural state on the stability of cordierite is unknown and is not considered in this investigation. Although Schreyer and Yoder (1964) concluded that synthetic hydrous cordierites contain only molecular $\mathrm{H}_{2} \mathrm{O}$, the role of water in cordierite is still subject to controversy. The influence of water content on the stability of cordierite cannot be evaluated.

\subsection{INTERSECTIONS OF REACTIONS (1) AND (6) WITH DEHYDRATION}

\section{REACTIONS INVOLVING BIOTITE}

Since in most natural metamorphic rocks containing cordierite-garnet assemblages, biotite is present as a major phase, it is important to consider the interactions between dehydration reactions involving biotite and the anhydrous solid-solid reactions studied in this investigation. The dehydration of biotite produces ferromagnesian silicate(s) + orthoclase + vapour. If we consider $\mathrm{Bi}+\mathrm{Or}+\mathrm{H}_{2} \mathrm{O}$ in addition to the phases cordierite, garnet, hypersthene, sillimanite

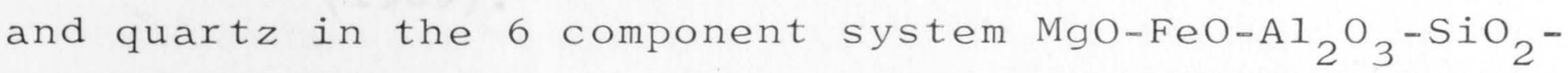
$\mathrm{K}_{2} \mathrm{O}-\mathrm{H}_{2} \mathrm{O}$, we can deduce five silica-saturated, univariant reactions, given the relative $\mathrm{Mg} / \mathrm{Mg}+\mathrm{Fe}^{2+} \mathrm{ratios}$ 
UNIVARIANT REACTION (HY)

Divariant reactions

$$
\begin{aligned}
& \Delta \mathrm{V}_{\mathrm{S}}{ }^{1}\left(\mathrm{~cm}^{3}\right) \\
& 2 \mathrm{Bi}+6 \mathrm{Si}+9 \mathrm{Qz} \rightleftharpoons 3 \mathrm{Cd}+2 \mathrm{Or}+2 \mathrm{H}_{2} \mathrm{O}+81.3 \quad \text { (Ga, Hy) } \\
& 4 \mathrm{Bi}+3 \mathrm{Cd}+3 \mathrm{Qz} \rightleftharpoons 6 \mathrm{Ga}+4 \mathrm{Or}+4 \mathrm{H}_{2} \mathrm{O} \quad-215 \quad \text { (Si, Hy) }
\end{aligned}
$$$$
\mathrm{Bi}+\mathrm{Si}+2 \mathrm{Qz} \rightleftharpoons \mathrm{Ga}+\mathrm{Or}+\mathrm{H}_{2} \mathrm{O}-22.3 \text { (Cd, Hy) }
$$$$
3 \mathrm{Cd} \rightleftharpoons 2 \mathrm{Ga}+4 \mathrm{Si}+4 \mathrm{Qz} \text { (1) }-129.5 \quad\left(\mathrm{Bi}, \mathrm{Or}_{2} \mathrm{H}_{2} \mathrm{O}, \mathrm{Hy}\right)
$$

UNIVARIANT REACTION (Si)

Divariant reactions

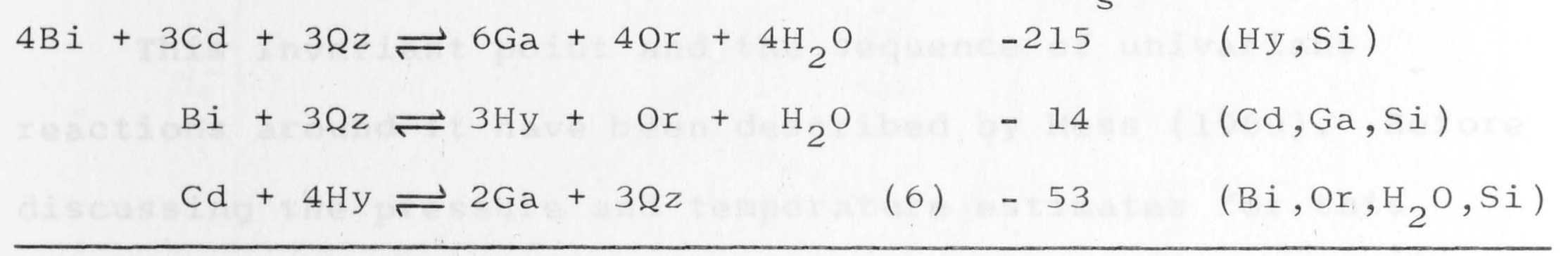

BACKBENDING REACTIONS

Reaction

Change in sign of $\Delta v^{2}$ )

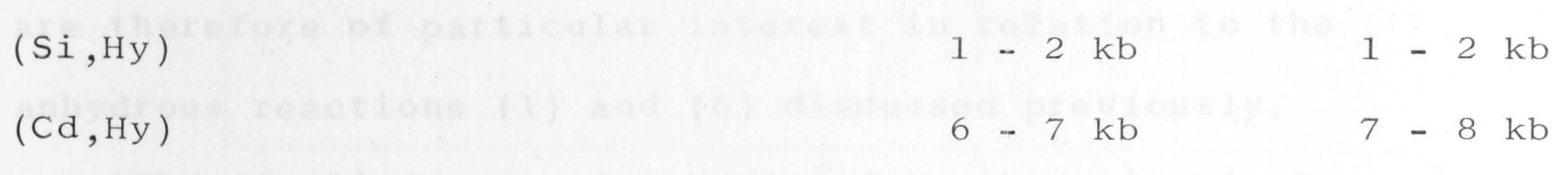

1) Volumes are the same as used by Hess (1969)

i.e. $\mathrm{V}_{\mathrm{C}}=223 ; \mathrm{V}_{\mathrm{Bi}}=151 ; \mathrm{V}_{\mathrm{Ga}}=115, \mathrm{~V}_{\mathrm{Hy}}=32 ;$
$\mathrm{V}_{\mathrm{Si}}=49.9$. 2) Using the volume data for water by Burnham et al.
$(1969)$. 
of the ferromagnesian phases (i.e. $\mathrm{x}_{\mathrm{Cd}}>\mathrm{x}_{\mathrm{Bi}}>\mathrm{X}_{\mathrm{Hy}}>\mathrm{X}_{\mathrm{Ga}}$ ). These reactions are:

$\Delta V$

$$
\begin{aligned}
& \mathrm{Bi}+\mathrm{Si}+\mathrm{Qz} \rightleftharpoons \mathrm{Cd}+\mathrm{Ga}+\mathrm{Or}+\mathrm{H}_{2} \mathrm{O}+\mathrm{Ve} \\
& \mathrm{Bi}+\mathrm{Ga}+\mathrm{Qz} \rightleftharpoons \mathrm{Cd}+\mathrm{Hy}+\mathrm{Or}+\mathrm{H}_{2} \mathrm{O} \text { +ve } \\
& \mathrm{Bi}+\mathrm{Si}+\mathrm{Qz} \rightleftharpoons \mathrm{Cd}+\mathrm{Hy}+\mathrm{Or}+\mathrm{H}_{2} \mathrm{O} \text { + } \mathrm{Oe} \\
& \mathrm{Bi}+\mathrm{Ga}+\mathrm{Qz} \rightleftharpoons \mathrm{Hy}+\mathrm{Si}+\mathrm{Or}+\mathrm{H}_{2} \mathrm{O} \text { +ve } \\
& \mathrm{Cd}+\mathrm{Ga} \rightleftharpoons \mathrm{Hy}+\mathrm{Si}+\mathrm{Qz} \quad-\mathrm{ve}
\end{aligned}
$$

Theoretically, these reactions would be expected to intersect and produce an invariant point.

This invariant point and the sequence of univariant reactions around it have been described by Hess (1969). Before discussing the pressure and temperature estimates for this possible invariant point, the univariant reactions (Hy) and (Si) and the related divariant reactions will be considered. Reactions ( $\mathrm{Hy}$ ) and ( $\mathrm{Si}$ ) both involve cordierite and garnet, and are therefore of particular interest in relation to the anhydrous reactions (1) and (6) discussed previously.

The divariant reactions related to the univariant boundaries (Hy) and (Si) are given in Table 9.1.

Table 9.1 shows that reactions (1) and (6) intersect the univariant boundaries ( $\mathrm{Hy}$ ) and (Si) respectively. In this

1) The univariant reactions are characterised by one non.participating phase, whereas the divariant reactions are denoted by two missing phases (with the exception of those reactions not involving biotite). 


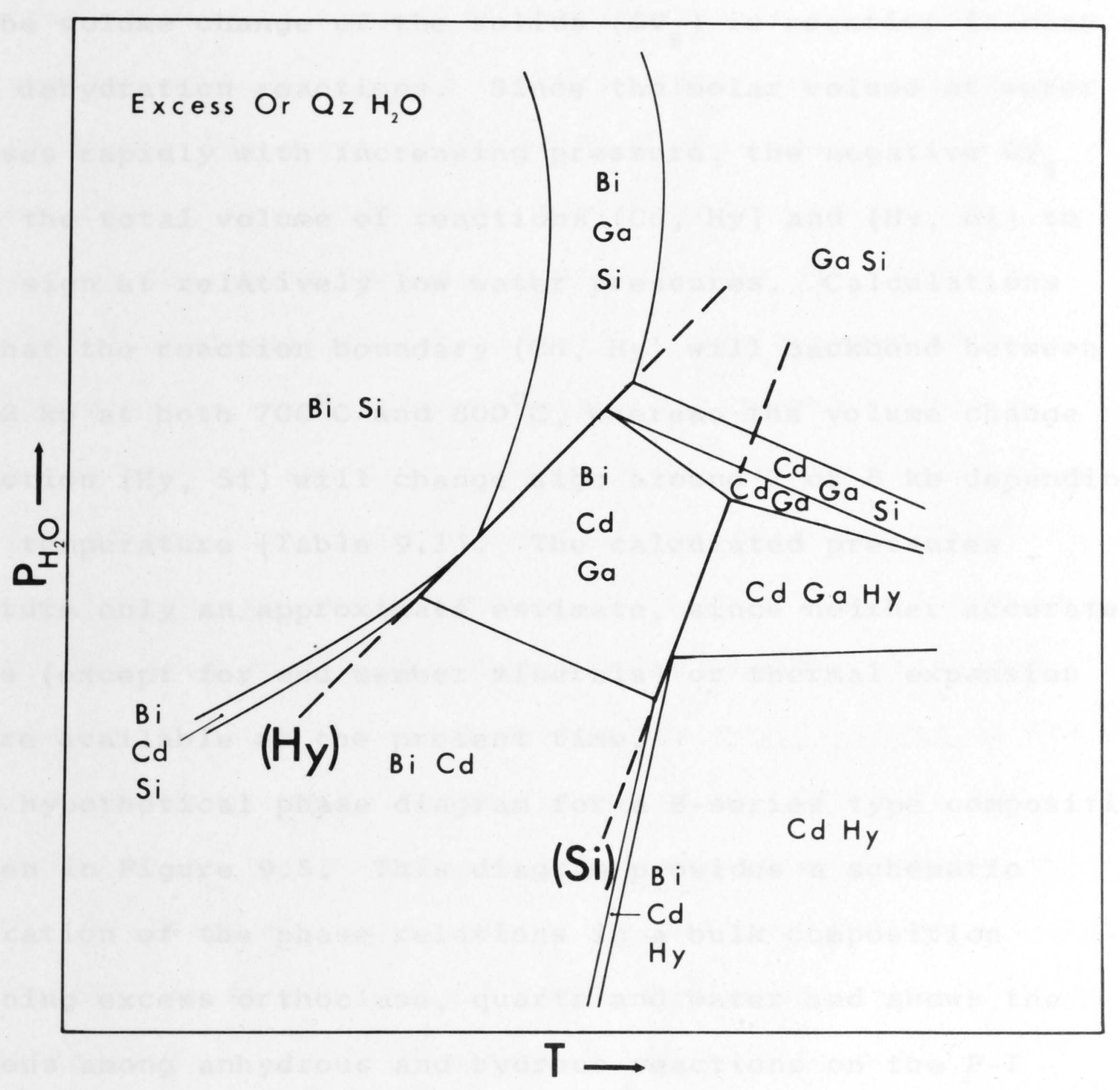

Fig. 9.5. Hypothetical phase diagram for a B-type composition at low temperature $\left(700-800^{\circ} \mathrm{C}\right)$ showing relation to dehydration reactions of anhydrous equilibria. (Hy) and (Si) are univariant boundaries (Table 9.1). 
fashion, the anhydrous reactions are tied in with the dehydration reactions.

The volume change of the solids $\left(\Delta V_{s}\right)$ is negative in many of the dehydration reactions. Since the molar volume of water decreases rapidly with increasing pressure, the negative $\Delta V_{s}$ causes the total volume of reactions (Cd, Hy) and (Hy, Si) to change sign at relatively low water pressures. Calculations show that the reaction boundary (Cd, Hy) will backbend between 1 and $2 \mathrm{~kb}$ at both $700^{\circ} \mathrm{C}$ and $800^{\circ} \mathrm{C}$, whereas the volume change of reaction (Hy, Si) will change sign around 7 or 8 kb depending on the temperature (Table 9.1). The calculated pressures constitute only an approximate estimate, since neither accurate volumes (except for end member minerals) or thermal expansion data are available at the present time.

A hypothetical phase diagram for a B-series type composition is given in Figure 9.5. This diagram provides a schematic illustration of the phase relations in a bulk composition containing excess orthoclase, quartz and water and shows the relations among anhydrous and hydrous reactions on the P-T plane.

The $X_{C d}$ and $x_{G a}$ contours for reactions (1) and (6) pass through the univariant curves uninterrupted. On the low temperature side of reaction ( $\mathrm{Si}$ ) both the divariant assemblages $\mathrm{Cd}-\mathrm{Ga}-\mathrm{Hy}-\mathrm{Qz}-\mathrm{Bi}-\mathrm{H}_{2} \mathrm{O}$, and $\mathrm{Cd}-\mathrm{Ga}-\mathrm{Hy}-\mathrm{Qz}-\mathrm{Bi}-\mathrm{Or}$ can occur (the latter only in a $\mathrm{H}_{2} \mathrm{O}$-deficient environment). In both these assemblages 
we are basically dealing with equilibrium (6), since biotite cannot react without orthoclase and water being produced. If biotite reacts the number of phases exceeds that possible for divariant equilibrium and either cordierite or garnet has to break down. The coexistence of $\mathrm{Bi}-\mathrm{Hy}-\mathrm{Qz}-\mathrm{Cd}-\mathrm{Ga}-\mathrm{Or}-\mathrm{H}_{2} \mathrm{O}$ is only possible on the univariant phase boundary (Si). It follows from the above that the presence of biotite does not affect the (anhydrous) divariant equilibrium between the phases cordierite, hypersthene, garnet and quartz. However, because the biotite may have a Mg/Mg $+\mathrm{Fe}^{2+}$ ratio different from that of the bulk composition, its presence can alter the relative proportions of the phases in divariant equilibrium and may also lead to the disappearance of one of the phases. The presence of biotite cannot change the compositions of the phases in divariant equilibrium (reaction Bi, Or, $\mathrm{H}_{2} \mathrm{O}$, $\mathrm{Hy}$; Table 9.1), since these compositions area unique function of $\mathrm{P}$ and $\mathrm{T}$. The same also applies on the low temperature side of reaction (Hy) where we can have thé assemblages Cd-Ga-Si-Qz-Bi- $\mathrm{H}_{2} \mathrm{O}$ $\left(\mathrm{K}_{2} \mathrm{O}\right.$-deficient) and Cd-Ga-Si-Qz-Bi-Or $\left(\mathrm{H}_{2} \mathrm{O}\right.$-deficient). The $\mathrm{Mg} / \mathrm{Mg}+\mathrm{Fe}^{2+}$ ratio of each ferromagnesian phase increases with increasing pressure along the univariant boundaries in Figure 9.5. With increasing temperature the $\mathrm{Mg} / \mathrm{Mg}+\mathrm{Fe}^{2+}$ ratio of biotite decreases when it coexists with cordierite (reaction (Ga, Hy)), but increases when it occurs with garnet (reaction $(\mathrm{Cd}, \mathrm{Hy})$ ). This is a result of the 
fact that $\mathrm{x}_{\mathrm{Cd}}>\mathrm{X}_{\mathrm{Bi}}$, whereas $\mathrm{x}_{\mathrm{Ga}}<\mathrm{x}_{\mathrm{Bi}}$, and follows from the general rule that when the $\mathrm{Mg} / \mathrm{Mg}+\mathrm{Fe}^{2+}$ ratio is increased the stability field of the phase with the highest value of $\mathrm{X}$ is extended. This provides an explanation for the observation that cordierite becomes more iron-rich with increasing grade of metamorphism (Best and Weiss, 1964; Seifert, 1970).

On the other hand, garnet coexisting with biotite, orthoclase, sillimanite and quartz will become more magnesian with increasing grade (temperature).

Hess (1969) tentatively estimated the position of the invariant point involving the phases biotite, cordierite, garnet, hypersthene, sillimanite, quartz, orthoclase and water at $790^{\circ} \mathrm{C}$ and $4.5 \mathrm{~kb}$ (see page 187). This estimate does not agree with the present experimental evidence, which suggests it occurs at considerably higher pressure (ca. $10-11 \mathrm{~kb}$ ) and temperature $\left(\mathrm{ca} .900^{\circ} \mathrm{C}\right)$. The high temperature is required because at lower temperature at this pressure the intersection would fall in the kyanite stability field (compare Figure 9.1). Cordierite must be extremely magnesian ( $\left.\mathrm{X}_{\mathrm{Cd}}>90\right)$ in the temperature interval $875-1000^{\circ} \mathrm{C}$ within which the invariant point could occur according to the present experimental data. 
Factors bearing on the role of biotite in natural rocks

In the foregoing discussion it has been assumed that biotite is a pure annite-phlogopite solid solution. However, natural biotites from high grade metamorphic terranes contain (1) high $\mathrm{Al}_{2} \mathrm{O}_{3}$; Best and Weiss (1964) and Rutherford (1968). (2) high Ti; up to 4.5 weight $\% \mathrm{TiO}_{2}$, Kwak (1.968); Barker (1962) and (3) may have considerable fluorine and chlorine substituting for hydroxyl group. The incorporation of $\mathrm{Al}_{2} \mathrm{O}_{3}$ in the biotite would affect the divariant reactions extending the stability field of biotite (Chapter 9.4), but should not affect the univariant boundaries. Factors (2) and (3) could extend the stability of biotite to higher temperature and could also significantly influence the hypothetical univariant boundaries of Figure 9.5. These boundaries could be displaced to higher temperatures and may become divariant or multi-variant. The importance of $\mathrm{Ti}$ in biotite, like that of $\mathrm{Ca}$ and $\mathrm{Mn}$ in garnet, may be of major significance and merits investigation.

1) In addition $\mathrm{fO}_{2}$ must also be taken into account, since biotites are known to contain ferric iron. 
CHAPTER 10

\section{SUMMARY AND GEOLOGICAL APPLICATIONS}

\section{General Statement}

The aim of this experimental study has been to obtain an insight into the phase relations among the minerals cordierite, garnet and associated ferromagnesian phases, e.g. hypersthene, sapphirine and spinel, in compositions with the chemical complexity of natural rocks. Rather than studying simple end member systems and subsequently attempting to predict the behaviour in complex systems from the simple system data, it was decided to use model "natural rock" compositions and study the effect of selected chemical variables on the mineral equilibria in these compositions.

The main chemical parametérs chosen for study were (1) the $\mathrm{Al}_{2} \mathrm{O}_{3} / \mathrm{FeO}+\mathrm{MgO}$ ratio, which subdivides the field of cordieritegarnet-bearing rocks into two major compositional categories, i.e. rocks with excess sillimanite $\left(\mathrm{Al}_{2} \mathrm{O}_{3} / \mathrm{FeO}+\mathrm{MgO}>1\right.$; C-series of compositions in this work) and rocks containing hypersthene ( $\mathrm{A}$ - and $\mathrm{B}$-series), and (2) the $\mathrm{Mg} / \mathrm{Mg}+\mathrm{Fe}{ }^{2+} \mathrm{ratio}$. In addition, the influence of grossular component on the stability of garnet in the equilibria of interest has been investigated by comparing phase relations in the complex compositions with those of two calcium-free systems (Chapters 7 and 8 ). The influence of variables such as the $\mathrm{Mn} / \mathrm{Mg}+\mathrm{Fe}^{2+}+\mathrm{Mn}$ 
ratio and oxygen fugacity, which have not been covered in this investigation, need further study and should provide additional information relevant to natural metamorphic assemblages.

During the investigation it became necessary to arrive at an overall theoretical framework within which the observed variations in mineralogy could be interrelated. Within this framework, the observed phase relationships have been interpreted in terms of univariant and divariant equilibria, thus introducing theoretical constraints which have been used to test the experimental data for internal consistency. This also involved making use of distribution coefficients defining the $\mathrm{Mg} / \mathrm{Fe}$ partition relations between coexisting ferromagnesian phases, an aspect which has received much attention in recent petrological-mineralogical studies of metamorphic rocks, but which has as yet received little attention experimentally.

The results obtained in this study have provided a general phase diagram for metapelitic rocks (Figure 9.1), which delineates the maximum stability fields of mineral associations of interest to petrologists, such as cordierite-garnet, hypersthene-sillimanite-quartz, hypersthene-kyanite-quartz, cordierite-garnet-sillimanite, and sapphirine-quartz.

Most of these assemblages were found to be stable over a wide range of P-T conditions and thus the univariant phase boundaries separating the assemblages can only provide limiting conditions for their formation. 
More specific temperature-pressure estimates for cordierite-garnet-bearing rocks can be derived by the use of the P-T-X relations of quasi-divariant equilibria, which have been obtained by the combined use of experimental and analytical techniques (Chapters 4 and 5). The contoured P-T diagrams discussed in Chapter 9 (Figure 9.2 and 9.3) are most appropriate for this purpose. Ideally, the load pressure and temperature of a quasi-divariant cordierite-garnet assemblage can be determined, given the $\mathrm{Mg} / \mathrm{Mg}+\mathrm{Fe}^{2+} \mathrm{ratio}$ of a single garnet-cordierite pair. Similarly, the garnets or cordierites of two different assemblages from neighbouring rocks can be used for the same purpose.

It must be emphasized that the present results cannot be regarded as final. Improved pressure corrections for solid media apparatus may change the absolute values and the slopes of the phase boundaries and compositional contours presented in the $\mathrm{P}-\mathrm{T}, \mathrm{P}-\mathrm{X}$ and contoured $\mathrm{P}-\mathrm{T}$ diagrams. However, the present results demonstrate the viability of the method used and show where more detailed experimental work is needed to complete the picture. The results also indicate to petrologists working on natural metamorphic rocks the key assemblages on which to obtain detailed chemical data for use as indicators of physical conditions of metamorphism. 
Application to natural as semblages

While recognizing the limitations of the present data and the need for continued experimental study, the experimentally derived P-T-X relations for reactions (1) and (6), as represented in Figures 9.2 and 9.3 , can be tentatively applied to natural assemblages. In high grade amphibolite and granulite facies terranes, both the assemblages cordierite-garnet-sillimanitequartz-alkali feldspars-plagioclase + biotite (corresponding to reaction (1)) and cordierite-hypersthene-garnet-quartzalkali feldspars-plagioclase + biotite (corresponding to reaction (6)) are commonly found (Wynne-Edwards and Hay, 1963; De waard, 1966). However, very few reliable chemical analyses ${ }^{1}$ ) of coexisting pairs from the required assemblages are available. Pressure-temperature conditions of formation have been estimated for some selected data from the literature together with a small number of new electron probe analyses (Table 10.1). The estimated physical conditions of formation of cordieritegarnet assemblages are plotted in Figure 10.1 and cover a wide range of pressure and temperature. The diagram illustrates that by the present estimates cordierite-garnet rocks have formed over a wide range of physical conditions. The majority of garnet-cordierite-sillimanite-quartz assemblages (1) plot

1) For further comment on the quality of analyses from the literature, see section on Distribution Coefficients. 
TABLE 10.1

Chemical data on coexisting cordierite and garnet from natural rocks

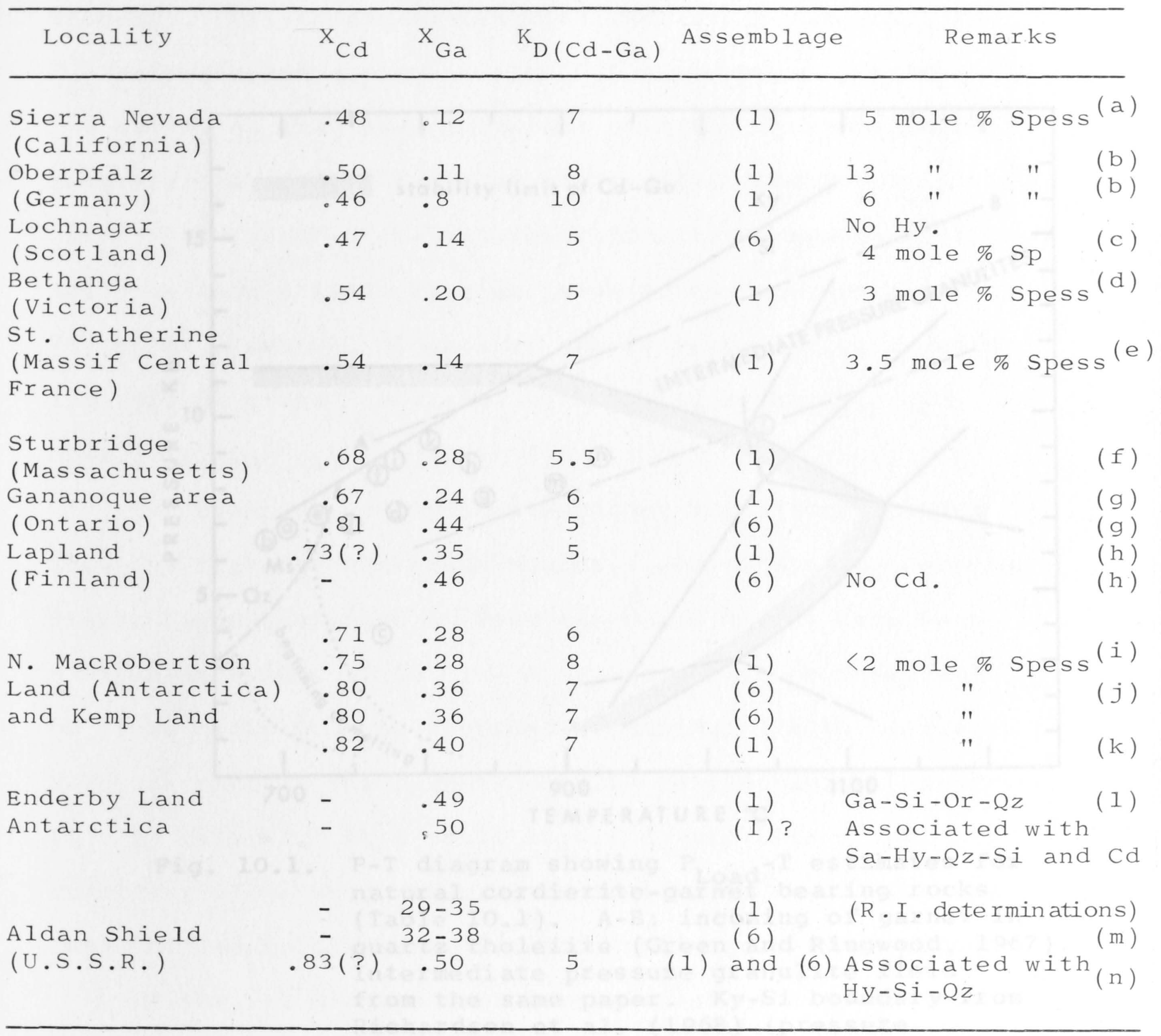

References: (a) Best and Weiss (1964); (b) OKrusch (1969);

(c) Chinner (1962); (d) Hensen (unpublished );

(e) Hensen (unpublished ${ }^{1}$ ); (f) Barker (1962);

(g) Reinhardt (1968); (h) Eskola (1952);

(i), (j), (k), ( 1 ) Hensen (unpublished ${ }^{1}$;

(m), (n) Marakushev and Kudryavtsev (1965)

1) Microprobe analyses.

Assemblage (1): Cd-Ga-Si-Qz; assemblage (6): Cd-Hy-Ga-Qz 。 


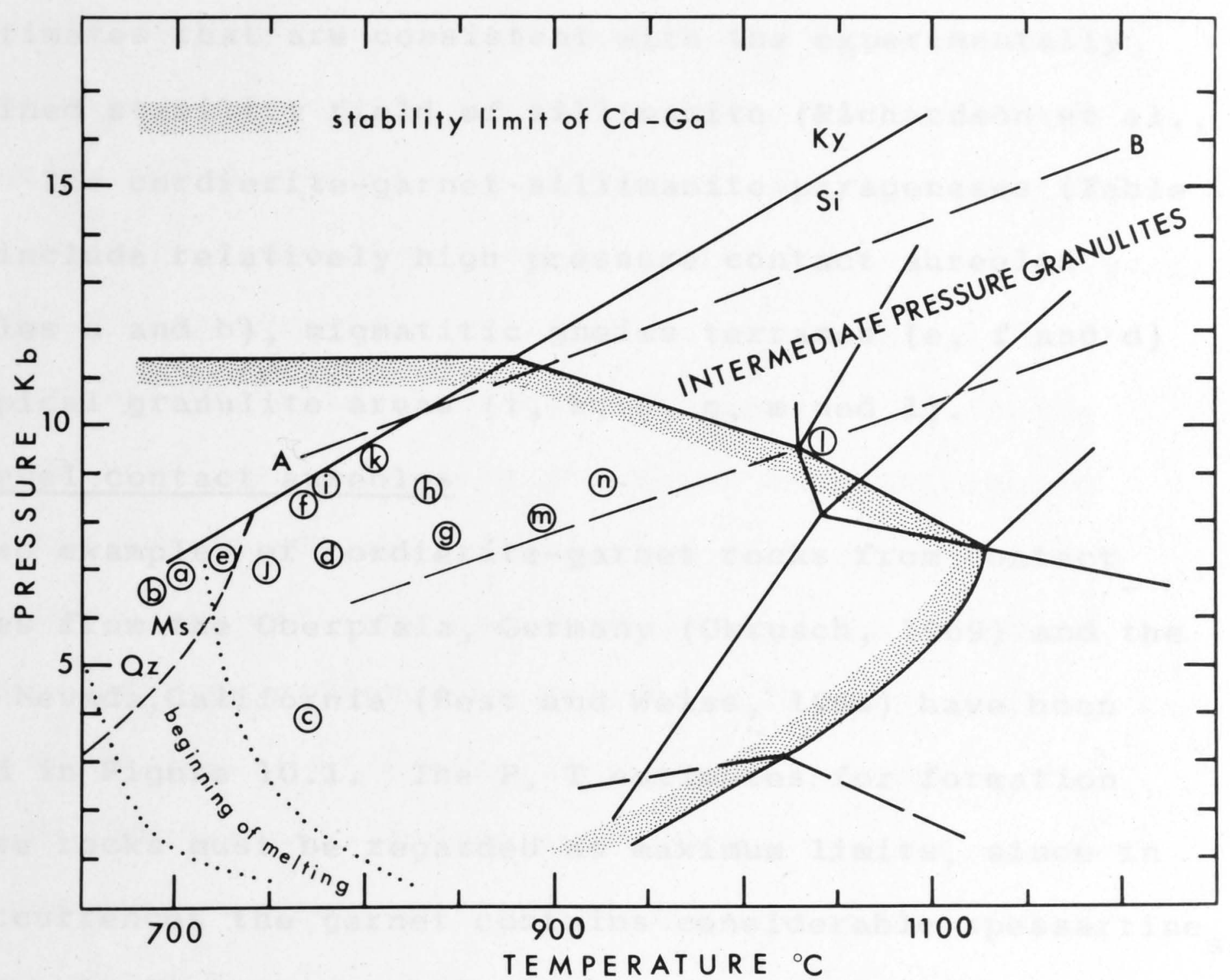

Fig. 10.1. P-T diagram showing $\mathrm{P}_{\text {Load }}{ }^{-\mathrm{T}}$ estimates for natural cordierite-garnet bearing rocks

(Table 10.1). A-B: incoming of garnet in quartz tholeitte (Green and Ringwood, 1967). Intermediate pressure granulite field from the same paper. Ky-Si boundary from Richardson et al. (1968) (pressure correction applied). Muscovite + quartz breakdown after Evans (1965) as extrapolated by Hess (1969). Beginning of melting interval in metasedimentary rocks from Winkler (1967). 
on the low pressure side of the kyanite boundary. This demonstrates that the extrapolated $\mathrm{x}_{\mathrm{Cd}}$ and $\mathrm{X}_{\mathrm{Ga}}$ contours, as applied to natural assemblage, provide P-T estimates that are consistent with the experimentally determined stability field of sillimanite (Richardson et al., 1968). The cordierite-garnet-sillimanite parageneses (Table 10.1) include relatively high pressure contact aureoles (examples a and b), migmatitic gneiss terranes (e, $f$ and $d$ ) and typical granulite areas (i, k, h, g, m and l).

Deep level contact aureoles

Two examples of cordierite-garnet rocks from contact aureoles from the Oberpfalz, Germany (Okrusch, 1969) and the Sierra Nevada, California (Best and Weiss, 1964) have been plotted in Figure 10.1. The P, T estimates for formation of these rocks must be regarded as maximum limits, since in both occurrences the garnet contains considerable spessartine ss (5 - 13 mole \%). This could significantly affect the stability of garnet, allowing it to form at lower pressure than the spessartine-free garnets studied experimentally. On the P-T diagram, both occurrences plot on the low temperature side of the breakdown curve for muscovite + quart $z^{1}$ ) (Evans, 1965). This may seem anomalous, since muscovite is

\footnotetext{
1) Extrapolation of the curve above $4 \mathrm{~kb}$ from Hess (1964).
} 
absent from these rocks. The above authors have attributed the absence of muscovite to its breakdown by dehydration. However, as argued by Winkler (1967), at water pressures. above $5 \mathrm{~kb}$ muscovite will be eliminated by partial melting at a temperature below the (metastable) extension of the dehydration boundary. It may be significant in this context that migmatitic rocks have been described from the high grade portions of both aureoles. Hirschberg and Winkler (1967) have drawn attention to the general absence of muscovite from garnet-cordierite-bearing rocks and have attributed this to the effect of the intersection of the muscovite dehydration curve with the boundary marking the beginning of melting. Their experiments on pelitic bulk compositions, in which a small amount of Mn was also present, support the present P-T estimates. According to their results, garnet coexisting with cordierite, sillimanite and quartz still contains less than 10 mole \% pyrope ss at $700^{\circ} \mathrm{C}, 6 \mathrm{~kb}$, which is in excellent agreement with the present experimental results. As discussed previously (Chapter 9.4), the fact that in their experiments biotite is also present should not affect the equilibrium (1) between garnet and cordierite. The Lochnagar aureole

This aureole described by Chinner (1962) is of particular interest because of the absence of the assemblage biotitesillimanite-quartz (Biotite-sillimanite is only found in 
silica-undersaturated assemblages). This led Chinner to disregard the biotite-sillimanite tie lines, commonly observed in many other quartz-bearing metamorphic assemblages, in his otherwise excellent analysis of cordierite-garnet paragenesis (see discussion by Best and Weiss, 1964). The absence of the association biotite-sillimanite-quartz indicates that in this aureole, the temperatures have exceeded those for the univariant ${ }^{1}$ ) boundary

$$
\mathrm{Bi}+\mathrm{Si}+\mathrm{Qz} \rightleftharpoons \mathrm{Cd}+\mathrm{Ga}+\mathrm{Or}+\mathrm{H}_{2} \mathrm{O}
$$

discussed in Chapter 9.4. In complex pelitic rocks, this quasi-univariant reaction which will have a positive slope, must pass below $3 \mathrm{~kb}$ at $700^{\circ} \mathrm{C}$, according to the experimental results of Hirschberg and Winkler (1967).

The estimated P-T point for the Lochnagar aureole (c) in Figure 10.1 on the one hand provides a minimum estimate, hypersthene being absent from the assemblage, which means that the rock must have formed on the high pressure side of the particular $\mathrm{X}_{\mathrm{Ga}}$ contour for assemblage (6). On the other hand, the natural garnet contains 4 mole \% spessartine ss $_{\text {which }}$ probably allows the garnet to be stable at lower pressure. In the aureole, both the assemblages garnet-biotite-quartz and cordierite-hypersthene-orthoclase are present, possibly

1) In natural rock systems this reaction is not strictly univariant. 
indicating conditions near to those for the univariant reaction

$$
\mathrm{Ga}+\mathrm{Bi}+\mathrm{Qz} \rightleftharpoons \mathrm{Cd}+\mathrm{Hy}+\mathrm{Or}+\mathrm{H}_{2} \mathrm{O}
$$

Alternatively the occurrence in the one aureole of the reactants and products of this reaction may indicate either that it constitutes a divariant equilibrium in natural rocks, or that ${ }^{\mathrm{P}_{\mathrm{H}_{2}} \mathrm{O}}$ was lower than $\mathrm{P}_{\text {total }}$. The latter is a possible situation 2 when metasediments that have previously lost all excess water are reheated in a thermal aureole. Migmatitic gneisses from amphibolite facies terranes

The rocks from St. Catherine (Massif Central, France) and from the Bethanga gneiss, Victoria, both containing assemblage (1), were probably formed under conditions intermediate between those of the deep seated aureoles and granulite terranes. The garnets have a higher pyrope content than in the aureoles and are generally lower in Mn, and thus more comparable to the experimental garnets. The garnets from the Bethanga gneiss are strongly zoned, having more magnesian core $\left(100 \mathrm{x}_{\mathrm{Ga}}=20\right)$ and more Fe-rich $\left(100 \mathrm{X}_{\mathrm{Ga}}=10\right)$ and Mn-rich rim, indicating retrograde metamorphism. This illustrates the danger of indiscriminately using wet analyses for the purpose of pressure and temperature estimation by the present method or for determining distribution coefficients.

\footnotetext{
1) See Chapter 9.4 .
} 
Wet analyses by Williams ${ }^{1}$ ) (1969) gave $x$ values intermediate between those quoted above and would necessarily have led to an erroneous interpretation.

Sturbridge (Massachusetts)

For the sturbridge migmatitic gneisses, described by Barker (1962), the $x_{\mathrm{Ga}}$ and $\mathrm{x}_{\mathrm{Cd}}$ contours give an intersection not far below the kyanite-sillimanite boundary. The garnet is intermediate in composition between those in the amphibolite terranes and most of the granulitic rocks.

Gananoque area, Ontario, Canada

The cordierite-garnet rocks described by Rheinhardt (1968) occur in a metamorphic terrane also containing pyroxene granulites. A discussion of Rheinhardt's paper has been given in Hensen and Green (1970), but a few more aspects of the data deserve attention. From a comparison of Rheinhardt's Tables I and II (pages 457-460), it is apparent that his classification of mineral assemblages into three phase assemblages is artificial. Notably, the inclusion of the two specimens (D-87 and R-114) containing the highest modal proportion of sillimanite in class C (cordierite-garnet-biotite) in which biotite and sillimanite ares upposed to be incompatible, is unfounded. It is worth noting that it is in these two

1) Reference: Williams, N. 1969, Palaeozoic geology of the Bethanga gold field area, N.E. Victoria, Unpubl. B.Sc. Hons. thesis, Australian National University. 
specimens that the $\mathrm{Mg} / \mathrm{Mg}+\mathrm{Fe}^{2+}$ ratio is lowest, suggesting they may be the only rocks in which the cordierite and garnet were in actual equilibrium with sillimanite as well as quartz. The chemical data for $\mathrm{X}_{\mathrm{Cd}}$ and $\mathrm{X}_{\mathrm{Ga}}$ in Table 10.1 have been in part recalculated ${ }^{1}$ ) from Reinhardt's data. The interesting aspect of these data is the co-occurrence of two cordieritegarnet-bearing assemblages, i.e.Cd-Ga-Si-Qz (I) and $\mathrm{Cd}-\mathrm{Ga}-\mathrm{Hy}-\mathrm{Qz}$ (6). The $\mathrm{X}_{\mathrm{Ga}}$ and $\mathrm{X}_{\mathrm{Cd}}$ contours for assemblage (6) and the $\mathrm{X}_{\mathrm{Ga}}$ contour of assemblage (1) all intersect in one point (point (g) in Figure 10.1). Only the $x_{\mathrm{Cd}}$ is not in agreement ${ }^{2}$ ) (this is also evident from the difference in $K_{D}$ values from both assemblages). The chemical analysis in question (R-114, Table III, page 461) does not seem very reliable. It contains 2.09 weight $\% \mathrm{~K}_{2} \mathrm{O}$, which is rather high for a cordierite analysis, and weight loss on ignition is given as 5.7 weight \%. Retrograde alteration of cordierite to biotite may have occurred in this rock. Since the $\mathrm{Mg} / \mathrm{Mg}+\mathrm{Fe}^{2+}$ ratio of biotite and cordierite increases, with decreasing grade, this could provide an explanation for the anomalous high value for $x_{C d}$. Assuming the other chemical data to be correct, the Ontario rocks show the experimental 1) $\mathrm{Fe}^{3+} / \mathrm{Fe}^{2+}$ was readjusted as required by structural formulae. 2) The $x_{\text {Cd }}$ seems too high. 
data to be internally consistent to the extent that the P-X estimates for two different assemblages from natural rocks are in close agreement.

\section{Lapland granulites}

The Lapland cordierite-bearing granulites have been described by Eskola (1952). The present estimate indicates a pressure of formation of around 8 - $9 \mathrm{~kb}$ total pressure and a temperature of $850^{\circ} \mathrm{C}$. This estimate is based on a cordieritegarnet pair from a sillimanite-bearing assemblage. ${ }^{1)}$ The compositions of garnets coexisting with hypersthene and quartz provide an additional low pressure limit using the $X_{G a}$ contours for reaction (6). The high pyrope content of these garnets $\left(100 \mathrm{X}_{\mathrm{Ga}}=44\right.$ - 46) supports a high pressure origin. The alumina content of the coexisting hypersthene is high $\left(\mathrm{Al}_{2} \mathrm{O}_{3}=8.26\right)$ suggesting high temperature. One occurrence of an assemblage containing both hypersthene and sillimanite is also reported. Eskola describes two-pyroxene granulites and ultrabasic rocks containing the assemblage olivineplagioclase from the same area. The occurrence of these assemblages and the low $\mathrm{Al}_{2} \mathrm{O}_{3}$ content of coexisting pyroxenes in the basic granulites have led Green and Ringwood (1967) 1) The original garnet analysis contains 7.3 weight $\% \mathrm{Fe}_{2} \mathrm{O}_{3}$, Recalculation with all iron as $\mathrm{Fe}^{2+}$ produces a more satisfactory garnet formula. 
to postulate a low pressure origin for the Lapland granulites. As can be seen from Figure 10.1, the present estimate would put the conditions of formation of these granulites well within the intermediate granulite field as defined by Green and Ringwood. Within the latter field, olivine and plagioclase would not be compatible together. The discrepancy remains unresolved, but deserves attention in the future.

MacRobertson Land and Kemp Land (Antarctica)

The Antarctic rocks ( $i, j, k)$ were collected by I.R. McLeod in Northern MacRobertson Land and Kemp Land. Since they were collected over a large area, it is reasonable to assume therefore, that cordierite and garnet compositions probably reflect true differences in conditions of formation of these rocks. The $\mathrm{K}_{\mathrm{D}(\mathrm{Cd}-\mathrm{Ga})}$ in most of these specimens is rather high. For this reason, example (i) plots outside the sillimanite field. However, kyanite was not found in any of these rocks. The pelitic rocks are associated with twopyroxene granulites (locally containing garnet) and high grade amphibolites (or hornblende granulites), (McLeod, personal communication).

Aldan Shield, U.S.S.R.

The Aldan shield occurrence has been described by Khlestov (1964) and Marakushev and Kudryavtsev (1965). Note the unusually high values of $x_{G a}$ in these rocks. The above authors have described the difference in garnet composition 
in assemblages (1) and (6), ( $\left.X_{\mathrm{Ga}}(1)<\mathrm{X}_{\mathrm{Ga}}(6)\right)$, and have

found that this difference decreases with increasing grade until garnet has the same composition in both assemblages. The $\mathrm{Mg} / \mathrm{Mg}+\mathrm{Fe}^{2+}$ ratio of the garnet at this point is reported to be "approximately 50". In the part of the complex where this occurs, the assemblage hypersthenesillimanite-quartz has been found. This has been interpreted by the above authors as an indication of the instability of the cordierite-garnet pair under the prevailing metamorphic conditions and they propose the reaction

$$
\mathrm{Cd}+\mathrm{Ga} \rightleftharpoons \mathrm{Hy}+\mathrm{Si}+\mathrm{Qz}
$$

Khlestov (1964) estimates the compositions of the phases at this boundary to be $100 \mathrm{x}_{\mathrm{Cd}}=68 ; 100 \mathrm{x}_{\mathrm{Ga}}=36 ; 100 \mathrm{x}_{\mathrm{Hy}}=59$. On the other hand, Marakushev and Kudryavtsev give the values $100 \mathrm{x}_{\mathrm{Cd}}=83 ; 100 \mathrm{x}_{\mathrm{Ga}}=50$ and $100 \mathrm{x}_{\mathrm{Hy}}=67$. In the latter paper, an analysis of hypersthene is given with $100 \mathrm{x}_{\mathrm{Hy}}=67$. The hypersthene is extremely aluminous $\left(9.35 \% \mathrm{Al}_{2} \mathrm{O}_{3}\right)$ and contains very high ferric iron $\left(\mathrm{Fe}_{2} \mathrm{O}_{3}=6.05 \% ; \mathrm{Fe}^{3+} / \mathrm{Fe}^{3+}+\mathrm{Fe}^{2+}\right.$ $=0.23)$. The high $\mathrm{Fe}^{3+}$ is attributed to a $\mathrm{Si}+\mathrm{Fe}^{2+} \rightleftharpoons \mathrm{Al}+\mathrm{Fe}^{3+}$ type substitution.

This apparently well documented occurrence of hypersthenesillimanite is of great interest in relation to the data given on $x_{\mathrm{Ga}}, \mathrm{x}_{\mathrm{Cd}}, \mathrm{x}_{\mathrm{Hy}}$. If the (mainly optical) data on garnet composition are taken to be at least approximately correct, these natural assemblages are in disagreement with 
the experimental data. The $x_{\mathrm{Ga}}$ and $\mathrm{x}_{\mathrm{Cd}}$ curves for divariant assemblages (1) and (6) (Figures 9.2 and 9.3) do not intersect within the garnet + cordierite stability field. At $800^{\circ} \mathrm{C}$ and $900^{\circ} \mathrm{C}$, the $\mathrm{x}_{\mathrm{Ga}_{50}}$ contour for reaction (1) occurs at approximately three and two kilobars respectively higher pressure than that for reaction (6). Assuming the high ferric iron content of the analysed hypersthene to be correct, then the type of substitution advocated by Marakushev and Kudryavtsev (1965) may provide an explanation for the discrepancy between the experimental and natural data. The stability field of a hypersthene containing major ferric iron may be extended with respect to cordierite and garnet by high oxygen fugacity. Thus the assumption that $\mathrm{fO}_{2}$ does not significantly affect reactions (1) and (6) may not hold for the latter reaction. Under conditions of high oxygen fugacity, $\mathrm{x}_{\mathrm{Ga}}$ and $\mathrm{x}_{\mathrm{Cd}}$ contours for reaction (6) could possibly be displaced towards higher pressure compared to their position determined in the present experiments under relatively reducing conditions. If this were the case, the intersection of $\mathrm{x}_{\mathrm{Ga}_{50}}$ in reactions (1) and (6) could take place at lower temperature, which implies that the univariant reaction

$$
\mathrm{Cd}+\mathrm{Ga} \rightleftharpoons \mathrm{Hy}+\mathrm{Si}+\mathrm{Qz} \quad \text { (Figure 9.1 to 9.3) }
$$

will occur at considerably lower pressure. Provided the assumption that reaction (1) will remain unaffected is correct, the univariant boundary could then occur between 900 and $950^{\circ} \mathrm{C}$ 
at ca. $9 \mathrm{~kb}$. These are extreme conditions, but it must be kept in mind that the hypersthene is very high in alumina. If the aluminium content of enstatite in equilibrium with sillimanite can be used for comparison, this temperature estimate does not seem unreasonable (compare Chapter 8 ).

Furthermore, it must be emphasized that the assemblage hypersthene-sillimanite-quartz is extremely rare. Only two other occurrences are known to the author. One is from Lapland (Eskola, 1952) and another from the Anabar Massif, U.S.S.R. (Luts and Kopanova, 1968). Chemical data from these occurrences are not available. Enderby Land, Antarctica

An interesting occurrence of a Sa-Qz bearing rock from the Antarctic has been described by Dallwitz (1968). The experiments indicate that the assemblage sapphirine-quartz can only occur stably at very high temperature (around $1050^{\circ} \mathrm{C}$ ) and pressure (above $8 \mathrm{~kb}$ ). The chemical formula for the sapphirine is

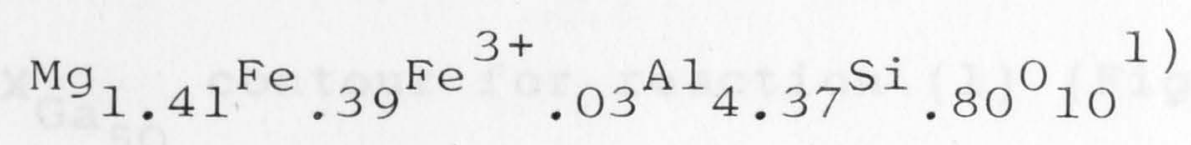

The sapphirine coexists with an extremely aluminous hypersthene ( 10.6 weight $\% \mathrm{Al}_{2} \mathrm{O}_{3}$ ) and a garnet of the composition $\left(\mathrm{Py}_{50} \mathrm{Al}_{48} \mathrm{Gr}_{1}\right.$ Spess $\left._{1}\right)$. As described by Dallwitz, most sapphirine grains are in direct contact with quartz. Although the very

1) Microprobe analysis, $\mathrm{Fe}^{3+}$ calculated. 
high Al-content of the hypersthene and the coexistence of sapphirine and quartz indicate a very high temperature of formation, it should be pointed out, that the results of ${ }^{B} 70$ and $C_{70}$ are not directly applicable since the experimentally produced sapphirine (Chapter 4.1) at $1150^{\circ} \mathrm{C}$ does not show the $\mathrm{Al}+\mathrm{Al} \rightleftharpoons\left(\mathrm{Mg}, \mathrm{Fe}^{2+}\right)+\mathrm{Si}$ substitution found in the natural mineral. The lower Al-content of the experimentally produced sapphirine may be due to the fact that the mineral was not in equilibrium with sillimanite, which constituted a minor phase in the experiments at $1150^{\circ} \mathrm{C}$ (Chapter 4.1).

In an adjoining outcrop, a garnet-sillimanite-quartzK-feldspar rock contains a garnet with the composition $\left(\mathrm{Py}_{46} \mathrm{Al}_{48} \mathrm{Gr}_{3} \text { Spess }_{2}\right)^{1)}$ Note that this garnet is very close in composition to that in the sapphirine-quartz rock. The occurrence of a garnet with 50 mole \% pyrope indicates a pressure in the order of $9 \mathrm{~kb}$ and a temperature of at least $900^{\circ} \mathrm{C}$. The temperature restriction follows from the position of the kyanite $\rightleftharpoons$ sillimanite phase boundary in relation to the $\mathrm{X}_{\mathrm{Ga}_{50}}$ contour for reaction (1) (Figure 9.2). The occurrence of sapphirine and quartz, the extremely high Al-content of the hypersthene and the high pyrope-content of the garnet all point towards extreme conditions of metamorphism.

1) Analysis by N. Ware, Australian National University. 


\section{Cordierite-Kyanite Paragenesis}

Cordierite and kyanite are only very rarely found together. A few occurrences have been described (Hietanen, 1956; Wenk, 1968; Fonteilles et al.1964). The experimental data indicate that under relatively dry conditions and below ca. $850^{\circ} \mathrm{C}$, the stability fields of Mg-rich cordierite and kyanite have a considerable overlap (Figure 10.1). Schreyer (1968) in hydrothermal experiments, found that Mg-cordierite and kyanite are compatible at $800^{\circ} \mathrm{C}$ and $10 \mathrm{~kb}$. In the presence of K-feldspar the assemblage phlogopite-kyanite-quartz is probably stable at high water pressures. Therefore, the stable coexistence of cordierite and kyanite will be restricted either to rocks which formed under conditions of $\mathrm{P}_{\mathrm{E}_{\mathrm{H}_{2}} \mathrm{O}}<\mathrm{P}_{\text {Load }}$ or to rocks without K-feldspar (i.e. $\mathrm{K}_{2} \mathrm{O}$ deficient environments). The absence of cordierite from amphibolite grade metapelites

Cordierite is not only absent from most kyanite-bearing rocks but also from numerous occurrences where sillimanite is the stable $\mathrm{Al}_{2} \mathrm{SiO}_{5}$ polymorph. This may be due to the fact that at pressures from 4 - $10 \mathrm{~kb}$ the univariant reaction

$$
\mathrm{Cd}+\mathrm{Ga}+\mathrm{Or}+\mathrm{H}_{2} \mathrm{O} \rightleftharpoons \mathrm{Bi}+\mathrm{Si}+\mathrm{Qz} \quad \Delta \mathrm{V}=-\mathrm{ve} \text { (Fig.9.5) }
$$

essentially represents the low temperature limit of cordierite stability in most pelitic rocks with excess K-feldspar and water. This follows from the observation that cordierite and biotite are both very magnesian and close in composition, whereas garnet is much more Fe-rich. Therefore, the above 
mentioned univariant reaction will involve the breakdown of cordierite in most bulk compositions and the breakdown of garnet only in very magnesian bulk compositions. The situation is comparable to that for the reaction Cd $+\mathrm{Ga} \rightleftharpoons \mathrm{Hy}+\mathrm{Si}+\mathrm{Qz}$ (Figure 3.5). This may explain why garnet rather than cordierite is found in most low grade ("wet") amphibolite terranes, whereas cordierite in addition to garnet is more common in high grade amphibolite and granulite areas. Or, the statement of Chinner (1962):

The wide rock composition field of almandine in the amphibolite facies may be contingent upon the inhibition of cordierite by hydrous minerals under relatively high partial pressure of water

can now be further specified by saying that under "wet" amphibolite facies conditions in rocks with excess alkali

feldspar the field of stability of cordierite is restricted by the quasi-univariant boundary:

$$
\mathrm{Cd}+\mathrm{Ga}+\mathrm{Or}+\mathrm{H}_{2} \mathrm{O} \rightleftharpoons \mathrm{Bi}+\mathrm{Si}+\mathrm{Qz}
$$

From the foregoing it is clear that the factors controlling the stability of cordierite at low temperature are numerous. Factors favouring cordierite formation are: high temperature, low $\mathrm{P}_{\text {total }}$, low $\mathrm{P}_{\mathrm{E}_{2} \mathrm{O}}$, high $\mathrm{Mg} / \mathrm{Mg}+\mathrm{Fe}^{2+}$ ratio and low $\mathrm{K}_{2} \mathrm{O}$. The present experimental evidence indicates that $P_{\text {total }}$ is less important than previously advocated. 
The role of partial melting in the formation of cordierite

Conditions of deficiency of $\mathrm{H}_{2} \mathrm{O}$ and $\mathrm{K}_{2} \mathrm{O}$ can be achieved by partial melting. If a rock in which most of the water is bound in hydrous minerals, e.g. biotite, muscovite, amphiboles etc., is subjected to high temperatures, these hydrous phases, in particular the micas, will melt incongruently to form a water saturated, $\mathrm{SiO}_{2}-\mathrm{K}_{2} \mathrm{O}-\mathrm{rich}$ melt. The residual material will thus be impoverished in these components and will consist of an increasing proportion of anhydrous ferromagnesian phases and sillimanite, as the temperature is raised (von platen and Höller (1966), Grant (1968)). Thus a situation is brought about in which the melting residuum still forming the bulk of the rock, becomes essentially water and $\mathrm{K}_{2} \mathrm{O}$ deficient. These are exactly the conditions believed to be governing the presence of cordierite in pelitic rocks at low temperature. Thus, rather than placing the P-T field of metamorphic rocks with cordierite-garnet assemblages below the beginning of melting, e.g. Turner (1969) under conditions of $\mathrm{P}_{\mathrm{H}_{2} \mathrm{O}}=\mathrm{P}_{\text {total }}$, these rocks should be expected to occur on the high temperature side of the granitic water-saturated solidus.

Distribution of $\mathrm{Fe}$ and $\mathrm{Mg}$ between coexisting garnet and cordierite

A large number of analyses of coexisting cordierite and garnet are available in the literature. Attempts to relate the $\mathrm{K}_{\mathrm{D}(\mathrm{Cd}-\mathrm{Ga})}$ to the temperature of formation of the mineral 
pairs have been rather unsuccessful (Saxena and Hollander, 1968; Gorbatshev, 1968)). From the data reviewed, Saxena and Hollander (1969) suggested that cordierite is an ideal Fe-Mg solid solution at low temperature by may be non-ideal at high temperature. This is rather the opposite from what would be theoretically expected. Both the restricted number and the poor quality of the analyses used could well be responsible for this anomalous result.

From a close scrutiny of the analytical data from the literature it is apparent that a large proportion of the analyses are highly inaccurate. In many cases structural formulae of the minerals analysed are not provided with the analyses; they show the analyses to be of doubtful quality. The total number of available analyses is reduced by at least half by rejecting the analyses on the basis of the structural formula criterion alone. But even for the remaining few which appear to represent accurate analyses of uncontaminated material, it is still not possible to know whether the minerals are unzoned and are of uniform composition within the specimen analysed (compare Blackburn, 1968). Careful micro-probe analyses are necessary to obtain the accuracy required for a meaningful study of $\mathrm{K}_{\mathrm{D}}$-temperature relationships.

The available data indicate that $\mathrm{K}_{\mathrm{D}(\mathrm{Cd}-\mathrm{Ga})}$ values range from 5 to 10. At the present time no definite correlation between $\mathrm{K}_{\mathrm{D}}$ and $\mathrm{T}$ can be made, although a decrease with 
increasing temperature may be present. For the cordieritegarnet pairs produced experimentally at $900^{\circ}-1100^{\circ} \mathrm{C}$, low values of $\mathrm{K}_{\mathrm{D}(\mathrm{Cd}-\mathrm{Ga})}$ were found $(3-5)$, also indicating a decrease of $\mathrm{K}_{\mathrm{D}}$ with increasing temperature (i.e. a theoretically expected relationship). Physical conditions of granulite facies metamorphism Natural cordierite-garnet-bearing metapelites have apparently formed over a wide range of pressure-temperature conditions. Almost all estimated P-T points fall in the field of intermediate pressure granulites as defined by Green and Ringwood (1967) (Figure 10.1). From most areas it is as yet unclear how the mineralogy of basic granulites is related to that in the accompanying cordierite-garnet-bearing rocks. This is a point of great interest and merits detailed investigation in field studies.

Exceptional temperature conditions must have prevailed in the earth's crust during high grade metamorphic events, since all rocks discussed above have formed at temperatures well above those of the "normal" geothermal gradient. The assemblages sapphirine-quartz and hypersthene-sillimanite indicate that temperatures at $950-1050^{\circ} \mathrm{C}$ may have been reached in some cases. The heat source causing such high temperatures could have been the intrusion of large volumes of essentially dry basic magmas into the lower crust. Such melts could have liquidus temperatures around $1200-1300^{\circ} \mathrm{C}$ and could therefore 
raise temperatures in adjacent metasediments to the required temperatures. The metasedimentary rocks would have to be essentially dry, having lost their water in previous metamorphic events since otherwise they would be largely melted. In most granulite areas, extremely complex structural relations indicating several stages of deformation, recrystallisation, heating and cooling, make it difficult to generalize about their possible mode of formation, Winkler (1967); Fyfe et al. (1958); Turner (1968).

The experimental results show that under "dry" conditions, the mineral cordierite is stable throughout the continental crust at temperatures from $600^{\circ} \mathrm{C}$ to $1100^{\circ} \mathrm{C}$. Therefore, the presence or absence of this mineral can by itself tell us very little about metamorphic conditions. However, when its paragenesis and composition are taken into account, cordierite may prove one of the most useful indicators of physical conditions to be found in metamorphic rocks.

From the foregoing discussion of natural occurrences it is evident that no sharp distinction exists between various modes of occurrence, and that the use of isograds defined by univariant reactions as a means of determining physical conditions of formation, can only provide very wide pressuretemperature limits within which the various mineral assemblages may have formed. On the other hand the use of divariant equilibria potentially enables us to obtain a much more 
detailed view of the gradual changes taking place as a function of temperature and pressure. These gradual changes, which are reflected in the chemical compositions of the coexisting phases, are believed to constitute the key to a better understanding of the conditions of formation of natural metamorphic rocks. By a combination of evidence from solid-solid equilibria providing estimates of load pressure and temperature on the one hand, and dehydration, decarbonation and oxidation-reduction reaction on the other, it may eventually be also possible to evaluate fluid pressures during high grade metamorphism. 


\section{BIBLIOGRAPHY}

BARKER, F. 1961: Phase relations in cordierite-garnetbearing kinsman quartz monzonite and the enclosing schist, Lovewell mountain quadrangle, New Hampshire. Am. Min. 46, $1166-76$.

BARKER, F. 1962: Cordierite-garnet gneiss and associated mic rocline-rich pegmatite at sturbridge, Massachusetts and Union, Connecticut. Am. Min. 47, 907-18.

BARKER, F. 1964: Reaction between mafic magmas and pelitic schist, Cortlandt, New York.

Am. J. Sci. 262, 614-34.

BARKER, F. 1964: Sapphirine-bearing rock, Val Codera, Italy。 Am. Min. 49, 146-52.

BEST, M.G. and WEISS, L.E. 1964: Mineralogical relations in some pelitic hornfelses from the southern Sierra Nevada. Am. Min. 49, 1240-66.

BLACKBURN, W.H. 1968: The spatial extent of chemical equilibrium in some high-grade metamorphic rocks from the Grenville of Southeastern Ontario.

Contr. Mineral. and Petrol. 19, 72-92.

BOYD, F.R. and ENGLAND, J.L. 1959: Pyrope. Carnegie Inst. Washington Year Book 58, 83-87.

BOYD, F.R. and ENGLAND, J.L. 1960: Apparatus for phaseequilibrium measurements at pressures up to 50 kilobars and temperatures up to $1750^{\circ} \mathrm{C}$.

J Geophys.Res. 65, 741-48.

BOYD, F.R. and ENGLAND, J.L. 1964: The system enstatite-pyrope。 Carnegie Inst. Washington Year Book 63, 157-61.

BURNHAM, C.W., HOLLOWAY, J.R. and DAVIS, N.F. 1969: The specific volume of water in the range 1 , OOO8,900 bars, $20^{\circ}-900^{\circ} \mathrm{C}$.

Am. J.Sci. Schairer, Vol., 70-95. 
CHATtERJEE, N.D. and SCHREYER, W. 1969: Stabilitätsbeziehungen der paragenese sapphirin und quartz.

Deutsche Min. Ges. Referate der Vortrage auf der 47 Jahrestagung, Bern. 7-8.

CHINNER, G.A. 1962: Almandine in thermal aureoles.

J. Petrol。3, 316-40。

CHINNER, G.A. and SWEATMAN, T.R. 1968: A former association of enstatite and kyanite.

Min. Mag. London, 36, 1052-60.

DALLWITZ, W.B. 1968: Coexisting sapphirine and quartz in granulite from Enderby Land, Antarctica. Nature, Lond. 219, 476-77.

DE WAARD, D. 1966: The biotite-cordierite-almandinesubfacies of the hornblende-granulite facies. Canad. Mineralogist 8, 481-92.

DUNCUMB, P. and REED, S.J.B. 1968: The calculation of stopping power and backscatter effects in electron-probe micro analysis. Quantitative Electron-Probe Microanalysis (ed. K.F.J. Heinrich) 133-45. U.S. Bureau of Standards Special publication, 298.

DUNCUMB, P. and SHIELD, P.K. 1966: The effect of excitation potential on the absorption correction. The elctron microprobe (ed. T.D. McKinley, K.F.J. Heinrich and D.B. Wittry) pp. 284-95. Wiley.

ESKOLA, P. 1952: On the granulites of Lapland. Am. J. Sci. Bowen Volume, 133-171.

EUGSTER, H.P. and WONES, D.R. 1962: Stability relations of the ferruginous biotite, annite.

J. Petr. 3, 82-125.

EUGSTER, H.P. and SKIPPEN, G.B. 1967: Igneous and metamorphic reactions involving gas equilibria. Researches in Geochem.2,492-520。

EVANS, B.W. 1965: Application of reaction-rate method to the breakdown equilibria of muscovite and muscovite + quartz. Am. J. Sci. 263, 647 . 
FONTEIlles, M., GUITARD, G. and RAGUIN, E. 1964: Sur

la presence de gneiss à disthène et

cordierite dans le massif du Saint Barthélemy, Pyrenées de 1'Ariege

C.R. Acad. Sci., Paris, 258, 3524-25.

FRENCH, B.M. and EUGSTER, H.P. 1965: Experimental control of oxygen fugacities by graphite-gas equilibriums. J. Geophys. Res. 70, 1529.

FYFE, W.S., TURNER, F.J. and VERHOOGEN, J. 1958:

Metamorphic reactions and metamorphic facies. Geol. Soc. Am. Mem. 73, 1-252.

GRANT, J.A. 1968: Partial melting of common rocks as a possible source of cordierite-anthophyllite bearing assemblages.

Am. J. Sci. 266, 908-31.

GREEN, D.H. 1969: Mineralogy of two Norwegian eclogites. Contrib. to physico-chemical petr., I, 37-44 (in Russian).

GREEN, D.H. and RINGWOOD, A.E. 1967: An experimental investigation of the gabbro to eclogite transformation and its petrological applications. Geochim. et Cosmochim. Acta 31, 767-833.

GREEN, T.H. and RINGWOOD, A.E. 1968: Origin of garnet phenocrysts in calc-alkaline rocks. Contr. Mineral. and Petrol. 18, 163-74.

GREEN, T.H., RINGWOOD, A.E. and MAJOR, A. 1964: Friction effects and pressure calibration in a pistoncylinder apparatus at high pressure and temperature.

J. Geophys. Res. 71, 3589-94.

GOLDSCHMIDT, V.M. 1911: Die Kontaktmetamorphose im Kristianagebiet.

Kristiana Vidensk. Skr., I, Math.-Naturv. K1. 11.

GORBATSCHEV, R. 1968: Distribution of elements between cordierite, biotite and garnet. $\mathrm{N}$. Jb. Miner. Abh., 110 (1), 57-80. 
HENSEN, B.J. and GREEN, D.H. 1969: Experimental data on the stability of garnet and cordierite in high-grade metamorphic rocks.

Spec. Publs Geol. Soc. Aust. 2, 345-347.

HENSEN, B.J. and GREEN, D.H. 1970: Experimental data on coexisting cordierite and garnet under high grade metamorphic conditions.

Phys. Earth Planet. Int. 3, 431-40.

HESS, P.C. 1969: The metamorphic paragenesis of cordierite in pelitic rocks.

Contr. Mineral. and Petrol. 24, 191-207.

HIETANEN, A. 1956: Kyanite, andalusite, and sillimanite in the schist in Boehls Butte quadrangle, Idaho.

Am. Miner. 41, 1-27.

HIETANEN, A. 1967: On the facies series in various types of metamorphism.

J Geol. 75, 2, 187-214.

HIRSCHBERG, A. and WINKLER, H.G.F. 1968: Stabilitätsbeziehungen zwischen Chlorit, Cordierite und Almandin bei der Met amorphose.

Contr. Mineral. Petrol. 18, 17-42.

HSU, L.C. 1968: Selected phase relationships in the system Al-Mn-Fe-Si-O-H: A model for garnet equilibria. J. Petrol. 9, 40-83.

HSU, L.C. and BURNHAM, C.W. 1969: Phase relationships in the

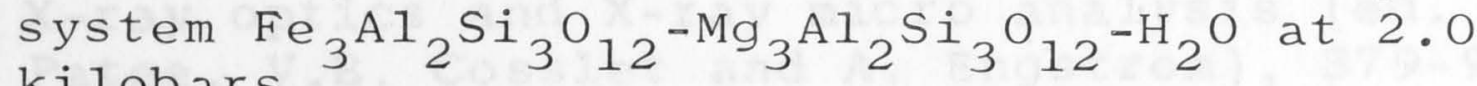
kilobars.

Geol. Soc. Am.Bul1. 80, 2393-2408.

KHLESTOV, V.V. 1964: Garnets from cordierite-bearing rocks of the sharyzhalgay complex (southwestern Transbaikal). Dokl. Akad. Nauk SSSR, 154, 4, 842-45.

KWAK, T.A.P. 1968: Ti in biotite and muscovite of metamorphic grade in almandine amphibolite facies rocks from Sudbury, Ontario.

Geochim. et Cosmochim. Acta, 32, 1222-29.

LINDSLEY, D.H., MacGREGOR and DAVIS, B.T.C. 1964: Synthesis and stability of ferrosilite.

Carnegie Inst. Washington Year Book 63, 174-76. 
LUTS, B.G. and KOPANEVA, L.N. 1968: Dok1. Akad. Nauk SSSR 1179,1200 .

MARAKUSHEV, A.A. and KUDRYAVTSEV, V.A. 1965: Hypersthenesillimanite paragenesis and its petrological implication.

Dokl. Akad. Nauk. SSSR, 164, 1, 179-82.

MIYASHIRO, A. 1956: Osumilite, a new silicate mineral and its crystal structure.

Am. Miner. 41, 104-16.

MIYASHIRO, A. 1961: Evolution of metamorphic belts.

J. Petrol. 2, 277-311.

MacGREGOR, I.D. and RINGWOOD, A.E. 1964: The natural system enstatite-pyrope.

Carnegie Inst. Washington Year Book 161-65.

NEWTON, R.C. and SMITH, J.V. 1967: Investigations concerning the breakdown of albite at depth in the earth.

J. Geol. 3, 268-86.

OKRUSCH, M. 1969: Die Gneishornfelse um Steinach in der Oberpfalz.

Contr. Miner. and Petrol. 22, 32-72.

OLSEN, E. and BUNCH, T.E. 197O: Composition of natural osumilites.

Am. Miner. 55, 875-80.

PHILIBERT, J. 1963: A method for calculating the absorption correction in electron-probe micro analysis. X-ray optics and X-ray micro analysis (ed. H.H. Patee, V.E. Cosslet and A. Engstrom), 379-92, Academic Press.

RAMBERG, H. 1964: Chemical thermodynamics in mineral studies. Physics and Chemistry of the Earth, 5 (ed. L.H. Ahrens, F. Press and S.K. Runcorn) 225-53.

REED, S.J.B. 1965: Characteristic fluorescence corrections in electron-probe micro analysis.

Brit. J. Appl. Phys. 16, 913-26.

REINHARDT, E.W. 1968: Phase relations in cordierite-bearing gneisses from the Gananoque area, Ontario.

Can.J. Earth Sci. 5, 455-82. 
RICHARDSON, S.W. 1968: Staurolite stability in a part of the system $\mathrm{Fe}-\mathrm{Al}-\mathrm{Si}-\mathrm{O}-\mathrm{H}$.

J. Petrol. 9, 467-88。

RICHARDSON. S.W., BELL, P.M. and GILBERT, M.C. 1968 :

Kyanite-sillimanite equilibrium between $700^{\circ} \mathrm{C}$ and $1500^{\circ} \mathrm{C}$.

Am.J.Sci.266,513-41.

R ICHARDSON, S.W., GILBERT, M.C. and BELL, P.M. 1969 :

Experimental determination of kyanite-andalusite and andalusite-sillimanite equilibria; the aluminium silicate triple point.

Am.J. Sci. 267, 259-272.

R INGWOOD, A.E., MacGREGOR, I.D. and BOYD, F.R. 1964 :

Petrological constitution of the upper mantle.

Carnegie Inst. Washington Year Book 63, 147-52.

ROBIE, R.A., BETHKE, P.M. AND BEARDSLEY, K.M. 1967: Selected X-ray crystallographic data molar volumes, and densities of minerals and related substances. Geol. Survey Bull. 1248 .

ROBIE, R.A. and WALDBAUM, D.R. 1969: Thermodynamic properties of minerals and related substances at $298.15^{\circ} \mathrm{K}$ (25. ${ }^{\circ} \mathrm{C}$ ) and one atmosphere (1.013 Bars) pressure and at higher temperatures.

Geol. Survey Bull. 1259.

RUTHERFORD, M.J. 1969: An experimental determination of iron biotite-alkali feldspar equilibria.

J. Petrol.10, 381-408。

RUTHERFORD, M.J. 1968: An experimental study of biotite phase equilibria.

John Hopkins University, Ph.D. 1968.

SAXENA, S.K. and HOLLANDER, N.B. 1969: Distribution of iron and magnesium in coexisting biotite, garnet and cordierite.

Am。J.Sci. 267, 210-16.

SCHREINEMAKERS, F.A.H. 1965: In-, mono-, and divariant equilibria.

Penn. State Univ。Publ.2, 322 p. 
SCHREYER, W. 1968: A reconnaissance study of the system $\mathrm{MgO}-\mathrm{Al}_{2} \mathrm{O}_{3}-\mathrm{SiO}_{2}-\mathrm{H}_{2} \mathrm{O}$ at pressures between $1 \mathrm{O}$ and $25 \mathrm{~kb}$.

Carnegie Inst. Washington Year Book 67, 380-392.

SCHREYER, W. and SEIFERT, F. 1967: Metastability of an osumilite end member in the system $\mathrm{K}_{2} \mathrm{O}-\mathrm{MgO}-\mathrm{Al}_{2} \mathrm{O}_{3}-\mathrm{SiO}_{2}-\mathrm{H}_{2} \mathrm{O}$ and its possible bearing on the rarity of natural osumilites.

Contr. Mineral. and Petrol. 14, 343-358.

SCHREYER, W. and SEIFERT, F. 1969a: Compatibility relations of the aluminium silicates in the systems $\mathrm{MgO}-\mathrm{Al}_{2} \mathrm{O}_{3}-\mathrm{SiO}_{2}-\mathrm{H}_{2} \mathrm{O}$ and $\mathrm{K}_{2} \mathrm{O}-\mathrm{MgO}-\mathrm{Al}_{2} \mathrm{O}_{3}-\mathrm{SiO}_{2}-\mathrm{H}_{2} \mathrm{O}$ at high pressures.

Am. J.Sci. 267, 371-388.

SCHREYER, W. and SEIFERT, F. 1969b: High pressure phases in the system $\mathrm{MgO}-\mathrm{Al}_{2} \mathrm{O}_{3}-\mathrm{SiO}_{2}-\mathrm{H}_{2} \mathrm{O}$.

Am. J. Sci. $267-A^{2}, 407-443$.

SCHREYER, W. and SEIFERT, F. 1970: Pressure dependence of crystal structures in the system $\mathrm{MgO}_{-} \mathrm{Al}_{2} \mathrm{O}_{3}-\mathrm{SiO}_{2}-\mathrm{H}_{2} \mathrm{O}$ at pressures up to 30 kilobars.

Phys. Earth Planet Int. 3, 422-30.

SCHREYER, W. and YODER, H.S., Jr. 1960: Instability of anhydrous Mg-cordierite at high pressures. Carnegie Inst. Washington Year Book 59, 90-91.

SCHREYER, W. and YODER, H.S. 1964: The system Mg-cordierite- $\mathrm{H}_{2} \mathrm{O}$ and related rocks.

N. Jb. Miner. Abh. 101, 271-342.

SEIFERT, F. 1970: Low-temperature compatibility relations of cordierite in haplopelites of the system \begin{tabular}{l}
$\mathrm{K}_{2} \mathrm{O}-\mathrm{MgO}-\mathrm{Al}_{2} \mathrm{O}_{3}-\mathrm{SiO}_{2}-\mathrm{H}_{2} \mathrm{O}$. \\
$\mathrm{J}^{2}$ Petrol. \\
\hline
\end{tabular}

SMITH, D. 1970: Stability of iron-rich orthopyroxene. Carnegie Inst. Washington Year Book 68, 229-31.

SPEIDEL, D.H. 1970: Effect of magnesium on the iron-titanium oxides. Am. J.Sci. 268, 341-53.

SPEIDEL, D.H. and OSBORN, E.F. 1967: Element distribution among coexisting phases $\mathrm{MgO}-\mathrm{FeO}-\mathrm{Fe}_{2} \mathrm{O}_{3}$ as a function of temperature and oxygen fugacity. Am. Miner. 52, 1139-52. 
DEN TEX, E. 1965: Metamorphic lineages of orogenic plutonism. Geol. and Mijnb. 44, 105-32.

THOMPSON, J.B. 1957: The graphical analysis of mineral assemblages in pelitic schists.

Am. Miner., $42,842-58$.

TURNER, F.J. 1968: Metamorphic Petrology. McGraw-Hill.

TURNER, F.J. and VERHOOGEN, J. 1960: Igneous and metamorphic petrology.

McGraw-Hill.

TUR NOCK. A.C. and EUGSTER, H.P. $1962 ;$ Fe-Al oxides: phase relationships below $1000^{\circ} \mathrm{C}$.

J.Petrol. 3, 533-65.

WENK, E. 1968: Cordierit in Val Verzasca.

Schweiz. Miner. u. Petrograph. Mitteilungen, Band $48,2,455-57$.

WINKLER, H.G.F. 1967: Die Genese der metamorphen Gesteine. 2. Auflag, Berlin-Heidelberg-New York, Springer.

WONES, D.R. and EUGSTER, H.P. 1965: Stability of biotite: Experiment, Theory, and Application.

Am. Miner., 50, 1228-72.

WYNNE-EDWARDS, H.R. and HAY, P.W. 1963: Coexisting cordierite and garnet in regionally metamorphosed rocks from the Westport area, Ontario.

Can. Miner. 7, 453-78.

YODER, H.S. Jr. and CHINNER, G.A. 1960b: Almandite-pyrope-water system at 10.000 bars.

Carnegie Inst. Washington Year Book 59, 81-84.

ZECK, H.P. 1968: Anatectic origin and further petrogenesis of almandine-bearing biotite-cordierite-labradoritedacite with many inclusions of restite and basaltoid material, Cerro del Hoyazo, S.E. Spain. University of Amsterdam, Ph.D. 1968 .

ZEN, E. 1966: Construction of pressure-temperature diagrams for the multicomponent systems after the method of Schreinemakers, a geometric approach.

U.S. Geol. Surv. Bull. 1225, 56. 